
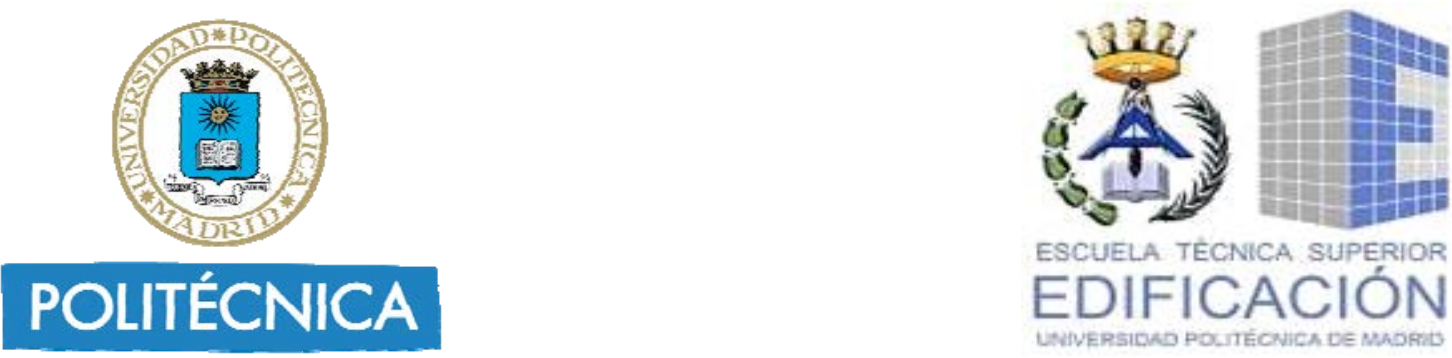
ESCUELA TECNICA SUPERIOR EDIFICACIÓN

\title{
ANÁLISIS Y DIAGNÓSTICO EVOLUTIVO DE LA INTEGRACIÓN DE LA GESTIÓN PREVENTIVA EN LOS PLANES DE SEGURIDAD Y SALUD
}

TESIS DOCTORAL

BLASA MARÍA VILLENA ESCRIBANO 



\title{
UNIVERSIDAD POLITÉCNICA DE MADRID \\ ESCUELA TÉCNICA SUPERIOR DE EDIFICACIÓN
}

\author{
TESIS DOCTORAL \\ ANÁLISIS Y DIAGNÓSTICO EVOLUTIVO DE LA INTEGRACIÓN \\ DE LA GESTIÓN PREVENTIVA EN LOS PLANES DE \\ SEGURIDAD Y SALUD
}

\author{
AUTORA: \\ BLASA MARÍA VILLENA ESCRIBANO
}

Arquitecta

DIRECTORAS DE TESIS:

Da. MARÍA DE LAS NIEVES GONZÁLEZ GARCíA

Dra. por la Universidad Politécnica de Madrid

Da. MARÍA SEgarRa CAÑAMARES

Dra. por la Universidad de Castilla-La Mancha

SUBDIRECCIÓN DE INVESTIGACIÓN, DOCTORADO Y POSTGRADO 



\section{TESIS DOCTORAL}

\section{ANÁLISIS Y DIAGNÓSTICO EVOLUTIVO DE LA INTEGRACIÓN DE LA GESTIÓN PREVENTIVA EN LOS PLANES DE SEGURIDAD Y SALUD}

\section{Autora:}

\section{Blasa María Villena Escribano}

Directoras de Tesis:

María de las Nieves González García María Segarra Cañamares

Tribunal nombrado por el Mgfco. y Excm. Sr. Rector de la Universidad Politécnica de Madrid, el día de de 2019.

- Presidente:

- Vocal:

- Vocal:

- Vocal:

- Secretario:

Realizado el acto de defensa y lectura de la Tesis Doctoral acuerda otorgarle la calificación de:

EL PRESIDENTE

LOS VOCALES

EL SECRETARIO

Madrid de de 2019 



\section{DEDICATORIA}

Por y para Álvaro. Y a mis padres, siempre.

"La prevención de accidentes no debe ser considerada como una cuestión de legislación, sino como un deber ante los seres humanos, y como una razón de sentido económico".

Ernst Werner M. von Siemens 



\section{AGRADECIMIENTOS}

La elaboración de este documento ha llevado aparejada una estrecha colaboración con instituciones públicas de Castilla-La Mancha, en conjunción con los Jefes de Servicio de Seguridad y Salud Laboral y el Cuerpo de Técnicos de Prevención de Riesgos Laborales que integran las distintas sedes provinciales de la Junta de Comunidades de Castilla-La Mancha, perteneciente a la Consejería de Economía, Empresas y Empleo; a todos ellos les agradezco haberme abierto las puertas de las sedes, además de su profesionalidad y amabilidad latente durante todo el proceso de cumplimiento de las visitas.

Gracias de todo corazón a la Dirección de Trabajo, Formación y Seguridad Laboral de la Junta de Comunidades de Castilla-La Mancha, en especial a D. Francisco Javier de la Cruz González, por creer en este proyecto desde el primer momento y coordinar esta investigación para que pudiera ver la luz.

Merece un agradecimiento especial por su involucración, ayuda, dedicación y complicidad con el desarrollo del proyecto D. Álvaro Romero Barriuso, compañero de investigación del grupo de investigación PEPCYMAE de la Universidad Politécnica de Madrid y compañero del camino en mi vida personal y en el desarrollo de mi actividad profesional.

Así mismo, a mis directoras de tesis, Dña. María de las Nieves González García (Universidad Politécnica de Madrid) y Dña. María Segarra Cañamares (Universidad de Castilla-La Mancha), sin cuyo tesón e implicación en el proyecto habría resultado imposible conseguir establecer un convenio con la Junta de Comunidades de Castilla-La Mancha, y bajo cuyas directrices se ha desarrollado este trabajo de tesis doctoral; pero sobre todo, por estar siempre que las he necesitado.

A mis padres, Blas y Josefa, a quienes les debo mi carácter, por ser mis pilares de apoyo y por inculcarme los valores que hoy en día representan mi vida. Sin vosotros este proyecto no hubiera sido posible.

Para todos ellos, mi agradecimiento siempre eterno. 



\section{RESUMEN}

La presente tesis se elabora a raíz de un trabajo de investigación que ahonda en la realidad preventiva de las obras de construcción, desde el punto de vista del cumplimiento formal de la normativa vigente y desde el prisma del correcto uso en obra de los instrumentos preventivos a disposición de las empresas y trabajadores del Sector de la Construcción en España.

Para ello, se realiza un análisis prospectivo mediante la técnica de la consulta in situ del instrumento preventivo por excelencia, el Plan de Seguridad y Salud en el Trabajo. Esta herramienta preventiva queda recogida de forma explícita en el artículo 7 del RD 1627/1997, siendo expuesta su obligatoriedad en el artículo 19 de la citada norma, por el que se establece que "la comunicación de apertura del centro de trabajo a la autoridad laboral competente deberá incluir el Plan de Seguridad y Salud...".

Para que el estudio sea relevante y extrapolable, a la par que competente, se conforma una muestra con los 3.600 Planes de Seguridad y Salud en el Trabajo consultados para el período de tiempo comprendido entre los años 2008 a 2016 (ambos incluidos), y para las cinco sedes de la Autoridad Laboral que integran la Junta de Comunidades de Castilla-La Mancha. La recolección de la información, realizada mediante el empleo de técnicas de orden cuantitativo, se efectúa mediante la aplicación de un cuestionario o checklist pre-elaborado, de tipo dicotómico, con los ítems más relevantes que afectan a la investigación y que conforman el contenido de los Planes de Seguridad y Salud.

Los resultados extraídos ponen de manifiesto por un lado el mal uso que se hace del instrumento preventivo del Plan y su escasa aplicación a nivel preventivo. Por otro lado, se observa que se trata de un documento cuya vida útil es demasiado acotada, y que, en la mayoría de las ocasiones, no cubre la ejecución total de la obra, sino que finaliza antes si quiera de comenzar los trabajos.

Es por ello que resulta necesaria la creación de una herramienta viva que actualice el estado de la obra y que sea accesible a todos los agentes implicados en los procesos constructivo-preventivos, ya sean pertenecientes al ente público o al privado. Esta herramienta integrará por tanto los sistemas preventivos en los procesos constructivos de las obras de edificación. 



\section{ABSTRACT}

This thesis has been developed as a result of a research work that deals with the preventive reality on construction sites, using the exact point of view of the formal compliance with the current regulations and from the prism of the correct use of all the preventive instruments that can be used by the firms and workers of the Construction Sector in Spain.

To do that, a prospective analysis is carried out by using the on-site consultation technique of the preventive instrument par excellence, the Safety and Health Plan. This preventive tool is explicitly included in the 7th article of the Royal Decree 1627/1997, and its obligation is set in the 19th article of the aforementioned law, which establishes that "the opening communication of the work center to the competent labor authority must include the Safety and Health Plan..."

In order to make the research relevant and extrapolated, and at the same time competent, a simple is formed with 3,600 Safety and Health Plans consulted for the period of time between the years 2008 to 2016 (both included), and for the five Labor Authority sites that compose the Regional Government of Castile-La Mancha. The collection of information, carried out by using quantitative techniques, through the compliance of a questionnaire or a pre-prepared checklist, of a dichotomous type, with regard to the most relevant items that directly affect this research and that set up the content of the Health and Safety Plans.

The extracted results show on the one hand the bad use that is actually made of the preventive instrument of the Plan and its scarce validity at a preventive level. On the other hand, it is observed that it is a document whose useful life is too limited, and that in most cases does not cover the total execution of the work, but rather that it ends before the work begins.

That is the reason why it is of imperative necessity to create a living tool that updates the state of the work and that is accessible to all the agents involved in the constructive-preventive processes, whether they belong to the public or private entity. This tool must therefore integrate the constructive-preventive processes of the work. 



\section{ABREVIATURAS}

\begin{tabular}{|c|c|}
\hline AENOR & Asociación Española de Normalización y Certificación \\
\hline BOE & Boletín Oficial del Estado \\
\hline CD & Compact Disk \\
\hline CEE & Comunidad Económica Europea \\
\hline CGSC & Convenio General del Sector de la Construcción \\
\hline CNAE & Clasificación Nacional de Actividades Económicas \\
\hline CNC & Confederación Nacional de la Construcción \\
\hline CSS & Coordinador de Seguridad y Salud \\
\hline CSSFE & Coordinador de Seguridad y Salud en fase de ejecución \\
\hline CSSFP & Coordinador de Seguridad y Salud en fase de proyecto \\
\hline DIRCE & Directorio Central de Empresas \\
\hline EBSS & Estudio Básico de Seguridad y Salud \\
\hline EPA & Encuesta de Población Activa \\
\hline EPI & Equipo de Protección Individual \\
\hline EBSS & Estudio Básico de Seguridad y Salud \\
\hline ESS & Estudio de Seguridad y Salud \\
\hline EUROSTAT & Oficina Europea de Estadística \\
\hline FLC & Fundación Laboral de la Construcción \\
\hline INE & Instituto Nacional de Estadística \\
\hline INSHT & Instituto Nacional de Seguridad e Higiene en el Trabajo \\
\hline ITSS & Inspección de Trabajo y Seguridad Social \\
\hline LGSS & Ley General de Seguridad Social \\
\hline LPRL & Ley de Prevención de Riesgos Laborales \\
\hline MESS & Ministerio de Empleo y Seguridad Social \\
\hline OIT & Organización Internacional del Trabajo \\
\hline OSHAS & Occupational Safety and Health Administration \\
\hline PIB & Producto Interior Bruto \\
\hline PRL & Prevención de Riesgos Laborales \\
\hline PSS & Plan de Seguridad y Salud \\
\hline PSSs & Planes de Seguridad y Salud \\
\hline PYME & Pequeña y Mediana Empresa \\
\hline RD & Real Decreto \\
\hline REA & Registro de Empresas Acreditadas \\
\hline RERA & Registro de Empresas con Riesgo de Amianto \\
\hline RSP & Reglamento de los Servicios de Prevención \\
\hline SPA & Servicio de Prevención Ajeno \\
\hline SPP & Servicio de Prevención Propio \\
\hline TGPE & Trabajador encargado de la Gestión Preventiva de la Empresa \\
\hline TGPO & Trabajador encargado de la Gestión Preventiva en Obra \\
\hline TPC & Tarjeta Profesional de la Construcción \\
\hline UNE & Una Norma Española \\
\hline VAB & Valor Añadido Bruto \\
\hline
\end{tabular}



ÍNDICE

DEDICATORIA VII

AGRADECIMIENTOS IX

RESUMEN XI

ABSTRACT XIII

ABREVIATURAS XV

ÍNDICE XVII

1. INTRODUCCIÓN

1.1. EL MOTIVO DE LA INVESTIGACIÓN 3

1.2. ESTRUCTURA DEL DOCUMENTO 8

2. OBJETIVOS DE LA INVESTIGACIÓN 11

2.1. OBJETIVOS GENERALES 13

2.2. OBJETIVOS ESPECÍFICOS 14

3. ESTADO DEL ARTE

3.1. EVOLUCIÓN DE LA PRL Y MARCO NORMATIVO DEL SECTOR 17

3.1.1. Hitos históricos relacionados con la Prevención de Riesgos Laborales y su evolución

3.1.2. Evolución normativa en materia de Prevención de Riesgos Laborales en la Unión Europea

3.1.3. Evolución normativa en materia de Prevención de Riesgos Laborales en España

3.1.4. Estudios realizados en materia de Prevención de Riesgos Laborales en el Sector de la Construcción

3.2. LA TRANSPOSICIÓN DE LA DIRECTIVA COMUNITARIA 92/57 CEE AL RD 1627/97

3.3. EL PLAN DE SEGURIDAD Y SALUD (PSS) 60

3.4. APRENDER DEL REAL DECRETO 396/2006 64

4. METODOLOGÍA $\quad 67$

4.1. FASES DEL ESTUDIO 69

4.2. LA CONSULTA COMO ESTRATEGIA DE INVESTIGACIÓN 72

4.2.1. Justificación de la consulta como estrategia de investigación $\quad 75$

4.2.2. Delimitación del tamaño de la muestra y del tipo de muestreo 77

4.2.3. Diseño del cuestionario 78 
4.2.3.1. Listado de ítems/preguntas que integran el cuestionario

80

5. RESULTADOS DE LA INVESTIGACIÓN

85

5.1. INTRODUCCIÓN RESULTADOS DE LA INVESTIGACIÓN

87

5.2. FIGURAS JURÍDICAS QUE INTERVIENEN EN OBRAS DE CONSTRUCCIÓN

5.2.1. Promotor, contratista, proyectista

5.2.2. Recurso Preventivo 95

5.2.2.1. Recurso Preventivo es el empresario 99

5.2.3. Subcontratista 101

5.2.4. Trabajador autónomo 106

5.2.5. Trabajador por cuenta ajena 108

5.2.6. Dirección Facultativa 110

5.2.7. Coordinador de Seguridad y Salud 112

5.2.7.1. Coordinador de Seguridad y Salud en fase de Proyecto 112

5.2.7.2. Coordinador de Seguridad y Salud en fase de Ejecución 115

5.2.7.3. Incompatibilidades de la figura del Coordinador de Seguridad y Salud

5.3. ASPECTO FORMAL DEL DOCUMENTO (PSS) 121

5.3.1. Unidades o fases de obra 121

5.3.2. PSS contiene material gráfico 123

5.3.2.1. PSS contiene material gráfico relacionado con la obra o la 125 maquinaria

5.3.3. PSS cuenta con pautas de actuación ante emergencias 127

5.3.4. PSS cuenta con itinerarios para llegar a centros asistenciales 129

5.3.5. PSS contiene pautas de actuación en caso de riesgo grave e inminente

5.3.6. PSS cuenta con Plan de Evacuación en caso de incendio 134

5.3.7. PSS cuenta con procedimientos de control de Seguridad Vial 136

5.3.7.1. PSS cuenta con Plan de Seguridad Vial específico 138

5.3.8. PSS cuenta con capítulo dedicado a la Seguridad y Salud en las Mediciones y Presupuesto

5.4. EVALUACIÓN DE RIESGOS DE LA OBRA 142

5.4.1. PSS evalúa cada fase/trabajo/puesto/actividad de la obra 143 
5.4.1.1. Los riesgos y medidas preventivas de cada fase/trabajo/puesto/actividad son específicos de cada 145 fase/trabajo/puesto/actividad

5.4.2. EI PSS identifica la maquinaria/equipos que se utilizan en obra

5.4.2.1. El PSS identifica y evalúa la maquinaria/equipos que se utilizan en obra

5.4.3. EI PSS identifica los medios auxiliares que se prevén utilizar en obra

5.4.3.1. El PSS identifica y evalúa los medios auxiliares que se prevén utilizar en obra

5.4.3.2. El PSS integra el manual de instrucciones y/o procedimientos de los medios auxiliares que se prevén utilizar en 154 obra

5.4.4. El PSS incluye los productos químicos que se van a utilizar en la obra

5.4.4.1. El PSS incluye las fichas de seguridad de los productos químicos que se van a utilizar en la obra

5.4.5. La Evaluación de Riesgos integrada en el PSS se ajusta a los determinado en el artículo 7 del Real Decreto 39/1997

5.4.6. Existe una planificación preventiva en el PSS como resultado de la Evaluación de Riesgos

5.4.6.1. La planificación preventiva se ajusta a los dispuesto en el artículo 9 del Real Decreto 39/1997

5.5. ANOMALÍAS E INCIDENCIAS RESEÑABLES

5.5.1. PSS en papel en blanco

5.5.2. CD que contiene PSS en blanco o no se puede abrir

5.5.3. PSS no guarda relación alguna con la obra descrita en el título

5.5.4. Mismo PSS para distintas obras

5.5.5. Se hace referencia al Estudio o Estudio Básico de Seguridad y Salud en el PSS

5.5.6. PSS no está firmado

6. CONCLUSIONES Y PROPUESTAS

6.1. PUNTO DE PARTIDA

6.2. CONCLUSIONES GENERALES

6.3. CONCLUSIONES ESPECÍFICAS 
6.3.1. Figuras jurídicas que intervienen en una obra de construcción 183

6.3.1.1. Promotor, contratista, proyectista 183

6.3.1.2. Recurso Preventivo 183

6.3.1.2.1. Recurso Preventivo es el empresario 184

6.3.1.3. Subcontratista 184

6.3.1.4. Trabajador Autónomo 184

6.3.1.5. Trabajador por cuenta ajena 184

6.3.1.6. Dirección Facultativa 185

6.3.1.7. Coordinador de Seguridad y Salud 185

6.3.1.7.1. Coordinador de Seguridad y Salud en fase de proyecto 185

6.3.1.7.2. Coordinador de Seguridad y Salud en fase de ejecución 186

6.3.2. Aspecto formal del documento 187

$\begin{array}{ll}\text { 6.3.2.1. Unidades o fases de obra } & 187\end{array}$

6.3.2.2. PSS contiene material gráfico 187

6.3.2.2.1. PSS contiene material gráfico relacionado con la obra o la maquinaria

187

6.3.2.3. PSS cuenta con pautas de actuación ante emergencias 188

6.3.2.4. PSS cuenta con itinerarios para llegar a centros asistenciales 188

6.3.2.5. PSS contiene pautas de actuación en caso de riesgo grave e inminente

188

6.3.2.6. PSS cuenta con Plan de Evacuación en caso de incendio 189

6.3.2.7. PSS cuenta con procedimientos de control de Seguridad Vial 189

6.3.2.7.1. PSS cuenta con Plan de Seguridad Vial específico 189

6.3.2.8. PSS cuenta con capítulo dedicado a la Seguridad y Salud en las mediciones y presupuesto

6.3.3. Evaluación de Riesgos de la obra 191

6.3.3.1. PSS evalúa cada fase/trabajo/puesto/actividad de la obra 191

6.3.3.1.1. Los riesgos y medidas preventivas de cada fase/trabajo/puesto/actividad son específicos de esa 191

fase/trabajo/puesto/actividad

6.3.3.2. EI PSS identifica la maquinaria/equipos que se utilizan en obra

6.3.3.2.1. PSS identifica y evalúa la maquinaria/equipos que se utilizan en obra 
6.3.3.3. EI PSS identifica los medios auxiliares que se prevén utilizar en obra

6.3.3.3.1. El PSS identifica y evalúa los medios auxiliares que se prevén utilizar en obra

6.3.3.3.2. El PSS integra el manual de instrucciones $y / 0$ procedimientos de los medios auxiliares que se prevén utilizar en 193 obra

6.3.3.4. El PSS incluye los productos químicos que se van a utilizar en la obra

6.3.3.4.1. EI PSS incluye las fichas de seguridad de los productos químicos que se van a utilizar en la obra

6.3.3.5. La Evaluación de Riesgos integrada en el PSS se ajusta a los determinado en el artículo 7 del Real Decreto 39/1997

6.3.3.6. Existe una Planificación Preventiva en el PSS como resultado de la Evaluación de Riesgos

6.3.3.6.1. La Planificación Preventiva se ajusta a los dispuesto en el artículo 9 del Real Decreto 39/1997

6.3.4. Anomalías e incidencias

6.3.4.1. PSS en papel en blanco

6.3.4.2. CD que contiene PSS en blanco o no se puede abrir

6.3.4.3. PSS no guarda relación alguna con la obra descrita en el título

6.3.4.4. Mismo PSS para distintas obras

6.3.4.5. Se hace referencia al Estudio o Estudios Básico de Seguridad y Salud en el PSS 

CAPÍTULO 1

INTRODUCCIÓN 



\subsection{EL MOTIVO DE LA INVESTIGACIÓN}

En el modelo productivo español, las pequeñas y medianas empresas (PYMES) concentran la mayor parte de la actividad comercial y son un elemento imprescindible para el correcto funcionamiento del engranaje empresarial español (Ministerio de Industria y Energía, 2016; Fariñas e Ituergo, 2015; Círculo de Empresarios, 2014), con una representación en el año 2015 del 99,68\% del total de empresas con asalariados a su cargo, inscritas en la Seguridad Social (Tabla 1.1). La proporción es muy similar a la de otros países, como es el caso de Portugal, donde las PYMES representan el 99,5\% de la actividad nacional (Santos et al., 2013).

\begin{tabular}{|c|c|c|c|c|c|c|c|c|}
\hline Tamaño empresa & Empresas & $\%$ & $\Sigma \%$ & Total & $\Sigma \%$ & Trabajadores & $\%$ & $\Sigma \%$ \\
\hline $\begin{array}{l}\text { Microempresas } \\
(1-9 \text { a.) }\end{array}$ & 1.124 .298 & 87,39 & & 39,80 & & 2.911 .052 & 21,03 & \\
\hline $\begin{array}{l}\text { Pequeñas } \\
(10-49 \text { a.) }\end{array}$ & 137.178 & 10,66 & 99,68 & 4,86 & 45,40 & 2.630 .534 & 19,00 & 54,92 \\
\hline $\begin{array}{l}\text { Medianas } \\
\text { (50-249 a.) }\end{array}$ & 21.010 & 1,63 & & 0,74 & & 2.060 .848 & 14,89 & \\
\hline PYME (1-249 a.) & 1.282 .486 & 99,68 & & 45,40 & & 7.602 .434 & 54,92 & \\
\hline $\begin{array}{l}\text { Grandes } \\
(\geq 250 \text { a.) }\end{array}$ & 4.079 & 0,32 & 100,00 & 0,14 & 45,54 & 4.703 .439 & 33,97 & 88,89 \\
\hline $\begin{array}{l}\text { Empresas } \\
\text { con a. }\end{array}$ & 1.286 .565 & & & 45,54 & 100,00 & 12.305 .873 & 88,89 & 100,00 \\
\hline Empresas sin a. & 1.538 .757 & & & 54,46 & & 1.538 .757 & 11,11 & \\
\hline Total & 2.825 .322 & & & & & 13.844 .630 & & \\
\hline
\end{tabular}

Tabla 1.1. Empresas y Trabajadores inscritos en la Seguridad Social en diciembre de 2015. Fuente: Ministerio de Empleo y Seguridad Social (MEySS) (Ministerio de Industria, Energía y Turismo, 2016).

Donde: a. (asalariados). Elaboración propia.

Las PYMES, que representan el 45,40 \% del total de empresas (sumatorio de empresas con y sin asalariados), y las grandes empresas, que actualmente representan el 0,14 \% del total, sí están obligadas a realizar actividades preventivas en el ejercicio de su actividad. No obstante, debido a su diferente estructura corporativa, las exigencias preventivas son menores en las PYMES que en las grandes empresas. En la presente investigación se analizan todas las figuras con responsabilidad que aparecen en las obras de construcción, haciendo especial hincapié en las obligaciones de estas figuras 
Ejemplo de ello es la aplicación restrictiva de ciertos instrumentos preventivos, como es el caso del Comité de Seguridad y Salud, que en España se constituye a partir de 50 o más trabajadores, mientras que, en otros países, como es el caso de Dinamarca, se establece una Organización de Seguridad y Salud con 20 o más trabajadores (Ozmec et al., 2015).

El Sector de la Construcción representa una parte importante en el tejido empresarial español (Camino et al., 2008), siendo las PYMES las que asumen la mayor parte de los trabajos de externalización en las obras de gran tamaño y las actividades menores, relacionadas con los trabajos de obra civil y la rehabilitación y reforma de edificios (Paramio, 2009; Biggs et al., 2005; REA, 2015), por lo que una buena gestión corporativa de la seguridad contribuiría a mejorar la siniestralidad (Bottani et al, 2009; Suraji et al., 2001).

A pesar del desarrollo normativo y del empeño de las Administraciones Públicas por implantar la seguridad industrial en las empresas, y fomentar la formación en materia preventiva de sus trabajadores, la construcción es un sector especialmente crítico desde el punto de vista de la siniestralidad laboral (Kanchana et al., 2015), especialmente en las pequeñas y medianas empresas, donde la falta de compromiso en la gestión puede comprometer la seguridad (Häkkinen, 1995). La integración de la seguridad en el sistema de gestión corporativa de las pequeñas y medianas empresas minimizaría el riesgo de accidentes, con un mayor control de los procesos de producción y una comunicación directa con los trabajadores implicados en ellos (Fernández-Muñiz et al., 2009).

Si analizamos nuestro entorno más próximo, España presenta una alta tasa de siniestralidad laboral en comparación con el resto de países de Europa (López et al, 2012; Segarra et al., 2017). En efecto, si tomamos como referencia la población de España (46.439.864 habitantes) con respecto a otros países similares como es el caso de Polonia (38.005.614 habitantes) o de Italia (60.795.612 habitantes) (Eurostat, 2016) (Fig. 1.1), se puede observar que el índice de incidencia de los accidentes de trabajo en las PYMES es superior en todos los Sectores Productivos (Fig. 1.2), llegando a mostrar un repunte en el último año del estudio en comparación con el resto de países. Lo mismo ocurre cuando analizamos los datos pertenecientes al Sector de la Construcción (Fig. 1.3), en el periodo comprendido entre los años 2008 a 2013. 


\section{Población}

Millones de habitantes

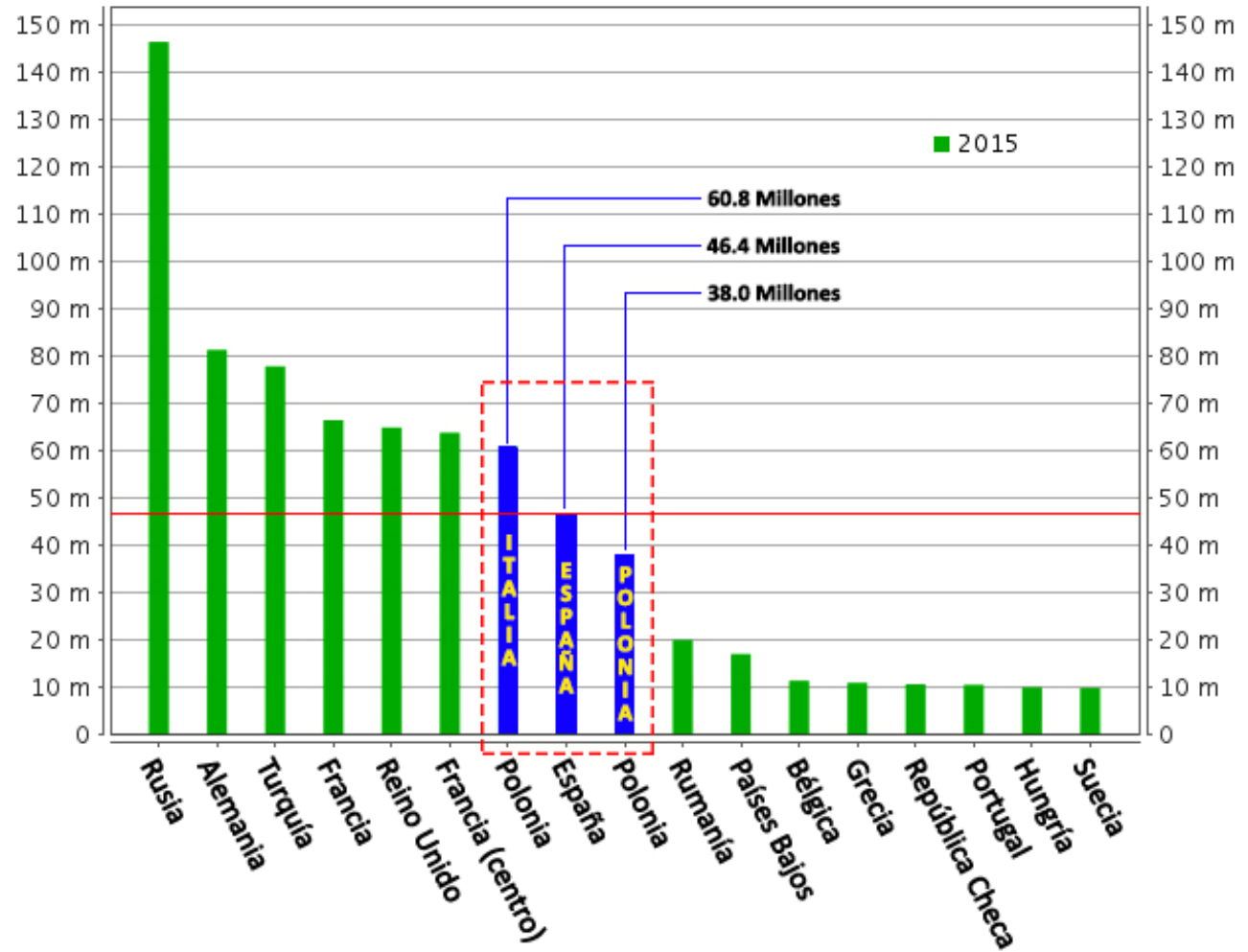

Fig. 1.1. Distribución de la población europea en millones de habitantes (orden descendiente). Fuente: Eurostat, 2016. Elaboración propia.

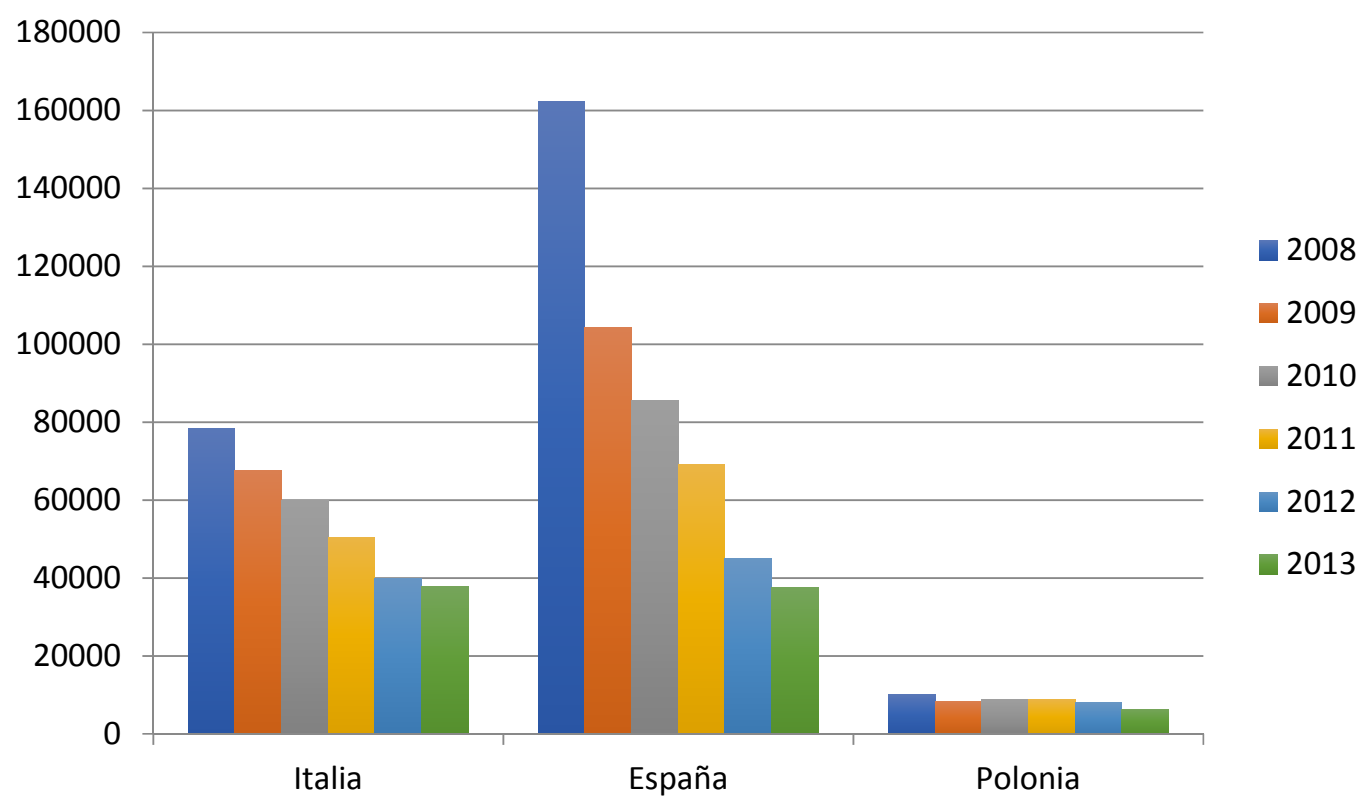

Fig. 1.2. Distribución de los accidentes de trabajo en PYMES de todos los sectores: Índice de Incidencia. Fuente: Eurostat, 2016. Elaboración propia. 


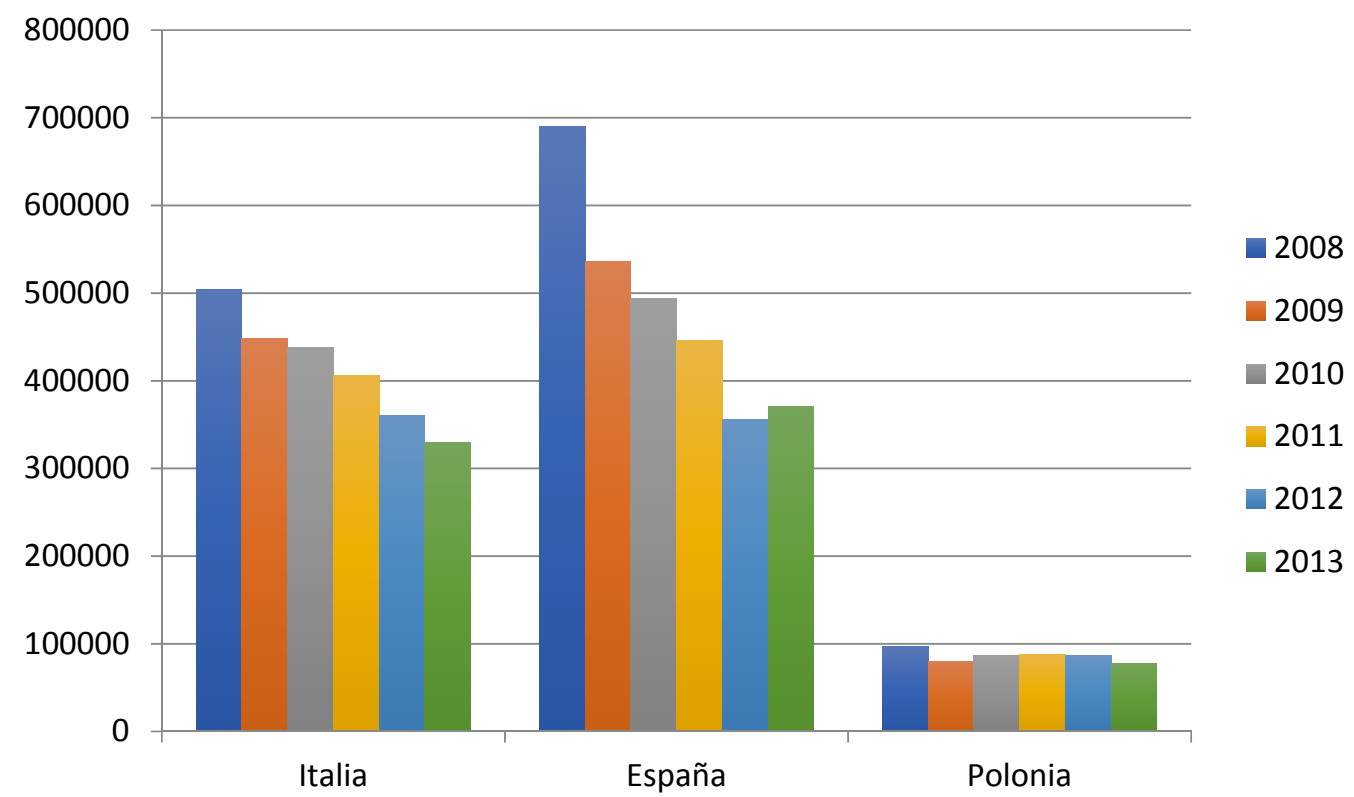

Fig. 1.3. Distribución de los accidentes de trabajo en PYMES del sector de la construcción: Índice de Incidencia. Fuente: Eurostat, 2016. Elaboración propia.

No obstante, se puede comprobar una desaceleración importante del Índice de Incidencia a partir del año 2008 en el Sector de la Construcción, que puede explicarse por tres motivos destacables:

En primer lugar, por la promulgación de normativa derivada del Marco Legal de referencia establecido por la Ley 31/1995, de 8 de noviembre, de Prevención de Riesgos Laborales (LPRL) (BOE, 1995), del Real Decreto (RD) 39/1997, de 17 de enero, por el que se aprueba el Reglamento de los Servicios de Prevención (BOE, 1997a) y del RD 1627/97, de 24 de octubre, por el que se establecen disposiciones mínimas de seguridad y salud en las obras de construcción (BOE, 1997b), especialmente en lo referido a la Coordinación de Actividades Empresariales (BOE, 2004; INSHT, 2011), modificaciones introducidas en la LPRL (BOE, 2003) y los condicionantes establecidos a la facultad de subcontratar en el Sector de la Construcción (BOE, 2006a).

Con este marco regulador se incrementó la actividad de la Inspección de Trabajo y de la Seguridad Social, con actuaciones especialmente contundentes en sectores con mayor siniestralidad, como en el caso de la construcción. También se crearon los Planes de Acción Preferente (Peláez, 2006) y la figura del Fiscal de Sala Coordinador de la Siniestralidad Laboral, que pretendía dar una respuesta especializada al problema de la alta accidentalidad (Gutiérrez, 2002; Huete, 2007). 
Por último, indicar que a partir de 2008 el Sector de la Construcción en España se encuentra ya sumido en plena crisis, con una caída importante de la actividad y la desaparición de empresas y puestos de trabajo, tanto directos como indirectos (INSHT, 2009; INSHT, 2014a), lo que también explica la reducción de la siniestralidad por la pérdida de protagonismo del sector en la actividad productiva.

La siniestralidad del sector está íntimamente asociada al modelo de gestión (Segarra et al., 2017) y al nivel de formación e información de sus responsables y de todos los agentes involucrados en los procesos constructivo-preventivos (Romero et al., 2018). La deficiente estructura organizativa de las empresas del Sector, compuesto en su inmensa mayoría por PYMES (Ministerio de Industria y Energía, 2016), unida a la escasa, y en muchos casos inexistente, integración de la prevención en la estructura misma de las empresas (Segarra, M., 2015), explican el escaso éxito en la gestión de los riesgos en este tipo de empresas (Lyons y Skitmore, 2004; Kim y Bajaj, 2000). Lo que traducido al entorno de las obras de construcción, en las que el centro de trabajo es la propia obra, esta integración de la gestión preventiva se realiza a través del documento común de trabajo que es el Plan de Seguridad y Salud en el Trabajo (PSS), que recoge la propia estructura organizativa del centro de trabajo.

Esta investigación aporta datos acerca del instrumento preventivo por excelencia que se utiliza en las obras de construcción, el PSS, al tratarse de un requisito obligatorio impuesto por Ley, junto con el Comunicado de Apertura de Centro de Trabajo. A partir de la aplicación y efectividad del Marco de Referencia Normativo y del entorno en el que realiza su actividad productiva (Sobotka y Czarnigowska, 2005), con el propósito de conseguir una mayor implicación de los agentes que participan en los procesos de construcción, se analiza la efectividad real de este instrumento preventivo dentro de la realidad de las obras de construcción. 


\subsection{ESTRUCTURA DEL DOCUMENTO}

En aras de conseguir una lectura estructurada del documento de la Tesis, se decide dividir el mismo en capítulos y subcapítulos que desarrollen el contenido general y/o específico que le corresponda. Es por ello que en la Figura 1.4. se recoge el esquema empleado al principio de cada capítulo del documento de la Tesis que estructura esta división en capítulos y que ayuda en la comprensión lectora del documento, permitiendo localizar cada capítulo de forma rápida y eficaz, a la vez que sitúa cada capítulo en el contexto general del documento.

\begin{tabular}{l|}
\hline Capítulo 1 \\
Capítulo 2 \\
Capítulo 3 \\
Capítulo 4 \\
Capítulo 5 \\
Capítulo 6 \\
Capítulo 7 \\
\hline
\end{tabular}

\section{INTRODUCCIÓN}

OBJETIVOS

ESTADO DEL ARTE

METODOLOGÍA

RESULTADOS DE LA INVESTIGACIÓN

CONCLUSIONES Y PROPUESTAS

ORIENTACIÓN PARA FUTUROS TRABAJOS

Figura 1.4. Esquema de la estructura capitular de la Tesis doctoral.

Tal y como ejemplifica el esquema, se procede a resaltar con otros colores a los mostrados en la Figura 1.4 el capítulo en el que nos encontramos, para facilitar la lectura global del documento.

Dicho esto, se pasa a especificar, de forma esquemática, el contenido que desarrolla cada capítulo del documento:

En el Capítulo 1 se analiza el complejo Sector de la Construcción, su influencia en la economía española, la importancia de las PYMES (que representan el $99,68 \%$ del tejido empresarial del sector), así como la elevada siniestralidad laboral que asola dicho sector productivo, los cuales fundamentan los motivos por los que se realiza la presente investigación, basados en el conocimiento de los instrumentos preventivos de que se dispone en obra. Asimismo, se muestra el modelo estructural seleccionado para compartimentar del documento, que permite 
poder presentar de forma coherente y estructurada las diferentes fases de la investigación en las que se fundamenta el documento de la Tesis, así como enfatizar el capítulo en el que nos encontramos.

En el Capítulo 2 se hace mención expresa a los objetivos generales y específicos de la investigación objeto de la presente Tesis, en relación con la utilidad real o no del actual documento preventivo por excelencia utilizado en obras de construcción, el Plan de Seguridad y Salud.

El Capítulo 3 integra la evolución de la Prevención de Riesgos Laborales a lo largo de la historia de este país, además de la legislación europea que afecta al sector. Se muestran las figuras con responsabilidad en obras de construcción que posteriormente se analizarán en el aparatado de resultados del documento, con sus principales obligaciones. Todo esto se realiza mediante un estudio pormenorizado del estado del arte que afecta de forma directa e indirecta al objeto de la presente investigación.

En este mismo capítulo se estudian los hitos relacionados con la Prevención de Riesgos Laborales, así como su evolución histórica.

Por último, se recopilan los estudios e investigaciones realizadas que pueden servir como guía o punto de partida para la presente investigación.

En el Capítulo 4 se muestra la metodología empleada para la presente investigación, en combinación con los procedimientos y fases de la investigación. Se dedica especial atención a la técnica prospectiva empleada para obtener los datos, mediante la consulta in situ de los Planes de Seguridad y Salud en el Trabajo para el período de tiempo de 2008 a 2016 y para las cinco sedes de la Autoridad Laboral que integran la Junta de Comunidades de Castilla-La Mancha. En este capítulo también se muestra el cronograma de trabajos planteado para la ejecución de las visitas a las sedes, previo a la firma del convenio que permitió realizar las visitas a las sedes y recopilar la información.

En el Capítulo 5 se recogen y analizan los resultados obtenidos a raíz de la investigación llevada a cabo en las cinco sedes de la Autoridad Laboral de la Junta de Comunidades de Castilla-La Mancha. Los mismos se han compartimentado en apartados y subapartados para facilitar su comprensión y lectura en cascada, 
realizando una primera división en tres grandes grupos, que a su vez se subdividen en:

1. Figuras jurídicas que intervienen en obras de construcción.

2. Aspecto formal del documento (PSS).

3. Anomalías e incidencias reseñables.

En el Capítulo 6 se aúnan las conclusiones emanadas a raíz de los resultados obtenidos en el capítulo anterior, que a su vez se dividen en conclusiones generales y específicas. En el mismo capítulo se recogen las propuestas de mejora que se proponen en aras de mejorar la utilidad del instrumento preventivo objeto de análisis.

En el Capítulo 7 se recopilan las futuras líneas de investigación que pueden ser llevadas a cabo en base a los datos obtenidos en la presente investigación, que pueden servir como guía o de punto de partida. 
CAPÍTULO 2

OBJETIVOS 



\subsection{OBJETIVOS GENERALES}

El objetivo general, razón de la presente investigación, es determinar si los actuales instrumentos preventivos, nacidos de la necesidad de reducir la siniestralidad laboral en el Sector de la Construcción, desempeñan una utilidad real; o si por el contrario, la funcionalidad y aplicabilidad de dichas herramientas preventivas, resultan poco útiles o prácticamente nulas en la realidad del entorno de las obras de construcción.

Se propone por lo tanto analizar y evaluar el instrumento preventivo desde su concepción inicial, su posible verificación e intervención por parte de la Autoridad Laboral competente, hasta llegar a su materialización y puesta en funcionamiento. Para hacer lo anteriormente descrito, se recurre al instrumento preventivo conocido como Plan de Seguridad y Salud, como herramienta empleada desde la concepción inicial de la obra en materia de Seguridad y Salud y que ha de ir siendo modificado a la vez que avanza la obra, por lo que se podría establecer un cierto paralelismo entre el progreso de la obra y lo recogido en el Plan. Por supuesto, esto supone entender la obra como un organismo vivo en constante cambio, lo que ha de extrapolarse a su instrumento preventivo, el Plan de Seguridad y Salud. 


\subsection{OBJETIVOS ESPECÍFICOS}

A modo de ítems reseñables se esquematizan los principales objetivos específicos que de la presente investigación se extractan:

1. Analizar y evaluar el contenido de un instrumento preventivo analizando la figura del Plan de Seguridad y Salud para identificar posibles deficiencias en el mismo.

2. Proponer medidas de mejora en el contenido específico del Plan de Seguridad y Salud para posteriormente implementar la prevención en las obras.

3. Conocer las obligaciones de todos los agentes implicados en la elaboración y aprobación del Plan de Seguridad y Salud.

4. Analizar el Plan de Seguridad y Salud como documento integrador del conjunto de actuaciones y acciones llevadas a cabo en las obras de construcción, incluyendo las acciones preventivas.

5. Realizar los análisis pertinentes de los datos extraídos de las comparativas realizadas a los instrumentos preventivos; respecto a su provincia de origen, por Comunidades Autónomas, para finalizar con el extracto de conclusiones a nivel estatal.

6. Evaluar las diferencias y similitudes entre los contenidos de los Planes de Seguridad y Salud atendiendo a razones geográficas.

7. Analizar la evolución y/o transformación en la redacción de los Planes de Seguridad y Salud en el período de estudio. 
CAPÍTULO 3

ESTADO DEL ARTE 



\subsection{EVOLUCIÓN DE LA PREVENCIÓN DE RIESGOS LABORALES (PRL) Y MARCO NORMATIVO DEL SECTOR}

En este apartado se estudia la línea temporal que recoge todos aquellos hitos relevantes en materia de $P R L$ que han afectado de una manera $u$ otra a la actual concepción de dicho concepto, la prevención. Esto se torna meridiano al comprender que el hombre, como especie animal, siempre ha tenido que trabajar para poder subsistir, ya fuese recolectando frutas, cazando, o en una sociedad más avanzada realizando un oficio, en cualquier caso, el trabajo lleva intrínseco un riesgo para la salud del trabajador, debiéndose tomar conciencia de la peligrosidad que entrañan las diversas tareas o trabajos y debiendo actuar en consecuencia para paliar esos peligros o riesgos inherentes a la actividad profesional.

Posteriormente, se analiza el camino andado en materia de legislación de PRL hacia la correcta integración de dicha materia en los distintos sectores productivos y profesiones existentes, en aras de conseguir mejorar la seguridad y la salud de los trabajadores expuestos a los riesgos derivados del ejercicio de su actividad. Para ello, se analiza la normativa en materia de Prevención, tanto a nivel europeo como a nivel nacional, de forma pormenorizada, hasta llegar a la normativa que afecta de manera concreta al instrumento preventivo objeto de la presente investigación, el Plan de Seguridad y Salud.

\subsubsection{HITOS HISTÓRICOS RELACIONADOS CON LA PRL Y SU EVOLUCIÓN}

A modo de resumen se recogen los hitos más relevantes que se han producido a lo largo de la historia en materia de PRL, entendiendo que esta debería ir de la mano de la evolución en las técnicas y los trabajos. Es de sobra conocido que la causa de que millones de personas hayan muerto, mueran y que sigan muriendo en el trabajo (aplíquese los mismo para las lesiones que derivan en invalidez o las enfermedades producidas a consecuencia de la realización del trabajo) es la ineficacia a la hora de una correcta integración de la prevención en el entorno laboral, tan prioritaria a la hora de evitar esta consecuencia funesta. Conocedores de la necesidad del individuo de trabajar en una sociedad en la que la evolución de la técnica ha transformado el mundo tal y como lo conocemos, lo que produce 
que el trabajador se enfrente a un riesgo para poder subsistir, tal y como se deduce de las definiciones que el diccionario de la lengua española, de la Real Academia Española da del término trabajo:

1. Acción y efecto de trabajar.

2. Ocupación retribuida.

3. Obra (cosa producida por un agente).

4. Cosa que es resultado de la actividad humana.

5. Operación de la máquina, pieza, herramienta o utensilio que se emplea para algún fin.

6. Esfuerzo humano aplicado a la producción de riqueza, en contraposición a capital.

7. Lugar donde se trabaja.

8. Dificultad, impedimento o perjuicio.

9. Penalidad, molestia, tormento o suceso infeliz.

10. Producto de la fuerza por la distancia que recorre su punto de aplicación.

11. Preparación por medio de poderes sobrenaturales de una persona para protegerla o para perjudicarla, y de una cosa para usarla como amuleto.

12. Estrechez, miseria y pobreza o necesidad con que se pasa la vida.

De lo que se puede extractar que varias de las distintas acepciones del término "trabajo" acarrean una connotación negativa, con calificativos como penalidad, molestia, miseria, perjuicio, etc. lo que es entendido al conocer que dicha palabra deriva del latín "tripalium" (Werner, 2008), como "instrumento de tortura constituido por tres varas" (de ahí que tripaliare signifique tortura, causar dolor o atormentar) lo que vuelve a poner de manifiesto la connotación negativa del término.

A continuación, se muestran en la Tabla 3.1 los hitos históricos (García, 2008; Calderón, 2006; Segarra, 2015) que han marcado la concepción que a día de hoy tenemos de la Prevención, estrechamente ligada a la seguridad y salud laboral. 
Época o período

Neolítico

Prehistoria

2200 a.C

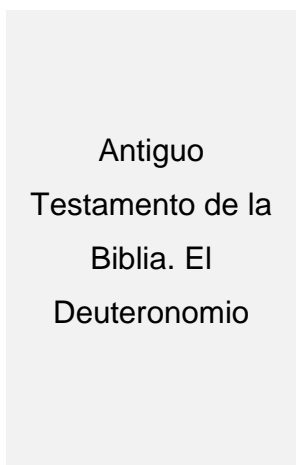

Antiguo Egipto

\section{Hito}

Accidente de trabajo

Actividades

preventivas

\section{Código Legal de}

Hammurabi

Adopción de

medidas

preventivas para

evitar daños

Implantación de

medidas

preventivas en

obra
Desarrollo

Derrumbamiento de una galería subterránea de la cantera de sílice en la zona de Oubourg, Bélgica. Se trata de la primera referencia conocida sobre un accidente de trabajo en donde se relaciona el daño producido con la causa (el accidente de trabajo).

Empleo de amuletos y/o danzas rituales para proteger a los cazadores, invocando a los espíritus protectores.

Ley del Talión: prescripciones derivadas de los daños sufridos.

Si un trabajador perdía un brazo debido a un descuido o negligencia del capataz, se procedía a cortar el brazo del mismo en contraprestación a la pérdida sufrida por el trabajador.

Al constructor que edificase una casa, si ésta se derrumbase causando la muerte del dueño, se le castigaba con la pena de muerte. Los derrumbes que no producían daños corporales eran sentenciados con la reconstrucción a cargo del contratista (medida muy similar a la actual responsabilidad de promotores $y$ contratistas durante los diez años siguientes a la ejecución de la obra).

Se hace referencia a los peligros que entrañan determinados trabajos de construcción, así como los derivados del plomo. Se incluyen las sanciones que llevan aparejadas las infracciones de ciertas normas laborales, p.e.: “...cuando construyas una casa nueva, harás un pretil a tu terrado y así no cargarás culpa de sangre sobre tu casa si alguien cae sobre él".

Durante las labores de izado de una estatua del Templo de Amón, debido a las extremadamente altas temperaturas, se dispuso el empleo de aguadores especiales para los esclavos que tiraban de las cuerdas. 
Grecia clásica.

Hipócrates. Siglo

V a.c.

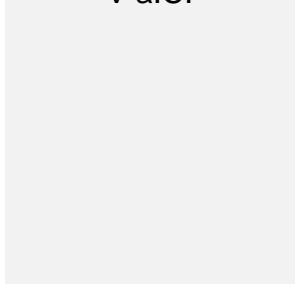

Época clásica.

Estrabón, Plinio y

Dioscovides

Platón (429-347

a.C.)

Aristóteles (384-

322 a.C.)

Platón,

Aristóteles,

Cicerón y Séneca

Lex Aquilia. 286

a.C.

Areteo de

Capadocia. 250

a.C.
Estudio sobre la

pérdida de salud a

consecuencia del

trabajo

Análisis de

accidentes

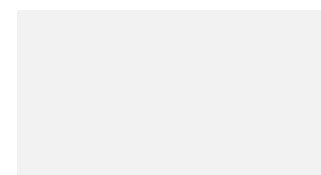

Análisis postural

Medicina

preventiva

Penosidad del

trabajo. Leyes

Manú

Indemnización por

daño a esclavo

Medicina

preventiva
Apodado Padre de la Medicina, fue Hipócrates el que primero se preocupó de las enfermedades profesionales, estableciendo relaciones entre la enfermedad y el medio ambiente laboral y social. En sus escritos se encuentran recogidas las intoxicaciones por plomo producidas al respirar en las minas, la impotencia que presentaban los jinetes debido a cabalgar por largas horas, los beneficios que los baños de limpieza producían en la prevención contra intoxicaciones (como las saturnianas).

Reflexionan sobre los peligrosos accidentes que afectan a los recolectores de esparto, llegando a recomendar medidas específicas de seguridad para dichas labores.

Observa y define las deformaciones encontradas en los esqueletos de algunos hombres dedicados a profesiones de peligro. Plinio el Viejo señaló la forma de evitar el saturnismo en los trabajos que se realizaban en las minas de plomo, mediante la utilización de caretas protectoras.

Previene enfermedades de los corredores.

"Todas las ocupaciones manuales carecen de nobleza, pues es imposible a quien cultiva la sabiduría, poder vivir la vida de un obrero".

"Es propio del hombre bien nacido, despreciar el trabajo".

Se consagró por primera vez la posibilidad de que el daño inferido a las cosas permitiese a su propietario reclamar una reparación equivalente al valor máximo que aquéllas adquiriesen durante los treinta días siguientes a la producción del daño.

Describe las intoxicaciones derivadas del trabajo con plomo. 
Viriato. 145 a.C.

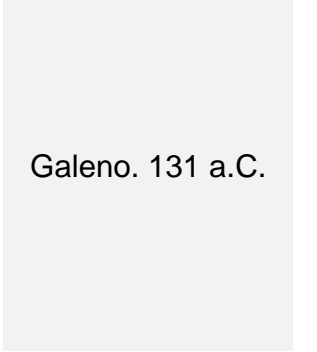

Varrón. Siglo I

a.C.

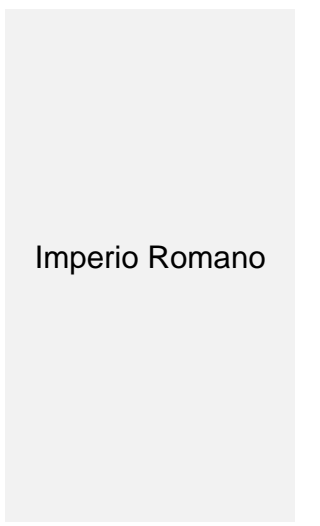

Imperio romano

Imperio romano
Añade un valor

social

Medicina

preventiva

Tratado sobre

Agricultura

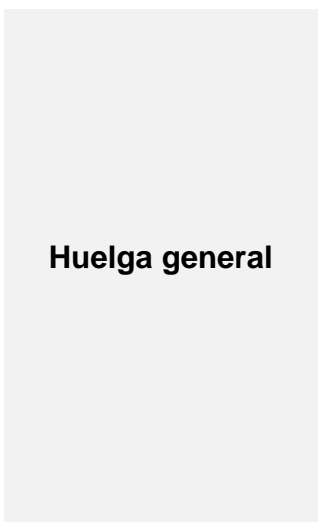

Collegia Funeraria

\section{Contratos de} trabajo
Instigador de las guerras reivindicativas de los derechos sociales.

Trata el saturnismo, así como otras enfermedades relacionadas con el oficio de minero, curtidor, batanero, cargador, etc. También realiza las mismas acciones con los gladiadores pertenecientes a la Escuela de Pérgamo.

Denomina a los esclavos como "instrumentos parlantes", en alusión directa a que los esclavos, que son la base de la producción, son tratados como si fueses objetos.

En los enfrentamientos entre Patricios, se produce la considerada como primera huelga general de la historia. Nacida de los enfrentamientos entre los Patricios (ciudadanos con ciertos derechos públicos) y los plebeyos (artesanos, comerciantes, agricultores, etc.). El resultado, lo recoge la Ley de las XII Tablas, generalización del Derecho.

De sobra son conocidas las rebeliones de esclavos, producidas durante el expansionismo romano, que ante la escasez de los mismos, se genera un trato más humano con ellos. Las corporaciones que agrupan a los esclavos son conocidas por Collegia Funeraria, y proporcionan servicios de asistencia en caso de enfermedad o accidente de trabajo (antecedente de las Mutuas de Accidentes de Trabajo y Enfermedades Profesionales), además de su objetivo necrológico.

De esas mejoras del esclavo se derivan los primeros contratos de trabajo a través de la Locatio operis (trabajo autónomo a obra completa) y la posterior Locatio operarum (contratación formal por cuenta ajena). Este es el origen del trabajo autónomo y de los servicios profesionales, además del contrato de trabajo. 
Germanización

III Concilio de

Toledo. 589 d.C.

Auxerre. 600 d.C.

IV Concilio de

Toledo. 633 d.C.

Concilio de

Verberic. 756

d.C.

Islamismo

\section{Avicena (980 - \\ 1037 d.C.)}

Edad Media.

Siglo XI
Código de

Recesvinto

Contratos de

trabajo

\section{Mejoras sociales}

del trabajador

Mejoras de las

condiciones de

trabajo

Mejora de la

técnica

Mejora social

El Corán

Canon de

medicina

Actas

catedralicias de

León
Es considerado como un importante precedente sobre las normas de seguridad e higiene en el trabajo. Llegando a encontrar aclaraciones a una pretendida gestión de la salud.

Al igual que sucediese en el Imperio Romano, el trabajo del siervo es la base del sustento económico de la sociedad, debiéndose ejecutar para su señor natural (trabajador por cuenta ajena), aunque se encuentran también situaciones de trabajo por cuenta propia.

La producción se alcanza a través de la servidumbre y en la transición de esclavo a siervo, la ideología católica tiene una influencia clara y determinante en dichas medidas a partir del citado concilio.

Se prohíbe a los esclavos trabajar en domingo.

Se establecen cánones arquitectónicos y modelos constructivos.

Se autoriza el matrimonio entre esclavos y se prohíbe al dueño el separar a los casados cuyo matrimonio hubiese aprobado.

Se convierte en norma de comportamiento y de actuación en el ámbito de trabajo. Se divide en tres grupos: el artesano, el comercio y la agricultura, imponiéndose el sistema de explotación en aparcería, en contrato entre dos hombres libres (el señor de la tierra y el colono).

Llegó a relacionar los cólicos saturninos con el empleo de pintura con sales de plomo.

Aparece el trabajo asalariado y se establecen normas concretas que regulan todo lo relacionado con el pago de haberes a los operarios que sufrían accidentes. 


\begin{tabular}{|c|c|c|}
\hline 1020 d.C. & $\begin{array}{c}\text { Fuero de } \\
\text { Villavencio }\end{array}$ & Permite la compensación en especies. \\
\hline $\begin{array}{c}\text { Zamora } 1158 \\
\text { d.C. }\end{array}$ & Motín de la Trucha & $\begin{array}{l}\text { Estallan gran cantidad de conflictos unidos a } \\
\text { condiciones laborales, sociales, fiscales, etc. a } \\
\text { circunstancias relacionadas con el trabajo. }\end{array}$ \\
\hline Edad Media & $\begin{array}{l}\text { Análisis de las } \\
\text { condiciones de } \\
\text { trabajo }\end{array}$ & $\begin{array}{l}\text { Se consideran los accidentes de trabajo como } \\
\text { resultado de acciones fortuitas y sólo desde la } \\
\text { voluntariedad puede ejercitarse la justicia } \\
\text { reparadora. El análisis de las condiciones de } \\
\text { trabajo a través de los fueros municipales y de } \\
\text { las cartas pueblas, da como resultado unos } \\
\text { verdaderos "contratos de trabajo" firmados o } \\
\text { convenidos entre el señor y los nuevos } \\
\text { moradores. }\end{array}$ \\
\hline $\begin{array}{l}\text { Alfonso X el } \\
\text { Sabio (1252- } \\
1284 \text { d.C.) }\end{array}$ & $\begin{array}{l}\text { Sustitución del } \\
\text { Fuero Viejo por el } \\
\text { Fuero Real }\end{array}$ & $\begin{array}{l}\text { Primera obra legislativa de su reinado. Una } \\
\text { parte de la misma está dedicada a la gestión } \\
\text { del trabajo y entiende el accidente derivado del } \\
\text { mismo en función de las categorías sociales, } \\
\text { obligando a la toma de medidas preventivas } \\
\text { que lo eviten; p.e.: aviso previo en las talas de } \\
\text { árboles o derribos de pared, protección de } \\
\text { huecos de silos o pozos en carreteras y plazas, } \\
\text { devengo de salario estipulado en despido sin } \\
\text { causa. }\end{array}$ \\
\hline $\begin{array}{l}28 \text { de agosto de } \\
1265 \text { d.C. }\end{array}$ & $\begin{array}{c}\text { Ley de las Siete } \\
\text { Partidas }\end{array}$ & $\begin{array}{l}\text { La "democracia laboral" pierde hegemonía en } \\
\text { beneficio de la iglesia. Se diferencia el trabajo } \\
\text { que se hace en el campo y el que se efectúa } \\
\text { en talleres o en la propia casa y desaparece la } \\
\text { norma de inspiración castellana del despido } \\
\text { sin causa. El concepto de asistencia social no } \\
\text { alcanza todavía el sentido que se le dará más } \\
\text { tarde, y el paro obrero no es comprendido sino } \\
\text { como signo de vagancia. }\end{array}$ \\
\hline $\begin{array}{l}\text { Cortes de Sevilla. } \\
\qquad 1252 \text { d.C. }\end{array}$ & $\begin{array}{l}\text { Regulación del } \\
\text { desempeño del } \\
\text { trabajo }\end{array}$ & $\begin{array}{l}\text { Se prohíben las Cofradías mercantiles que no } \\
\text { estuviesen sujetas al control público, por } \\
\text { considerarlas como subversivas. }\end{array}$ \\
\hline $\begin{array}{l}\text { Cortes de } \\
\text { Valladolid. } 1258 \\
\text { d.C. }\end{array}$ & $\begin{array}{l}\text { Regulación del } \\
\text { desempeño del } \\
\text { trabajo }\end{array}$ & $\begin{array}{l}\text { Se prohíben las Corporaciones de Oficios, } \\
\text { mercantiles y laborales "rebeldes", es decir, } \\
\text { independientes y no controladas por el poder } \\
\text { público. }\end{array}$ \\
\hline
\end{tabular}


Cortes de Jerez.

1268 d.C

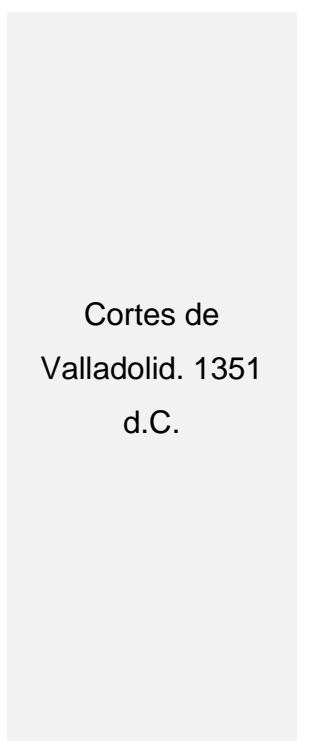

Libro del

Consulado del

Mar. 1300 d.C.

Barcelona 1357

d.C.

Cortes de Toro.

1369 d.C

\section{Regulación del}

desempeño del

trabajo

\section{Regulación del}

desempeño del

trabajo

\section{Primer código de}

derecho marítimo

\section{Gremio de los}

Vayneros

\section{Regulación del \\ desempeño del trabajo}

Se prohíben los Gremios en términos similares a los anteriormente recogidos.

Se establece el "ordenamiento de Menestrales y Posturas" aprobados por el rey de Castilla, Pedro I, y en el que se relacionan las distintas actividades económicas reguladas por el Rey: los jornales de carpinteros, tundidores, zapateros, armeros, pastores, canteros, etc. De esta forma se prohíben los monopolios comerciales ante las quejas presentadas al respecto, así como también por la proliferación de asociaciones surgidas en la clandestinidad. Se establece también que los que trabajen en la construcción en calidad de jornaleros, sean contratados en la plaza pública.

La política y gobierno de embarcaciones de Barcelona ofertaban un rosario de derechos y deberes, así como de gestión de las condiciones de trabajo en el mar. Se regula el jornal del marinero y su derecho a poder reclamarlo, se obliga a que el marinero reciba el género en la escotilla y no tenga obligación de estibar, salvo abono por parte convenida. Se prohíbe el despido libre de un marinero, para contratar a otro y se obliga a pagar todo el salario al marinero accidentado. Más tarde se promulga el Seguro de Accidentes del Trabajo en el mar.

Se prohíbe a sus asociados trabajar con luz artificial, debiéndose de realizar el trabajo en momentos de luz diurna.

Se aprobó otra disposición laboral de interés relativa a la obligación de trabajar, salvo a menores, accidentados, enfermos y ancianos (como antecedente previo a la jubilación). Se ratifica lo ordenado en las Cortes de Valladolid a los jornaleros, para salir cada día a la plaza pública "con sus herramientas y con su vianda", para trabajar de sol a sol. 
Cortes de

Burgos. 1373

d.C.

Europa. 1413

d.C.

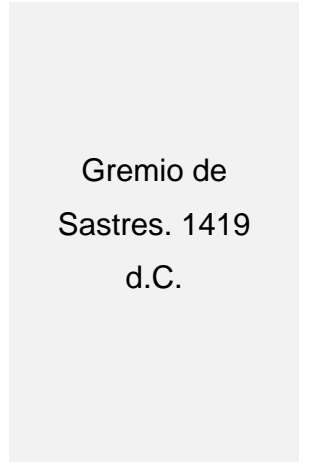

Europa. 1473

d.C.

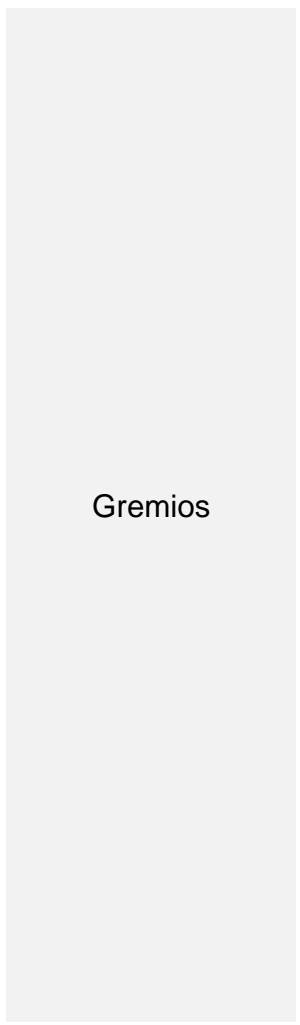

Gremios
Higiene Industrial

Historia

económica de

España

\section{Regulación del}

desempeño del trabajo

Ordenanzas en

Francia

Historia
económica de
España

\section{Regulación de las}

Condiciones de

Trabajo

\section{Mejoras Gestión}

de la Salud y

Seguridad en el

Trabajo
Los Concejos fijan los salarios de los menestrales y otros hombres a jornal.

Se recomienda velar por la seguridad de los obreros.

Les permitía prohibir cualquier coalición de los jóvenes trabajadores que quisieran reclamar un aumento de salario. Las condiciones de trabajo derivadas del contrato firmado desde los Gremios, incluía la duración del mismo, así como el tipo, el horario, los descansos, etc. También regulaba el acceso de la mujer a diversos trabajos y su promoción.

Ulrich Ellembog publica obras relacionadas con la Higiene del Trabajo, en concreto un folleto dirigido a Plateros, indicando el peligro de los humos y vapores del carbono, NO2, plomo y mercurio.

Concesión de la Licencia de Actividad, poniendo trabas a las industrias o actividades que contaminen el ambiente.

Establecimiento de salarios y jornada laboral, prohibiendo el trabajo nocturno o en días de fiesta.

Contratación directa de especialistas para trabajos en el Concejo, como cirujanos, relojeros, etc.

Establecimiento de normas de calidad del producto elaborado y lucha contra el fraude del mismo.

Nombramiento de veedores para la inspección sobre cumplimiento de la normativa y el control del mercado.

Uso de los espacios de trabajo y actividad mercantil.

Establecen las bases iniciales de conquistas sociales. Destacan los subsidios económicos por accidentes, asistencia médica $y$ farmacéutica, asistencia hospitalaria y un conjunto de medidas proteccionistas para el 


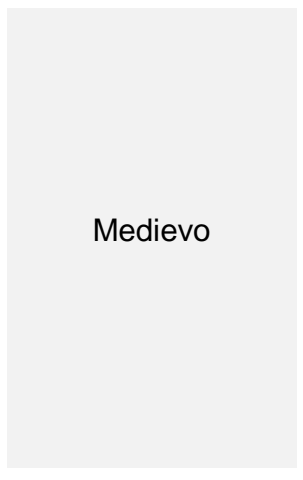

Medievo

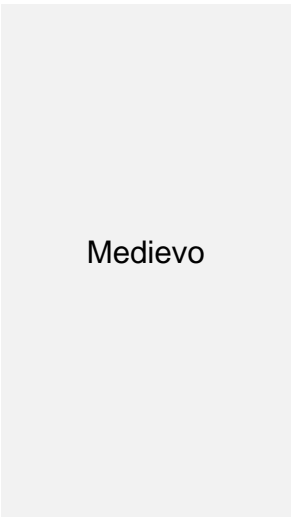

Reyes Católicos

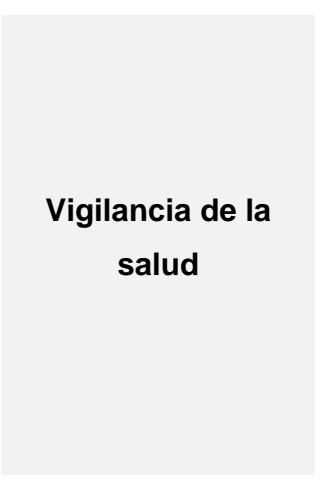

\section{Calendario}

Laboral

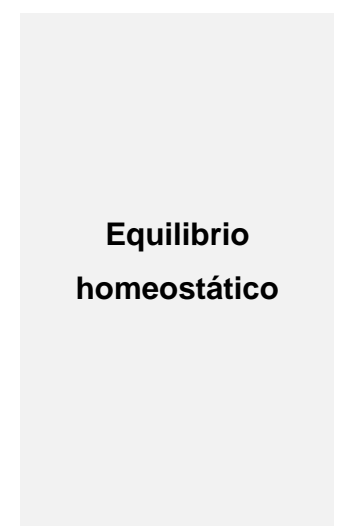

Ordenanzas

Reales de Castilla obrero lesionado por el trabajo. Sistema de pensiones establecido por el obispo en la construcción de la Catedral de León, recaudación de derechos de examen, sanciones etc. por parte del Gremio de Carpinteros a fin de socorrer a herederos fallecidos por el trabajo $y$ enfermos a consecuencia del mismo.

Eran sometidas a juicio y condenadas circunstancias como: la herida de un hombre por espada caída del clavo de donde se sujetara (actual lesión por desplome), lesiones a un niño provocadas por un caballo sin control que lo arrolle (actual accidente ocasionado por seres vivos), la plaga de langostas asolando una comarca (actual agente biológico).

Se establece la prohibición de trabajar en domingos y festivos, ampliamente extendido como consecuencia de la influencia religiosa en la vida laboral.

Esta idea toma fuerza entre filósofos, médicos físicos y astrónomos. El hombre es un ser en equilibrio con la naturaleza y así se refleja en la definición medieval de Salud: "la salud es posible cuando el cuerpo como un todo (y cada una de sus partes), consigue y mantiene un adecuado equilibrio entre sus cualidades, a la vez que una adecuada correspondencia con las partes del cosmos".

Prohibición de trabajar en domingo, procurando el descanso semanal, aunque tenga ello una raíz de carácter religioso.

Prohibición de trabajos "bajos y viles que no gocen de la franqueza de la caballería" a los hidalgos.

Fijación de horario de trabajo, marcándolo desde la salida del sol hasta el ocaso, incluyendo en dicho horario el desplazamiento del trabajador hasta el lugar donde se desempeñe la actividad. 
Establecimiento del salario por el Concejo y percibiéndolo en la noche del día trabajado.

Prohibición de espigar rastrojos a las mujeres de los segadores, yugueros y jornaleros, a excepción de las "viejas y flacas y las menores, que no son para ganar jornal".

Producto de la necesidad de regular las condiciones más extremas y duras de trabajo, que tenían los americanos colonizados por españoles. Se basan en el empeño por impedir la esclavitud de los indios, tratándoles como hombres libres.

Se establece la figura del Veedor, identificado también como Visitador o Alarife (en el Sector de la Construcción), verdadero cuerpo de inspección del grado de cumplimiento de las Ordenanzas, así como de la instrucción religiosa, tan unida al proceso colonizador llevado por España. Esas 35 leyes se incrementaron con disposiciones que eximían a las mujeres indígenas y a menores de 14 años, de trabajar en las minas. También se crearon por ley instituciones semejantes a la protección y seguridad social, como hospitales, cajas de previsión, cotizaciones Burgos 1512 d.C.

Protección de la salud y dignidad del trabajador hispanoamericano obreras, prestación por accidentes de trabajo, etc.

Existencia de hospitales para curación de obreros accidentados.

Prohibición de que los indios que habiten en climas fríos, sean llevados a trabajar a climas cálidos y viceversa.

Obligación de lavar la lana en los batanes con agua caliente, los días fríos.

Prohibición de trabajos para los que no estén debidamente formados los indios que los lleven a cabo, como por ejemplo en los desagües de las minas, las pesquerías de perlas, ingenios del añil y de azúcar, etc.

Prohibición del acarreo de cargas a mano por indios menores de 18 años de edad, no 
pudiendo exceder, en cualquier caso, el peso

de la carga las 2 arrobas.

Obligación de construir chimeneas de hornos altos y fundiciones, apartadas de otros edificios, a fin de que los vapores de mercurio que se emitan, no dañen la salud de los habitantes de las comunidades.

Uso de ropa de trabajo limpia y seca.

Abono por parte del patrono de la mitad del jornal del indio obrero accidentado en las minas.

Fijación de horario de menestrales.

Prohibición de labrar minas peligrosas a la salud y vidas de los indios.

Establecimiento de medidas de seguridad sobre huecos.

Percibimiento de salarios fijados.

Asistencias de médico y cirujano en las instalaciones de obtención de coca y añil, que deben ser asalariados por los patronos con carácter obligatorio.

Carlos IX dicta normas de seguridad para los

Europa. 1556

d.C.

Prevención

Hospital de

Rey Felipe II. 1571 d.C.

Laborantes de

San Lorenzo del Escorial

Rey Felipe II

$(1527-1598$

d.C.)

\section{Regulación condiciones de trabajo} trabajos en cubiertas, multando su incumplimiento. Se trata del comienzo de la prevención tal y como es entendida hoy en día.

La mayoría de los trabajadores vivían en condiciones muy duras, con jornadas laborales de 9 horas en invierno $y$ de 11 horas en verano, necesitando también servicios de carácter material y espiritual, por ello manda construir una capilla provisional, además de un hospital de "laborantes" (primera institución europea especializada en accidentes de trabajo).

Regula el tiempo de trabajo en 8 horas diarias (distribuidas en 4 horas por la mañana y 4 horas tras el almuerzo) en horario acomodado a la luz solar y la temperatura de la época para los trabajos en las Minas del Franco Condado. 


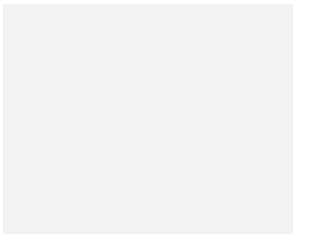

Europa. 1633 -

1714 d.C.

1725 d.C.

Rey Carlos IV.

1796 d.C.

Revolución

Industrial
Medicina

preventiva

Bando del Alcalde

de la Corte de

Madrid

Informe médico

de la Junta de

Gobierno de

Medicina

\section{Empeoramiento} de las

condiciones de

trabajo
El Rey prohíbe construir hornos de yeso dentro de las obras ni en el centro de Madrid, por su condición de insalubridad y peligro para trabajadores y habitantes.

El padre de la medicina preventiva, Bernardino Ramazzini, llega a descubrir 54 enfermedades profesionales distintas, que son recogidas en su famoso tratado "De Morbis Artificum Diatriba", en el que relaciona las mismas con las condiciones de trabajo y los productos $y$ materiales que utilizan los trabajadores. A él se le atribuye el origen de una pregunta que aún se considera fundamental en la atención de la salud de los trabajadores “¿Usted, a qué se dedica?".

Exigir a los Maestros de Obras encargados de hacer reparaciones en casas y balcones que las maromas $y$ andamios fuesen 10 suficientemente seguros para no generar desgracias.

Se informa sobre las funestas consecuencias del establecimiento de fábricas y manufacturas que alteren e infeccionen la atmósfera, como jabonerías, tenerías, fábrica de velas de sebo $y$ otras actividades similares. Intentos de relacionar la pérdida de la salud en el trabajo, a través de la descripción de Enfermedades Profesionales.

A mediados del siglo XVIII se produjo un detrimento de las condiciones de trabajo. En las fábricas, llenas de humos y sin apenas ventilación, las condiciones de trabajo eran terribles, lo que afectaba muy particularmente a los niños de corta edad que trabajaban jornadas interminables, y a las mujeres, especialmente en relación con la maternidad. Los primeros informes disponibles sobre esas condiciones de trabajo ponían de manifiesto lo inhumano de la situación y la necesidad de introducir mejoras tales como la ventilación en 


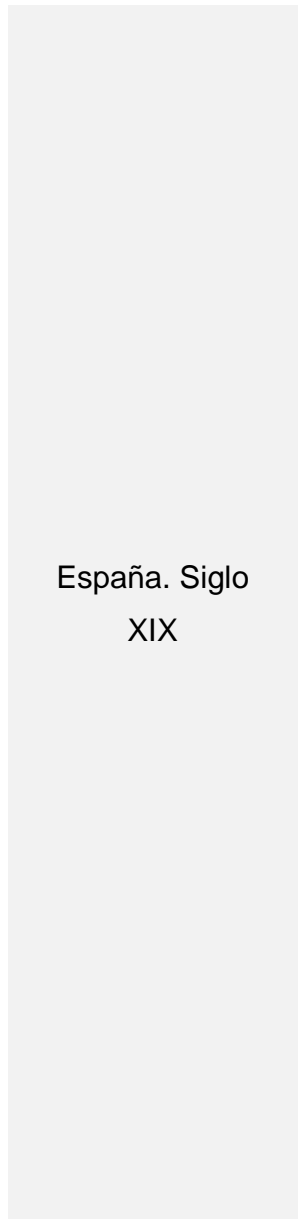

España. Siglo

XIX

Francia. 1841

d.C. los centros de trabajo, como medida preventiva a implantar.

A pesar de las deficientes condiciones de Seguridad y Salud de los trabajadores a lo largo del siglo XIX, los principios liberales incorporados a la legislación establecen la responsabilidad que asume el obrero entre las obligaciones que tiene encomendadas. Esto se traducirá en un cambio sustancial entre las relaciones laborales, sobre todo en la prohibición de los Gremios por Decreto, por entender que no son necesarios para el desarrollo de la industria. Resulta evidente la inhumana explotación del trabajo infantil y de la mujer, con salarios inferiores a las necesidades mínimas para la subsistencia, acompañadas de una elevada siniestralidad laboral (trabajo infantil de 66 horas semanales en Reus, entrando a trabajar a partir de los 6 años de edad; trabajo infantil de 69 horas semanales en Barcelona; trabajo infantil de 12 horas diarias en Valls, Tarragona; trabajo infantil de 13 horas diarias en Igualada, Lérida).

Las primeras leyes "verdaderamente" preventivas fueron en buena medida el resultado de las movilizaciones obreras del siglo XIX, las cuales consiguieron que en el año 1873 se aprobara la denominada Ley sobre Condiciones de Trabajo en las Fábricas,
Movilizaciones obreras Talleres y Minas que prohíbe el trabajo a los menores de diez años, limita la jornada a cinco horas para los niños menores de trece años y las niñas menores de catorce, y obliga a los empresarios cuyos establecimientos estuvieran "a más de cuatro kilómetros de lugar poblado a crear escuelas, cuyos gastos serán indemnizados por el Estado".

Se regula el trabajo de los niños, a partir de los 8 años, limitándolo a 8 horas hasta que cumplieran los 12 años de edad. Se trata de la primera ley francesa del trabajo. 
Italia. 1842 d.C.

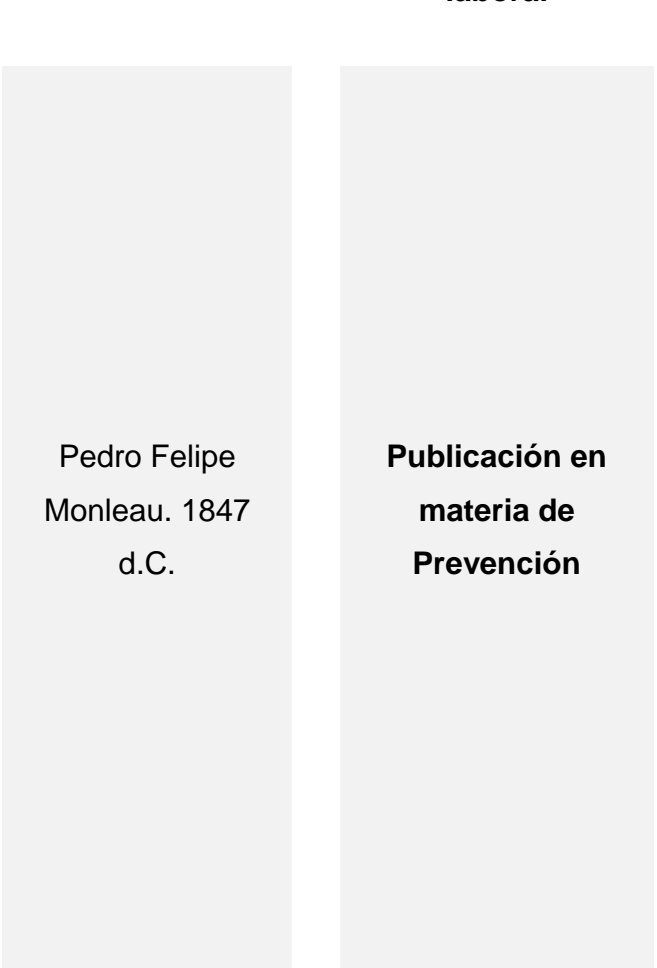

España. 1873

d.C.

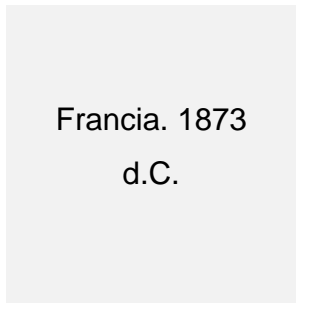

Francia. Finales

del siglo XIX
Legislación

laboral

Publicación en

materia de

Prevención
Primera Ley

española de

Accidentes de

Trabajo

\section{Moulhouse}

Iniciativas en

materia de

Prevención
Se prohíbe el trabajo a menores de 9 años y a menores de 14 años en el caso de que las industrias fueran consideradas como nocivas.

El Catedrático e Higiene y miembro de la Real Academia Española, publica "Elementos de Higiene Pública o el Arte de conservar la Salud de los pueblos".

En el mismo se recomienda no superar las 10 horas de trabajo al día, promocionando la formación a los trabajadores, evitar los accidentes que ocasionan las máquinas (citando los 12.000 accidentes mortales que ocurren anualmente en Inglaterra por peculiaridades del oficio), aconseja el establecimiento del Médico de Empresa o del Trabajo (provisto de botiquín), además de la indemnización a la que pudieran tener derecho en el caso de que la culpa del accidente fuera achacable al fabricante.

El trabajo de Monleau y de otros son antecedentes inmediatos de la conocida Ley Benot, sobre el trabajo en los talleres y la instrucción en las escuelas de los niños obreros de ambos sexos. En ella se preveía la creación del primer órgano de inspección en el ámbito laboral: los Jurados Mixtos.

Entre otros aspectos, esta Ley regula el trabajo de niños en fábricas y talleres, prohibiéndolo a menores de 10 años, reduciendo la jornada de los menores de 15 años y de las mujeres menores de 17 años.

Engel Dollfus, ingeniero alsaciano, establece la relación causal del accidente con los factores de orden técnico, fundando Moulhouse, la primera Asociación para la Prevención de Accidentes de Trabajo.

Se crea el cuerpo de Inspectores de Trabajo, a través de la Ley que reglamenta oficialmente la Higiene y Seguridad del Trabajo.

Emil Muller funda la Asociación de Industriales contra los Accidentes de Trabajo. Los 
Inglaterra. 1883

d.C.

Alemania. 1884

d.C.

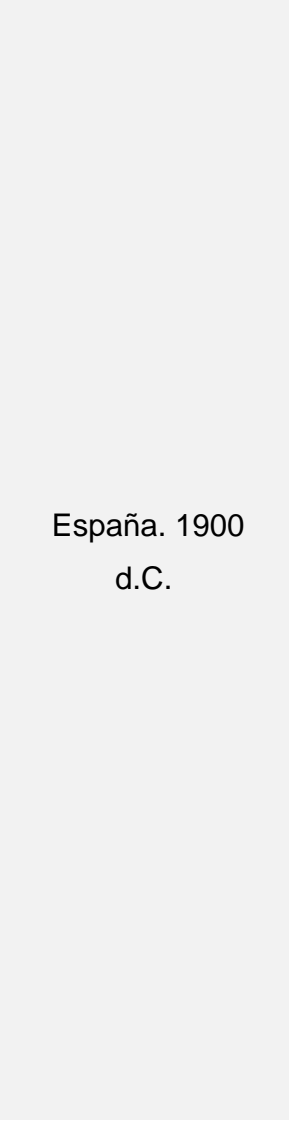

España. Primera

mitad del siglo $X X$

\section{Legislación en}

Prevención

\section{Legislación en}

Prevención

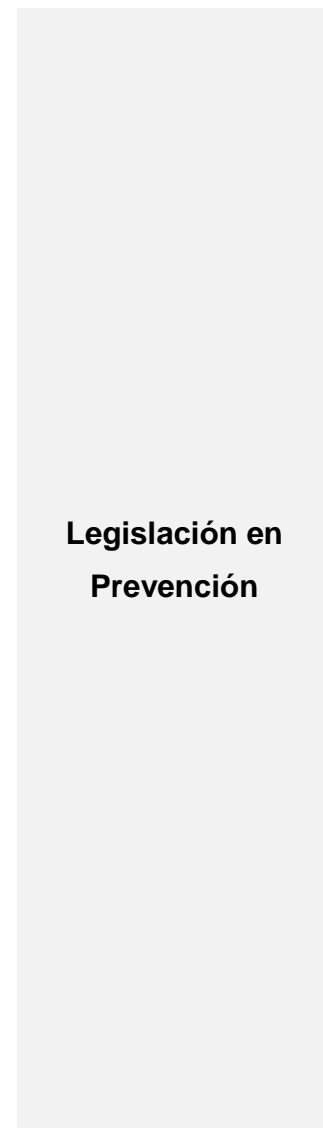

Legislación e

Instituciones en

Prevención empresarios son obligados a contribuir con una cuota, a cambio de asesoramiento y ayuda en materia de Prevención de Riesgos.

Se crea una nueva Ley sobre protección de la salud en el trabajo en las fábricas.

Se aprueba la cobertura obligatoria por parte del estado de la invalidez por Accidente de Trabajo y Enfermedad Profesional, siendo el primer país en conseguirlo.

Conocida como ley Dato, se aprueba el Acta de Compensación de los Trabajadores, de 30 de enero, que constituye la primera Ley española sobre Accidentes de Trabajo. Se establece un nuevo principio: "el patrono es responsable de los accidentes ocurridos a sus operarios" y en consecuencia, "los obreros tendrán derecho a indemnización por los accidentes sufridos con ocasión o por consecuencia del trabajo". La autorización que la ley daba al empresario para contratar un seguro que cubriese las indemnizaciones, propició el nacimiento de las mutuas de accidentes de trabajo. Se generó la necesidad de crear una "Administración Laboral" para vigilar, controlar y penalizar los incumplimientos de la ley.

Ese mismo año, el 30 de mayo, se aprueba la Ley sobre Condiciones de Trabajo de las Mujeres y de los Niños.

1903: sustitución de la Comisión de Reformas Sociales por el Instituto de Reformas Sociales.

1904: se empiezan a publicar las primeras estadísticas de accidentes de trabajo.

1906: creación Inspección de Trabajo.

1908: creación del Instituto Nacional de Previsión. Se promulga una Real Orden por la que se obliga a notificar el Accidente de Trabajo producido en plazo reglamentario. 
1920: creación del Ministerio de Trabajo y Previsión Social. Creación del Servicios de colocación obrera.

1922: se reforma la ley mediante la nueva Ley de Accidentes de Trabajo (se introdujo el principio básico de que "la imprudencia profesional, o sea, la que es consecuencia del ejercicio habitual de un trabajo, no exime al patrono de su responsabilidad“. Se incorpora, como novedad, la obligatoriedad del descanso nocturno de la mujer trabajadora.

1924: se autoriza al gobierno para ratificar los Convenios Internacionales referentes al trabajo de mujeres y menores.

1925: se aprueba el Reglamento de establecimientos peligrosos, incómodos e insalubres.

1926: el Código de Trabajo es aprobado con rango de Real Decreto.

1927: se regula el descanso nocturno de la mujer trabajadora.

1929: se aprueba el Reglamento sobre Seguridad de recipientes para fluidos a presión.

1930: Reglamentos de Jornada de Trabajo.

1931: Reglamento sobre la prohibición del empleo de cerusa, sulfato de plomo y otros compuestos, para pintar interiores de edificios. Aplicación al sector agrario de la Ley de Accidentes de Trabajo.

Nueva fijación de la Jornada Laboral con un máximo de 8 horas diarias o 48 horas semanales.

Ley de Contrato de Trabajo.

Otros países.

Primera mitad del siglo $\mathrm{XX}$
Legislación en

Prevención
1905: Suecia crea la Asociación para la protección de los trabajadores.

1908: Se aprueba en los EE.UU. la primera Ley de aseguramiento obligatorio, que desemboca en 1913 en el National Safety Council. 
1912: Primer Congreso para la Prevención de Accidentes de Trabajo e Higiene Industrial en Milán.

1916: Portugal crea el Laboratorio de Higiene y Seguridad en los locales de Trabajo.

1919: Inglaterra crea la Real Sociedad para la Prevención de Accidentes.

Convenio de Washington sobre Jornada de Trabajo.

1919: nace la Organización Internacional del Trabajo (OIT). Asume las tareas internacionales en materia de seguridad $y$ salud en el trabajo.

1921: la OIT exige un descanso de 24 horas completas cada 7 días.

1928: se crea la Asociación Japonesa para el Bienestar en la Industria.

1931: se crea en India la Asociación proSeguridad.

1933: se aprueba en Portugal el Estatuto de Trabajo Nacional, que garantiza la higiene y la moral de los trabajadores.

1936: Creación en Cuba del Consejo Nacional de Seguridad.

1938: se crea en Suecia del Consejo Mixto de Seguridad Industrial.

España ratifica el Convenio 18 de la OIT, sobre enfermedades profesionales.

Se fija por Ley el nuevo Código de Trabajo, que establece indemnizaciones por accidentes de trabajo.

España. 1932

d.C.

\section{Legislación en}

Prevención
Texto refundido de la legislación de Accidentes de Trabajo en la Industria, con desarrollo reglamentario en el que se incluyó a todos los efectos como accidente laboral, el ocurrido en el desempeño de tareas en el campo. Es en el sector agrario en el que el gobierno de la época hizo mayor énfasis en materia de salud laboral. 


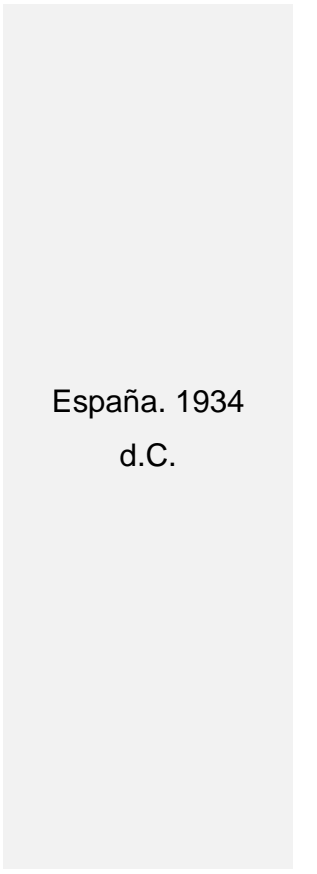

España. 1935

d.C.

España. 1936

d.c.

España. 1937

d.C.

España. 1938

d.C.

España. 1939

d.C.

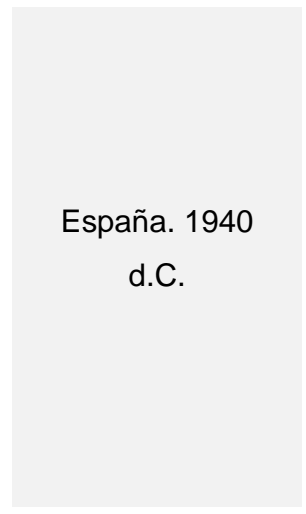

Legislación en

Prevención

\section{Legislación en}

Prevención

\section{Legislación en}

Prevención

\section{Legislación en}

Prevención

\section{Legislación en}

Prevención

\section{Legislación en}

Prevención

\section{Legislación en}

Prevención
Se crea la Inspección Médica de Trabajo, cuya función consiste en "la continuada observación y estudio de las industrias... al objeto de preparar las ponencias... que deberán ser tenidas en cuenta [en el momento de] establecer reformas... legales".

Reglamento de Policía Minera, se incluyen medidas a adoptar para la seguridad e higiene de las exportaciones y protecciones de la salud de los mineros. Se incluyen no sólo las actividades mineras, sino también las fábricas metalúrgicas, las de abonos, los túneles de ferrocarril y actividades similares.

Se prohíben los trabajos agrícolas a niños durante el horario escolar.

Se prohíbe mediante Decreto la utilización de sacos, fardos o cualquier utensilio similar, para el transporte, carga o descarga, que haya de hacerse a brazo y cuyo peso sea superior a los $80 \mathrm{~kg}$.

Se aprueba la Ley de Enfermedades Profesionales (Ley de Bases).

Seguros y Fianzas de Accidentes de Trabajo.

Los locales destinados a comedores de obreros son motivo de reglamentación especial, al igual que los de aseo personal, cocinas, dormitorios, etc.

Ley de Ordenación y Defensa de la Industria. Ley sobre organización de la Inspección de Trabajo.

Reglamento General de Seguridad e Higiene en el Trabajo, disposición que "resulta la reparación económica del daño causado" desde la Ley de Accidentes de Trabajo de 1900. Su objetivo es el de que el accidente "no tenga lugar o, cuando menos, disminuir su número y gravedad mediante una intensa labor preventiva en la que deberán intervenir todos cuantos tienen relación con este 
problema y que el Estado habrá de dirigir y orientar mediante normas y reglamentos adecuados". Se trata del primer Reglamento que se aprueba en España sobre Seguridad e Higiene en el Trabajo, con carácter propiamente técnico. El control del Reglamento se encomienda a la Inspección de Trabajo.

1940: Normativa sobre la iluminación de los centros de trabajo.

Se regula el descanso dominical.

Se regula el accidente de trabajo.

Obligación de comunicar los accidentes ocurridos en las minas.

1941: ordena las indemnizaciones y salarios de los accidentados.

1944: nace el Instituto Nacional de Medicina, Higiene y Seguridad en el Trabajo (actual INSHT).

Declaración obligatoria de las Enfermedades Profesionales.

Se regula la propaganda para la prevención de

España.

Mediados siglo

$\mathrm{XX}$

\section{Legislación en}

Prevención accidentes de trabajo y utilización del material de protección personal del trabajador.

Se aprueba una norma consistente en el establecimiento de mecanismos representativos $y$ participativos en las empresas (los Comités de Seguridad e Higiene en el Trabajo), con el objetivo de vigilar el cumplimiento de lo legislado sobre seguridad e higiene en el trabajo, efectuar investigación de accidentes laborales $y$ enfermedades profesionales, configurar estadísticas, organizar la lucha contra los incendios y todo los relativo a la formación y propaganda

1945: obligación de medidas preventivas en las minas.

1946: se regulan los reconocimientos médicos preventivos de Silicosis. 
Se establecen las dotaciones mínimas de prendas de protección personal para menores de 21 años.

Creación del Instituto Nacional de Medicina y Seguridad del Trabajo, con competencias de investigación y asesoramiento en riesgos del trabajo y prevención de accidentes laborales y enfermedades profesionales.

1947: se crea el Seguro de Enfermedades Profesionales, definiéndolas.

Creación de los Jurados de Empresa.

1948: se crea la Escuela Nacional de Medicina del Trabajo.

1952: se aprueba el reglamento de Seguridad del Trabajo en la Industria de la Construcción.

1955: aprobación del reglamento electrotécnico de Baja Tensión.

Ley de Accidentes de Trabajo que unifica los ocurridos en la industria y en la agricultura.

1956: se aprueba el reglamento para la aplicación del texto refundido de la legislación de accidentes de trabajo.

Se crean los Servicios Médicos de Empresa (encargados del control de la Gestión de la Seguridad e Higiene en el Trabajo).

1957: relación de industrias y trabajos prohibidos a mujeres y menores por peligrosos e insalubres.

1959: se regula la Clínica de Enfermedades Profesionales.

Medidas de prevención contra la silicosis en las minas de plomo.

Creación de la Organización de los Servicios Médicos de Empresa (OSME) adscrito al Instituto Nacional de Previsión.

Regulación de la fabricación y empleo de disolventes y otros preparados que contengan benceno.

Se aprueba el Reglamento de los Servicios Médicos de Empresa. 
Se dictan normas de protección contra

radiaciones ionizantes.

1960: se aprueba el reglamento de Actividades Molestas, Insalubres, Nocivas y Peligrosas.

1961: se organiza el Fondo compensador, diagnóstico y calificación de enfermedades profesionales y la Obra de Grandes Inválidos y Huérfanos de fallecidos por accidentes de trabajo y enfermedades profesionales.

Promulgación de normas de aplicación del Seguro por Desempleo.

1962: se aprueba el reglamento de Policía Minera y Metalúrgica en materias de explosivos.

1963: normas reglamentarias médicas para reconocimientos, diagnóstico y calificación de Enfermedades Profesionales.

1966: texto articulado de la Ley de Bases de la Seguridad Social.

1967: nuevas normas sobre aplicación de la prestación por incapacidad laboral transitoria, obligando a las empresas, a notificar los accidentes de trabajo cuando se encuentren en el Régimen General.

1968: nueva normativa sobre estadísticas de accidentes de trabajo y enfermedad profesional.

1969: se aprueba el modelo oficial de Parte de Accidente de Trabajo.

1970: mediante Orden Ministerial se encomienda la realización de un Plan Nacional de Higiene y Seguridad en el Trabajo a la Dirección General de la Seguridad Social.

Se amplía la obligación de notificación del Parte de Accidente de Trabajo a todos los Regímenes de la Seguridad Social.

Mejora de los derechos laborales de la mujer.

Ordenanza de Trabajo de la Construcción, Vidrio y Cerámica. 
1971: se aprueba la Ordenanza General de Seguridad e Higiene en el Trabajo (se analiza al trabajador, el diseño del puesto de trabajo y el lugar o ambiente donde se realice el trabajo). Esta Ordenanza General ha estado conviviendo con la Ley de PRL de 1995 hasta 1997.

Se crea el Instituto Nacional de Seguridad e Higiene en el Trabajo (INSHT, después Instituto Nacional de Seguridad, Salud y Bienestar en el Trabajo, INSSBT, $y$ actualmente Instituto Nacional de Seguridad y Salud en el Trabajo, INSST) (BOE, 2018).

Constitución Española.

España. 1995

d.C.

España. 1997

d.C.

España.

Comienzos siglo

$\mathrm{XXI}$
Institución

preventiva

Legislación en

Prevención

Legislación en

Prevención

Legislación en

Prevención
Ley de PRL.

Real Decreto 39/1997, por el que se aprueba el Reglamento de los Servicios de Prevención.

2003: $1^{a}$ edición de la Guía Técnica para la Evaluación y Prevención de los Riesgos relativos a las obras de construcción.

2004: Real Decreto $171 / 2004$ por el que se desarrolla el artículo 24 de la Ley de PRL en materia de coordinación de actividades empresariales.

2006: Ley reguladora de la subcontratación en el Sector de la Construcción.

2007: IV Convenio Colectivo General del Sector de la Construcción.

Real Decreto regulador de la subcontratación en el Sector de la Construcción.

2012: $2^{a}$ edición de la Guía Técnica para la Evaluación y Prevención de los Riesgos relativos a las obras de construcción.

V Convenio Colectivo General del Sector de la Construcción.

2017: VI Convenio Colectivo General del Sector de la Construcción. 
Estrategia Española de Seguridad y Salud en

España. 2007 2012 d.C.

\section{Estrategia} preventiva el Trabajo, concebida como medida de mejora

para intentar paliar la elevada siniestralidad laboral

Tabla 3.1. Hechos históricos relacionados con la PRL. Fuente: García, 2008; Calderón, 2006; Segarra, 2015. Elaboración propia. 


\subsubsection{EVOLUCIÓN NORMATIVA EN MATERIA DE PRL EN LA UNIÓN EUROPEA}

Al igual que en el apartado 3.1.1., en esta sección del documento de tesis se estudia el camino que se ha recorrido desde la Unión Europea para la correcta integración de la PRL. Para ello, se elabora la Tabla 3.2. que recoge todos aquellos hitos y momentos que merecen ser contados, debido a la importancia que han tenido a la hora de conseguir dicha implantación.

\section{Fecha o período}

Años 50

1957

1965

1986
Hito

\section{Primeras}

iniciativas

Tratados preventivos

Tratado de

Bruselas

Acta Única

Europea

\section{Desarrollo}

Tratado constitutivo de la Comunidad Europea del Carbón y el Acero, firmado por Alemania, Bélgica, Francia, Italia, Luxemburgo y Países Bajos. Se fomenta la investigación sobre la seguridad en el trabajo de las industrias.

Se firman en Roma los "Tratados de Roma". El primero constituía una Comunidad Económica Europea (CEE) y el segundo una Comunidad Europea de la Energía Atómica (EURATOM).

Si bien es cierto que en el tratado fundacional de la CEE las preocupaciones sociales tienen escasa importancia, se recoge en el artículo 117: "los estados miembros convienen en la necesidad de promover la mejora de las condiciones de vida $y$ de trabajo de los trabajadores, a fin de conseguir su equiparación por la vía del progreso".

Por su parte, con el EURATOM se anuncia el establecimiento de "normas básicas para la protección sanitaria de las radiaciones ionizantes".

Se firma el Tratado europeo de Fusión, que combina los cuerpos ejecutivos de CECA, EURATOM y la CEE en una sola estructura institucional.

Firmada en Luxemburgo por doce estados miembros, supone la primera modificación de gran alcance del Tratado constitutivo de la 


\section{Programa de} acción
Comunidad Económica Europea. Con el mismo se consigue un espacio sin fronteras para la libre circulación de mercancías, personas, servicios y capitales.

Se abren nuevas expectativas a la adopción de normativa comunitaria en materia de seguridad y salud en el trabajo, en tanto en cuanto adiciona el artículo 118 al Tratado de la CEE: "se encomienda a los estados miembros promover la mejora del medio de trabajo, la seguridad y la salud de los trabajadores, fijándose como objetivo la armonización dentro del progreso".

El Consejo de Comunidades adoptó en su Resolución de 21 de diciembre (DOCE, 1988) el tercer programa de acción relativo a la seguridad, a la higiene y a la salud de los trabajadores.

En este programa se recoge la necesidad de que las Directivas insistan en la adopción de disposiciones esenciales relativas a un nivel de protección elevado de los trabajadores, la obligatoriedad de observar $y$, en su caso, considerar al momento de elaborar los planes de trabajo, el número de trabajadores expuestos a riesgos y las posibilidades de prevención, así como el fomento de la participación de los interlocutores sociales en la elaboración de las Directivas.

El programa se estructura en cinco áreas:

i. Seguridad y ergonomía en lugares de trabajo.

ii. Salud e higiene en el trabajo.

iii. Formación e información.

iv. Iniciativas específicas a favor de las PYMES.

v. Diálogo social, a través del Comité Consultivo para la Seguridad, la Higiene y la Protección de la Salud en el lugar de trabajo. supone un punto de inflexión en la utilización 
por la Unión Europea de los instrumentos normativos para controlar la lesividad del trabajo humano. En efecto, la existencia de demasiados accidentes de trabajo $y$ enfermedades profesionales, de plurales $y$ diferentes sistemas legislativos en materia de seguridad y salud en el trabajo, así como la necesidad de evitar que se apliquen condiciones deficientes en tal materia con motivaciones inspiradas en la competencia, exigieron la armonización de las legislaciones de los estados miembros frente a los riesgos profesionales.

Considerada la "piedra angular del edificio comunitario en materia de seguridad" (Sempere y Cardenal, 2000), establece disposiciones con finalidad preventiva $y$ protectora que habrán de aplicarse en los lugares de trabajo.

En primer lugar, "la mejora de la seguridad, de la higiene y de la salud de los trabajadores en el trabajo representa un objetivo que no podrá subordinarse a consideraciones de carácter puramente económico".

En segundo lugar, la Directiva "no afecta a las disposiciones nacionales y comunitarias, existentes o futuras, que sean más favorables para la protección de la seguridad y de la salud de los trabajadores en el trabajo".

En tercer lugar, es relevante por su objetivo de acción normativa de carácter global frente a los riesgos laborales.

En cuarto lugar, destaca su filosofía preventiva, orientada a la evaluación y planificación de la prevención desde una óptica integral de la salud laboral, que tome en consideración la técnica, la organización del trabajo, las condiciones de trabajo, las relaciones sociales y la influencia de los factores ambientales en el trabajo, que otorgue prevalencia a la adaptación del trabajo a la persona. 
Se establece el deber del empresario de "garantizar la seguridad y la salud de los trabajadores en todos los aspectos relacionados con el trabajo, lo que implica la adopción de las medidas necesarias para la protección de la seguridad y de la salud de los trabajadores".

Así mismo, se fijan los principios generales de la actividad preventiva: evitar los riesgos y evaluar los riesgos que no se puedan evitar, combatir los riesgos en su origen, adaptar el trabajo a la persona (concepción del puesto de trabajo), además de la elección de los equipos de trabajo y los métodos de trabajo y producción, planificar la prevención buscando un conjunto coherente que integre la técnica, la organización del trabajo, las condiciones de trabajo, las relaciones sociales y la influencia de los factores ambientales, y por último, adoptar medidas que antepongan la protección colectiva a la individual.

La Directiva también establece la obligación empresarial de prevención en relación con los primeros auxilios, lucha contra incendios, evacuación de los trabajadores y riesgo grave e inminente.

De cara al desarrollo de las actividades de prevención, el empresario debe recurrir a servicios de protección o prevención, bien internos a la empresa (SPP, nombramiento de trabajadores) o externos a ella (SPA, SPM).

También se establecen las obligaciones de la adecuada vigilancia de la salud de los trabajadores, la información y formación de los trabajadores en materia preventiva, el derecho de participación y consulta a los trabajadores y sus representantes en "todas las cuestiones que afecten a la seguridad y a la salud en el trabajo".

Se completan las medidas tendentes a promover la mejora de la seguridad y de la salud en el trabajo de los trabajadores con una 
relación laboral de duración determinada o de empresas de trabajo temporal (Directiva, 1991).

Aplicación de medidas para promover la mejora de la seguridad y de la salud en el trabajo de la trabajadora embarazada, que haya dado a luz o en período de lactancia (Directiva, 1992a).

Se establecen las disposiciones mínimas de 1992

\section{Directiva} seguridad y de salud que deben aplicarse en las obras de construcción temporales o móviles (Directiva, 1992b).

Tabla 3.2. Hechos e iniciativas que han marcado el camino hacia la integración de la PRL en la Unión Europea. Fuente: Segarra, 2015. Elaboración propia. 


\subsubsection{EVOLUCIÓN NORMATIVA EN MATERIA DE PRL EN ESPAÑA}

En consecuencia con lo mostrado en el apartado anterior, en esta sección del documento de tesis se estudia el camino legislativo que se ha recorrido en España para la correcta integración de la $\mathrm{PRL}$, desde finales del siglo $X X$ hasta comienzos del siglo XXI. Para ello, se muestran en la Tabla 3.3. los hitos que han marcado el marco normativo español en materia de PRL.

Fecha o período

1978

1995
Constitución

Española

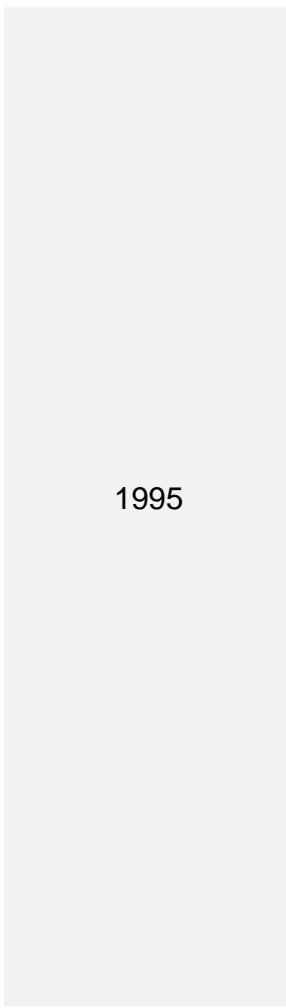

\section{Desarrollo}

El artículo 40.2 de la Constitución Española (BOE, 1978) recoge que: "Asimismo, los poderes públicos fomentarán una política que garantice la formación y readaptación profesionales; velarán por la seguridad e higiene en el trabajo y garantizarán el descanso necesario, mediante la limitación de la jornada laboral, las vacaciones periódicas retribuidas y la promoción de centros adecuados", haciendo mención expresa a la PRL en la Carta Magna que sienta el precedente o la base para el resto legislación que desarrolle este concepto.

La Ley 31/1995 (BOE, 1995), de PRL tiene por objeto determinar el cuerpo básico de garantías y responsabilidades para establecer un adecuado nivel de protección de la salud de los trabajadores frente a los riesgos derivados de las condiciones de trabajo, y ello en el marco de una política coherente, coordinada y eficaz de PRL, tal y como se recoge en la exposición de motivos de la Ley (en donde se hace mención expresa al mandato constitucional contenido en el artículo 40.2 de la ley de leyes y la comunidad jurídica establecida por la Unión Europea en esta materia.

Esta Ley opera sobre el principio básico de promover la Seguridad y la Salud de los trabajadores mediante la aplicación de medidas y el desarrollo de las actividades 
necesarias para la Prevención de Riesgos derivados del Trabajo. Así mismo, se establecen los principios generales relativos a la prevención de los riesgos profesionales para la protección de la seguridad y de la salud, la eliminación o disminución de los riesgos derivados del trabajo, la información, la consulta, la participación equilibrada y la formación de los trabajadores en materia preventiva.

En el artículo 14.2 del Capítulo III de la Ley se establece la obligación que tiene el empresario de garantizar la Seguridad y la Salud de los trabajadores a su servicio en todos los aspectos relacionados con el trabajo.

El resto de obligaciones al empresario se distribuyen en los artículos 16 a 28 de la Ley, y que pueden englobarse en cuatro bloques:

I. Obligaciones relacionadas con las condiciones y organización del trabajo (garantizar que los equipos de trabajo sean los adecuados para el trabajo a realizar, proporcionar a los trabajadores dichos equipos de protección adecuados para el desempeño de sus funciones, analizar las medidas a adoptar en situaciones de emergencia, adoptar las medidas y dar las instrucciones necesarias en caso de riesgo grave e inminente).

II. Obligaciones de organización de la prevención (evaluación de riesgos, plan de prevención, realizar controles periódicos de las condiciones de trabajo cuando sea pertinente, elaborar y conservar a disposición de la autoridad laboral y sanitaria la documentación relativa a las obligaciones establecidas).

III. Obligaciones respecto de los trabajadores (informar y formar a los trabajadores, garantizar los 
reconocimientos médicos periódicos, consultar a los trabajadores y permitir su participación en las cuestiones relativas a la Seguridad y Salud en el trabajo).

IV. Obligaciones para colectivos específicos (garantizar la protección de los trabajadores sensibles a determinados riesgos derivados del trabajo, protección para trabajadoras en situación de embarazo o parto inminente, en la evaluación de riesgos se considerará los riesgos específicos para la salud, seguridad y desarrollo de los trabajadores menores de edad, los trabajadores temporales deberán disfrutar del mismo nivel de protección en materia de seguridad $y$ salud que los restantes trabajadores).

Con el Real Decreto 39/1997 (BOE, 1997a), por el que se aprueba el RSP, como desarrollo de la $L P R L$, se regula la organización de la PRL y afecta a todos los centros de trabajo de la empresa y estructura organizativa $y$ funcional. Se incluyen las normas reglamentarias de desarrollo del procedimiento de la evaluación de riesgos, como punto de partida que puede conducir a la

Reglamento de los Servicios de

Prevención planificación de la actividad preventiva que sea necesaria, a través de alguna de las modalidades de organización en función del tamaño de la empresa y los riesgos o de la peligrosidad de las actividades que se desarrollen.

“La organización de los recursos necesarios para el desarrollo de las actividades preventivas se realizará por el empresario con arreglo a alguna de las modalidades siguientes:

1. Asumiendo personalmente tal actividad. 
2. Designando a uno o varios trabajadores para llevarla a cabo.

3. Constituyendo un servicio de prevención propio.

4. Recurriendo a un servicio de prevención ajeno".

En el caso de la construcción, no puede asumir el empresario tal función.

Con el Real Decreto 1627/97 (BOE, 1997b), de disposiciones mínimas de Seguridad y Salud en construcción, constituye un desarrollo reglamentario de la $L P R L$ para su aplicación en todas las obras de construcción (públicas o privadas, en las que se realicen trabajos de construcción o ingeniería civil).

Se establecen las obligaciones del promotor, del proyectista, del contratista, del subcontratista y de los trabajadores autónomos. Además, se introduce la figura del Coordinador en materia de Seguridad y Salud en fase de elaboración del proyecto y en fase de ejecución de la obra.

Disposiciones

mínimas de

Seguridad y Salud

en Construcción
Ley sobre Infracciones y
Se tienen en cuenta aquellos aspectos que se han revelado de utilidad para la Seguridad y Salud en las obras y que están presentes en el Real Decreto 555/1986 (BOE, 1986), de 21 de febrero, por el que se estableció la obligatoriedad de inclusión de un Estudio de Seguridad e Higiene en los proyectos de edificación y obras públicas, modificado por el Real Decreto 84/1990 (BOE, 1990), de 19 de enero. Se incluye en su ámbito de aplicación a cualquier obra, pública o privada, en la que se realicen trabajos de construcción o ingeniería civil.

También se constituyen mecanismos específicos para la aplicación de la LPRL y del Reglamento de los Servicios de Prevención.

Se aprueba el Real Decreto Legislativo 5/2000 (BOE, 2000), de 4 de agosto, por el que se aprueba el texto refundido de la Ley sobre 
Sanciones en el

Orden Social

\section{Coordinación de}

actividades

empresariales
Infracciones y Sanciones en el Orden Social.

En el mismo, se califican las infracciones como leves, graves y muy graves en atención a la naturaleza del deber infringido y la entidad del derecho afectado. Las infracciones no podrán ser objeto de sanción sin previa instrucción del oportuno expediente, a propuesta de la Inspección de Trabajo y Seguridad Social, tal y como se recoge en las disposiciones generales de la citada normativa.

El Real Decreto 171/2004 (BOE, 2004), por el que se desarrolla el artículo 24 de la LPRL en materia de coordinación de actividades empresariales, viene a dar cumplimiento al mandato de desarrollar dicho artículo, con objeto de reforzar la Seguridad y Salud en los supuestos de concurrencia de actividades empresariales en un mismo centro de trabajo.

Los objetivos de la coordinación se establecen en el artículo 3, y que son los que siguen: la aplicación coherente y responsable de los principios de la acción preventiva (art. 15 de la $L P R L)$, la aplicación correcta de los métodos de trabajo por las empresas concurrentes en el centro de trabajo, el control de las interacciones de las diferentes actividades desarrolladas en el centro de trabajo (en particular, cuando puedan generar riesgos calificados como graves o muy graves, o cuando se desarrollen actividades incompatibles entre sí debido a su incidencia en la Seguridad y Salud de los trabajadores), así como la adecuación entre los riesgos existentes en el centro de trabajo que puedan afectar a los trabajadores de las empresas concurrentes y las medidas aplicadas para su prevención.

Se establece el intercambio de información preventiva entre los empresarios concurrentes en la obra, además de la clarificación de las medidas que deben adoptar los diferentes sujetos intervinientes en las obras. 
Es en la Disposición Adicional Primera que se recogen las obligaciones en materia de coordinación para el promotor, coordinador de Seguridad y Salud durante la ejecución de la obra y el contratista.

Es el empresario titular (promotor) el que deberá informar a los otros empresarios concurrentes en la obra sobre los riesgos del centro de trabajo que puedan afectar a las actividades por ellos desarrolladas, las medidas referidas a la prevención de tales riesgos y las medidas de emergencia que se deben aplicar (esta información ha de ser suficiente y proporcionarse antes del inicio de las actividades, así como cuando se produzcan cambios en los riesgos propios del centro de trabajo).

La Ley 32/2006 (BOE, 2006a), reguladora de la subcontratación en el Sector de la Construcción y el Real Decreto 1109/2007 (BOE, 2007b), que la desarrolla tienen por objeto controlar la subcontratación masiva en cadena, el "destajismo", los falsos autónomos y la precariedad laboral.

La Ley establece principalmente tres tipos de medidas para regular la subcontratación del sector:

I. Se determinan una serie de requisitos

Ley de

Subcontratación de calidad, solvencia y estabilidad en el empleo, que deberán reunir todas las empresas y profesionales que participen en la cadena de subcontratación (en el artículo 4 se determinan los requisitos exigibles a los contratistas y subcontratistas).

II. Se establece un nuevo régimen de ordenación y limitación de la misma. En este sentido se prohíbe que el subcontratista de tercer nivel o que el profesional autónomo pueda subcontratar. También se limita la subcontratación en el caso de los 
"subcontratistas intensivos", es decir, subcontratistas que solamente aportan mano de obra y herramientas manuales, incluidas las motorizadas portátiles. Tan sólo de forma excepcional se podrá extender la subcontratación establecida a un nivel adicional.

III. Se añade a todo el proceso de subcontratación unas determinadas exigencias de transparencia $y$ documentación especiales, entre las que destaca la obligación de todo contratista de disponer de un libro de subcontratación, que deberá permanecer en todo momento en la obra y en el cual se harán constar todas las subcontrataciones realizadas en la misma hasta su finalización. Con ello se fomenta la calidad del trabajo y se garantiza el cumplimiento de la normativa en materia de Seguridad y Salud laboral.

\section{Real Decreto} $337 / 2010$
El Real Decreto 337/2010 (BOE, 2010), por el que se modifica el Real Decreto 39/1997 (BOE, 1997a); el Real Decreto 1109/2007 (BOE, 2007b), y el Real Decreto 1627/1997 (BOE, 1997b), responde a la adaptación del ordenamiento jurídico a los objetivos fijados por la Estrategia Española de Seguridad y Salud en el Trabajo 2007-2012.

La práctica totalidad del contenido de la citada normativa se dirige a la modificación del Reglamento de los Servicios de Prevención, dividiéndose en áreas temáticas:

I. Facilitar el cumplimiento de la normativa de prevención a las empresas, en particular para las PYMES, para ello, y sin merma de la calidad, se pretende racionalizar $y$ 
simplificar su gestión en PRL, lo que se consigue permitiendo a las empresas de hasta cincuenta trabajadores que no desarrollen actividades del Anexo I del RSP que puedan utilizar de manera simplificada el Plan de PRL, la Evaluación de Riesgos y la planificación de la actividad preventiva, siempre que ello no suponga una reducción del nivel de protección de la Seguridad y Salud de los trabajadores. Además, estas mismas empresas que realicen las actividades preventivas mediante recursos propios dispongan de un proceso simplificado de auditoría de su sistema de gestión de la prevención, y por último se amplía de seis a diez el número de trabajadores de las empresas en las que el empresario puede asumir de manera personal el desarrollo de la actividad preventiva.

II. Se incide en importantes cuestiones que influyen significativamente en la calidad y eficacia del sistema de PRL de las empresas (homogeneidad en la acreditación de la entidad especializada en todo el territorio nacional, definición más competa del contenido de los conciertos de SPA con las empresas, potenciación de la interdisciplinaridad de IoS SPA que habrán de disponer para su acreditación de las cuatro especialidades $\quad$ disciplinas preventivas, definición y clarificación de los requisitos de los Servicios de Prevención Mancomunados de acuerdo con las recomendaciones de la Estrategia Española de Seguridad y Salud en el Trabajo 2007-2012. 


\begin{abstract}
No obstante lo anterior, se incluyen
modificaciones puntuales del resto de la legislación mencionada al comienzo, como la determinación para el desempeño de las funciones correspondientes al nivel superior donde será necesario contar con una Titulación Universitaria Oficial y poseer formación mínima acreditada por una universidad con el contenido específico no inferior a seiscientas horas; se modifica el porcentaje mínimo de trabajadores contratados con carácter indefinido, etc.
\end{abstract}

Tabla 3.3. Repaso a los principales hitos en materia legislativa que han marcado el camino hacia la integración de la PRL en España. Fuente: Segarra, 2015. Elaboración propia. 


\subsubsection{ESTUDIOS REALIZADOS EN MATERIA DE PRL EN EL SECTOR DE LA CONSTRUCCIÓN}

En la Tabla 3.4 se recogen, a modo de resumen, los principales trabajos en materia de PRL (tesis, libros, artículos, etc.) que han servido de inspiración para la redacción del presente trabajo de tesis, que siguen una línea clara en la materia anteriormente mencionada.

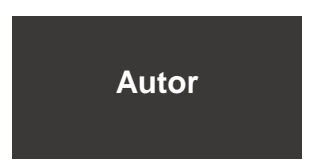

José Ignacio

Cantonnet

Mendía

María Teresa

Igartua Miro

Francisco Antonio

González Díaz

Federico Durán

López

INSHT

Antonio Ros

Serrano y Rafael

Anduiza Arriola

Federico Durán

López et al.

Miguel Ángel

Camino López et

al.

\section{Mesa Técnica de}

Seguridad

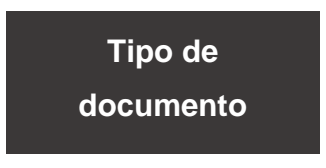

Tesis doctoral

Tesis doctoral

Tesis doctoral

Informe

Guía Técnica

Libro

Informe Durán

Artículo de

investigación

Guía Técnica

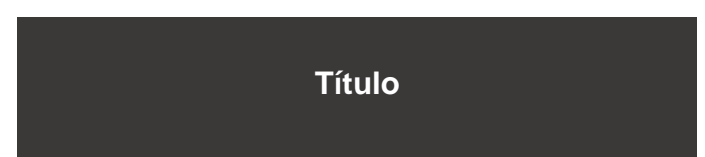

Análisis empírico comparativo de la siniestralidad en el sector de la construcción: tendencias de ajustes (Cantonent, 1999).

La obligación empresarial de garantizar la seguridad y salud en el trabajo (Igartua, 1999).

La obligación empresarial de PRL (González, 2001).

Informe sobre riesgos laborales y su prevención, la seguridad y la salud en el trabajo en España. "Informe Durán” (Durán, 2001).

Guía Técnica para la evaluación y prevención de los riesgos relativos a las obras de construcción (INSHT, 2003).

Bases para la redacción de los Estudios de Seguridad y Salud. Proyectos de Arquitectura e Ingeniería (Ros y Anduiza, 2007).

Informe sobre la situación de la PRL en el sector de la construcción en España (Durán et al., 2008).

Construction industry accidents in Spain (Camino et al., 2008).

Guía de contenidos recomendables de un Plan de Seguridad y Salud (MTSC, 2012). 
Laboral en la

Construcción

Ministerio de

Empleo y

Estrategia

Seguridad Social

Estrategia Española de Seguridad y Salud en

el Trabajo (2007-2012) (INSHT, 2013).

Un proceso de intervención sobre las

Marta Becerril

Galindo

Tesis doctoral

conductas de seguridad y las condiciones de seguridad y salud en las obras de construcción (Becerril, 2013)

María Segara

Cañamares

Rafael Vicente

Lozano Díez

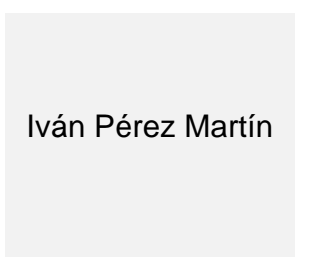

María Segarra

Cañamares et al.

Antonio José

Carpio de los

Pinos

Francisco J.

Forteza et al.

\section{Álvaro Romero \\ Barriuso et al.}

María Luisa

Cantonnet et al.

\section{Tesis doctoral}

Tesis doctoral

Tesis doctoral

\section{Artículo de}

investigación

Tesis doctoral

Artículo de

investigación

Artículo de

investigación

Artículo de

investigación
Integración de la PRL en las PYMES del Sector de la Construcción (Segarra, 2015).

Optimización de la figura del técnico coordinador de seguridad y salud en obras de edificación (Lozano, 2015).

Estudio internacional sobre la figura del "promotor" como integrador de PRL en la materialización de proyectos. Modelo de gestión preventiva desarrollado (Pérez, 2016).

Occupational risk-prevention diagnosis: A study of construction SMEs in Spain (Segarra et al., 2017).

Nueva metodología de evaluación de riesgos laborales adaptada a obras de edificación: nivel de la acción preventiva (Carpio, 2017).

Occupational risks, accidents on sites and economic performance of construction firms (Forteza et al., 2017).

Analysis and diagnosis of risk-prevention training actions in the Spanish construction sector (Romero et al., 2018).

New and emerging management in small and medium-sized Spanish enterprises (Cantonnet et al., 2019).

Tabla 3.4. Cuadro resumen de las principales investigaciones realizadas en la línea de investigación de la tesis doctoral que han servido de referencia para la elaboración del trabajo. 


\subsection{LA TRANSPOSICIÓN DE LA DIRECTIVA COMUNITARIA 92/57 CEE AL RD 1627/97}

El Real Decreto 1627/97 (BOE, 1997b) es la norma de desarrollo de la Ley de PRL en obras de construcción y establece de forma manifiesta mecanismos específicos para la aplicación de la PRL (BOE, 1995) así como del Real Decreto 39/1997 (BOE, 1997a). Dicha normativa, perteneciente al ordenamiento jurídico español, es transposición directa de la Directiva Comunitaria 92/57 CEE (Directiva, 1992b), que establece las disposiciones mínimas de seguridad y salud que deben aplicarse en las obras de construcción temporales o móviles.

A continuación, la Tabla 3.5 muestra la comparativa del articulado entre ambas normativas.

Ley 31/1995
El artículo 6 establece la
necesidad de reglamentar las
medidas preventivas que
garanticen la protección de los
trabajadores. En concreto, en
obras de construcción se realiza
a través del Real Decreto
$1627 / 97$ (BOE, 1997b).

\section{Directiva Comunitaria $92 / 57$}

El artículo 2, publica definiciones específicas en materia de seguridad y salud, en concreto: obras de construcción temporal o móviles, la propiedad, director de obra, trabajador autónomo, coordinador en materia de seguridad y salud durante la elaboración del proyecto y coordinador en

\section{Real Decreto 1627/97}

El artículo 2, del capítulo I establece las siguientes definiciones específicas en materia de seguridad y salud: obra de construcción $u$ obra, trabajos con riesgos especiales, promotor, proyectista, coordinador en materia de seguridad y salud durante la elaboración

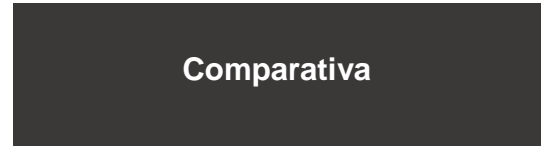

El Real Decreto 1627/97 (BOE, 1997b) transpone todas las definiciones establecidas en la Directiva Comunitaria 92/57 (Directiva, 1992b) y añade la definición de los siguientes agentes intervinientes en obra: proyectista, contratista y subcontratista. 
materia de seguridad y de

salud durante la

realización de la obra.

El artículo 3.1 establece que la designación del coordinador de seguridad y salud corresponde a la propiedad o al director de obra.

El artículo 3.2 indica que la propiedad o el director de obra velará para que se establezca un plan de seguridad y salud.

El punto c del artículo 5 considera que el coordinador en fase de proyecto constituirá un expediente adaptado a las características de la obra en el que se indiquen los elementos útiles en materia de seguridad y salud a tomar en consideración. del

proyecto,

coordinador en materia de seguridad y de salud durante la ejecución de la obra, dirección facultativa, contratista, subcontratista trabajador autónomo.

El artículo 3, del capítulo

II expone que la designación del coordinador de seguridad y salud corresponde al promotor.

El artículo 7.1 especifica que el plan de seguridad y salud será elaborado por cada contratista en aplicación al estudio de seguridad y salud.

El artículo 5 y 6 define respectivamente estudio de seguridad y salud y estudio básico de seguridad y salud. Esta herramienta debe ser elaborada por técnico competente designada por el promotor.
El punto b del artículo 5 muestra que el coordinador en fase de
El artículo 7.2 establece que el plan de seguridad y salud debe ser
En el Real Decreto 1627/97 (BOE, 1997b) se restringe la responsabilidad de designación del coordinador de seguridad y salud al promotor, eliminando la posibilidad de designación por parte del director de obra.

La Directiva Comunitaria 92/57 (Directiva, 1992b) no concreta quién es la figura encargada de elaborar el plan de seguridad y salud, sino que implica a varios agentes para que velen por su elaboración (el director de obra y la propiedad), y será el coordinador de seguridad y salud en fase de proyecto el encargado de elaborar un estudio previo de las características de la obra y los elementos de seguridad y salud a tener en cuenta. Sin embargo, el Real Decreto 1627/97 (BOE, 1997b) considera que exclusivamente el contratista podrá elaborar el plan de seguridad y salud, en aplicación al estudio de seguridad y salud, elaborado por técnico competente y designado por el promotor a diferente de la Directiva Comunitaria 92/57 (Directiva, 1992b).

La Directiva Comunitaria 92/57 (Directiva, 1992b) considera que el coordinador en fase de proyecto es 
proyecto establecerá el plan de seguridad y de salud o bien hará que se establezca.

El artículo 6c indica que el coordinador de seguridad y salud en fase de ejecución realizará o hará que se realicen las posibles modificaciones del plan de seguridad $y$ salud así como del expediente contemplado en el artículo 5c.

El Artículo 7 determina que la designación del coordinador no exime la responsabilidad de la propiedad o el director de obra.

El Artículo 9 especifica las obligaciones preventivas de los empresarios en la obra. aprobado, antes del inicio de la obra, por el coordinador en materia de seguridad y de salud durante la ejecución de la obra.

El artículo 7.4 expone que el contratista puede modificar el plan de seguridad y salud en función de la evolución de los trabajos y el proceso de ejecución de la obra, pero siempre con la aprobación del coordinador de seguridad y salud en fase de ejecución.

Artículo 3.4 del Capítulo II indica la responsabilidad del promotor aunque se haya designación a un coordinador.

El Artículo 11 establece las obligaciones de los contratistas y subcontratistas. el agente encargado de establecer las normas aplicables a la obra. EI Real Decreto 1627/97 (BOE, 1997b) por el contrario, considera y especifica que el coordinador de seguridad y salud en fase de ejecución será el encargado de aprobar el plan de seguridad y salud.

El Real Decreto 1627/97 (BOE, 1997b) establece que únicamente el contratista es el encargado de modificar el plan y posteriormente debe ser aprobado por el coordinador de seguridad y salud en fase de ejecución. La Directiva Comunitaria 92/57 (Directiva, 1992b) especifica que el coordinador de seguridad y salud en ejecución podrá realizar las modificaciones del plan de seguridad y salud o encargárselo a otro agente si así lo considera oportuno.

En este punto, observamos una transposición directa del artículo 7 de La Directiva Comunitaria 92/57 al Real Decreto 1627/97 (BOE, 1997b), no eximiendo de responsabilidad al promotor aunque se encuentre designado el coordinador de seguridad y salud.

El Artículo 11 del Real Decreto 1627/97 (BOE, 1997b) desarrolla más extensamente las obligaciones preventivas de los agentes intervinientes en obra.

Tabla 3.5. Cuadro resumen comparativa Directiva 92/57 CEE (Directiva, 1992b) y el RD 1627/97 (BOE, 1997b). 


\subsection{EL PLAN DE SEGURIDAD Y SALUD (PSS)}

En el presente apartado del documento, se estudia la importancia que este documento presenta a la hora de una correcta integración de la gestión preventiva en las obras de construcción, al entenderse este instrumento preventivo como el conjunto de actuaciones preventivas que se van a realizar en la obra por parte de las empresas intervinientes (contratista, subcontratista y trabajador autónomo) y en el que deben figurar los agentes intervinientes en materia de PRL (coordinador, recurso preventivo, jefe de obra, etc.). Es a través de este documento preventivo que el contratista realiza las tareas de: identificación, planificación, organización y control de todas y cada una de las actividades que se van a ejecutar, siempre desde el prisma de la Seguridad y Salud. Así mismo, se han de integrar los procedimientos preventivos de trabajo, los riesgos que pudiesen derivar de la actividad que se realice y las medidas preventivas que se han de adoptar en cada caso para la eliminación o control de los mismos (MTSC, 2012).

Se analiza en detalle el artículo 7 del Real Decreto 1627/97 (BOE, 1997b), se observa cómo afecta de forma directa a esta herramienta preventiva (PSS):

“1. En aplicación del estudio de seguridad y salud o, en su caso, del estudio básico, cada contratista elaborará un plan de seguridad y salud en el trabajo en el que se analicen, estudien, desarrollen y complementen las previsiones contenidas en el estudio o estudio básico, en función de su propio sistema de ejecución de la obra. En dicho plan se incluirán, en su caso, las propuestas de medidas alternativas de prevención que el contratista proponga con la correspondiente justificación técnica, que no podrán implicar disminución de los niveles de protección previstos en el estudio o estudio básico.

En el caso de planes de seguridad y salud elaborados en aplicación del estudio de seguridad y salud las propuestas de medidas alternativas de prevención incluirán la valoración económica de las mismas, que no podrá implicar disminución del importe total, de acuerdo con el segundo párrafo del apartado 4 del artículo 5.

2. El plan de seguridad y salud deberá ser aprobado, antes del inicio de la obra, por el coordinador en materia de seguridad y de salud durante la ejecución de la obra. 
En el caso de obras de las Administraciones públicas, el plan, con el correspondiente informe del coordinador en materia de seguridad y de salud durante la ejecución de la obra, se elevará para su aprobación a la Administración pública que haya adjudicado la obra.

Cuando no sea necesaria la designación de coordinador, las funciones que se le atribuyen en los párrafos anteriores serán asumidas por la dirección facultativa.

3. En relación con los puestos de trabajo en la obra, el plan de seguridad y salud en el trabajo a que se refiere este artículo constituye el instrumento básico de ordenación de las actividades de identificación y, en su caso, evaluación de los riesgos y planificación de la actividad preventiva a las que se refiere el capítulo II del Real Decreto por el que se aprueba el Reglamento de los Servicios de Prevención.

4. El plan de seguridad y salud podrá ser modificado por el contratista en función del proceso de ejecución de la obra, de la evolución de los trabajos y de las posibles incidencias o modificaciones que puedan surgir a lo largo de la obra, pero siempre con la aprobación expresa en los términos del apartado 2. Quienes intervengan en la ejecución de la obra, así como las personas u órganos con responsabilidades en materia de prevención en las empresas intervinientes en la misma y los representantes de los trabajadores, podrán presentar, por escrito y de forma razonada, las sugerencias y alternativas que estimen oportunas. $A$ tal efecto, el plan de seguridad y salud estará en la obra a disposición permanente de los mismos.

5. Asimismo, el plan de seguridad y salud estará en la obra a disposición permanente de la dirección facultativa".

De ello se puede extractar la importancia que el Estudio de Seguridad y Salud o el Estudio Básico de Seguridad y Salud tienen en la redacción del Plan, de cara a poder reflejar de forma fidedigna lo recogido en dichos documentos, pudiendo plantear medidas preventivas eficaces a cada uno de los riesgos recogidos en dicho documento, previo a la redacción del Plan. Al ser el contratista el encargado de la redacción del Plan, será éste (o en su defecto la persona redactora del Plan) el encargado de adaptar las previsiones incluidas en el ESS o en el EBSS al sistema de ejecución propio de la empresa, es decir, adaptando sus procedimientos de trabajo a lo recogido en dichos documentos para la ejecución 
de los trabajos de forma segura. Es por ello, que el ESS debería de elaborarse de forma conjunta con el proyecto de la obra, para conseguir un contenido detallado y que se ajuste a la obra que se pretende ejecutar. Esto se clarifica al estudiar el artículo 8 del citado Real Decreto, sobre los principios generales aplicables al proyecto de obra:

"1. De conformidad con la Ley de PRL, los principios generales de prevención en materia de seguridad y de salud previstos en su artículo 15 deberán ser tomados en consideración por el proyectista en las fases de concepción, estudio y elaboración del proyecto de obra y en particular:

a) Al tomar las decisiones constructivas, técnicas y de organización con el fin de planificar los distintos trabajos o fases de trabajo que se desarrollarán simultánea o sucesivamente.

b) Al estimar la duración requerida para la ejecución de estos distintos trabajos o fases del trabajo.

2. Asimismo, se tendrán en cuenta, cada vez que sea necesario, cualquier estudio de seguridad y salud o estudio básico, así como las previsiones e informaciones útiles a que se refieren el apartado 6 del artículo 5 y el apartado 3 del artículo 6, durante las fases de concepción, estudio y elaboración del proyecto de obra.

3. El coordinador en materia de seguridad y de salud durante la elaboración del proyecto de obra coordinará la aplicación de lo dispuesto en los apartados anteriores".

En el artículo 8 de este Real Decreto encontramos mención expresa al artículo 15 (principios de la acción preventiva) de la LPRL, que viene a decir que los principios de Seguridad y Salud previstos en el artículo 15 deberán de ser tenidos en cuenta por el proyectista de la obra "en las fases de concepción, estudio y elaboración del proyecto de obra, tomando las decisiones constructivas, técnicas y de organización con el fin de planificar los distintos trabajos, que se desarrollen simultáneamente y estimando la duración requerida para la ejecución de estos trabajos. Esto es, que durante la elaboración del proyecto muchos de los riesgos que puedan presentarse durante la ejecución de la obra deben ser eliminados o minimizados. 
Esto facilitará la elaboración y simplificación del PSS. Por ejemplo, si el proyecto y el ESS definen una unidad de obra en la cual el sistema de ejecución permite que sea realizado con protección colectiva, se evitarán protecciones individuales.

Por consiguiente, para la elaboración adecuada del PSS y sus anexos se debería comenzar con un análisis previo del contenido del referido proyecto de ejecución de obra y del ESS. Este análisis será contrastado con la información que posee el contratista, sobre los medios, equipos de trabajo, medios auxiliares, sistemas de protección y procedimientos de trabajo que, efectivamente, serán utilizados en la obra. Esta información, podrá obtenerse del examen de documentos tales como: la evaluación de riesgos, la planificación de la actividad preventiva, el plan de prevención de cada empresa presente en la misma, o de los manuales de instrucciones de los equipos y medios auxiliares que vayan a utilizarse por parte de las mismas. No olvidemos que el contratista, al igual que los subcontratistas, en su condición de empresarios, tiene la obligación de garantizar la protección eficaz de sus trabajadores, $y$ de aquellos otros pertenecientes a las empresas por ellas subcontratadas." (MTSC, 2012). 


\subsection{APRENDER DEL REAL DECRETO 396/2006}

Para la presente investigación, se hace necesario aprender de lo expuesto en el contenido del Real Decreto 396/2006 (BOE, 2006c), por el que se establecen las disposiciones mínimas de seguridad y salud aplicables a los trabajos con riesgo de exposición al amianto, en aras de poder extrapolar directrices de mejora a aplicar a la hora de la redacción del Plan de Seguridad y Salud, que complementen su normativa específica y le otorguen un mayor calado. La importancia de esta normativa radica en que se engloba todo el proceso preventivo, desde la formación e información que han de recibir los trabajadores que vayan a estar expuestos a dichos trabajos con amianto (artículos 13 y 14 respectivamente), la vigilancia específica de la salud de los trabajadores (artículo 16), se prevé la consulta y participación de los trabajadores (artículo 15), se especifica el contenido mínimo de los Planes de Trabajo (artículo 11) (que se asemejaría en gran medida al Plan de Seguridad y Salud), la tramitación de los Planes de Trabajo (artículo 12), las disposiciones específicas para determinadas actividades (artículo 10), las medidas de higiene personal y de protección individual (artículo 9), se hace mención específica a los equipos de protección individual de las vías respiratorias (artículo 8), las medidas organizativas y las medidas técnicas generales de prevención (artículo 7 y 6 respectivamente), la evaluación y el control del ambiente de trabajo (artículo 5), los límites de exposición y prohibiciones que aseguren que ningún trabajador vaya a estar expuesto a altas concentraciones de amianto (artículo 4), así como la medida de obligatoriedad de inscripción en el Registro de empresas con riesgo de amianto o RERA (artículo17) (lo que en el caso de las obras de construcción sería el REA o Registro de Empresas Acreditadas).

Es por todo ello, que queda demostrado que se trata de una normativa de mayor calado y que contempla todo el espectro que engloba una obra con riesgo de exposición al amianto, por lo que sería interesante poder extrapolar la minuciosidad y la lectura global de dicha normativa para poder implementarlo en la normativa referida a los Planes de Seguridad y Salud, el Real Decreto 1627/97 (BOE, 1997b). 
A continuación, la Tabla 3.6 muestra la comparativa del articulado entre ambas normativas.

Real Decreto 396/2006

El artículo 9 expone las medidas de higiene personal y de protección individual que se deberá adoptar en obras con riesgo de exposición a amianto.

El artículo 11 determina las medidas preventivas que debe contemplar el plan de amianto $y$ establece los contenidos que debe especificar $y$ desarrollar.

El artículo 12 establece que la aprobación de los planes de amianto la realizará la autoridad laboral.

El artículo 13 establece el contenido formativo que tienen que recibir los trabajadores para poder

\section{Real Decreto $1627 / 97$}

No se especifican las medidas de higiene personal y de protección individual.

El artículo 7.1 indica que el plan de seguridad y salud debe analizar, estudiar, desarrollar $y$ complementar las previsiones contenidas en el estudio o estudio básico, así como, las propuestas de medidas alternativas propuestas por el contratista.

El artículo 7.2 expone que la aprobación de los planes de seguridad y salud recae en la figura del coordinador de seguridad y salud en fase de ejecución.

No existe ningún articulado que haga mención a la formación

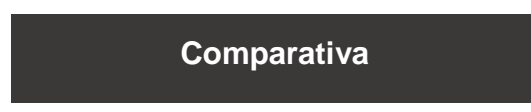

En el plan de amianto debe aparecer de forma específica las medidas de higiene y de protección individual que se van a utilizar. Sin embargo, en el Real Decreto 396/2006 (BOE, 2006c) sólo se hace una mención a los equipos de protección individual, concretamente en el apartado $f$ del artículo 12 que hace referencia a la elección y utilización de los equipos de protección individual en el caso de trabajadores autónomos.

El Real Decreto 396/2006 (BOE, 2006c) específica de forma pormenorizada el contenido que debe contemplar del plan de amianto, sin embargo, el Real Decreto 1627/97 (BOE, 1997b) no concreta los contenidos específicos del plan de seguridad y salud.

La figura del plan de amianto es aprobada por la autoridad laboral, sin embargo el plan de seguridad y salud es aprobado por un agente externo a la administración pública, el coordinador de seguridad y salud en fase de ejecución, designado por el promotor.

El Real Decreto 396/2006 (BOE, 2006c) determina los contenidos específicos de la formación que tienen que recibir los trabajadores y se debe incluir en el plan de 


\begin{tabular}{ll|l|l|l}
$\begin{array}{l}\text { realizar trabajos de } \\
\text { desamiantado. }\end{array}$ & $\begin{array}{l}\text { que deben recibir los } \\
\text { trabajadores. }\end{array}$ & $\begin{array}{l}\text { amianto. Sin embargo, el Real } \\
\text { Decreto 1627/97 (BOE, 1997b) no }\end{array}$ \\
& & concreta los contenidos formativos, \\
& & ni su inclusión en el plan de \\
& seguridad y salud.
\end{tabular}

Tabla 3.6. Cuadro resumen comparativa RD 396/2006 (BOE, 2006c) y el RD 1627/97 (BOE, 1997b). 
CAPÍTULO 4

METOdOLOGÍA 



\subsection{FASES DEL ESTUDIO}

Una vez estudiado el aspecto legislativo que afecta al documento preventivo del Plan de Seguridad y Salud, así como a su estructura formal e implicación en obra, se ha realizado un estudio de orden cuantitativo con el fin de conocer la utilidad real que este documento desempeña en la integración e implantación de la prevención en las obras de construcción, mediante el estudio de dicho documento preventivo para la Comunidad Autónoma de Castilla-La Mancha.

Esto ha sido posible gracias al convenio establecido entre la universidad y la Junta de Comunidades de Castilla-La Mancha, para ello se ha contado con la ayuda e implicación del grupo de investigación GECO (perteneciente a la Universidad de Castilla-La Mancha) para conseguir el establecimiento del convenio, que ha permitido realizar las visitas a las distintas sedes de la Autoridad Laboral que integran dicha Comunidad Autónoma, siendo éstas: Albacete, Ciudad Real, Cuenca, Guadalajara y Toledo (determinadas por orden alfabético). Esto permite obtener un abanico de documentos representativo, en cuanto al tamaño de la muestra, y variado, al incluir los Planes de Seguridad y Salud realizados por distintas empresas/servicios de prevención (tanto de carácter público como privado), lo que asegura la imparcialidad y la varianza. Además de todo esto, se añadió un componente de aleatoriedad en cuanto a la selección de los Planes de Seguridad y Salud, eligiendo las cajas de registro que contiene los Planes de forma no consecutiva y azarosa por cada año consultado (período de tiempo investigado: del año 2008 al año 2016, ambos incluidos).

Para conseguir abarcar de forma eficaz la gran cantidad de información que contempla el estudio, se ejecutó la labor de análisis de datos mediante dos investigadores desplazados a cada sede de la Autoridad Laboral de Castilla-La Mancha, elaborando un cronograma de las visitas a realizar muy acotado, en combinación con el cronograma de trabajos y solapes producidos, que se fue modificando en función de la disponibilidad de las sedes y de los propios investigadores, dentro de que la totalidad de los trabajos de consulta debían de realizarse a lo largo de un año completo.

A continuación, se adjunta la Tabla 4.1 con el calendario orientativo, que desglosa los días previstos que los investigadores se desplazarían a las diferentes delegaciones para realizar la consulta de los Planes de Seguridad y Salud. Este 
cronograma sufrió modificaciones, principalmente en función de la disponibilidad de los investigadores y de la propia Administración Pública en las diferentes delegaciones.

\begin{tabular}{|c|c|c|c|c|c|c|c|c|c|c|c|c|c|c|c|c|c|c|c|c|}
\hline \multicolumn{10}{|c|}{ Mayo } & \multicolumn{10}{|c|}{ Junio } \\
\hline $\mathbf{L}$ & $\mathbf{M}$ & $\mathbf{X}$ & $\mathbf{J}$ & $\mathbf{V}$ & $\mathbf{S}$ & $\mathbf{D}$ & $\mathbf{L}$ & $\mathbf{M}$ & $\mathbf{X}$ & $\mathbf{J}$ & $\mathbf{V}$ & $\mathbf{S}$ & $\mathbf{D}$ & $\mathbf{L}$ & $\mathbf{M}$ & $\mathbf{X}$ & $\mathbf{J}$ & $\mathbf{V}$ & $\mathbf{S}$ & $\mathbf{D}$ \\
\hline 1 & 2 & 3 & 4 & 5 & 6 & 7 & & & & 1 & 2 & 3 & 4 & & & & & & 1 & 2 \\
\hline 8 & 9 & 10 & 11 & 12 & 13 & 14 & 5 & 6 & 7 & 8 & 9 & 10 & 11 & 3 & 4 & 5 & 6 & 7 & 8 & 9 \\
\hline 15 & 16 & 17 & 18 & 19 & 20 & 21 & 12 & 13 & 14 & 15 & 16 & 17 & 18 & 10 & 11 & 12 & 13 & 14 & 15 & 16 \\
\hline 22 & 23 & 24 & 25 & 26 & 27 & 28 & 19 & 20 & 21 & 22 & 23 & 24 & 25 & 17 & 18 & 19 & 20 & 21 & 22 & 23 \\
\hline 29 & 30 & 31 & & & & & 26 & 27 & 28 & 29 & 30 & & & 24 & 25 & 26 & 27 & 28 & 29 & 30 \\
\hline & & & & & & & & & & & & & & 31 & & & & & & \\
\hline
\end{tabular}

\begin{tabular}{|c|c|c|c|c|c|c|c|c|c|c|c|c|c|c|c|c|c|c|c|c|}
\hline \multicolumn{10}{|c|}{ Agosto } & \multicolumn{10}{|c|}{ Septiembre } & \multicolumn{1}{|c|}{ Octubre } \\
\hline L & M & X & J & V & S & D & L & M & X & J & V & S & D & L & M & X & J & V & S & D \\
\hline & 1 & 2 & 3 & 4 & 5 & 6 & & & & & 1 & 2 & 3 & & & & & & & 1 \\
\hline 7 & 8 & 9 & 10 & 11 & 12 & 13 & 4 & 5 & 6 & 7 & 8 & 9 & 10 & 2 & 3 & 4 & 5 & 6 & 7 & 8 \\
\hline 14 & 15 & 16 & 17 & 18 & 19 & 20 & 11 & 12 & 13 & 14 & 15 & 16 & 17 & 9 & 10 & 11 & 12 & 13 & 14 & 15 \\
\hline 21 & 22 & 23 & 24 & 25 & 26 & 27 & 18 & 19 & 20 & 21 & 22 & 23 & 24 & 16 & 17 & 18 & 19 & 20 & 21 & 22 \\
\hline 28 & 29 & 30 & 31 & & & & 25 & 26 & 27 & 28 & 29 & 30 & & 23 & 24 & 25 & 26 & 27 & 28 & 29 \\
\hline & & & & & & & & & & & & & & 30 & 31 & & & & & \\
\hline
\end{tabular}

\begin{tabular}{|c|c|c|c|c|c|c|c|c|c|c|c|c|c|c|c|c|c|c|c|c|}
\hline \multicolumn{10}{|c|}{ Noviembre } & \multicolumn{10}{|c|}{ Diciembre } \\
\hline L & M & X & J & V & S & D & L & M & X & J & V & S & D & L & M & X & J & V & S & D \\
\hline & & 1 & 2 & 3 & 4 & 5 & & & & & 1 & 2 & 3 & 1 & 2 & 3 & 4 & 5 & 6 & 7 \\
\hline 6 & 7 & 8 & 9 & 10 & 11 & 12 & 4 & 5 & 6 & 7 & 8 & 9 & 10 & 8 & 9 & 10 & 11 & 12 & 13 & 14 \\
\hline 13 & 14 & 15 & 16 & 17 & 18 & 19 & 11 & 12 & 13 & 14 & 15 & 16 & 17 & 15 & 16 & 17 & 18 & 19 & 20 & 21 \\
\hline 20 & 21 & 22 & 23 & 24 & 25 & 26 & 18 & 19 & 20 & 21 & 22 & 23 & 24 & 22 & 23 & 24 & 25 & 26 & 27 & 28 \\
\hline 27 & 28 & 29 & 30 & & & & 25 & 26 & 27 & 28 & 29 & 30 & 31 & 29 & 30 & 31 & & & & \\
\hline
\end{tabular}

Tabla 4.1. Calendario orientativo de los días designados a cada una de las diferentes delegaciones de la JCCM.

Asimismo, en cada sede se llevó a cabo una reunión con el Jefe del Servicio de la Autoridad Laboral correspondiente en conjunción con los técnicos de prevención en plantilla, ya fuesen habilitados o no, para aportar su punto de vista y opinión sobre la realidad de dicho documento en las obras de construcción y de cara a su utilidad en las posibles inspecciones. Esta reunión, previa a los trabajos de consulta de los Planes de Seguridad y Salud, establecía las bases sobre los ítems a consultar, si bien ya se había elaborado un checklist previo que ayudaba a focalizar los ítems sobre los que 
centrar las miras, que fueron establecidos a raíz de la primera reunión y que están recogidos en el Anexo I.

Si bien es cierto que en un principio este estudio pretendía abarcar tanto el estudio de los Planes de Seguridad y Salud como las Evaluaciones de Riesgos, este último documento preventivo mencionado fue descartado debido a que no llega a constituir una muestra significativa, en relación a las Evaluaciones de Riesgos visualizadas en las distintas sedes, por lo que este documento se descarta del documento final de la Tesis doctoral.

Se determina por tanto que la consulta de datos es la forma más imparcial y eficaz de obtener resultados, combinando la técnica de orden cuantitativo con la de orden cualitativo, como la metodología que mejor se ajusta al propósito del presente estudio. 


\subsection{LA CONSULTA COMO ESTRATEGIA DE INVESTIGACIÓN}

La consulta in situ de los PSSs ha permitido obtener un gran volumen de datos, que son los que se muestran recogidos en la presente investigación (Capítulo 5. Resultados de la Investigación), entendiendo por datos la definición recogida en la política institucional de la Universidad Australiana de Melbourne: "Los datos de la investigación son hechos, observaciones o experiencias en que se basa el argumento, la teoría o la prueba. Los datos pueden ser numéricos, descriptivos o visuales. Los datos pueden ser en estado bruto o analizado, pueden ser experimentales u observacionales. Los datos incluyen: cuadernos de laboratorio, cuadernos de campo, datos de investigación primaria (incluidos los datos en papel o en soporte informático), cuestionarios, cintas de audio, videos, desarrollo de modelos, fotografías, películas, y las comprobaciones y las respuestas de la prueba. Las colecciones datos para la investigación pueden incluir diapositivas; diseños y muestras. En la información sobre la procedencia de los datos también se podría incluir: el cómo, cuándo, donde se recogió y con que (por ejemplo, instrumentos). El código de software utilizado para generar, comentar o analizar los datos también pueden ser considerados datos".

El consiguiente paso ha de ser la categorización de los datos obtenidos en las visitas a las cinco sedes de la Autoridad Laboral de Castilla-La Mancha, que según la National Science Foundation éstos pueden englobarse en tres tipologías:

- Datos observacionales.

- Datos experimentales.

- Datos computacionales.

en función de la variedad de tipo y sus distintas necesidades a la hora de gestionarse, quedando los datos obtenidos durante la investigación incluidos en la categoría de datos observacionales. Según la definición que establece la National Science Foundation para los datos observacionales, éstos "son registros históricos, se pueden obtener únicamente en un lugar y en un momento en el tiempo. Esta característica los hace especialmente importantes a la hora de preservarlos ya que en caso de que se perdiesen no podrían volver a reproducirse. Ejemplos: Ios barómetros del Centro de Investigaciones Sociológicas (CIS), son encuestas de opinión sobre diversos temas que preocupan a los españoles. El 
Banco Nacional de Datos Climatológicos sería otro caso de este tipo ya que posee información sobre precipitaciones registradas en España desde hace 150 años".

Quedando los datos obtenidos para la investigación como observacionales, se ha de hacer una subdivisión que se ajuste a la disciplina científica, obteniendo como resultados que se trata de datos cuantitativos, de entre las subcategorías posibles: cualitativos, cuantitativos, geográficos, espaciales, u otros, tal y como categoriza la Fundación Española para la Ciencia y la Tecnología (FECYT, 2012).

Dicho esto, se pasa a especificar, de forma esquemática y cronológica, el proceso empleado en la gestión de los datos obtenidos, tal y como se recoge a continuación:

1. Estudio de la normativa vigente que atañe al documento preventivo objeto del análisis, así como su contexto en obra.

2. Análisis previo del contenido de un Plan de Seguridad y Salud, detección de los puntos fuertes y las deficiencias existentes.

3. Elaboración de un checklist (Anexo I) que ahonde en las cuestiones que pretenden ser analizadas.

4. Se tienen en cuenta las cuestiones éticas y legales acerca de los datos personales sensibles. Se dejan de lado este tipo de datos, únicamente se decide obtener datos estadísticos.

5. Volcado de los puntos del Plan sobre los que se ha de reflexionar en la reunión de equipo.

6. Reelaboración del checklist (Anexo I) en función de lo expuesto en la reunión y de los objetivos que se quieren alcanzar con la investigación, proceso de reorganización de los ítems.

7. Tras otra posterior reunión se deciden descartar todas aquellas preguntas que no sean de naturaleza dicotómica, para evitar interpretaciones que puedan empañar la imparcialidad de los resultados.

8. Planificación de las visitas y cronograma de tiempos detallado para llevar a cabo la extracción de datos en el tiempo estipulado para ello, se 
establecen tiempos de demora en caso de no alcanzar los objetivos en alguna de las sedes debido a causas de fuerza mayor.

9. Documentación y reestructuración de los datos registrados, se visita la primera sede de la Autoridad Laboral, se decide redimensionar el tamaño de la muestra, y se pasa de 50 a 100 PSSs consultados por año.

10. Las reuniones mantenidas con los Jefes de Servicio y técnicos de la Junta refuerzan los puntos sobre los que se ha de centrar la fase de documentación y posterior análisis del volumen de datos obtenido.

11. En las reuniones de equipo se vuelcan los datos obtenidos y se decide la estrategia para afrontar el gran volumen de datos y cómo ha de ser abordado.

12. Se procede a las labores de escrutinio de los datos y de análisis de los resultados obtenidos que se pueden extractar.

Si bien los puntos expuestos sobre estas líneas podrían pasar a completar el contenido del apartado anterior, han de ser expuestos en el presente apartado como justificación del tratamiento que se ha hecho de los datos, desde su concepción, hasta la criba y posterior obtención de los resultados de la investigación.

El papel que desarrolla el investigador, en este caso, en la gestión de los datos (Lyon, 2007) y su responsabilidad para con los mismos viene detallada en la definición de investigadores/productores de datos (FECYT, 2012): "Proporcionan la evidencia y validación científica de las investigaciones. Si bien esta categoría se compone fundamentalmente de investigadores, en algunos casos hay conjuntos de datos que ya existen y los científicos los utilizan para validar sus tesis. La comunidad investigadora puede ser considerada como productores, autores, y usuarios de los datos de investigación."

De esta forma, queda explicada la elección de este tipo de metodología para la recopilación de datos, así como su fiabilidad e imparcialidad en la obtención de resultados, al ser la que mejor se adapta a los objetivos del estudio. 


\subsubsection{JUSTIFICACIÓN DE LA CONSULTA COMO ESTRATEGIA DE INVESTIGACIÓN}

Dado que se trata de una investigación novedosa, que no tiene precedentes en nuestro país, en parte dada por la inaccesibilidad de los datos, que han de ser consultados in situ en las distintas sedes de la Autoridad Laboral, previa firma de un convenio que permita la extracción de los datos (debido a la naturaleza sensible de los datos a consultar), ésta era la única metodología que se adaptaba a los requisitos de imparcialidad y varianza de datos necesarios para ejecutar el estudio de forma que los resultados obtenidos pudiesen ser extrapolables a otras Comunidades Autónomas o provincias del territorio español.

En un principio, la consulta de datos se iba a realizar con los PSSs recopilados en varios Servicios de Prevención Ajenos implantados en el territorio nacional, pero al analizar los mismos, se identificó un mismo patrón en su elaboración, lo que echaba por tierra el criterio de varianza que se pretendía conseguir. Así mismo, tampoco se cumplía con el criterio de imparcialidad, ya que no se contemplaban los PSSs elaborados por Administraciones Públicas de diversa índole, lo que lastraba el estudio en el campo de la imparcialidad, además de que en estos casos, se cumplía con el "visto uno visto el resto". Es por ello, que se decide solicitar un convenio de colaboración para poder consultar una muestra representativa de PSSs que integren a partes iguales PSSs pertenecientes a obras del sector público como del privado, y que han sido elaborados por diversos agentes, constructores, empresas, SPAs, etc. Lo que aseguraba los valores de varianza e imparcialidad necesarios. La imparcialidad se implementó con una serie de medidas, entre las que destaca la de la elección de los Planes, que se llevó a cabo de forma aleatoria y no consecutiva, para conseguir una mezcolanza de los PSSs guardados en los registros de las distintas sedes visitadas.

Dado que se pretende conseguir que los resultados del estudio puedan ser extrapolables a otras provincias, la muestra pasó de estar configurada para 50 PSSs a 100 PSSs por año, siempre y cuando esto fuese posible, en función de los registros que se tuviesen para los distintos períodos de tiempo consultados (2008 a 2016, ambos incluídos), tal y como se recoge en la Tabla 5.1. perteneciente al Capítulo 5. Resultados de la Investigación. 
Es debido al gran volumen de los datos a consultar que se otorga el plazo de doce meses para llevar a cabo las visitas, las reuniones en las sedes y de equipo, así como el análisis de los datos. Debido a que se trata de un convenio que no conlleva una retribución económica, los recursos humanos y económicos, salieron de los propios investigadores, lo que hizo que se llevase un cronograma muy marcado de los objetivos y de los tiempos dedicados a cada fase del proyecto. 


\subsubsection{DELIMITACIÓN DEL TAMAÑO DE LA MUESTRA Y DEL TIPO DE MUESTREO}

En función de las diferentes disponibilidades del registro de cada sede de la Autoridad Laboral de Castilla-La Mancha, dado que los PSSs consultados se encontraban en su gran mayoría en formato papel (es únicamente en los últimos años del estudio en los que empezaban a apreciar más PSSs en formato digital), y debían de ser visualizados in situ, se configuró la Tabla 5.1 perteneciente al Capítulo 5. Resultados de la Investigación que muestra el total de PSSs consultados por sede y año, de entre el período de tiempo estipulado para el estudio, de 2008 a 2016, ambos incluidos. Tal y como se explica en el subapartado anterior, el tamaño de la muestra viene dada por los criterios de varianza e imparcialidad previstos, amén de tratarse de una muestra considerable para que los resultados obtenidos puedan ser extrapolables a otros territorios dentro del panorama nacional.

Dicho lo cual, la muestra quedó configurada con los 3.600 PSSs, pertenecientes tanto a obras de carácter público como privado, lo que asegura una muestra representativa de dicho documento preventivo, y que asegura la imparcialidad, al encontrar PSSs elaborados por diversos Servicios de Prevención, empresas, etc.

Las diferencias obtenidas entre las distintas sedes, en lo que al número de PSSs consultados se refiere, es debido a los criterios de registro que cada sede realiza, ya que muchos de ellos, eran enviados al archivo central, y la consulta de los mismos debía ser realizada previa solicitud con antelación. 


\subsubsection{DISEÑO DEL CUESTIONARIO}

Una vez que se ha procedido a definir el tamaño de la muestra a consultar, asegurando las variables de varianza, imparcialidad y aleatoriedad previstas en el estudio, se procede a la elaboración del cuestionario que integrará los diversos ítems a analizar en las visitas a las sedes.

Dado que la intención del presente estudio es la de obtener datos meramente estadísticos, dejando de lado los datos sensibles que contienen los PSSs, se evalúan las distintas posibilidades que la formulación correcta de las preguntas del cuestionario puede aportar a la investigación. Debido a los criterios de la investigación, mencionados con anterioridad, se analiza la clasificación de los distintos tipos de preguntas (Azofra, 2005) para elegir el que mejor se adapte al estudio a realizar.

1. Preguntas según las respuestas que se admitan:
a. Preguntas abiertas.
b. Preguntas cerradas.
c. Preguntas semicerradas.

2. Preguntas dicotómicas:
a. Preguntas categorizadas o de escala nominal.
b. Preguntas de escala numérica.
c. Preguntas de valoración.

3. Preguntas directas.

4. Preguntas indirectas.

5. Preguntas de respuesta única.

6. Preguntas de respuesta variable. 
Puesto que el objetivo del presente estudio es el de obtener datos estadísticos, imparciales por completo, el tipo de pregunta que mejor se adapta para dicho objetivo es el tipo dicotómico, que nada más nos permite obtener un sí (1, en sistema binario, utilizado en la recopilación de los datos) o un no (0, en sistema binario).

Para la elaboración de los ítems que integran el cuestionario (Anexo I) se tuvieron en cuenta la $2^{\mathrm{a}}$ Edición de la Guía Técnica del INSHT (INSHT, 2012), así como la Guía de Contenidos Recomendables de un Plan de Seguridad y Salud elaborada por la Mesa Técnica de Seguridad Laboral en la Construcción (MTSC, 2012), tomando como base para iniciar el mismo la normativa de aplicación, el Real Decreto 1627/97 (BOE, 1997b).

De esta forma el cuestionario quedó configurado y estructurado por apartados, tal y como se recoge en la Tabla 5.2 perteneciente al Capítulo 5. Resultados de la Investigación que esquematiza los apartados y subapartados contemplados en el cuestionario. A modo de croquis, las cuestiones se dividen en cuatro grandes grupos o apartados:

1. Figuras jurídicas que intervienen en obras de construcción.

2. Aspecto formal del documento (PSS).

3. Evaluación de riesgos de la obra.

4. Anomalías e incidencias reseñables.

El cuestionario empleado en las visitas a las sedes se encuentra recogido en el Anexo I, y en el mismo se recopilan las treinta y ocho preguntas o ítems utilizados en la consulta de los PSSs (treinta y nueve si se incluye el año de registro del documento). 


\subsubsection{LISTADO DE ÍTEMS/PREGUNTAS QUE INTEGRAN EL CUESTIONARIO}

El primer ítem o pregunta que se rellenó en cada caso fue el año de elaboración del Plan, según fecha de registro, asignando un código numérico a cada año para diferenciarlo del resto e incluirlos por períodos, del 2008 al 2012 (del 1 al 5, asignando al 2008 el valor de 1) y del 2013 al 2016 (del 6 al 9).

Posteriormente se pasó a analizar uno por uno cada bloque de preguntas, tal y como se recoge en el apartado 5.2.3, que muestra los bloques de preguntas que configuran el estudio. En la Tabla 4.2 se encuentran recogidos los bloques y el número de preguntas o ítems evaluados pertenecientes a los mismos.

\section{Bloques o indicadores}

0. Datos generales: Año del Plan

1. Figuras jurídicas que intervienen en obras de construcción

2. Aspecto formal del documento (PSS)

3. Evaluación de Riesgos de la obra

4. Anomalías e incidencias reseñables

\section{$\mathbf{N}^{\circ}$ de preguntas}

TOTAL Preguntas

39

Tabla 4.2. Número de preguntas o ítems que conforman o integran cada bloque o indicador del cuestionario.

Una vez expuesto esto, se pasa a mostrar las preguntas o ítems que integran cada bloque. 


\section{Figuras jurídicas que intervienen en obras de construcción.}

En este bloque se analiza la presencia o no en el documento preventivo de dichas figuras con obligaciones en obras de construcción, dada su importancia en las distintas fases de la ejecución del proyecto.

1. ¿Aparecen reflejadas en el Plan las figuras del Promotor, Contratista y Proyectista?

2. ¿Se recoge el nombramiento de la figura del Recurso Preventivo?

3. ¿Es el Recurso Preventivo el propio empresario?

4. ¿Aparecen recogidos el/los Subcontratistas presentes en la obra?

5. ¿Aparecen recogidos los Trabajadores Autónomos?

6. ¿Se recopilan los Trabajadores por cuenta Ajena presentes en la obra?

7. ¿Se incluye la Dirección Facultativa de la obra?

8. ¿Se refleja la figura del Coordinador de Seguridad y Salud en fase de redacción del proyecto?

9. ¿Se refleja la figura del Coordinador de Seguridad y Salud en fase de ejecución de la obra?

10. El Coordinador de Seguridad y Salud de la obra, encargado de aprobar el PSS, ¿es el mismo que redacta el Plan?

\section{Aspecto formal del documento preventivo (PSS).}

En este bloque se procede a evaluar el contenido del Plan, centrando la mirada en los aspectos relevantes para los objetivos del presente estudio, descartando todos aquellos aspectos que no aporten valor a la investigación. Para ello, se analiza el cuerpo del documento en busca de los ítems que a continuación se recogen:

11. ¿Aparecen integradas en el documento las unidades o fases de obra (cronograma de trabajos)? 
12. ¿El PSS contiene material gráfico?

13. ¿EI PSS incluye material gráfico relacionado con la obra o la maquinaria que se va a emplear en la obra?

14. ¿Cuenta el PSS con pautas de actuación ante emergencias?

15. ¿Se recogen los itinerarios para llegar a los centros asistenciales/hospital en el PSS?

16. ¿Incluye el PSS pautas de actuación en caso de riesgo grave e inminente en obra?

17. ¿Cuenta el PSS con Plan de Evacuación en caso de incendio?

18. ¿Integra el PSS procedimientos de control de Seguridad Vial?

19. ¿Incluye el PSS un Plan de Seguridad Vial específico para la obra que se detalla?

20. ¿Se incorpora un capítulo específico para la Seguridad y Salud de la obra dentro del capítulo de Mediciones y Presupuesto del Plan?

\section{Evaluación de los Riesgos presentes en obra.}

En esta unidad se analizan todos aquellos aspectos relativos a la Evaluación de Riesgos de la obra, tal y como estipula el artículo 7 del Real Decreto 1627/97 (BOE, 1997b), así como lo recogido en el Capítulo II del Real Decreto 39/1997 (BOE, 1997a). Este aspecto del documento es de vital importancia para la correcta evaluación de los riesgos presentes en obra que pueden derivar en accidentes. Para lo cual, se estudian los aspectos relativos a los ítems que a continuación se recolectan:

21. ¿Se evalúa cada fase/trabajo/puesto/actividad de la obra en el Plan?

22. ¿Se evalúa cada fase/trabajo/puesto/actividad de la obra en el Plan de forma específica?

23. ¿Se identifica en el PSS la maquinaria/equipos que se prevén emplear en la obra? 
24. ¿Se identifica y evalúa la maquinaria/equipos que se prevén emplear en la obra?

25. ¿Se identifican en el PSS los medios auxiliares que se prevén emplear en obra?

26. ¿Se identifican y evalúan los medios auxiliares que se prevén emplear en la obra?

27. ¿Se incluye el manual de instrucciones y/o procedimientos de montaje/desmontaje/utilización de los medios auxiliares que se prevén emplear en la obra?

28. ¿Se incluyen en el PSS los productos químicos que se van a emplear en la obra?

29. ¿Se incluyen las fichas de seguridad de los productos químicos que se van a emplear en obra en el PSS?

30. La Evaluación de Riesgos integrada en el PSS ¿se ajusta a lo determinado en el artículo 7 del RD 39/1997?

31. ¿Existe Planificación Preventiva en el PSS como resultado de la Evaluación de Riesgos?

32. La Planificación Preventiva recogida en el PSS ¿se ajusta en el artículo 9 del RD 39/1997?

\section{Anomalías e incidencias reseñables del documento.}

En este último bloque del cuestionario se recogen todas aquellas anomalías e incidencias, que merecen ser mencionadas o reseñadas, que han sido encontradas durante el visionado de los Planes en las sedes. Algunas de las cuales ponen de relevancia la utilidad real o no de este documento preventivo, así como la importancia que se hace del mismo en la realidad de la obra de construcción. Para esto, se examinan los ítems que a continuación se muestran:

33. EI PSS en papel, ¿está vacío o en blanco?

34. El CD que contiene el PSS, ¿está vacío o no se puede abrir? 
35. EI PSS ¿guarda relación con la obra descrita en el título del documento?

36. ¿Se utiliza el mismo PSS para distintas obras?

37. ¿Se hace referencia al Estudio o Estudio Básico de Seguridad y Salud en el PSS?

38. ¿EI PSS está firmado? 
CAPÍTULO 5

RESULTADOS DE LA INVESTIGACIÓN 



\subsection{INTRODUCCIÓN RESULTADOS DE LA INVESTIGACIÓN}

Para contextualizar la presente investigación dentro de un marco normativo, se ha tenido en cuenta la legislación en materia de prevención de riesgos laborales (PRL) tanto a nivel nacional como internacional, dando como resultado la siguiente línea temporal que se recoge en la Figura 5.1.

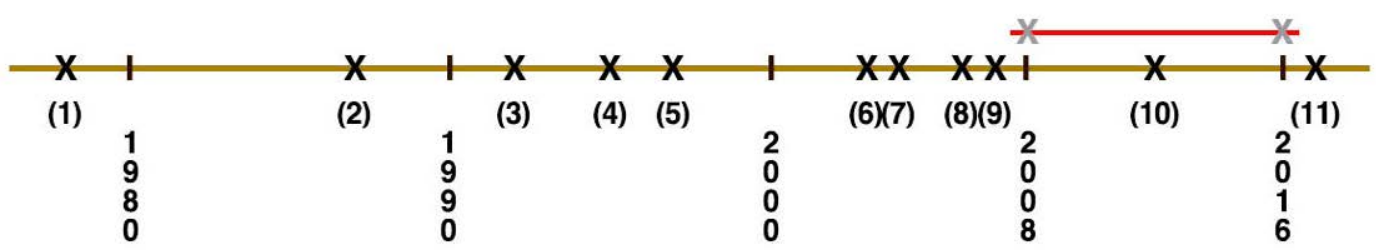

Figura 5.1. Línea temporal normativa en materia de PRL. Hitos más importantes:

(1) 1978. Constitución Española, de 29 de diciembre (BOE, 1978).

(2) 1987. Resolución del Consejo de 21 de diciembre (Resolución, 1988) (Diario Oficial $n^{\circ}$ C 028 de 03/02/1988). Relativa a la seguridad, la higiene y la salud en los lugares de trabajo.

(3) 1992. Directiva 92/57/CEE del Consejo, de 24 de junio de 1992 (BOE, 1992).

(4) 1995. Ley 31/1995, de 8 de noviembre (BOE, 1995), de Prevención de Riesgos Laborales.

(5) 1997. Real Decreto 39/1997, de 17 de enero (BOE, 1997a), por el que se aprueba el Reglamento de los Servicios de Prevención.

(5) 1997. Real Decreto 1627/97, de 24 de octubre (BOE, 1997b), por el que se establecen disposiciones mínimas de seguridad y salud en las obras de construcción.

(6) 2003. 1ª Edición de la Guía Técnica para la Evaluación y Prevención de los Riesgos relativos a las Obras de Construcción, de noviembre de 2003 (INSHT, 2003).

(7) 2004. Real Decreto 171/2004, de 30 de enero (BOE, 2004), por la que se desarrolla el artículo 24 de la Ley 31/1995, de 8 de noviembre, de Prevención de Riesgos Laborales, en materia de coordinación de actividades empresariales.

(8) 2006. Ley 32/2006, de 18 de octubre (BOE, 2006a), reguladora de la subcontratación en el Sector de la Construcción.

(9) 2007. IV Convenio Colectivo General del Sector de la Construcción, de 1 de agosto (BOE, 2007a).

(9) 2007. Real Decreto 1109/2007, de 24 de agosto (BOE, 2007b), por el que se desarrolla la Ley 32/2006, de 18 de octubre, reguladora de la subcontratación en el Sector de la Construcción.

(10) 2012. 2a Edición de la Guía Técnica para la Evaluación y Prevención de los Riesgos relativos a las Obras de Construcción, de marzo de 2012 (INSHT, 2012).

(11) 2017. VI Convenio Colectivo General del Sector de la Construcción, de 21 de septiembre (BOE, 2017). 
En la presente tesis se toma como punto de inflexión el año 2012, año en que se publica la $2^{\mathrm{a}}$ Edición de la Guía Técnica del INSHT (INSHT, 2012), puesto que es la única fecha, dentro de la línea temporal mostrada, que afecta a la recogida de datos, que comprende los Planes de Seguridad y Salud en el Trabajo (PSSs) registrados para el período de 2008 a 2016. A pesar de tratarse de una Guía Técnica orientativa, que no tiene rango de Ley (lo que implicaría un obligado cumplimiento), este tipo de documentos elaborados por el INSHT suelen ser bien acogidos y tenidos en cuenta a la hora de poner en práctica su contenido.

El plan de trabajo e investigación realizado a propósito de la tesis, se recoge a modo de resumen, en la siguiente Tabla 5.1, que relaciona los PSSs consultados con la Sede en la que se extrajeron los datos y los años a los que hacen mención. Para la consulta de los mismos se elaboró un documento de consulta y registro, que recoge de forma pormenorizada los PSSs consultados por año y por caja de registro del archivo pertinente. Puesto que la publicación de la $2^{a}$ Edición de la Guía Técnica del INSHT (INSHT, 2012) se produce en marzo del mencionado año, se toma como referencia el año 2013, entendiendo que se ha de dejar un espacio de tiempo para la completa y correcta integración y asimilación de una normativa. Se decide tomar este período de tiempo, un año, puesto que se trata de un documento de buena praxis a modo de guía y no de una ley que ha de ser cumplida, entendiendo que este período de adaptación es tiempo suficiente para la correcta comprensión y aprendizaje del citado documento. Dicho lo cual, los períodos de tiempo estudiados quedan divididos de la siguiente manera:

I. 1 $^{\text {er }}$ período: de 2008 a 2012 (ambos años incluidos), con un muestreo de 1.700 Planes analizados.

II. $\quad 2^{\circ}$ período: de 2013 a 2016 (ambos años incluidos), con un tamaño de la muestra que comprende 1.900 Planes estudiados. 


\begin{tabular}{|c|c|c|c|c|c|}
\hline & \multicolumn{5}{|c|}{ Delegación Provincial Autoridad Laboral de Castilla-La Mancha } \\
\hline Año & Albacete & Ciudad Real & Cuenca & Guadalajara & Toledo \\
\hline 2008 & 100 & 100 & - & 50 & - \\
\hline 2009 & 100 & 100 & - & 50 & - \\
\hline 2010 & 100 & 100 & 100 & 100 & - \\
\hline 2011 & 100 & 100 & 100 & 100 & - \\
\hline 2012 & 100 & 100 & 100 & 100 & - \\
\hline Subtotal & 500 & 500 & 300 & 400 & - \\
\hline T. Parcial & \multicolumn{5}{|c|}{1.700} \\
\hline 2013 & 100 & 100 & 100 & 100 & - \\
\hline 2014 & 100 & 100 & 100 & 100 & 100 \\
\hline 2015 & 100 & 100 & 100 & 100 & 100 \\
\hline 2016 & 100 & 100 & 100 & 100 & 100 \\
\hline Subtotal & 400 & 400 & 400 & 400 & 300 \\
\hline T. Parcial & \multicolumn{5}{|c|}{1.900} \\
\hline Total & \multicolumn{5}{|c|}{3.600} \\
\hline
\end{tabular}

Tabla 5.1. Volumen de Planes de Seguridad y Salud consultados por año y sede provincial (por orden alfabético) de Castilla-La Mancha con inclusión de totales parciales (por sede para el período de tiempo comprendido entre 2008 y 2016) y total de planes consultados.

Expuesta dicha división, se procede a compartimentar los resultados obtenidos en resultados parciales, por cada uno de los ítems analizados, mediante la técnica del checklist (Anexo II), durante la fase de análisis y estudio de los PSSs. Para la elaboración de dicho documento, se tuvieron en cuenta las disposiciones específicas en materia de seguridad y salud que vienen recogidas en el artículo 7 del Real Decreto 1627/97 (BOE, 1997b), acerca del Plan de Seguridad y Salud en el trabajo, así como en el Capítulo II del Real Decreto 39/1997 (BOE, 1997a) y en el Capítulo III de la Ley 31/1995 (BOE, 1995).

Asimismo, se tuvo en consideración la Guía de Contenidos Recomendables de un Plan de Seguridad y Salud elaborada por la Mesa Técnica de Seguridad Laboral en la Construcción (MTSC, 2012), acerca de los contenidos mínimos recomendables para este instrumento preventivo, el Plan de Seguridad y Salud.

Para la correcta comprensión de los resultados obtenidos durante las labores de estudio de los PSSs, para los períodos de tiempo mencionados y las sedes de la Autoridad Laboral consultadas, éstos se han dividido o compartimentado en función de sus características para facilitar su lectura y posterior análisis, quedando esta división tal y como se muestra en el siguiente esquema (Tabla 5.2): 
5.2. Figuras jurídicas que intervienen en obras de construcción:

5.2.1.

5.2 .2$.

5.2 .3

5.2 .4 .

5.2.5.

5.2.6.

5.2.7.
Promotor, contratista, proyectista

Recurso Preventivo

5.2.2.1.

Recurso Preventivo es el empresario

Subcontratista

Trabajador autónomo

Trabajador por cuenta ajena

Dirección Facultativa

Coordinador de Seguridad y Salud

5.2.7.1.

5.2.7.2.

Coordinador de Seguridad y Salud en fase de Proyecto

5.2.7.3. Coordinador de Seguridad y Salud en fase de Ejecución Incompatibilidades de la figura del Coordinador de Seguridad y Salud

5.3. Aspecto formal del documento (PSS):

5.3.1.

5.3.2.

5.3.3.

5.3.4.

5.3.5.

5.3.6.

5.3.7.

5.3.8.
Unidades o fases de obra

PSS contiene material gráfico

PSS contiene material gráfico relacionado con la obra o la maquinaria

PSS cuenta con pautas de actuación ante emergencias PSS cuenta con itinerarios para llegar a centros asistenciales

PSS contiene pautas de actuación en caso de riesgo grave e inminente

PSS cuenta con Plan de Evacuación en caso de incendio

PSS cuenta con procedimientos de control de Seguridad Vial

5.3.7.1.

PSS cuenta con Plan de Seguridad Vial específico

PSS cuenta con capítulo dedicado a la Seguridad y Salud en las Mediciones y Presupuesto
5.4 .1

5.4.1.1.

5.4.2.

5.4.2.1.

5.4.3.
PSS evalúa cada fase/trabajo/puesto/actividad de la obra PSS evalúa cada fase/trabajo/puesto/actividad de la obra de forma específica

PSS identifica la maquinaria/equipos que se utilizan en obra

PSS identifica y evalúa la maquinaria/equipos que se utilizan en obra

PSS identifica los medios auxiliares que se prevén utilizar en obra

\begin{tabular}{l|l} 
5.4.3.1. & PSS identifica y evalúa los medios auxiliares que se prevén
\end{tabular} emplear en obra

5.4.3.2.

PSS incluye el manual de instrucciones y/o procedimientos de los medios auxiliares que se prevén emplear en obra

PSS incluye los productos químicos que se van a emplear en obra 
5.4.4.1.

PSS incluye las fichas de seguridad de los productos químicos que se van a emplear en obra

5.4.5.

La Evaluación de Riesgos integrada en el PSS se ajusta a lo determinado en el artículo 7

5.4.6.

Existe planificación preventiva en el PSS como resultado de la Evaluación de Riesgos

5.4.6.1.

La planificación preventiva en el PSS se ajusta al artículo 9

\subsection{Anomalías e incidencias reseñables:}

5.5.1.

5.5.2.

5.5.3.

5.5.4.

5.5.5.

5.5.6.

PSS en papel en blanco

CD que contiene PSS en blanco o no se puede abrir

PSS no guarda relación alguna con la obra descrita en el título Mismo PSS para distintas obras

Se hace referencia al Estudio o Estudio Básico de Seguridad y Salud en el PSS

PSS no está firmado

Tabla 5.2. Esquema de contenidos de los resultados recogidos en el capítulo de Resultados del documento de la tesis, compartimentados por grupos de contenidos afines con indicación de su localización en el documento (apartado/subapartado). 


\subsection{FIGURAS JURÍDICAS QUE INTERVIENEN EN UNA OBRA DE CONSTRUCCIÓN}

El primer ítem estudiado es el correspondiente a los sujetos con obligaciones presentes en obras de construcción, es decir, promotor, contratista, subcontratista, trabajadores autónomos, trabajadores por cuenta ajena, coordinadores, dirección facultativa, proyectista y recursos preventivos. Dichos sujetos con obligaciones han de quedar recogidos en el PSS de la obra, o en su defecto, en la Evaluación específica de Riesgos, en función de una serie de condicionantes de la obra. En el artículo 2 del mencionado Real Decreto 1627/97 (BOE, 1997b), encontramos la definición de dichos sujetos. Ya en el cuerpo de la citada normativa encontramos las obligaciones de dichos sujetos intervinientes, distribuidas entre los artículos 9, 11 y 12 (obligaciones del coordinador en materia de seguridad y de salud durante la ejecución de la obra, obligaciones de los contratistas y subcontratistas, obligaciones de los trabajadores autónomos, respectivamente). Es debido a que se trata de figuras con responsabilidad (administrativa, penal, civil y de la seguridad social y que, al tratarse de construcción, la misma es solidaria entre todos los agentes intervinientes) y que han de quedar recogidas en el documento preventivo de la obra, que centramos las miras sobre dichos sujetos.

\subsection{1. ¿APARECEN REFLEJADAS EN EL PLAN LAS FIGURAS DEL PROMOTOR, CONTRATISTA Y PROYECTISTA?}

El promotor, como "cualquier persona física o jurídica, pública o privada, que individual o colectivamente, decide, impulsa, programa y financia, con recursos propios o ajenos, las obras de edificación para sí o para su posterior enajenación, entrega o cesión a terceros bajo cualquier título" tal y como recoge la Ley de Ordenación de la Edificación (BOE, 1999). Dentro de sus obligaciones, encontramos que se trata de la figura encargada de encomendar el proyecto de ejecución a un técnico competente, encomendar la elaboración de un Estudio de Seguridad o Salud o Estudio básico, designar la dirección facultativa y al Coordinador de Seguridad y Salud (tanto en fase de proyecto como en fase de ejecución). 
Ya en lo referente a la figura del contratista, cuya definición recoge el Real Decreto 1627/97 (BOE, 1997b), como la "persona física o jurídica que asume contractualmente ante el promotor, con medios humanos y materiales, propios o ajenos, el compromiso de ejecutar la totalidad o parte de las obras con sujeción al proyecto y al contrato". Cabe destacar de entre sus obligaciones, la de elaborar el Plan de Seguridad y Salud para los trabajos contratados, cumplir y velar por el cumplimiento del Plan de Seguridad y Salud, presentar la comunicación de apertura de la obra, designar a las personas que realizarán las funciones de recurso preventivo (dejar reflejado su nombramiento en el Plan de Seguridad y Salud), cumplir con las obligaciones que le impone la Ley de Subcontratación (BOE, 2006a), cumplir las instrucciones de coordinación establecidas y cumplir y vigilar el cumplimiento de los requisitos en materia de Seguridad y Salud contenidos en el Anexo IV del RD 1627/97 (BOE, 1997b).

Por último, respecto de la figura del proyectista, el Real Decreto 1627/97 (BOE, 1997b) la define como el "agente que, por encargo del promotor y con sujeción a la normativa técnica y urbanística correspondiente, redacta el proyecto". Definición similar a la que recoge la Ley de Ordenación de la Edificación (BOE, 1999). Nos encontramos con que el proyecto deberá ser elaborado teniendo en cuenta los principios de la acción preventiva de cara a la ejecución de la obra, tal y como recoge el artículo 15 de la Ley de Prevención de Riesgos Laborales (BOE, 1995). Así mismo, estos principios de la acción preventiva deberán de ser aplicados para los posteriores trabajos de mantenimiento que se tengan que realizar. En lo que respecta a sus obligaciones, éstas quedan recogidas en el apartado 2 del artículo 10 de la Ley de Ordenación de la Edificación (BOE, 1999).

Expuestas las obligaciones de dichas figuras jurídicas y su importancia en el correcto cumplimiento e integración de la Seguridad y Salud en las obras de construcción, se observa, para el primer período de tiempo estudiado, que en el 91,00\% de los PSSs consultados, se encuentran recogidas dichas figuras. Entrando en detalle, se observan porcentajes de cumplimiento similares para las cuatro sedes, con una diferencia porcentual del entorno de los doce puntos entre la sede con mayor cumplimiento (Guadalajara, con un 97,75\%) y la de menor cumplimiento (Ciudad Real, con un 85,80\%). Para el segundo período de tiempo analizado, el porcentaje se eleva significativamente a un 99,00\%. Analizando dicho dato de forma pormenorizada, observamos un cumplimiento muy similar en 
las cinco sedes, llegando a encontrar dos sedes con un cumplimiento completo de este requerimiento $(100,00 \%$ en los casos analizados de las sedes de Ciudad Real y Cuenca); en cualquier caso, todas las sedes reflejan valores superiores al $97,00 \%$, lo que refleja un alto grado de cumplimiento de este requisito. En la Tabla 5.3 se recoge el escrutinio del presente requisito de forma pormenorizada, por cada sede y período de tiempo analizados. Por ello, se puede concluir, que el aumento significativo en el número de documentos que cumplen con dicho requisito, viene dado por la efectiva implantación de la $2^{\mathrm{a}}$ Edición de la Guía Técnica del INSHT (INSHT, 2012).

\begin{tabular}{|c|c|c|c|c|c|}
\hline \multirow[b]{2}{*}{ Período } & \multicolumn{5}{|c|}{ Promotor, Contratista, Proyectista } \\
\hline & Albacete & Ciudad Real & Cuenca & Guadalajara & Toledo \\
\hline 2008-2012 & 451 & 429 & 276 & 391 & - \\
\hline$(\%)$ & 90,20 & 85,80 & 92,00 & 97,75 & - \\
\hline T. Parcial/\% & \multicolumn{5}{|c|}{$1.547(91,00 \%)$} \\
\hline 2013-2016 & 395 & 400 & 400 & 393 & 293 \\
\hline$(\%)$ & 98,75 & 100,00 & 100,00 & 98,25 & 97,67 \\
\hline T. Parcial/\% & \multicolumn{5}{|c|}{$1.881(99,00 \%)$} \\
\hline Total & \multicolumn{5}{|c|}{$3.428(95,22 \%)$} \\
\hline
\end{tabular}

Tabla 5.3. Volumen de Planes de Seguridad y Salud consultados que cumplen con el requisito del presente apartado, organizados por período de tiempo y sede provincial (por orden alfabético) de Castilla-La Mancha con inclusión de totales parciales por período y total global sobre el conjunto de PSSs consultados.

Lo que hace, que sobre el cómputo global de PSSs consultados, 3.600 PSSs, la cifra se sitúe prácticamente en la media de ambos períodos de tiempo analizados, con un $95,22 \%$ de grado de cumplimiento frente a dicho requisito.

Se estima que este requisito presenta un alto porcentaje de cumplimiento debido en parte a que, al realizar el comunicado de apertura de centro de trabajo, se solicitan dichos datos, los del proyectista, el contratista y el promotor de la obra. 


\subsection{2. ¿SE RECOGE EL NOMBRAMIENTO DE LA FIGURA DEL RECURSO PREVENTIVO?}

Esta figura, creada a raíz de la Ley 54/2003 (BOE, 2003), posterior al Real Decreto 1627/97 (BOE, 1997b), resulta de vital importancia en las obras de construcción, al tratarse de una figura designada por el contratista y cuya principal obligación es la de vigilar y velar por el cumplimiento de los requisitos de seguridad previstos en obra, así como de los medios de coordinación establecidos. Esta figura de nueva creación, permite poder ser realizada por un técnico de prevención (perteneciente a un Servicio de Prevención Propio o Ajeno), un trabajador designado por la empresa (dentro de su organización preventiva) o por un trabajador asignado por la empresa (que posea formación suficiente y adecuada), tal y como se recoge en la Figura 5.2, según el artículo 32 bis de la Ley de Prevención de Riesgos Laborales (BOE, 1995). Si bien es cierto que, tal y como recoge la ley, esta función no puede ser asumida por el empresario, se han encontrado casos documentados en los que es el propio empresario el que ha asumido las labores de recurso preventivo.

\section{¿Quién puede actuar como Recurso Preventivo?}

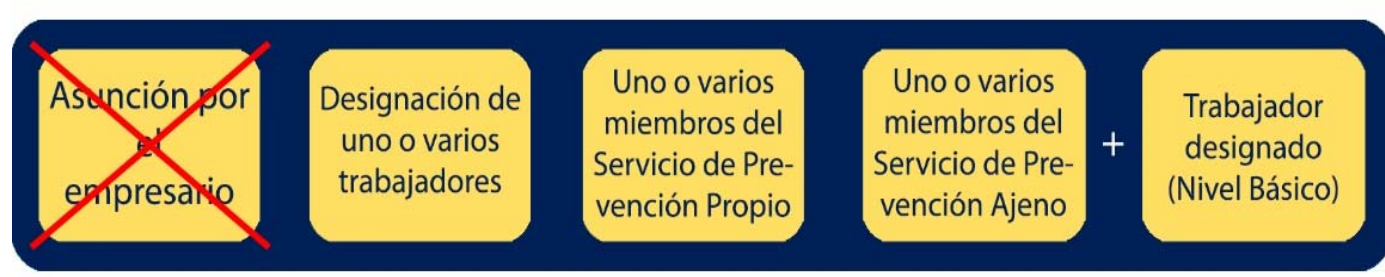

\section{Modalidades}

Figura 5.2. Organización de las figuras que pueden ser designadas o asignadas para las labores de recurso preventivo, según lo recogido por el artículo 32 bis de la Ley de Prevención de Riesgos Laborales (BOE, 1995).

Resulta interesante observar cómo, para el primer período de tiempo analizado, encontramos que esta figura/s se encuentra recogida (figura de recurso preventivo con nombre y apellidos o acta de nombramiento del mismo) en un escaso $9,76 \%$ de los PSSs consultados. Si analizamos en detalle los datos relativos al período de tiempo mencionado, se puede observar una variación porcentual del entorno de un punto entre la sede con mayor cumplimiento (Ciudad Real, con un 10,20\%) y la de menor cumplimiento (Guadalajara, con un $9,00 \%)$, dentro de las cuatro sedes analizadas, lo que nos indica un cumplimiento bastante homogéneo de dicho requisito. Es a partir del segundo 
período de tiempo analizado, que el porcentaje se eleva considerablemente a un $40,79 \%$, lo que supone un incremento de treintaiún puntos con respecto al primer período analizado. Ya en este período, la variación porcentual entre las cinco sedes se dispara, con un valor de veintitrés puntos de diferencia porcentual entre la sede que muestra un menor cumplimiento (Toledo, con un 31,33\%) y la sede con mayor cumplimiento del presente requisito (Ciudad Real, 45,25\%), recogiendo valores heterogéneos de cumplimiento en las cinco sedes estudiadas. Este aumento sustancial en el cumplimiento del citado requisito, viene en parte dado por la implementación, a través de la Ley 54/2003 (BOE, 2003) que reforma la Ley 31/1995 (BOE, 1995) e incorpora el artículo 32 bis, en parte por el Real Decreto 604/2006 (BOE, 2006b), que modifica el Reglamento de los Servicios de Prevención (art. 22 bis del RD 39/1997) y en parte por el Anexo II perteneciente al RD 1627/97 (BOE, 1997b) en conjunción con su Disposición Adicional Única, también en parte por la Disposición Adicional $10^{\mathrm{a}}$ del RD 39/19997 (BOE, 1997a) que incluye como actividades o procesos englobados en la categoría de peligroso o que entrañan riesgos especiales (lo que hace necesaria la presencia del recurso preventivo) algunos de los supuestos más comunes en obra, como son:

1. Trabajos con riesgos especialmente graves de caída de altura.

2. Trabajos con riesgo de sepultamiento o hundimiento.

3. Actividades en las que se utilicen máquinas que carezcan de declaración CE de conformidad por ser su fecha de comercialización anterior a la exigencia de tal declaración con carácter obligatorio.

4. Trabajos en espacios confinados.

5. Trabajos con riesgo de ahogamiento por inmersión salvo trabajos con equipos subacuáticos.

Se observa de forma clara, que el aumento exponencial en el cumplimiento de dicho requisito, viene dado por la implementación del Real Decreto 604/2006 (BOE, 2006b), además de por la efectiva implantación de la $2^{\text {a }}$ Edición de la Guía Técnica del INSHT (INSHT, 2012).

Sobre el cómputo global de PSSs analizados, la cifra se sitúa en un $26,14 \%$ de grado de cumplimiento frente a dicho requisito (Tabla 5.4), lo que indica un 
cumplimiento bajo, que se traduce en una incorrecta implantación de la Guía durante la elaboración de los PSSs.

\begin{tabular}{|c|c|c|c|c|c|}
\hline \multirow[b]{2}{*}{ Período } & \multicolumn{5}{|c|}{ Recurso Preventivo } \\
\hline & Albacete & Ciudad Real & Cuenca & Guadalajara & Toledo \\
\hline 2008-2012 & 49 & 51 & 30 & 36 & - \\
\hline$\%$ & 9,80 & 10,20 & 10,00 & 9,00 & - \\
\hline T. Parcial $/ \%$ & \multicolumn{5}{|c|}{$166(9,76 \%)$} \\
\hline 2013-2016 & 174 & 181 & 153 & 173 & 94 \\
\hline$\%$ & 43,50 & 45,25 & 38,25 & 43,25 & 31,33 \\
\hline T. Parcial/\% & \multicolumn{5}{|c|}{$775(40,79 \%)$} \\
\hline Total & \multicolumn{5}{|c|}{$941(26,14 \%)$} \\
\hline
\end{tabular}

Tabla 5.4. Volumen de Planes de Seguridad y Salud consultados que cumplen con el requisito del presente apartado, organizados por período de tiempo y sede provincial (por orden alfabético) de Castilla-La Mancha con inclusión de totales parciales por período y total global sobre el conjunto de PSSs consultados.

Para concluir, se observa asimismo que, en la mayoría de los casos (en un 95,01\% de los 941 PSSs) en los que se encontraba nombrada dicha figura, ésta hacía referencia al nombramiento de una única persona como Recurso Preventivo, lo cual dificulta las labores de actuación de dicha figura, en aras de prever que dicha persona pueda enfermar, ausentarse de la obra de forma puntual o que se requiera su presencia en distintos sitios (en función del tamaño de la obra). En un exiguo porcentaje, un 4,99 \% de los 941 PSSs consultados en los que dicha figura aparecía recogida, encontramos que el nombramiento del Recurso Preventivo es para más de un sujeto, favoreciendo el correcto control de la seguridad en la obra.

De la misma forma, se ha reseñar que, en el 1,81\% sobre el total de los casos consultados con presencia de esta figura preventiva, encontramos que se constata la formación recibida y la experiencia de la persona/s que ejerce/n las labores de Recurso Preventivo.

La importancia de los resultados obtenidos nos hace reflexionar acerca del escaso valor que se le da a esta figura hoy en día, denostada al mero cumplimiento formal por miedo a la sanción económica, siendo exigida su constancia en el propio Plan de Seguridad y Salud tal y como se recoge en la Disposición Adicional Única del RD 1627/97 (BOE, 1997b) y en el RD 604/2006 (BOE, 2006b), cosa que no se cumple, al igual que sucede en el comunicado de apertura de centro de trabajo, donde tampoco es recogida dicha figura. 
No hemos de olvidar que la obra es un medio de trabajo peligroso, tal y como se constata año tras año, con un Sector productivo que presenta los más altos índices de siniestralidad laboral desde finales del siglo $X X$, con tendencia alcista desde comienzos del siglo XXI hasta la llegada de la crisis económica en 2008, cuando se produce un ligero descenso progresivo de la siniestralidad, debido en gran medida a la desaparición de empresas del Sector de la Construcción, así como de empresas pertenecientes a sectores auxiliares al de la construcción. Esto motiva una serie de legislaciones a nivel laboral, como el Real Decreto $1627 / 1997$ (BOE, 1997b), de 14 de octubre, por el que se establecen las disposiciones mínimas de seguridad y salud en las obras de construcción y que nos proporciona unas pautas sobre cuándo debe exigirse la figura del recurso preventivo, concretamente en su Anexo II, en donde se enumera una serie de en trabajos o actividades que implican riesgos especiales y en los que deberá estar presente la figura del/de los Recurso/s Preventivo/s. Es por ello que resulta de interés, y relevante para el correcto funcionamiento de la obra, que dicha figura apareciese reflejada en el comunicado de apertura de centro de trabajo, permitiendo a la autoridad laboral poder realizar las labores de seguimiento y control pertinentes. 


\subsubsection{1. ¿ES EL RECURSO PREVENTIVO EL PROPIO EMPRESARIO?}

Si ya hemos pasado a analizar la figura del Recurso Preventivo en el apartado anterior, en este apartado se pretende analizar, de entre los casos en los que esta figura aparece recogida en el Plan de Seguridad y Salud, los casos en los que se produce fraude de ley, al ser el propio empresario el que asume dichas funciones. Como ya hemos recogido en el apartado 5.2.2., según lo expuesto en el artículo 32 bis de la Ley de Prevención de Riesgos Laborales (BOE, 1995), ésta figura sólo puede ser asumida por:

a) Uno o varios trabajadores designados de la empresa.

b) Uno o varios miembros del servicio de prevención propio de la empresa.

c) Uno o varios miembros del o los servicios de prevención ajenos concertados por la empresa.

En la Tabla 5.5 se recoge el número total de incidencias producidas respecto al citado cumplimiento. Cabe destacar que, debido al motivo de la investigación, se han de detectar e incluir en la misma todos los aspectos mejorables de la herramienta preventiva que es el Plan de Seguridad y Salud, así como de todos los aspectos que se ejecutan de forma incorrecta o maliciosa, en aras de evaluar la realidad de esta herramienta y su utilidad real en obras de construcción.

\begin{tabular}{|c|c|c|c|c|c|}
\hline & \multicolumn{5}{|c|}{ Recurso Preventivo es el Empresario } \\
\hline Período & Albacete & Ciudad Real & Cuenca & Guadalajara & Toledo \\
\hline 2008-2012 & 9 & 6 & 3 & 7 & - \\
\hline$\%$ & 1,80 & 1,20 & 1,00 & 1,75 & - \\
\hline T. Parcial $/ \%$ & \multicolumn{5}{|c|}{$25(1,47 \%)$} \\
\hline 2013-2016 & 8 & 7 & 7 & 5 & 6 \\
\hline$\%$ & 2,00 & 1,75 & 1,75 & 1,25 & 2,00 \\
\hline T. Parcial/\% & \multicolumn{5}{|c|}{$33(1,74 \%)$} \\
\hline Total & \multicolumn{5}{|c|}{$58(1,61 \%)$} \\
\hline
\end{tabular}

Tabla 5.5. Volumen de Planes de Seguridad y Salud consultados que cumplen con el requisito del presente apartado, organizados por período de tiempo y sede provincial (por orden alfabético) de Castilla-La Mancha con inclusión de totales parciales por período y total global sobre el conjunto de PSSs consultados.

Se observa, para ambos períodos de tiempo, un porcentaje de casos en los que se produce este "fraude de ley" muy bajo, con valores que no llegan al 2,00\%, en concreto en el 1,61\% del total de PSSs consultados, 3.600 PSSs. 
Si analizamos en detalle el primer período, podemos observar un cumplimiento similar para las cuatro sedes, con una diferencia porcentual de menos de un punto entre la sede en la que se registraron más casos (Albacete, con un 1,80\%) y la sede con menos casos documentados (Cuenca, con un 1,00\%). Lo que deja un número de casos registrados que supone un 1,47\% sobre el total parcial de PSSs consultados para el primer período.

Ya en el segundo período se produce un ligero aumento, alcanzando un 1,74\% sobre el total parcial de los PSSs consultados para el segundo período. A nivel de cinco sedes, se produce una diferencia porcentual inferior al punto entre la sede con más casos registrados (Albacete y Toledo, ambas con un 2,00\%) y la que menos (Guadalajara, con un 1,25\%).

Desgraciadamente, estos resultados son fiel reflejo del desconocimiento que de la figura del Recurso Preventivo se tiene en la actualidad. Esta casuística hace que sea recomendable la subsanación de este requerimiento mediante, por ejemplo, la inclusión de dicha figura en el comunicado de apertura de centro de trabajo, tal y como se ha expuesto en el apartado anterior.

De esta forma, todas las figuras intervinientes en la obra aparecerían recogidas de forma sencilla en el comunicado de apertura de centro de trabajo y, por ende, el aplicativo y/o formulario debería permitir las subsanaciones y modificaciones del mismo hasta la finalización de la obra. Estas modificaciones convendría también que fuesen recogidas mediante anexos al Plan.

Por ejemplo, resultaría de utilidad poder marcar mediante una casilla la presencia de recurso preventivo en obra en el libro de subcontratación. 


\subsection{3. ¿APARECEN RECOGIDOS EL/LOS SUBCONTRATISTAS PRESENTES EN LA OBRA?}

El subcontratista queda definido como "la persona física o jurídica que asume contractualmente ante el contratista, empresario principal, el compromiso de realizar determinadas partes o instalaciones de la obra, con sujeción al proyecto por el que se rige su ejecución" tal y como recoge el Real Decreto 1627/97 (BOE, 1997b). De entre sus obligaciones, destacamos la de cumplir y velar por el cumplimiento del Plan de Seguridad y Salud (ha de adherirse al Plan de Seguridad y Salud del contratista), cumplir con las obligaciones que le impone la Ley de Subcontratación (BOE, 2006a), cumplir las instrucciones de coordinación establecidas, además de cumplir y vigilar el cumplimiento de los requisitos de Seguridad y Salud contenidos en el Anexo IV del RD 1627/97 (BOE, 1997b). Al igual que suceda con el contratista, el subcontratista ha de estar inscrito en el Registro de Empresas Acreditados, que es puesto en marcha a través del Real Decreto 1109/2007 (BOE, 2007b), de 24 de agosto, por el que se desarrolla el reglamento de la Ley 32/2006 (BOE, 2006a). Es este Registro el que establece de forma expresa que: "Toda empresa que pretenda ser contratada o subcontratada para trabajos en una obra de construcción, deberá estar inscrita en el Registro de Empresas Acreditadas dependiente de la autoridad laboral donde esté ubicado el domicilio social de la empresa" (Ministerio de Trabajo, Migraciones y Seguridad Social, 2018a). De igual forma, este registro establece una serie de exigencias, condición sine qua non, para que las empresas puedan registrarse y operar como contratistas o subcontratistas en actividades de construcción en España, "cuando éstas contraten o subcontraten la realización de cualquier trabajo en una obra" (Ministerio de Trabajo, Migraciones y Seguridad Social, 2018a). Los condicionantes principales hacen referencia al cumplimiento de los requerimientos formales y materiales de su estructura organizativa y productiva en materia de recursos humanos, así como con las obligaciones en materia de prevención y seguridad respecto de sus trabajadores.

Asimismo, las empresas contratistas y subcontratistas deben acreditar documentalmente que disponen de una estructura organizativa, con medios humanos y materiales para poder dirigir y realizar con solvencia los trabajos contratados (Figura 5.3). De igual forma, deben asumir la gestión preventiva de 
los riesgos propios de la actividad de construcción, de acuerdo con las obligaciones y responsabilidad de la actividad empresarial.

\section{Acreditación de recursos humanos y materiales}

Recursos materiales

\section{Estructura Corporativa Empresarial}

Recursos

humanos

productivos

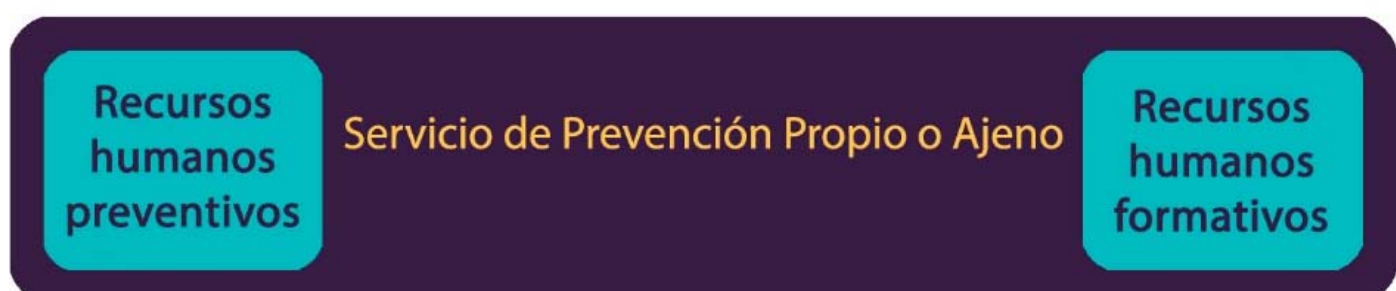

Figura 5.3. Requisitos de acreditación de los recursos humanos y materiales de las empresas subcontratistas establecidos en el REA.

Es a raíz de la entrada en vigor de la Ley 32/2006 (BOE, 2006a), que se establecen límites en la cadena de subcontratación en las obras de construcción, no pudiéndose superar los tres niveles (excepcionalmente la Ley permite un cuarto nivel de subcontratación bajo ciertos requerimientos), tal y como se muestra, a modo de resumen, en la Figura 5.4. 


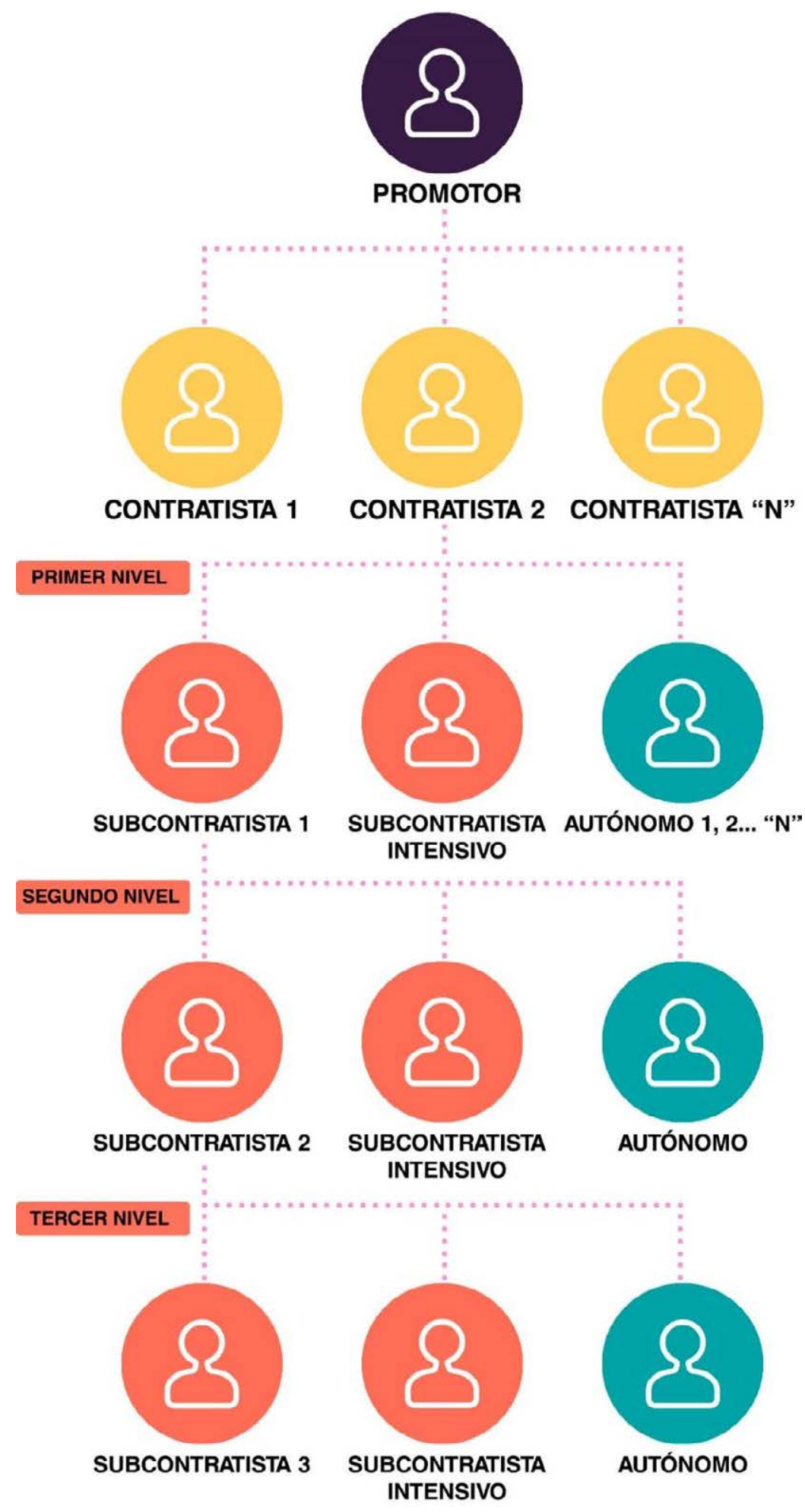

Figura 5.4. Limitación de los niveles máximos permitidos en la cadena de subcontratación dentro de las obras de construcción según se recoge en la Ley de Subcontratación (BOE, 2006).

Expuesta la importancia y la relevancia en materia de Seguridad dentro de la obra de la presente figura, se pasa a desglosar los resultados obtenidos en los períodos de tiempo escrutados. Para el primer período de tiempo estudiado, encontramos que esta figura se encuentra recogida en tan sólo un 36,24\% de los 
PSSs consultados. Para este período de tiempo, la diferencia porcentual entre las cuatro sedes es de tan sólo siete puntos, por lo que se puede afirmar que se produce un cumplimiento homogéneo de dicho requerimiento. Esta diferencia porcentual se traduce en los valores de cumplimiento del requisito, situando a Albacete como la sede con mayor cumplimiento, con un 39,00\%, seguida muy de cerca por Cuenca, con un 36,67\%, y por Ciudad Real, con un 36,60\%, para dar paso a Guadalajara, con un $32,00 \%$, como la sede con menor cumplimiento. Para el segundo período de tiempo, encontramos que el porcentaje se eleva sustancialmente a un 58,05\% (Tabla 5.6). Con una variación porcentual cercana a los dieciocho puntos, entre la sede con mayor tasa de cumplimiento (Ciudad Real, con un 68,00\%) y la sede con menor tasa de cumplimiento (Cuenca, con un $50,50 \%$ ), se observa un cumplimiento heterogéneo de dicho requerimiento con respecto a las cinco sedes estudiadas.

\begin{tabular}{|c|c|c|c|c|c|}
\hline & \multicolumn{5}{|c|}{ Subcontratista } \\
\hline Período & Albacete & Ciudad Real & Cuenca & Guadalajara & Toledo \\
\hline 2008-2012 & 195 & 183 & 110 & 128 & - \\
\hline$\%$ & 39,00 & 36,60 & 36,67 & 32,00 & - \\
\hline T. Parcial/\% & \multicolumn{5}{|c|}{$616(36,24 \%)$} \\
\hline 2013-2016 & 247 & 272 & 202 & 215 & 167 \\
\hline$\%$ & 61,75 & 68,00 & 50,50 & 53,75 & 55,67 \\
\hline T. Parcial/\% & \multicolumn{5}{|c|}{$1.103(\mathbf{5 8 , 0 5 \% )}$} \\
\hline Total & \multicolumn{5}{|c|}{$1.719(47,75 \%)$} \\
\hline
\end{tabular}

Tabla 5.6. Volumen de Planes de Seguridad y Salud consultados que cumplen con el requisito del presente apartado, organizados por período de tiempo y sede provincial (por orden alfabético) de Castilla-La Mancha con inclusión de totales parciales por período y total global sobre el conjunto de PSSs consultados.

Para finalizar, sobre el cómputo global de PSSs analizados, 3.600 PSSs, la cifra de cumplimiento de este requisito, que ha de estar recogido en el documento preventivo, se sitúa en un $47,75 \%$, rozando el $50,00 \%$, lo que se traduce en un cumplimiento aceptable del presente requisito.

La subcontratación en el sector de la construcción es una práctica que favorece unas altas tasas de siniestralidad laboral. A día de hoy, y aún con los esfuerzos realizados por el cuerpo legislador con la Ley 32/2006 (BOE, 2006a) y el Real Decreto 1109/2007 (BOE, 2007b), se sigue abusando de esta figura, conllevando elevados índices de infracciones en materia de prevención de riesgos laborales mediante acciones de mala praxis. 
Los datos obtenidos avalan la escasa conciencia real que de esta figura se tiene, debiendo de quedar reflejada en el Plan de Seguridad y Salud, cosa que no pasa en más de la mitad de los casos estudiados. En concreto, se estima que aparte de lo ya comentado en apartados anteriores, el Plan debería contar con los trabajos y/o actividades a realizar a modo de procedimientos de trabajo, la maquinaria y/o equipos de trabajo que se vayan a utilizar, los productos químicos y los puestos de trabajo. Así como dejábamos constancia con anterioridad, su nombramiento debe de quedar reflejado en el comunicado de apertura de centro de trabajo. Parece resultar imposible configurar el Plan con la realidad de todas las empresas involucradas en la obra, quedando configurado a día de hoy como un documento estático, y no dinámico como debería de ser, un documento vivo en constante cambio que se adapte a la realidad de la obra. 


\subsection{4. ¿APARECEN RECOGIDOS LOS TRABAJADORES AUTÓNOMOS?}

El trabajador autónomo (sin trabajadores por cuenta ajena), como "la persona física distinta del contratista y del subcontratista, que realiza de forma personal y directa una actividad profesional, sin sujeción a un contrato de trabajo, y que asume contractualmente ante el promotor, el contratista o el subcontratista el compromiso de realizar determinadas partes o instalaciones de la obra" según recoge el artículo 2 del Real Decreto 1627/97 (BOE, 1997b). Se ha de mencionar, asimismo, que el citado Real Decreto también expone que "Cuando el trabajador autónomo emplee en la obra a trabajadores por cuenta ajena tendrá la consideración de contratista o subcontratista a efectos del presente Real Decreto". Puesto que se trata de una figura con responsabilidades, sus principales obligaciones según recoge el artículo 12 del Real Decreto 1627/97 (BOE, 1997b) pasan por cumplir con: el Plan de Seguridad y Salud respecto a sus trabajos, los requisitos de seguridad que establece el anexo IV del Real Decreto 1627/97 (BOE, 1997b), las obligaciones preventivas que señala el art. 29 de la LPRL dirigidas a los trabajadores, las instrucciones recibidas de cara a la ejecución de los trabajos y las normas de coordinación establecidas, así como respetar el límite de subcontratación.

Hecha la exposición de motivos que incentiva la inclusión de esta figura, dada su relevancia en obra, en el presente documento de tesis, se pasa a exponer los datos obtenidos a través de los 3.600 PSSs consultados, tal y como se muestra en la Tabla 5.7.

\begin{tabular}{|c|c|c|c|c|c|}
\hline \multirow[b]{2}{*}{ Período } & \multicolumn{5}{|c|}{ Trabajador Autónomo } \\
\hline & Albacete & Ciudad Real & Cuenca & Guadalajara & Toledo \\
\hline $2008-2012$ & 0 & 2 & 0 & 0 & - \\
\hline$\%$ & 0,00 & 0,40 & 0,00 & 0,00 & - \\
\hline T. Parcial/\% & \multicolumn{5}{|c|}{$2(0,12 \%)$} \\
\hline 2013-2016 & 1 & 0 & 0 & 1 & 0 \\
\hline$\%$ & 0,25 & 0,00 & 0,00 & 0,25 & 0,00 \\
\hline T. Parcial/\% & \multicolumn{5}{|c|}{$2(0,11 \%)$} \\
\hline Total & \multicolumn{5}{|c|}{$4(0,11 \%)$} \\
\hline
\end{tabular}

Tabla 5.7. Volumen de Planes de Seguridad y Salud consultados que cumplen con el requisito del presente apartado, organizados por período de tiempo y sede provincial (por orden alfabético) de Castilla-La Mancha con inclusión de totales parciales por período y total global sobre el conjunto de PSSs consultados. 
Es debido a la distinción que se ha recogido en líneas anteriores, que cuando el trabajador autónomo cuenta con trabajadores a su cargo pasa a ser contratista o subcontratista a efectos de Real Decreto 1627/97 (BOE, 1997b), por lo que es en ese caso en el que sí queda recogido en el Plan. El matiz, que recoge el presente apartado, se produce cuando el trabajador autónomo no cuenta con trabajadores a su cargo, es entonces cuando se decide comprobar si el Plan de Seguridad y Salud recoge su figura con nombre y apellidos, como en el caso del resto de figuras involucradas en la obra, véase, proyectista, promotor, contratista, subcontratista, coordinador, recurso preventivo, etc.

La Tabla 5.7 muestra el nulo caso que de este requerimiento se hace por parte del redactor del Plan, se entiende que en parte es debido a que el contratista aún no ha decidido qué trabajador autónomo va a trabajar en obra y por tanto no puede ser incorporado en el cuerpo del documento. Otra posibilidad recae en la no exigencia que desde la Autoridad Laboral se hace sobre el nombramiento del autónomo cuando se tramita el comunicado de apertura de centro de trabajo. Es precisamente debido a ello que sería conveniente poder incorporar el nombramiento de los autónomos en el propio comunicado de apertura, conjuntamente con la inclusión en el Plan de Seguridad y Salud haciendo uso de los anexos al Plan.

Pasando a disgregar los resultados, se observa que sobre el total de los 3.600 PSSs consultados, nada más que se cumple con este requisito en un 0,11\%, porcentaje ínfimo y que no puede ser si quiera tenido en cuenta al no alcanzar la cifra de un punto porcentual.

Esto implica la obtención de resultados muy parejos para ambas sedes, en este caso, se obtiene un total parcial por período muy similar, alcanzando el 0,12\% sobre el total parcial de las cuatro sedes para el primer período y de un $0,11 \%$ sobre el total parcial de las cinco sedes para el segundo período. A nivel cuantificable nos encontramos únicamente con dos PSSs por período que integran dicho requisito en el cuerpo del documento, lo que puesto en perspectiva, sobre el total de PSSs consultados por período, muestra el irrisorio caso que de esta figura se hace en la obra. 


\subsection{5. ¿SE RECOPILAN LOS TRABAJADORES POR CUENTA AJENA PRESENTES EN LA OBRA?}

Sin esta figura, queda claro que la obra no existiría tal y como la conocemos hoy en día, y es que la mano de obra suele ser la figura más despreciada y sin cuyo trabajo sería imposible ejecutar la obra. Al ser esta figura la que representa el mayor porcentaje de personas que se encuentran en obra (si la comparamos con el porcentaje que representan los cuerpos técnicos presentes en obra), ha de ser analizada de forma separada al resto. El trabajador por cuenta ajena no ha de ser confundido en ningún momento con el trabajador autónomo, figura sobre la que versa el apartado anterior.

Dicho lo cual, se pasa a desgranar los resultados obtenidos sobre la presencia o no de esta figura en el documento preventivo analizado, es decir, se comprueba los casos en los que se especifica la cuadrilla que ejecutará los trabajos. Dichos resultados se muestran en la Tabla 5.8.

\begin{tabular}{|c|c|c|c|c|c|}
\hline \multirow[b]{2}{*}{ Período } & \multicolumn{5}{|c|}{ Trabajador por cuenta ajena } \\
\hline & Albacete & Ciudad Real & Cuenca & Guadalajara & Toledo \\
\hline 2008-2012 & 0 & 0 & 2 & 1 & - \\
\hline$\%$ & 0,00 & 0,00 & 0,67 & 0,25 & - \\
\hline T. Parcial/\% & \multicolumn{5}{|c|}{$3(0,18 \%)$} \\
\hline 2013-2016 & 4 & 1 & 3 & 2 & 0 \\
\hline$\%$ & 1,00 & 0,25 & 0,75 & 0,50 & 0,00 \\
\hline T. Parcial/\% & \multicolumn{5}{|c|}{$10(0,53 \%)$} \\
\hline Total & \multicolumn{5}{|c|}{$13(0,36 \%)$} \\
\hline
\end{tabular}

Tabla 5.8. Volumen de Planes de Seguridad y Salud consultados que cumplen con el requisito del presente apartado, organizados por período de tiempo y sede provincial (por orden alfabético) de Castilla-La Mancha con inclusión de totales parciales por período y total global sobre el conjunto de PSSs consultados.

Los resultados muestran un contundente cumplimiento prácticamente nulo de este requisito, obteniendo un $0,36 \%$ sobre el global total de los PSSs, si bien es cierto que no sorprende el resultado, sí que cabría esperar un porcentaje comprendido entre el 1 y el 5 por ciento.

Es debido a la importancia que esta figura tiene en la obra, por ejemplo, a nivel de la accidentalidad laboral, así como a nivel de planificación y solape de las cuadrillas de trabajadores durante la ejecución de las distintas fases del proyecto, que dejar constancia de su presencia en el Plan ayudaría al 
Coordinador de Seguridad y Salud a controlar el acceso a la obra de las personas recogidas en el documento como personas autorizadas.

Asimismo, sería conveniente adjuntar en el Plan la formación de los operarios en materia de prevención (ya sea mediante la acreditación por escrito del Servicio de Prevención o la empresa, o mediante la adjunción de los diplomas certificativos de los mismos), así como los certificados de aptitud médica. Esta serie de acciones facilitaría considerablemente las labores tanto del inspector o de los técnicos competentes de la Junta, así como del Coordinador, además de suponer un mayor control de la obra desde un punto de vista del control preventivo.

La creación de una aplicación actualizable en tiempo real y vinculada a la Autoridad Laboral, sería una solución de cara a dinamizar el proceso e incluir los vistos buenos del Coordinador, los procedimientos de trabajo de cada empresa, que permita modificar el organigrama del Plan según se incorporen empresas a la obra, permitiendo pasar de un modelo genérico (actual planteamiento del PSS) a un modelo dinámico y específico (anexos, procedimientos de trabajo, colaboración en tiempo real, etc.). 


\subsection{6. ¿SE INCLUYE LA DIRECCIÓN FACULTATIVA DE LA OBRA?}

Tal y como recoge el Real Decreto 1627/97 (BOE, 1997b) en su artículo 2, la dirección facultativa es definida como: "el técnico o técnicos competentes designados por el promotor, encargados de la dirección y del control de la ejecución de la obra". Se trata de una figura obligatoria en las obras siempre y cuando se cuente con proyecto de ejecución. Es la Ley de Ordenación de la Edificación (BOE, 1999) la que establece su composición mediante dos figuras diferenciadas:

- El director de la obra.

- El director de ejecución de la obra.

Dentro de la propia dirección facultativa se recoge también la figura del Coordinador de Seguridad y Salud en fase de ejecución, pero esta figura será analizada de forma separada en el siguiente apartado. Es por ello que, en el presente apartado, se analiza la mención expresa de esta figura en los PSSs analizados, tal y como se recoge en la Tabla 5.9.

\begin{tabular}{|c|c|c|c|c|c|}
\hline \multirow[b]{2}{*}{ Período } & \multicolumn{5}{|c|}{ Dirección Facultativa } \\
\hline & Albacete & Ciudad Real & Cuenca & Guadalajara & Toledo \\
\hline $2008-2012$ & 399 & 392 & 241 & 325 & - \\
\hline$\%$ & 79,80 & 78,40 & 80,33 & 81,25 & - \\
\hline T. Parcial/\% & \multicolumn{5}{|c|}{$1.357(79,82 \%)$} \\
\hline $2013-2016$ & 353 & 362 & 358 & 349 & 264 \\
\hline$\%$ & 88,25 & 90,50 & 89,50 & 87,25 & 88,00 \\
\hline T. Parcial/\% & \multicolumn{5}{|c|}{$1.686(88,74 \%)$} \\
\hline Total & \multicolumn{5}{|c|}{$3.043(84,53 \%)$} \\
\hline
\end{tabular}

Tabla 5.9. Volumen de Planes de Seguridad y Salud consultados que cumplen con el requisito del presente apartado, organizados por período de tiempo y sede provincial (por orden alfabético) de Castilla-La Mancha con inclusión de totales parciales por período y total global sobre el conjunto de PSSs consultados.

Sobre el cómputo global que representan los 3.600 PSSs consultados para las cinco sedes y períodos de tiempo planificados, se aprecia un elevado cumplimiento del citado requisito, con valores cercanos al 90,00\%, lo que se traduce en 3.043 PSSs que cumplen con el mismo, lo que representa un 84,53\%. Si comparamos el cumplimiento para ambos períodos, observamos un ligero incremento, muy próximo a los nueve puntos porcentuales, del primer con respecto al segundo período. 
Si examinamos en detalle los resultados obtenidos para el primer período de tiempo estudiado y las cuatro sedes analizadas, observamos unos valores altos de cumplimiento, muy próximos al $80,00 \%$, concretamente del $79,82 \%$, lo que se traduce en un cumplimiento elevado del presente requisito, con valores cercanos a los estimados y deseables. Ya a nivel de las cuatro sedes, se aprecia una diferencia porcentual de cerca de los tres puntos entre la sede en la que se da un mayor cumplimiento (Guadalajara, con un 81,25\%), y la sede con menor cumplimiento (Ciudad Real, con un $78,40 \%$ ), lo que implica un cumplimiento homogéneo para las cuatro sedes.

En lo que respecta al segundo período, se produce un incremento en el cumplimiento del citado requisito con respecto a los valores obtenidos en el primer período, dejando unos valores del 88,74\% sobre el total parcial para este período, lo que supone un elevado cumplimiento, rozando el 90,00\%. A nivel de las cinco sedes, se aprecia un cumplimiento homogéneo del requisito, con una diferencia porcentual inferior a los tres puntos entre la sede con mayor cumplimiento (Ciudad Real, con un 90,50\%) y la de menor cumplimiento (Toledo, con un 88,00\%). Se aprecia una inversión en la tendencia del cumplimiento, al ser Ciudad Real la sede con mayor cumplimiento para este segundo período, cuando para el primer período era la sede con menor cumplimiento.

Estos resultados son bastante elevados, teniendo en cuenta que se trata de una serie de datos que no se exigen cuando se realiza el comunicado de apertura de centro de trabajo, en el que únicamente se requiere recoger la figura del promotor de la obra y del Coordinador de Seguridad y Salud en fase de ejecución. 


\subsubsection{COORDINADOR DE SEGURIDAD Y SALUD}

El Real Decreto 1627/97 (BOE, 1997b) distingue entre la figura del Coordinador de Seguridad y Salud tanto en fase de redacción del proyecto como en fase de ejecución de la obra. Es por ello que se decide realizar la misma división sobre los resultados obtenidos durante la consulta de los PSSs en las cinco sedes de la Autoridad Laboral pertenecientes a la Junta de Comunidades de Castilla-La Mancha para el período de tiempo analizado.

\subsubsection{1. ¿SE REFLEJA LA FIGURA DEL COORDINADOR DE SEGURIDAD Y SALUD EN FASE DE REDACCIÓN DEL PROYECTO?}

Si bien es cierto que la figura del Coordinador de Seguridad y Salud es reconocida y valorada por todos los agentes involucrados en las obras de construcción, sus funciones y obligaciones más allá de la coordinación de actividades parecen no estar tan claras. $Y$ es que es muy común encontrarse con agentes y trabajadores de construcción que desconocen la distinción existente entre el Coordinador de Seguridad y Salud en fase de proyecto y en fase de ejecución (entendiendo en la mayoría de los casos que se trata de la misma figura), así como entre sus obligaciones. Para empezar, se ha de indicar, que según queda recogido en la Disposición Adicional Cuarta de la Ley 38/1999 (BOE, 1999), "las titulaciones académicas y profesionales habilitantes para desempeñar la función de coordinador de seguridad y salud en obras de edificación, durante la elaboración del proyecto y la ejecución de la obra, serán las de arquitecto, arquitecto técnico, ingeniero o ingeniero técnico, de acuerdo con sus competencias y especialidades". La figura del Coordinador de Seguridad y Salud en fase de proyecto se torna obligatoria cuando en la elaboración del proyecto intervengan varios proyectistas contratados de forma independiente por el promotor, amén de otros supuestos que quedan recogidos de forma clara en el artículo 3 del Real Decreto 1627/97 (BOE, 1997b). "En caso de no ser precisa su designación, por existir un único proyectista, será necesario que sea este último quien aplique al proyecto de obra los principios especificados en el artículo 8, apartados 1 y 2 del Real Decreto 1627/97 (BOE, 1997b)" (INSHT, 2012). Las obligaciones del Coordinador de Seguridad y Salud 
en fase de proyecto vienen recogidas en distintos artículos del Real Decreto 1627/97 (BOE, 1997b), entre éstas, encontramos las siguientes:

1. Coordinar, en la fase de proyecto, la aplicación de los principios preventivos aplicables al proyecto de obra, en particular al tomar decisiones constructivas, técnicas y de organización con el fin de planificar los distintos trabajos o fases de trabajo que se desarrollan simultánea o sucesivamente, así como al estimar la duración requerida para la ejecución de estos distintos trabajos o fases de trabajo.

2. Tener en cuenta las previsiones y las informaciones útiles para efectuar en su día, en las debidas condiciones de seguridad y salud, los previsibles trabajos posteriores.

3. Elaborar o hacer que se elabore bajo su responsabilidad el Estudio o Estudio Básico de Seguridad y Salud.

Es debido a lo anteriormente mencionado, que únicamente se ha de reflejar dicha figura para los supuestos que se recogen en el artículo 3 del Real Decreto 1627/97 (BOE, 1997b). Por ello, para el presente estudio, se analizan los PSSs que debiendo reflejar dicha figura debido a que cumplen con alguno de los requisitos que establece el artículo 3 del Real Decreto 1627/97 (BOE, 1997b), no la recogen. Sobre el total de PSSs consultados, se aprecia que, para el primer período de tiempo consultado, la tasa de cumplimiento se sitúa en valores marginales del 2,65\%, muy por debajo de los valores deseables. Si analizamos de forma pormenorizada los datos, observamos que, en proporción, son las sedes de Ciudad Real y Cuenca las que ostentan un mayor cumplimiento con respecto a este requisito, con un $3,80 \%$ y un $3,67 \%$ respectivamente, tasas que duplican los valores de las dos sedes restantes (Albacete y Guadalajara), tal y como se puede observar en la Tabla 5.10. 


\begin{tabular}{|c|c|c|c|c|c|}
\hline & \multicolumn{5}{|c|}{ Coordinador de Seguridad y Salud en fase de proyecto } \\
\hline Período & Albacete & Ciudad Real & Cuenca & Guadalajara & Toledo \\
\hline 2008-2012 & 8 & 19 & 11 & 7 & - \\
\hline$\%$ & 1,60 & 3,80 & 3,67 & 1,75 & - \\
\hline T. Parcial/\% & \multicolumn{5}{|c|}{$45(2,65 \%)$} \\
\hline 2013-2016 & 21 & 35 & 31 & 18 & 16 \\
\hline$\%$ & 5,25 & 8,75 & 7,75 & 4,50 & 5,33 \\
\hline T. Parcial/\% & \multicolumn{5}{|c|}{$121(6,37 \%)$} \\
\hline Total & \multicolumn{5}{|c|}{$166(4,61 \%)$} \\
\hline
\end{tabular}

Tabla 5.10. Volumen de Planes de Seguridad y Salud consultados que cumplen con el requisito del presente apartado, organizados por período de tiempo y sede provincial (por orden alfabético) de Castilla-La Mancha con inclusión de totales parciales por período y total global sobre el conjunto de PSSs consultados.

En lo que respecta al segundo período de tiempo estudiado, 2013 a 2016, observamos que el cumplimiento a nivel global es mayor que para el período de tiempo ulterior, con una tasa de cumplimiento del requisito de $6,37 \%$ (lo que supone duplicar la tasa obtenida en el período anterior, llegando casi a triplicarla), aún muy por debajo de los datos deseables. Analizando los datos en detalle, observamos una diferencia porcentual de cuatro con veinticinco puntos entre la sede con mayor tasa de cumplimiento (Ciudad Real, con un 8,75\%), y la de menor cumplimiento (Guadalajara, con un 4,50\%), de entre las cinco sedes analizadas.

Para terminar, se observa sobre el cómputo global de PSSs analizados, una cifra de cumplimiento de este requisito muy por debajo de lo esperado, que se sitúa en un $4,61 \%$, rozando el $5,00 \%$.

Estos resultados son fiel reflejo del desconocimiento de esta figura en nuestro país, así como de sus implicaciones y obligaciones, imprescindibles a la hora de integrar de forma correcta y efectiva la prevención en el diseño, tal y como recoge el informe del Consejo de la Unión Europea del año 2008 (COM, 2008), sobre la falta de integración preventiva en la fase de diseño de la obra. 


\subsubsection{2. ¿SE REFLEJA LA FIGURA DEL COORDINADOR DE SEGURIDAD Y SALUD EN FASE DE EJECUCIÓN DE LA OBRA?}

Ya son de sobra conocidas las titulaciones habilitantes para el ejercicio de las labores de coordinación, tal y como se muestra en el aparatado 5.1.4. del presente documento, extracto de lo recogido en la Disposición Adicional Cuarta de la Ley 38/1999 (BOE, 1999). Si bien se ha visto cómo en el caso de la figura del Coordinador de Seguridad y Salud en fase de proyecto las funciones del mismo pueden llegar a ser asumidas por el proyectista bajo los supuestos que marca la Ley, por existir un único proyectista, en el caso de la figura del Coordinador de Seguridad y Salud en fase de ejecución, su presencia es obligatoria para la práctica totalidad de supuestos que se recogen en la Tabla 5.11 (INSHT, 2012). Así mismo, la Guía Técnica del INSHT (INSHT, 2012), señala que "la obligación de nombrar un Coordinador en materia de Seguridad y Salud durante la ejecución de la obra es, en general, independiente del hecho de que los contratistas, subcontratistas o trabajadores autónomos tengan una presencia simultánea o sucesiva en la obra".

Posibles situaciones
- Un contratista.
- Una unión temporal de empresas (UTE) con trabajadores.
- Un trabajador autónomo con uno o varios trabajadores por
cuenta ajena a su cargo.
- Dos o más contratistas.
- Un contratista más uno o varios subcontratistas.
- Una unión temporal de empresas (UTE) con trabajadores,
que subcontrate a otra empresa.
- Un contratista más un trabajador autónomo.
- Una unión temporal de empresas con trabajadores, más un
trabajador autónomo.
- Un trabajador autónomo con uno o varios trabajadores por
cuenta ajena a su cargo, más otro trabajador autónomo.
- Dos o más trabajadores autónomos.

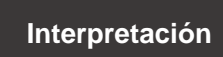

Coordinador ejecución

Una empresa

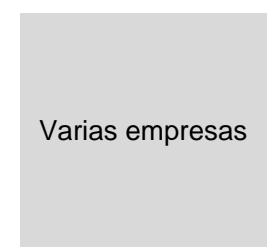

Una empresa y trabajadores autónomos

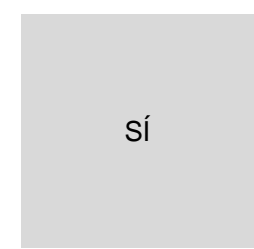$$
\text { (autonomos }
$$

Diversos trabajadores autónomos
NO

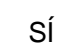

sí

Tabla 5.11. Situaciones más habituales que pueden darse y su equivalencia al respecto (a efectos del cómputo de empresas, únicamente se contabilizan aquellas que ejecutan obra), respecto de la determinación en obra del nombramiento de la figura del Coordinador de Seguridad y Salud en fase de ejecución. INSHT, 2012. 
La designación de dicha figura, ha de quedar recogida tanto en el comunicado de apertura de centro de trabajo (realizado por el o los posibles contratistas de la obra), así como en el libro de subcontratación. De igual forma, queda recogido en el acta de aprobación del Plan de Seguridad y Salud en el Trabajo. Vista la obligatoriedad de dicha figura, se pasa a desglosar sus obligaciones, que quedan recogidas en los artículos 9, 13 y 14 del Real Decreto 1627/97 (BOE, 1997b), entre las que destacan las que a continuación se muestran:

1. Coordinar en la fase de ejecución la aplicación de los principios generales de prevención y seguridad al tomar decisiones técnicas y de organización con el fin de planificar los distintos trabajos o fases de trabajo que vayan a desarrollarse simultánea o sucesivamente, así como al estimar la duración requerida para la ejecución de estos distintos trabajos o fases de trabajo.

2. Coordinar las actividades de la obra para garantizar que los contratistas $y$, en su caso, los subcontratistas y trabajadores autónomos apliquen de manera coherente y responsable los principios de la acción preventiva (art. $15 L P R L)$.

3. Aprobar el Plan de Seguridad y Salud elaborado por el contratista y, en su caso, las modificaciones introducidas en el mismo. En el caso de obras de las Administraciones Públicas, el Plan, con el correspondiente informe del coordinador en materia de seguridad y salud durante la ejecución de la obra, se elevará para su aprobación a la Administración Pública que haya adjudicado la obra. Cuando no sea necesaria la designación de coordinador, las funciones anteriores serán asumidas por la dirección facultativa.

4. Organizar la coordinación de actividades empresariales prevista en el art. 24 de la LPRL, desarrollado posteriormente por el RD 171/2004.

5. Coordinar las acciones y funciones de control de la aplicación correcta de los métodos de trabajo.

6. Adoptar las medidas necesarias para que sólo las personas autorizadas puedan acceder a la obra. La dirección facultativa asumirá esta función cuando no fuera necesaria la designación de coordinador. 
7. Diligenciar el Libro de Incidencias (deberá existir siempre que exista Plan de Seguridad y Salud) que será suministrado por el colegio profesional al que pertenezca el coordinador de seguridad y salud en fase de ejecución o, cuando no sea necesaria su asignación, el técnico integrado en la dirección facultativa que aprueba el Plan de seguridad y salud de la obra. Para obras cuyo promotor sea la Administración Pública es la oficina de supervisión de proyectos $u$ órgano equivalente el que facilita dicho Libro de Incidencias.

8. Mantener en su poder y en la obra el Libro de Incidencias. Cuando no sea necesaria la designación de coordinador en materia de seguridad y salud en fase de ejecución, el Libro de Incidencias estará en poder de la dirección facultativa.

Si bien es cierto que su presencia permanente en obra no es obligatoria, la realidad pasa por ser una figura bastante ausente en la obra, según los testimonios de los trabajadores y agentes de construcción. Esto es debido en parte al escaso sueldo que por dichas labores obtienen, lo que hace que un mismo coordinador lleva varias obras en cartera, lo que imposibilita el seguimiento continuo de la obra.

Analizada de forma superficial esta figura, pasamos a mostrar los resultados obtenidos acerca del cumplimiento de este requisito y de su constancia o no en los PSSs estudiados. Para el primer período de tiempo, encontramos que esta figura se encuentra recogida en un aceptable $77,71 \%$ de los PSSs consultados, tal y como se recoge en la Tabla 5.12. Se observa una diferencia porcentual de catorce puntos respecto de la sede con mayor cumplimiento de las cuatro consultadas (Cuenca, con un 83,33\%), con respecto a la de menor cumplimiento (Guadalajara, con un 69,25\%). 


\begin{tabular}{|c|c|c|c|c|c|}
\hline & \multicolumn{5}{|c|}{ Coordinador de Seguridad y Salud en fase de ejecución } \\
\hline Período & Albacete & Ciudad Real & Cuenca & Guadalajara & Toledo \\
\hline 2008-2012 & 392 & 402 & 250 & 277 & - \\
\hline$\%$ & 78,40 & 80,40 & 83,33 & 69,25 & - \\
\hline T. Parcial/\% & \multicolumn{5}{|c|}{$1.321(77,71 \%)$} \\
\hline 2013-2016 & 363 & 351 & 333 & 311 & 265 \\
\hline$\%$ & 90,75 & 87,75 & 83,25 & 77,75 & 88,33 \\
\hline T. Parcial/\% & \multicolumn{5}{|c|}{$1.623(85,42 \%)$} \\
\hline Total & \multicolumn{5}{|c|}{$2.944(81,78 \%)$} \\
\hline
\end{tabular}

Tabla 5.12. Volumen de Planes de Seguridad y Salud consultados que cumplen con el requisito del presente apartado, organizados por período de tiempo y sede provincial (por orden alfabético) de Castilla-La Mancha con inclusión de totales parciales por período y total global sobre el conjunto de PSSs consultados.

Para el segundo período de tiempo analizado, el porcentaje global de cumplimiento se sitúa en tasas del $85,42 \%$, siete con setenta y un puntos por encima de los datos obtenidos para el primer período. Si se analizan en detalle los datos, se observa una diferencia de trece puntos porcentuales entre la sede con mayor cumplimiento (Albacete, con un 90,75\%) y la de menor cumplimiento (Guadalajara, con un 77,75\%), de entre las cinco sedes analizadas. El porcentaje de cuatro de las cinco sedes (Albacete, Ciudad Real, Cuenca y Toledo) se encuentra dentro de una horquilla porcentual que comprende los valores de cumplimiento por encima del $80,00 \%$ y por debajo del $90,00 \%$.

En lo relativo al global de los PSSs consultados, 3.900 PSSs, se obtiene un valor de cumplimiento del $81,77 \%$, lo que certifica lo expuesto en el presente apartado, así como en el apartado anterior. Se aprecia un agravio comparativo entre la figura del Coordinador de Seguridad y Salud en fase de proyecto, con un cumplimiento global del 4,61\%, frente a la misma figura en fase de ejecución, con un cumplimiento del $81,77 \%$, lo que demuestra la diferencia cuantitativa y cualitativa de dicha figura, con un salto de setenta y siete puntos porcentuales entre ambas figuras.

A modo de conclusión, se puede extractar que el hecho de que esta figura no alcance cotas más próximas al $100,00 \%$ se debe en parte a las obras en las que no se hace necesaria su presencia, y que quedan recogidas en la Tabla 5.11, así como en los casos en los que por desconocimiento o mala praxis del redactor del Plan se omite dicha figura. También se encuentran casos en los que la misma persona que se encarga de las labores de coordinación en fase de redacción de proyecto, asume las labores de coordinación en fase de ejecución. 


\subsubsection{EL COORDINADOR DE SEGURIDAD Y SALUD DE LA OBRA, ENCARGADO DE APROBAR EL PSS, ¿ES EL MISMO QUE REDACTA EL PLAN?}

A modo de reseña, se recogen los datos extractados de la consulta de PSSs realizada en las cinco sedes de la Autoridad Laboral de Castilla-La Mancha, respecto de la incompatibilidad manifiesta que se produce en la figura del Coordinador de Seguridad y Salud. Si bien se ha estudiado que es el Coordinador el responsable de aprobar el Plan de Seguridad y Salud de la obra, también se ha visto que no puede ser quien lo redacte (obligación que le corresponde al contratista), ya que se produciría un conflicto de intereses, al ser la persona redactora del Plan la que posteriormente lo tiene que aprobar. Pues bien, este tipo de incompatibilidades se encuentran recogidas dentro de los PSSs consultados para el período de tiempo de 2008 a 2016 (ambos incluidos). En concreto, se encuentra con que dicha incompatibilidad queda recogida de forma escrita en los siguientes PSSs examinados, tal y como recoge la Tabla 5.13 , se incluyen por supuesto, los PSS en los que el redactor del plan es el técnico de prevención de la empresa (Servicio de Prevención Propio o Ajeno) y en los que el coordinador que aprueba el Plan pasa a ser la misma persona.

\begin{tabular}{|c|c|c|c|c|c|}
\hline \multirow[b]{2}{*}{ Período } & \multicolumn{5}{|c|}{ Incompatibilidad de la figura del Coordinador de Seguridad y Salud } \\
\hline & Albacete & Ciudad Real & Cuenca & Guadalajara & Toledo \\
\hline 2008-2012 & 12 & 23 & 10 & 13 & - \\
\hline$\%$ & 2,40 & 4,60 & 3,33 & 3,25 & - \\
\hline T. Parcial/\% & \multicolumn{5}{|c|}{$58(3,41 \%)$} \\
\hline 2013-2016 & 17 & 13 & 19 & 11 & 11 \\
\hline$\%$ & 4,25 & 3,25 & 4,75 & 2,75 & 3,67 \\
\hline T. Parcial/\% & \multicolumn{5}{|c|}{$71(3,74 \%)$} \\
\hline Total & \multicolumn{5}{|c|}{$129(3,58 \%)$} \\
\hline
\end{tabular}

Tabla 5.13. Volumen de Planes de Seguridad y Salud consultados que cumplen con el requisito del presente apartado, organizados por período de tiempo y sede provincial (por orden alfabético) de Castilla-La Mancha con inclusión de totales parciales por período y total global sobre el conjunto de PSSs consultados.

Resulta interesante observar que, si bien el porcentaje de casos en los que se produce esta incompatibilidad no es muy elevado, un 3,58\% sobre el cómputo global de PSSs consultados, 3.600 PSSs, resulta esclarecedor de lo poco que se conocen las funciones y obligaciones de la figura del coordinador, de ahí que se sigan dando estas incompatibilidades. Para el primer período de tiempo estudiado, en el $3,41 \%$ de los casos se produce esta incompatibilidad. 
Porcentaje muy similar es el obtenido para el segundo período de tiempo estudiado, con un 3,74\% de incompatibilidades encontradas. Si bien es cierto que, durante el segundo período de tiempo, el porcentaje de las cinco sedes ostenta valores bastante homogéneos (dos puntos de diferencia porcentual), durante el primer período se produce una diferencia porcentual del entorno de los dos con dos puntos porcentuales entre la sede con mayor tasa de incompatibilidades (Ciudad Real, con un 4,60\%) y la de menor tasa de incompatibilidades (Albacete, con un 2,40\%), para las cuatro sedes consultadas. De lo que se constata un incumplimiento homogéneo para ambos períodos de tiempo estudiados.

Este tipo de sucesos, se evitarían en gran medida si el documento no fuese únicamente registrado, si no que fuese revisado por la propia Autoridad Laboral, exigiendo las modificaciones pertinentes para cada Plan, realizando un seguimiento de la obra, y obligando a realizar las anexiones al Plan necesarias durante la ejecución de la misma. 


\subsection{ASPECTO FORMAL DEL DOCUMENTO (PSS)}

En este apartado se aglutinan distintos aspectos formales que deberían formar parte del documento final, para el enriquecimiento del mismo, así como para su mejor comprensión y adecuación a los requisitos de la obra. Éstos son aspectos tales como la inclusión de un cronograma de los trabajos que se van a realizar en obra, si el documento aporta imágenes de la maquinaria que se va a utilizar, del solar y demás, si el documento cuenta con medidas de emergencia y/o planos de evacuación, aparecen identificados los productos químicos que se van a emplear en la obra, etc.

\subsection{1. ¿APARECEN INTEGRADAS EN EL DOCUMENTO LAS UNIDADES O FASES DE OBRA (CRONOGRAMA DE TRABAJOS)?}

En este apartado se estudia si el contenido del Plan alberga un cronograma con las unidades o fases de obra (también conocido como diagrama de Gantt), indicando tiempos y solapes que se puedan producir durante la ejecución de los trabajos. La inclusión de un organigrama funcional de la obra ayuda al proyectista y al coordinador a concebir la obra como un conjunto de pequeñas acciones que convergen en la acción global que supone la obra. Al compartimentar los tiempos y procesos en obra, se tiene que hacer un ejercicio de prospección, adaptando las distintas unidades de la obra con tiempos razonables para la ejecución de dichas unidades, teniendo en cuenta los solapes entre distintas unidades que se puedan producir, lo que se traduce en el solape de distintos oficios trabajando en un mismo espacio de tiempo, lo que hace necesario un mayor control preventivo.

Esta herramienta, de vital importancia para poder marcar los tiempos que ha de llevar la obra y cumplir con los plazos establecidos para la misma, obliga a realizar un ejercicio de planificación y muestra los posibles solapes que puedan producirse durante la ejecución de los trabajos. Desde un punto de vista preventivo, las figuras involucradas en obra, como el jefe de obra y el Coordinador de Seguridad y Salud, pueden prestar mayor atención cuando se producen estos solapes, siempre y cuando queden documentados, ya sea por escrito o mediante un diagrama de Gantt, que permita enfatizar sus labores 
durante los solapes entre oficios. En la Tabla 5.14 se recogen los PSSs consultados para ambos períodos de tiempo que cumplen con este requisito.

\begin{tabular}{|c|c|c|c|c|c|}
\hline \multirow[b]{2}{*}{ Período } & \multicolumn{5}{|c|}{ PSS cuenta con organigrama o fases de obra } \\
\hline & Albacete & Ciudad Real & Cuenca & Guadalajara & Toledo \\
\hline 2008-2012 & 29 & 33 & 20 & 27 & - \\
\hline$\%$ & 5,80 & 6,60 & 6,67 & 6,75 & - \\
\hline T. Parcial//\% & \multicolumn{5}{|c|}{$109(6,41 \%)$} \\
\hline 2013-2016 & 59 & 62 & 51 & 61 & 41 \\
\hline$\%$ & 14,75 & 15,50 & 12,75 & 15,25 & 13,67 \\
\hline T. Parcial/\% & \multicolumn{5}{|c|}{$274(14,42 \%)$} \\
\hline Total & \multicolumn{5}{|c|}{$383(10,64 \%)$} \\
\hline
\end{tabular}

Tabla 5.14. Volumen de Planes de Seguridad y Salud consultados que cumplen con el requisito del presente apartado, organizados por período de tiempo y sede provincial (por orden alfabético) de Castilla-La Mancha con inclusión de totales parciales por período y total global sobre el conjunto de PSSs consultados.

Se observa cómo, sobre el cómputo global de PSSs consultados, el cumplimiento de este requerimiento se sitúa en cotas bajas, con un 10,64\%. Se observa, asimismo, un incremento en el cumplimiento en el segundo período con respecto al primer período, con una diferencia porcentual de ocho puntos.

Para el primer período de tiempo consultado, se obtienen cifras de cumplimiento similares para las cuatro sedes, con un total parcial del 6,41\%. Para el segundo período, hay una mayor variación porcentual entre la sede con mayor cumplimiento (Ciudad Real, con un 15,50\%) y la de menor cumplimiento (Cuenca, con un 12,75\%), de entre las cinco sedes estudiadas, obteniendo un total parcial del $14,42 \%$. 


\subsection{2. ¿EL PSS CONTIENE MATERIAL GRÁFICO?}

En este apartado se analiza únicamente la presencia o no de elementos gráficos, imágenes, en el cuerpo del documento, obviando la portada. Esto tiene un sencillo fin, y es que normalmente los PSSs suelen ser tratados como documentos que ganan al peso y no en función de la calidad del mismo. Estudiar si el Plan contiene cualquier tipo de imagen, esquema visual o dibujo, planimetría o detalle preventivo que ayude en la correcta comprensión del documento, es decir, se trata de un material de apoyo al propio documento per sé que ayuda a cualquier agente que vaya a visionar el Plan a asimilar su contenido de forma más rápida y eficaz. En la Tabla 5.15 se muestra, a modo de resumen, el total de los PSSs consultados para ambos períodos de tiempo que cumplen con este requisito que se plantea.

\begin{tabular}{|c|c|c|c|c|c|}
\hline \multirow[b]{2}{*}{ Período } & \multicolumn{5}{|c|}{ PSS contiene material gráfico } \\
\hline & Albacete & Ciudad Real & Cuenca & Guadalajara & Toledo \\
\hline 2008-2012 & 138 & 192 & 110 & 105 & - \\
\hline$\%$ & 27,60 & 38,40 & 36,67 & 26,25 & - \\
\hline T. Parcial/\% & \multicolumn{5}{|c|}{$545(32,06 \%)$} \\
\hline 2013-2016 & 205 & 280 & 271 & 263 & 188 \\
\hline$\%$ & 51,25 & 70,00 & 67,75 & 65,75 & 62,67 \\
\hline T. Parcial/\% & \multicolumn{5}{|c|}{$1.207(63,53 \%)$} \\
\hline Total & \multicolumn{5}{|c|}{$1.752(48,67 \%)$} \\
\hline
\end{tabular}

Tabla 5.15. Volumen de Planes de Seguridad y Salud consultados que cumplen con el requisito del presente apartado, organizados por período de tiempo y sede provincial (por orden alfabético) de Castilla-La Mancha con inclusión de totales parciales por período y total global sobre el conjunto de PSSs consultados.

Los datos obtenidos muestran que se trata de un requerimiento que se cumple en mayor o menor medida, obteniendo un porcentaje muy próximo al 50,00\%, del $48,67 \%$ sobre el total de los PSSs consultados para ambos períodos de tiempo estudiados.

Si desgranamos los resultados, obtenemos un total parcial del 32,06\% para el primer período de tiempo considerado. Lo que traducido a las cuatro sedes escrutadas produce una variación porcentual de más de doce puntos entre la sede con mayor cumplimiento de este requisito (Ciudad Real, con un 38,40\%) y la sede con menor cumplimiento (Guadalajara, con un $26,25 \%$ ). 
Para el segundo período de tiempo se aprecia un claro aumento en el cumplimiento de este requisito, obteniendo valores para el total parcial del $63,53 \%$, con una variación porcentual que supera los treintaiún puntos con respecto a los datos obtenidos en el total parcial del primer periodo. Si se pasa a desgranar los datos obtenidos en las cinco sedes estudiadas, se observa un cumplimiento heterogéneo, con una variación cercana a los veinte puntos porcentuales entre la sede con mayor cumplimiento (Ciudad Real, con un $70,00 \%$ ), al igual que sucediera en el primer período, y la sede con menor cumplimiento (Albacete, con un 51,25\%). Estos valores son fiel reflejo de que este requisito se cumple en gran medida, dejando para análisis posteriores la utilidad real de este material gráfico. 


\subsubsection{1. ¿EL PSS INCLUYE MATERIAL GRÁFICO RELACIONADO CON LA OBRA O LA MAQUINARIA QUE SE VA A EMPLEAR EN LA OBRA?}

Este apartado está en estrecha relación con el apartado 5.3.2. del presente documento, ya que en éste se analiza, sobre el total de PSSs consultados que contenían material gráfico del tipo que fuese, los que aportan datos específicos de la obra a realizar, ya sea a través de detalles preventivos específicos para la obra que se detalla, imágenes del solar y la obra, o imágenes de la maquinaria específica que se va a emplear durante la obra (no se aceptan fotos de archivo del tipo getty images o similares bancos de imágenes). Es decir, se trataría de un apoyo gráfico al documento que compone el plan que mostraría detalles específicos de la obra, maquinaria, sistemas preventivos a implantar en la fase de ejecución de la obra. Este tipo de material de apoyo son de gran ayuda, no sólo para los técnicos y agentes involucrados en la obra, sino para los propios inspectores, cuyo fácil entendimiento agiliza la consulta del documento de cara a posibles inspecciones. La Tabla 5.16 recoge el total de los PSSs consultados para ambos períodos de tiempo que cumplen con este requisito planteado.

\begin{tabular}{|c|c|c|c|c|c|}
\hline \multirow[b]{2}{*}{ Período } & \multicolumn{5}{|c|}{ PSS contiene material gráfico relacionado con la obra o la maquinaria } \\
\hline & Albacete & Ciudad Real & Cuenca & Guadalajara & Toledo \\
\hline $2008-2012$ & 13 & 14 & 8 & 11 & - \\
\hline$\%$ & 2,60 & 2,80 & 2,67 & 2,75 & - \\
\hline T. Parcial/\% & \multicolumn{5}{|c|}{$46(2,71 \%)$} \\
\hline 2013-2016 & 11 & 10 & 9 & 13 & 9 \\
\hline$\%$ & 2,75 & 2,50 & 2,25 & 3,25 & 3,00 \\
\hline T. Parcial/\% & \multicolumn{5}{|c|}{$52(2,74 \%)$} \\
\hline Total & \multicolumn{5}{|c|}{$98(2,72 \%)$} \\
\hline
\end{tabular}

Tabla 5.16. Volumen de Planes de Seguridad y Salud consultados que cumplen con el requisito del presente apartado, organizados por período de tiempo y sede provincial (por orden alfabético) de Castilla-La Mancha con inclusión de totales parciales por período y total global sobre el conjunto de PSSs consultados.

Los datos obtenidos son bastante descorazonadores, más bajos de lo que cabría esperar, aunque por desgracia son fiel reflejo de la realidad, de la ineficacia y la escasa utilidad que de esta herramienta preventiva se hace. A nivel global se obtiene un porcentaje de casos en los que los que se encuentra material gráfico de apoyo relacionado con la obra que recoge el Plan de tan sólo un 2,72\%. Este porcentaje es muy similar a los totales parciales obtenidos para ambos períodos de tiempo, con un 2,71\% para el primer período y un 2,74\% para el segundo período. Esto muestra la dejadez por parte del redactor del Plan por elaborar un 
documento fehaciente con la obra y los procesos que se van a llevar a cabo y que pueda servir como una herramienta preventiva eficaz. Asimismo, en muchas ocasiones, este documento se redacta de forma rápida y realizando acciones de copia-pega de otros planes para cumplir con este requisito, que al ser presentado en Registro termina con su vida útil.

En el primer período se aprecia un número muy similar de casos, con una varianza porcentual que no llega al cuarto de punto, lo que se traduce en una distribución muy homogénea entre las cuatro sedes consultadas, con Ciudad Real como la sede con mayor número de casos, 2,80\%, y Albacete como la sede con menos casos, con un 2,60\%. Resultados similares se exponen en el segundo período, con una variación porcentual de tres cuartos de punto entre la sede con más casos registrados (Guadalajara, con un 3,25\%) y la que menos (Cuenca, con un 2,25\%). 


\subsection{3. ¿CUENTA EL PSS CON PAUTAS DE ACTUACIÓN ANTE EMERGENCIAS?}

En este punto se analiza la presencia, dentro del documento, de pautas de actuación ante emergencias, sean del tipo que sean, entiéndase, médicas, contra incendios, accidentes con maquinaria involucrada, etc. Esto demuestra un nivel de previsión y prevención por parte del redactor del Plan, que consciente de la casuística especial que rodea al Sector de la Construcción, decide prever una abanico de posibles emergencias que puedan darse en el centro de trabajo, en este caso, en la obra. Para ello, se analiza el total de PSSs consultados en busca de este apartado recopilando los resultados encontrados en la Tabla 5.17. Cabe destacar que este aparatado resulta de gran utilidad al contemplar una serie de posibles emergencias que puedan darse durante la ejecución de los trabajos.

\begin{tabular}{|c|c|c|c|c|c|}
\hline & \multicolumn{5}{|c|}{ PSS cuenta con pautas de actuación ante emergencias } \\
\hline Período & Albacete & Ciudad Real & Cuenca & Guadalajara & Toledo \\
\hline 2008-2012 & 142 & 123 & 90 & 101 & - \\
\hline$\%$ & 28,40 & 24,60 & 30,00 & 25,25 & - \\
\hline T. Parcial/\% & \multicolumn{5}{|c|}{$456(26,82 \%)$} \\
\hline 2013-2016 & 170 & 147 & 179 & 122 & 113 \\
\hline$\%$ & 42,50 & 36,75 & 44,75 & 30,50 & 37,67 \\
\hline T. Parcial/\% & \multicolumn{5}{|c|}{$731(38,47 \%)$} \\
\hline Total & \multicolumn{5}{|c|}{$1.187(32,97 \%)$} \\
\hline
\end{tabular}

Tabla 5.17. Volumen de Planes de Seguridad y Salud consultados que cumplen con el requisito del presente apartado, organizados por período de tiempo y sede provincial (por orden alfabético) de Castilla-La Mancha con inclusión de totales parciales por período y total global sobre el conjunto de PSSs consultados.

Sobre el total de los 3.600 PSSs examinados, se obtiene un cumplimiento elevado de este requisito, con valores por encima del 30,00\%, concretamente del $32,97 \%$, lo que supone un cumplimiento aceptable, aunque por debajo de valores más próximos al 50,00\%, que sería lo deseable.

Se obtienen datos de cumplimiento para el primer período de un $26,82 \%$, sobre el total parcial de las cuatro sedes, lo que se traduce en un cumplimiento bajo. $Y$ a nivel de detalle, se puede ver una variación porcentual superior a los cinco puntos entre la sede con más datos constatados (Cuenca, con un 30,00\%) y la que menos (Ciudad Real, con un 24,60\%). Esta escasa variación porcentual implica resultados homogéneos para las cuatro sedes. 
Se observa un incremento en el cumplimiento para el segundo período, alcanzando valores próximos al 40,00\% (en concreto de 38,47\%), lo que implicaría un cumplimiento razonablemente aceptable. A nivel de detalle, se encuentra con una varianza porcentual de más de catorce puntos, lo que conlleva una heterogeneidad en los resultados obtenidos en las cinco sedes, con Cuenca como la sede con mayor número de casos registrados (con un 44,75\%), coincidente con el primer período, y con Guadalajara como la sede con menos casos. 


\subsection{4. ¿SE RECOGEN LOS ITINERARIOS PARA LLEGAR A LOS CENTROS ASISTENCIALES/HOSPITAL EN EL PSS?}

Este apartado no se integra dentro del anterior, ya que constituye su propio apartado, con entidad propia, al tratarse, a nuestro entender, de un must have o requisito imprescindible para el total de los Planes. Es por ello, que este tipo de acciones no se tienen en cuenta en el total de los PSSs del apartado anterior (se excluye del listado de pautas de actuación ante emergencias), ya que consideramos que su inclusión en el Plan es parte imprescindible para la utilidad real del documento y que, en consecuencia, ha de ser analizado por separado. Es por ello que la Tabla 5.18 muestra el cumplimiento del presente requerimiento para el período de tiempo estudiado y las cinco sedes consultadas.

\begin{tabular}{|c|c|c|c|c|c|}
\hline \multirow[b]{2}{*}{ Período } & \multicolumn{5}{|c|}{ PSS cuenta con itinerarios para llegar a centros asistenciales } \\
\hline & Albacete & Ciudad Real & Cuenca & Guadalajara & Toledo \\
\hline 2008-2012 & 59 & 64 & 40 & 43 & - \\
\hline$\%$ & 11,80 & 12,80 & 13,33 & 10,75 & - \\
\hline T. Parcial/\% & \multicolumn{5}{|c|}{$206(12,12 \%)$} \\
\hline 2013-2016 & 207 & 222 & 269 & 265 & 199 \\
\hline$\%$ & 51,75 & 55,50 & 67,25 & 66,25 & 66,33 \\
\hline T. Parcial/\% & \multicolumn{5}{|c|}{$1.162(61,16 \%)$} \\
\hline Total & \multicolumn{5}{|c|}{$1.368(38,00 \%)$} \\
\hline
\end{tabular}

Tabla 5.18. Volumen de Planes de Seguridad y Salud consultados que cumplen con el requisito del presente apartado, organizados por período de tiempo y sede provincial (por orden alfabético) de Castilla-La Mancha con inclusión de totales parciales por período y total global sobre el conjunto de PSSs consultados.

Si bien es cierto que las previsiones de cumplimiento eran más elevadas, debido a la utilidad real que la integración de las rutas de evacuación al centro asistencial/mutua y al hospital tienen a la hora de evacuar rápidamente y de forma eficaz al herido en la obra, los datos obtenidos durante el segundo período son más acordes. Sobre el cómputo global de sedes y períodos analizados, obtenemos un mediocre $38,00 \%$ de cumplimiento sobre el presente requisito. A pesar de ello, y dada la tendencia alcista que muestran los datos, en futuras revisiones, a cinco años vista, entendemos que este requisito se aproximará cada vez más a valores próximos al 80,00-90,00\%.

Para el primer período obtenemos un valor del $12,12 \%$ sobre el total de las cuatro sedes consultadas, con valores bastante homogéneo entre las mismas, con una desviación porcentual de tan sólo dos puntos y medio entre la sede con 
más casos registrados (Cuenca, con un 13,33\%) y la sede con menos casos registrados (Guadalajara, con un 10,75\%).

Resulta interesante observar que la desviación porcentual que se produce en el segundo período con respecto al primero, es de cuarenta y nueve puntos, lo que constata la tendencia alcista hacia el cumplimiento formal de este requisito. Sobre el cómputo total para este período obtenemos un 61,66\% de tasa de cumplimiento, con una diferencia porcentual de quince puntos y medio, lo que constata la heterogeneidad de los resultados obtenidos. 


\subsection{5. ¿INCLUYE EL PSS PAUTAS DE ACTUACIÓN EN CASO DE RIESGO GRAVE E INMINENTE EN OBRA?}

Para el presente apartado se analizan los PSSs que incluyen pautas de actuación en caso de riesgo grave e inminente, como la paralización de los trabajos, según los casos expuesto en el artículo 21 de la Ley de Prevención de Riesgos Laborales (BOE, 1995):

1. Cuando los trabajadores estén o puedan estar expuestos a un riesgo grave e inminente con ocasión de su trabajo, el empresario estará obligado a:

a) Informar lo antes posible a todos los trabajadores afectados acerca de la existencia de dicho riesgo y de las medidas adoptadas o que, en su caso, deban adoptarse en materia de protección.

b) Adoptar las medidas y dar las instrucciones necesarias para que, en caso de peligro grave, inminente e inevitable, los trabajadores puedan interrumpir su actividad y, si fuera necesario, abandonar de inmediato el lugar de trabajo. En este supuesto no podrá exigirse a los trabajadores que reanuden su actividad mientras persista el peligro, salvo excepción debidamente justificada por razones de seguridad y determinada reglamentariamente.

c) Disponer lo necesario para que el trabajador que no pudiera ponerse en contacto con su superior jerárquico, ante una situación de peligro grave e inminente para su seguridad, la de otros trabajadores o la de terceros a la empresa, esté en condiciones, habida cuenta de sus conocimientos y de los medios técnicos puestos a su disposición, de adoptar las medidas necesarias para evitar las consecuencias de dicho peligro.

2. De acuerdo con lo previsto en el apartado 1 del artículo 14 de la presente Ley, el trabajador tendrá derecho a interrumpir su actividad y abandonar el lugar de trabajo, en caso necesario, cuando considere que 
dicha actividad entraña un riesgo grave e inminente para su vida o su salud.

3. Cuando en el caso a que se refiere el apartado 1 de este artículo el empresario no adopte o no permita la adopción de las medidas necesarias para garantizar la seguridad y la salud de los trabajadores, los representantes legales de éstos podrán acordar, por mayoría de sus miembros, la paralización de la actividad de los trabajadores afectados por dicho riesgo. Tal acuerdo será comunicado de inmediato a la empresa y a la autoridad laboral, la cual, en el plazo de veinticuatro horas, anulará o ratificará la paralización acordada.

El acuerdo a que se refiere el párrafo anterior podrá ser adoptado por decisión mayoritaria de los Delegados de Prevención cuando no resulte posible reunir con la urgencia requerida al órgano de representación del personal.

4. Los trabajadores o sus representantes no podrán sufrir perjuicio alguno derivado de la adopción de las medidas a que se refieren los apartados anteriores, a menos que hubieran obrado de mala fe o cometido negligencia grave.

Esta acción de paralización de la actividad en caso de riesgo grave e inminente puede ser llevada a cabo por una serie de agentes intervinientes en obras de construcción, como son, el empresario (art. 21.1 LPRL), el trabajador (art. 21.1 LPRL), el comité de empresa o los delegados de personal (art. 21.3 LPRL), los delegados de prevención (art. 23.1 LPRL), el inspector de trabajo (art. 44.1 LPRL) o el Coordinador de Seguridad y Salud y/o cualquier persona integrada en la dirección facultativa de una obra (art. 14 RD 1627/97). Expuesto el resumen del articulado de la citada Ley, se pasa a analizar en la Tabla 5.19 el total de PSSs que cumplen con este importante requisito, para el total de las cinco sedes estudiadas y los dos períodos de tiempo escogidos. 


\begin{tabular}{|c|c|c|c|c|c|}
\hline & \multicolumn{5}{|c|}{ PSS contiene pautas de actuación en caso de riesgo grave e inminente } \\
\hline Período & Albacete & Ciudad Real & Cuenca & Guadalajara & Toledo \\
\hline 2008-2012 & 13 & 17 & 9 & 11 & - \\
\hline$\%$ & 2,60 & 3,40 & 3,00 & 2,75 & - \\
\hline T. Parcial/\% & \multicolumn{5}{|c|}{$50(2,94 \%)$} \\
\hline 2013-2016 & 58 & 65 & 59 & 62 & 51 \\
\hline$\%$ & 14,50 & 16,25 & 14,75 & 15,50 & 17,00 \\
\hline T. Parcial/\% & \multicolumn{5}{|c|}{$295(15,53 \%)$} \\
\hline Total & \multicolumn{5}{|c|}{$345(9,58 \%)$} \\
\hline
\end{tabular}

Tabla 5.19. Volumen de Planes de Seguridad y Salud consultados que cumplen con el requisito del presente apartado, organizados por período de tiempo y sede provincial (por orden alfabético) de Castilla-La Mancha con inclusión de totales parciales por período y total global sobre el conjunto de PSSs consultados.

Los resultados globales para ambos períodos muestran un bajo cumplimiento de este requisito, con valores por debajo del 10,00\%. Esto tiene una lectura clara, el desconocimiento de esta serie de procedimientos que han de ser previstos previo al devenir de la obra y que han de dar pautas eficaces para que los agentes responsables puedan paralizar los trabajos. También es cierto que se observa una tendencia alcista en el cumplimiento con una diferencia porcentual cercana a los trece puntos entre el primer y el segundo período.

Para el primer período, sobre el total de las cuatro sedes, se obtiene un cumplimiento global del 2,94\%, con valores de cumplimiento bastante homogéneos entre las cuatro sedes. Para este período, se observa que Ciudad Real, con un $3,40 \%$, es la sede con más casos registrados frente a Albacete, con un $2,60 \%$, que se convierte en la sede con menor tasa de cumplimiento.

Ya en el segundo período, la tasa global de cumplimiento para las cinco sedes se eleva a un $15,53 \%$, lo que demuestra una tendencia alcista en el cumplimiento, aunque por debajo de los valores deseables. A nivel de cada sede, Toledo, con un $17,00 \%$, es la sede con mayor tasa de cumplimiento, frente a los datos obtenidos en Albacete, que vuelve a convertirse en la sede con menor tasa de cumplimiento. 


\subsection{6. ¿CUENTA EL PSS CON PLAN DE EVACUACIÓN EN CASO DE INCENDIO?}

Como todos saben, la obra es un organismo vivo en constante cambio, y esto se traduce en que los peligros asociados a cada fase de la obra pueden cambiar en cualquier momento al modificar cualquier factor inherente a la misma, haciendo que los riesgos se tornen dinámicos con el trascurso de la obra, y en ningún momento estáticos, como parece entender este documento preventivo.

Recogida esta reflexión, se ha de dar una mayor importancia a todos los mecanismos que versen sobre la protección de los trabajadores ante cualquier tipo de riesgo inherente a la obra o su entorno inmediato, como pueden ser riesgos graves e inminentes no contemplados en el Plan, los riesgos derivados del solape de oficios que se produce en la obra, los riesgos por incendio o explosión, los riesgos debidos al uso de maquinaria sin marcado $\mathrm{CE}$, los riesgos que se producen en los trayectos in itinere, etc. Es por ello, que en este aparatado se divisan los PSSs que contemplan en su interior medidas de evacuación sobre riesgos derivados de incendios, como uno de los riesgos más comunes y probables que puedan darse en una obra. Es por ello, y debido al impacto positivo que su cumplimiento tiene sobre la seguridad y salud de los trabajadores que puedan verse implicados en la obra, que se torna como un ítem imprescindible que ha de ser incluido en el Plan de Seguridad y Salud.

Si bien se trata de una medida preventiva de primera necesidad, en conjunción con la realización de simulacros en los distintos centros de trabajo (simulacro de incendios, de evacuación de accidentados en obra, etc.), esta medida no suele preverse en las obras de construcción, a pesar del elevado peligro que entrañan las mismas para el personal involucrado. Es por ello, que en el presente apartado se analizan los PSSs que cuentan en el cuerpo del documento con medidas o inclusive con un Plan de evacuación en caso de incendio contemplado para la obra que se especifica. Todos los datos obtenidos para este requerimiento, dentro del período de tiempo analizado y para las cinco sedes de la Autoridad Laboral consultadas pertenecientes a la Junta de Comunidades de Castilla-La Mancha, quedan recogidos en la Tabla 5.20. 


\begin{tabular}{|c|c|c|c|c|c|}
\hline & \multicolumn{5}{|c|}{ PSS cuenta con Plan de Evacuación en caso de incendio } \\
\hline Período & Albacete & Ciudad Real & Cuenca & Guadalajara & Toledo \\
\hline 2008-2012 & 7 & 6 & 4 & 7 & - \\
\hline$\%$ & 1,40 & 1,20 & 1,33 & 1,75 & - \\
\hline T. Parcial/\% & \multicolumn{5}{|c|}{$24(1,41 \%)$} \\
\hline 2013-2016 & 36 & 29 & 38 & 30 & 22 \\
\hline$\%$ & 9,00 & 7,25 & 9,50 & 7,50 & 7,33 \\
\hline T. Parcial/\% & \multicolumn{5}{|c|}{$155(8,16 \%)$} \\
\hline Total & \multicolumn{5}{|c|}{$179(4,97 \%)$} \\
\hline
\end{tabular}

Tabla 5.20. Volumen de Planes de Seguridad y Salud consultados que cumplen con el requisito del presente apartado, organizados por período de tiempo y sede provincial (por orden alfabético) de Castilla-La Mancha con inclusión de totales parciales por período y total global sobre el conjunto de PSSs consultados.

Sobre el total de PSSs consultados se observa un cumplimiento muy bajo de este requisito, con valores muy próximos al 5,00\%, lo que se traduce en 179 PSSs que lo cumplen, lo que representa un 4,97\%. Se observa asimismo, un incremento en el cumplimiento cercano a los siete puntos porcentuales si se comparan los resultados parciales obtenidos para el primer período (con valores que no alcanzan el 2,00\%) con los obtenidos para el segundo período (con valores de cumplimiento cercanos al $8,00 \%)$.

Si se pasa a analizar en detalle los resultados parciales obtenidos para el primer período de tiempo analizado, se obtiene un porcentaje de cumplimiento del $1,41 \%$, lo que implica un escaso acatamiento de este requisito. A nivel de las cuatro sedes analizadas, se aprecia un cumplimiento homogéneo, con una variación porcentual de tan sólo medio punto, entre la sede con mayor número de casos registrados (Guadalajara, con un 1,75\%) y la de menor número de casos registrados (Ciudad Real, con un 1,20\%).

Se aprecia un incremento en el cumplimiento del requisito para el segundo período, con valores porcentuales que alcanzan el $8,16 \%$ sobre el total parcial para este período. Si examinamos la diferencia porcentual que se produce en este período, de sólo dos con veinticinco puntos, muestran un cumplimiento homogéneo para las cinco sedes. A nivel de las sedes, destacan Cuenca (con un $9,50 \%$ ) y Albacete (con un 9,00\%) como las sedes con mayor cumplimiento del requisito frente al resto de sedes (Guadalajara, Toledo y Ciudad Real), que presentan valores muy próximos de cumplimiento (con un 7,50\%, un 7,33\% y un $7,25 \%$ respectivamente). 


\subsection{7. ¿INTEGRA EL PSS PROCEDIMIENTOS DE CONTROL DE SEGURIDAD} VIAL?

Los accidentes de trabajo in itinere supusieron en España, tanto para el año 2016 como para el año 2017, un total de 133 accidentes mortales, según los datos recogidos por la Estadística de accidentes de trabajo elaborado por el Ministerio de Trabajo, Migraciones y Seguridad Social (Ministerio de Trabajo, Migraciones y Seguridad Social, 2018b). Estos datos vienen a constatar una tendencia alcista que se lleva produciendo desde el año 2012, en el que se registraron 112 muertes en este tipo de accidentes de trabajo. La gravedad de los datos del Ministerio demuestra que han de ser tenidos en cuenta e integrados en el documento preventivo objetivo de la presente tesis doctoral los procedimientos de control de Seguridad Vial. Por supuesto, este tipo de procedimientos serían extrapolables a otros sectores productivos nacionales, aunque en este caso, es el Sector de la Construcción el objeto sobre el que se centra la presente investigación y al que afecta de manera directa el Plan de Seguridad y Salud.

De forma concreta, en esta sección del documento de tesis, se estudia la mención expresa que de los procedimientos de control de Seguridad Vial se hace en el documento objeto del presente estudio, el Plan de Seguridad y Salud. Se dan por válidas las alusiones expresas al Plan de Seguridad Vial para la obra o los párrafos del documento que recojan mención a este requisito, aunque no se ajusten a la realidad de la obra a la que hace mención el documento del Plan. Es decir, en este aparatado se aceptan las menciones vagas o que no guarden relación con la obra pero que hablen sobre la Seguridad Vial, ya que en el subsiguiente apartado sí se analizará este requisito cuando se ajusta a la obra sobre la que versa el documento preventivo del Plan. Los resultados obtenidos para este requisito se muestran en la Tabla 5.21. 


\begin{tabular}{|c|c|c|c|c|c|}
\hline & \multicolumn{5}{|c|}{ PSS cuenta con procedimientos de control de Seguridad Vial } \\
\hline Período & Albacete & Ciudad Real & Cuenca & Guadalajara & Toledo \\
\hline $2008-2012$ & 10 & 12 & 9 & 9 & - \\
\hline$\%$ & 2,00 & 2,40 & 3,00 & 2,25 & - \\
\hline T. Parcial/\% & \multicolumn{5}{|c|}{$40(2,35 \%)$} \\
\hline 2013-2016 & 79 & 68 & 75 & 71 & 52 \\
\hline$\%$ & 19,75 & 17,00 & 18,75 & 17,75 & 17,33 \\
\hline T. Parcial/\% & \multicolumn{5}{|c|}{$345(18,16 \%)$} \\
\hline Total & \multicolumn{5}{|c|}{$385(10,69 \%)$} \\
\hline
\end{tabular}

Tabla 5.21. Volumen de Planes de Seguridad y Salud consultados que cumplen con el requisito del presente apartado, organizados por período de tiempo y sede provincial (por orden alfabético) de Castilla-La Mancha con inclusión de totales parciales por período y total global sobre el conjunto de PSSs consultados.

Los resultados globales, para los 3.600 PSSs analizados, muestran un cumplimiento bajo de este requisito, con valores del 10,69\%, en consonancia con los resultados previstos. Del mismo modo, se observa un claro incremento en el cumplimiento del primer al segundo período sobre los valores totales parciales para cada período.

Para el primer período, se obtiene un porcentaje de cumplimiento del 2,35\%, lo que muestra valores muy bajos de obediencia del citado requisito. La diferencia porcentual que se produce entre la sede con mayor porcentaje de cumplimiento (Cuenca, con un 3,00\%) y la sede con menor porcentaje de cumplimiento (Albacete con un 2,00\%) es de tan sólo un punto, lo que se traduce en un cumplimiento homogéneo del requisito para las cuatro sedes estudiadas.

Para el segundo período se produce un incremento con respecto al primer período de tiempo analizado, obteniendo un total parcial del 18,16\%. A nivel de las cinco sedes, se produce una diferencia porcentual cercana a los tres puntos, entre la sede con más casos registrados (Albacete, con un 19,75\%) en contraposición a la sede con menor índice de casos registrados (Ciudad Real, con un 17,00\%). Se aprecia asimismo una inversión en la tendencia, al pasar la sede de Albacete como la sede con menor cumplimiento durante el primer período a ser la sede con mayor cumplimiento de este requisito para el segundo período. 


\subsubsection{1. ¿INCLUYE EL PSS UN PLAN DE SEGURIDAD VIAL ESPECÍFICO PARA LA OBRA QUE SE DETALLA?}

En este subapartado se analizan los PSSs que disponen de un Plan de Seguridad Vial o de procedimientos de Seguridad Vial específicos, ya sea que se encuentren integrados en el cuerpo del documento o anexados mediante añadidos al Plan de Seguridad y Salud. Lo que se pretende es observar una serie de medidas encaminadas a la Seguridad Vial de la obra, que se ajuste a la obra definida en el Plan, que integre medidas específicas para la obra y todos los itinerarios planificados.

Por ello, en la Tabla 5.22 se recogen los PSSs que cuentan con este requisito para los períodos estudiados y las sedes consultadas.

\begin{tabular}{|c|c|c|c|c|c|}
\hline & \multicolumn{5}{|c|}{ PSS cuenta con Plan de Seguridad Vial específico } \\
\hline Período & Albacete & Ciudad Real & Cuenca & Guadalajara & Toledo \\
\hline 2008-2012 & 0 & 0 & 0 & 0 & - \\
\hline$\%$ & 0,00 & 0,00 & 0,00 & 0,00 & - \\
\hline T. Parcial/\% & \multicolumn{5}{|c|}{$0(\mathbf{0 , 0 0 \% )}$} \\
\hline 2013-2016 & 1 & 0 & 0 & 1 & 0 \\
\hline$\%$ & 0,25 & 0,00 & 0,00 & 0,25 & 0,00 \\
\hline T. Parcial/\% & \multicolumn{5}{|c|}{$2(0,11 \%)$} \\
\hline Total & \multicolumn{5}{|c|}{$2(0,06 \%)$} \\
\hline
\end{tabular}

Tabla 5.22. Volumen de Planes de Seguridad y Salud consultados que cumplen con el requisito del presente apartado, organizados por período de tiempo y sede provincial (por orden alfabético) de Castilla-La Mancha con inclusión de totales parciales por período y total global sobre el conjunto de PSSs consultados.

Los resultados muestran la nula importancia que a este tipo de acciones de planificación de los desplazamientos que se producen en obra parecen tener de cara a la redacción del Plan y a su previsión en materia de Seguridad Vial. Sobre el total de los PSSs consultados para ambos períodos de tiempo, únicamente encontramos dos PSSs que integren procedimientos específicos, lo que resulta en un $0,06 \%$ de cumplimiento de este requisito, lo que pone de manifiesto la nula planificación de este tipo de acciones en materia de Seguridad Vial.

Para el primer período de tiempo, no se encuentra ningún Plan de Seguridad y Salud que cumpla con este requisito. Es ya en el segundo período que se constatan dos PSSs con presencia de este importante requisito, lo que no se puede entender como una permutación en la tendencia, al no poderse 
considerar como relevantes los resultados para producir un necesario cambio en lo relativo al cumplimiento de este requisito. 


\subsection{8. ¿SE INCORPORA UN CAPÍTULO ESPECÍFICO PARA LA SEGURIDAD Y SALUD DE LA OBRA DENTRO DEL CAPÍTULO DE MEDICIONES Y PRESUPUESTO DEL PLAN?}

Para el presente apartado, se analiza la presencia de un capítulo específico dedicado a la Seguridad y Salud integrado dentro de las mediciones y presupuesto del Plan de Seguridad y Salud. Este capítulo se torna de vital importancia a la hora de comprobar que la empresa invierte en prevención, compra los Equipos de Protección Individuales (EPIs) para los trabajadores, evitando la mala praxis presente en el Sector en la que algunas empresas obligan a sus trabajadores a comprarse los EPIs. En este capítulo se integran también las protecciones colectivas, señalizaciones y demás ítems que integran el capítulo de Seguridad y Salud del Presupuesto de la obra. En la Tabla 5.23 se analizan los PSSs que cumplen con este requisito para los períodos de tiempo programados y las sedes consultadas.

\begin{tabular}{|c|c|c|c|c|c|}
\hline \multirow[b]{2}{*}{ Período } & \multicolumn{5}{|c|}{$\begin{array}{l}\text { PSS cuenta con capítulo dedicado a la Seguridad y Salud } \\
\text { en las Mediciones y Presupuesto }\end{array}$} \\
\hline & Albacete & Ciudad Real & Cuenca & Guadalajara & Toledo \\
\hline 2008-2012 & 98 & 92 & 55 & 71 & - \\
\hline$\%$ & 19,60 & 18,40 & 18,33 & 17,75 & - \\
\hline T. Parcial $/ \%$ & \multicolumn{5}{|c|}{$316(18,59 \%)$} \\
\hline 2013-2016 & 192 & 201 & 196 & 193 & 149 \\
\hline$\%$ & 48,00 & 50,25 & 49,00 & 48,25 & 49,67 \\
\hline T. Parcial/\% & \multicolumn{5}{|c|}{$931(49,00 \%)$} \\
\hline Total & \multicolumn{5}{|c|}{$1.247(34,64 \%)$} \\
\hline
\end{tabular}

Tabla 5.23. Volumen de Planes de Seguridad y Salud consultados que cumplen con el requisito del presente apartado, organizados por período de tiempo y sede provincial (por orden alfabético) de Castilla-La Mancha con inclusión de totales parciales por período y total global sobre el conjunto de PSSs consultados.

Sobre el cómputo global de los 3.600 PSSs consultados, se observa un cumplimiento medio, con un $34,64 \%$, por debajo de un deseable $50,00 \%$.

Si se analiza el primer período, se obtiene un total parcial del $18,59 \%$, con una desviación porcentual inferior a los dos puntos entre la sede con mayor cumplimiento de este requisito (Albacete, con un 19,60\%) y la sede con menor cumplimiento (Guadalajara, con un 17,75\%).

Ya en el segundo período, se obtiene un cumplimiento global del 49,00\%, que entra dentro de los valores esperados. Se produce un fuerte incremento de más 
de treinta puntos de este requisito con respecto a los datos obtenidos para el primer período. El cumplimiento a nivel de las cinco sedes es bastante homogéneo. 


\subsection{EVALUACIÓN DE RIESGOS DE LA OBRA}

En este subsecuente apartado, en continuidad con lo recogido en el apartado 5.3. (sobre el contenido formal del documento), se pasa a analizar los aspectos del Plan de Seguridad y Salud que se encuentran directamente relacionados con la Evaluación de Riesgos. Dada la importancia que una correcta evaluación de los riesgos tiene en la seguridad de la obra, desde el comienzo de los trabajos hasta su finalización, que se decide otorgarle un apartado propio para analizar en profundidad este aspecto tan importante del Plan.

Conforme lo establecido en el punto 3 del artículo 7 del Real Decreto 1627/97 (BOE, 1997b), de 24 de octubre, por el que se establecen disposiciones mínimas de seguridad y de salud en las obras de construcción: “... el plan de seguridad y salud constituye el instrumento básico de ordenación de las actividades de identificación y, en su caso, evaluación de los riesgos y planificación de la actividad preventiva a las que se refiere el capítulo II del Real Decreto por el que se aprueba el Reglamento de los Servicios de Prevención".

En el mismo, nos referencian al Capítulo II del Real Decreto 39/1997 (BOE, 1997a), sobre el Reglamento de los Servicios de Prevención, concretamente a los artículos del 3 al 9, en donde se establece el contenido mínimo de la Evaluación de Riesgos, así como la Planificación Preventiva de la obra, o lo que es lo mismo, qué se debe evaluar y cómo se debe planificar los trabajos. Estos contenidos se desarrollan en los artículos 7 y 9 respectivamente.

Por tanto, se puede deducir que este requisito es condición sine qua non que ha de contener el Plan de Seguridad y Salud, que consecuentemente ha de desarrollar la Evaluación de Riesgos y la planificación de la actividad preventiva de la obra recogida en el Plan.

Pero ¿quién debe realizar la Evaluación de Riesgos y la planificación preventiva de un Plan de Seguridad y Salud? El punto 1 del artículo 7 del Real Decreto 1627/97 (BOE, 1997b) no deja lugar a dudas, es el contratista quien debe elaborar dicho documento. Ahora bien, según lo expuesto anteriormente en el punto 3 del artículo 7 del citado Real Decreto, se menciona que el Plan constituye la Evaluación y la planificación preventiva, de lo que se deduce, según lo expuesto en el artículo 37 del Real Decreto 39/1997 (BOE, 1997a), que 
el Plan deberá elaborarlo un técnico superior de Prevención de Riesgos Laborales.

De lo anteriormente expuesto se puede extractar que será el contratista quien elabore el Plan de Seguridad y Salud, y en el mismo deberá existir una evaluación y planificación de la actividad preventiva desarrollado por un técnico superior de Prevención de Riesgos Laborales.

De lo que se deduce que, si es el contratista quien debe elaborar el Plan de Seguridad y Salud y éste no posee las funciones de nivel superior según marca el artículo 37 del RD 39/1997 (BOE, 1997a), será la organización preventiva del mismo (distintas modalidades de Servicio de Prevención que recoge el citado Real Decreto) quién desarrolle dicho documento y posteriormente deberá ser aprobado por éste.

Se pretende, por tanto, comprobar la existencia de Evaluación de Riesgos y su contenido, así como la existencia de planificación preventiva y su desarrollo en el total de PSSs consultados para el período de tiempo establecido en el estudio.

\subsection{1. ¿SE EVALÚA CADA FASE/TRABAJO/PUESTOIACTIVIDAD DE LA OBRA EN EL PLAN?}

En este apartado se analiza la presencia, dentro del cuerpo del documento preventivo, de la evaluación correspondiente a las distintas fases de trabajo, puesto de trabajo, así como de los trabajos o actividades a realizar en la obra. Los resultados obtenidos se muestran en la Tabla 5.24.

\begin{tabular}{|c|c|c|c|c|c|}
\hline & \multicolumn{5}{|c|}{ PSS evalúa cada fase/trabajo/puestolactividad de la obra } \\
\hline Período & Albacete & Ciudad Real & Cuenca & Guadalajara & Toledo \\
\hline 2008-2012 & 378 & 409 & 230 & 354 & - \\
\hline$\%$ & 75,60 & 81,80 & 76,67 & 88,50 & - \\
\hline T. Parcial/\% & \multicolumn{5}{|c|}{$1.371(80,65 \%)$} \\
\hline 2013-2016 & 313 & 319 & 325 & 312 & 259 \\
\hline$\%$ & 78,25 & 79,75 & 81,25 & 78,00 & 86,33 \\
\hline T. Parcial/\% & \multicolumn{5}{|c|}{$1.528(80,42 \%)$} \\
\hline Total & \multicolumn{5}{|c|}{$2.899(80,53 \%)$} \\
\hline
\end{tabular}

Tabla 5.24. Volumen de Planes de Seguridad y Salud consultados que cumplen con el requisito del presente apartado, organizados por período de tiempo y sede provincial (por orden alfabético) de Castilla-La Mancha con inclusión de totales parciales por período y total global sobre el conjunto de PSSs consultados. 
A tenor de los resultados globales obtenidos para las cinco sedes y el período de tiempo comprendido de 2008 a 2016, se puede hablar de un cumplimiento alto para el presente requisito, con un $80,53 \%$. Si se analiza la diferencia porcentual entre el primer y segundo período de tiempo, se obtiene que la misma es prácticamente inexistente, con valores por debajo del cuarto de punto porcentual, lo que denota un cumplimiento homogéneo en ambos períodos.

Para el primer período de tiempo analizado, se obtiene un valor de cumplimiento global del $80,65 \%$, obteniéndose una variación porcentual muy próxima a los trece puntos entre la sede con mayor cumplimiento (Guadalajara, con un $88,50 \%$ ) y la sede con menor cumplimiento (Albacete, con un $75,60 \%$ ), lo que denota un cumplimiento heterogéneo para las cuatro sedes analizadas.

Los datos recogidos para el segundo período muestran un cumplimiento muy similar del requisito con respecto al primer período, con un $80,42 \%$ sobre el global para este período tiempo. Analizando los datos en detalle, se muestra una variación porcentual cercana a los ocho puntos y medio entre la sede con mayor cumplimiento (Toledo, con un 86,33\%) y la sede con menor cumplimiento (Guadalajara, con un $78,00 \%$, invirtiendo la tendencia mostrada para el primer período, en donde era la sede con mayor porcentaje de cumplimiento). 


\subsubsection{1. ¿SE EVALÚA CADA FASE/TRABAJO/PUESTOIACTIVIDAD DE LA OBRA EN EL PLAN DE FORMA ESPECÍFICA?}

Este subapartado, directamente relacionado con el aparatado anterior, muestra los casos en los que los riesgos y las medidas preventivas contempladas en cada fase/trabajo/puesto y/o actividad son específicos de ese trabajo/puesto y/o actividad; siempre que se cumpla la premisa de existir una Evaluación de Riesgos que se integra en el Plan de Seguridad y Salud. Con ello, se pretende obviar la práctica habitual del copia-pega para intentar conseguir documentos lo más extensos posibles, así como genéricos, pero sin ningún valor a nivel preventivo.

Para ello, se evalúa que dichas medidas preventivas se ajusten a lo descrito en la fase/trabajo/puesto y/o actividad, recopilando los resultados obtenidos en la Tabla 5.25.

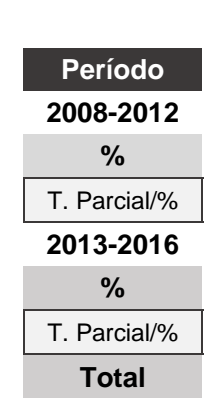

\begin{tabular}{|c|c|c|c|c|}
\hline Albacete & Ciudad Real & Cuenca & Guadalajara & Toledo \\
\hline 76 & 54 & 31 & 53 & - \\
\hline 15,20 & 10,80 & 10,33 & 13,25 & - \\
\hline \multicolumn{5}{|c|}{$214(12,59 \%)$} \\
\hline 69 & 37 & 48 & 71 & 58 \\
\hline 17,25 & 9,25 & 12,00 & 17,75 & 19,33 \\
\hline \multicolumn{5}{|c|}{$283(14,89 \%)$} \\
\hline & & $97(13,81$ & & \\
\hline
\end{tabular}

Tabla 5.25. Volumen de Planes de Seguridad y Salud consultados que cumplen con el requisito del presente apartado, organizados por período de tiempo y sede provincial (por orden alfabético) de Castilla-La Mancha con inclusión de totales parciales por período y total global sobre el conjunto de PSSs consultados.

De un primer vistazo se observa cómo se produce una considerable reducción en los valores de los porcentajes con respecto a los resultados obtenidos en el aparatado anterior, lo que es claramente significativo de la práctica tan extendida del copia-pega, de la falta de personalización de este documento preventivo, que es reutilizado una y otra vez para distintas obras y trabajos. Sobre el cómputo global de los 3.600 PSSs consultados, se obtienen unos valores de cumplimiento del $13,81 \%$, lo que pone de manifiesto el escaso cumplimiento que de este requisito se hace.

Los datos globales de cumplimiento son muy similares a los correspondientes a ambos períodos de tiempo consultados. Para el primer período, se obtiene un 
total parcial del $12,59 \%$, lo que muestra un bajo índice de cumplimiento para este requisito. Si se analizan el total de las cuatro sedes que atañen a este período, se aprecia una diferencia porcentual inferior a los cinco puntos, entre la sede con mayor porcentaje de cumplimiento (Albacete, con un 15,20\%) y la sede con menos casos registrados (Cuenca, con un 10,33\%), lo que implica porcentajes homogéneos de cumplimiento.

En lo relativo al segundo período, se obtiene un porcentaje de cumplimiento del $14,89 \%$, lo que indica una baja tasa de cumplimiento. Analizando en detalle las cinco sedes que conforman este período, se obtiene una diferencia porcentual muy próxima a los diez puntos, entre la sede con más casos registrados (Toledo, con un 19,33\%) y la sede con menos casos registrados (Ciudad Real, con un $9,25 \%)$. 


\subsection{2. ¿SE IDENTIFICA EN EL PSS LA MAQUINARIA/EQUIPOS QUE SE PREVÉN EMPLEAR EN LA OBRA?}

El presente apartado se centra en si en el Plan de Seguridad y Salud aparece recogida la maquinaria/equipos que se van a utilizar en la obra. Esto se torna de vital importancia de cara a poder evaluar los riesgos derivados de la utilización de dicha maquinaria, necesitando operarios con formación específica en algunos de los casos, además de tener que prever la circulación simultánea de maquinaria y operarios, por lo que se han de llevar a cabo medidas para evitar posibles accidentes derivados de la circulación y de las zonas de paso.

Los resultados referidos al cumplimiento del citado requisito se exponen en la Tabla 5.26, que analiza el total de los PSSs examinados para el período de tiempo establecido.

\begin{tabular}{|c|c|c|c|c|c|}
\hline & \multicolumn{5}{|c|}{ PSS identifica la maquinaria/equipos que se emplean en obra } \\
\hline Período & Albacete & Ciudad Real & Cuenca & Guadalajara & Toledo \\
\hline 2008-2012 & 61 & 49 & 45 & 77 & - \\
\hline$\%$ & 12,20 & 9,80 & 15,00 & 19,25 & - \\
\hline T. Parcial/\% & \multicolumn{5}{|c|}{$232(13,65 \%)$} \\
\hline 2013-2016 & 69 & 73 & 86 & 63 & 59 \\
\hline$\%$ & 17,25 & 18,25 & 21,50 & 15,75 & 19,67 \\
\hline T. Parcial/\% & \multicolumn{5}{|c|}{$350(\mathbf{1 8 , 4 2 \% )}$} \\
\hline Total & \multicolumn{5}{|c|}{$582(16,17 \%)$} \\
\hline
\end{tabular}

Tabla 5.26. Volumen de Planes de Seguridad y Salud consultados que cumplen con el requisito del presente apartado, organizados por período de tiempo y sede provincial (por orden alfabético) de Castilla-La Mancha con inclusión de totales parciales por período y total global sobre el conjunto de PSSs consultados.

El porcentaje de cumplimiento para el primer período de tiempo se sitúa por debajo del 15,00\%, concretamente en el 13,65\%. La diferencia porcentual que se produce entre la sede con más casos registrados (Guadalajara, con un 19,25\%) y la sede con menor cumplimiento (Ciudad Real, con un 9,80\%) es cercana a los diez puntos.

Ya para el segundo período se produce un incremento muy próximo a los cinco puntos porcentuales en el cumplimiento de este requisito, situando el total parcial correspondiente a este período en un $18,42 \%$. Sobre el total de las cinco sedes analizadas, se produce una diferencia próxima a los seis puntos porcentuales, entre la sede con mayor cumplimiento (Cuenca, con un 21,50\%) y la de menor cumplimiento (Guadalajara, con $15,75 \%$, lo que produce una inversión en la 
tendencia con respecto al primer período, en el que esta sede se situaba como la sede con mayor tasa de cumplimiento). Las tasas de cumplimiento para este período son bastante homogéneas para las cinco sedes.

Por último, el porcentaje de cumplimiento global para el total de las sedes visitadas y períodos consultados es inferior al 20,00\%, situándose en un $16,17 \%$, lo que implica un cumplimiento bajo para el citado requisito. 


\subsubsection{1. ¿SE IDENTIFICA Y EVALÚA LA MAQUINARIA/EQUIPOS QUE SE PREVÉN EMPLEAR EN LA OBRA?}

El presente subapartado, estrechamente relacionado con el apartado 5.4.2., analiza los casos en los que aparece recogida la maquinaria/equipos que se van a utilizar en la obra, y a la vez, éstos se evalúan, incluyéndose en el Plan de Seguridad y Salud. De esta forma, se evita el incluir maquinaria de forma genérica en el Plan y se asegura que el redactor del Plan realiza un ejercicio de implicación en la planificación preventiva de la obra, teniendo que consultar con el contratista la maquinaria/equipos que va a emplear en la obra. Para que dicha evaluación de la maquinaria/equipo que se va a emplear en obra pueda ser considerada como específica, se ha de incluir la marca, el modelo, así como la declaración de conformidad del marcado "CE" o en su caso, la puesta en conformidad según el Real Decreto 1215/97 (BOE, 1997c), según proceda para cada equipo/maquinaria evaluada.

En la Tabla 5.27 se publican los resultados obtenidos con respecto al cumplimiento para el requisito establecido en el presente apartado.

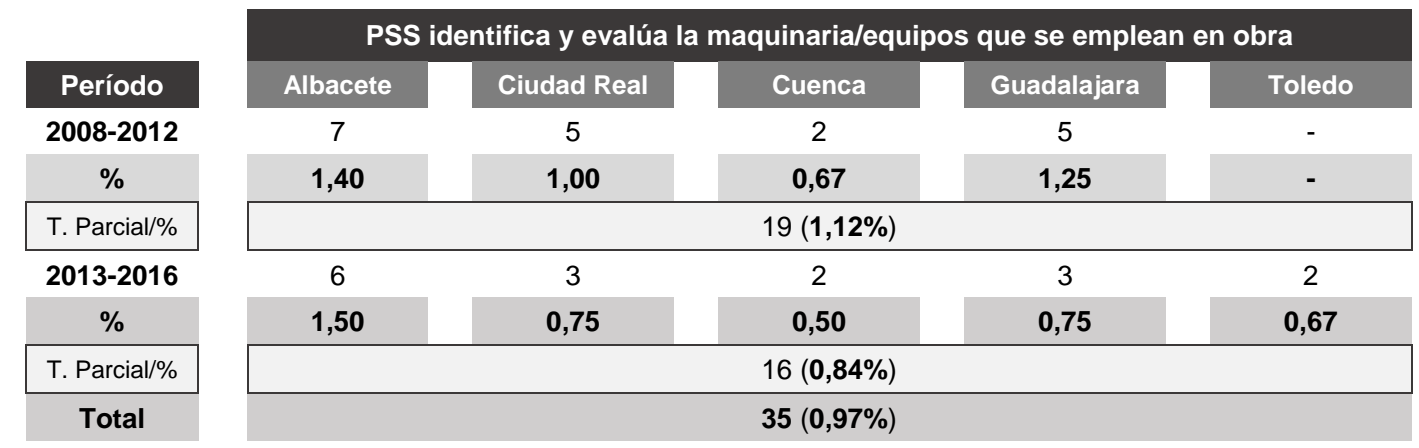

Tabla 5.27. Volumen de Planes de Seguridad y Salud consultados que cumplen con el requisito del presente apartado, organizados por período de tiempo y sede provincial (por orden alfabético) de Castilla-La Mancha con inclusión de totales parciales por período y total global sobre el conjunto de PSSs consultados.

Sobre el cómputo global de PSSs consultados, se obtienen datos de cumplimiento muy cercanos al 1,00\%, concretamente del $0,97 \%$, lo que indica el prácticamente nulo cumplimiento que de este requisito se hace, ya que realizarlo de forma correcta conlleva de labores de implicación en la redacción del Plan, estar en contacto con el contratista y todas las empresas que vayan a realizar trabajos en la obra, para poder integrar la maquinaria/equipos que vayan a utilizar. El porcentaje de cumplimiento es muy similar para ambos períodos, 
produciéndose un descenso en el cumplimiento en el segundo período, con respecto a los datos obtenidos en el primer período.

Para el primer período se obtienen unos datos sobre el total parcial del $1,12 \%$, lo que implica un muy bajo cumplimiento de este requisito. En lo que respecta a las cuatro sedes que atañen a este período, se produce una diferencia porcentual de tan solo cero con setenta y tres puntos, inferior al punto porcentual, entre la sede con mayor número de casos registrados (Albacete, con un 1,40\%) y la sede con menor cumplimiento del citado requisito (Cuenca, con un $0,67 \%$ ) para las cuatro sedes que integran este período.

Para finalizar, en lo que respecta al segundo período, se obtiene un total parcial inferior al $1,00 \%$, en concreto del $0,84 \%$, muy en consonancia con los datos obtenidos en el primer período. La diferencia porcentual que se obtiene en este período es de un punto, entre la sede con mayor cumplimiento (Albacete, con un 1,50\%), y la sede con menor cumplimiento (Cuenca, con un 0,50\%), sobre el total de las cinco sedes. Se puede apreciar que la sede con mayor y menor cumplimiento coinciden con las obtenidas en el primer período. 


\subsection{3. ¿SE IDENTIFICAN EN EL PSS LOS MEDIOS AUXILIARES QUE SE PREVÉN EMPLEAR EN OBRA?}

En este apartado se estudia la inclusión en el Plan de Seguridad y Salud de los medios auxiliares que se vayan a utilizar en la obra, lo que implica identificar la clase, y el tipo de medio auxiliar, o la marca y modelo.

Conforme a la definición que establece el Diccionario de la Construcción (FLC, 2018), de la Fundación Laboral de la Construcción, para los medios auxiliares: “En construcción, se entiende como medio auxiliar y equipo técnico cualquier máquina, aparato, instrumento o instalación utilizado en el trabajo. Algunos ejemplos son: plataformas de carga y descarga, escaleras, eslingas, puntales, etc. Estos medios introducen, en ocasiones, una serie de riesgos que pueden dar lugar a numerosos accidentes, llegando a ser graves en algunos casos. Los riesgos se producen, en general, por un montaje incorrecto o por una utilización imprudente." se analizan los medios auxiliares presentes en la obra de construcción que quedan recogidos en el documento preventivo.

Los resultados obtenidos del análisis de los PSSs consultados, se recogen a modo de resumen en la Tabla 5.28, que muestra los resultados organizados por sedes y períodos de tiempo establecidos.

\begin{tabular}{|c|c|c|c|c|c|}
\hline \multirow[b]{2}{*}{ Período } & \multicolumn{5}{|c|}{ PSS identifica los medios auxiliares que se prevén emplear en obra } \\
\hline & Albacete & Ciudad Real & Cuenca & Guadalajara & Toledo \\
\hline 2008-2012 & 50 & 49 & 46 & 78 & - \\
\hline$\%$ & 10,00 & 9,80 & 15,33 & 19,50 & - \\
\hline T. Parcial/\% & \multicolumn{5}{|c|}{$223(13,12 \%)$} \\
\hline $2013-2016$ & 67 & 73 & 86 & 65 & 60 \\
\hline$\%$ & 16,75 & 18,25 & 21,50 & 16,25 & 20,00 \\
\hline T. Parcial/\% & \multicolumn{5}{|c|}{$351(\mathbf{1 8 , 4 7 \% )}$} \\
\hline Total & \multicolumn{5}{|c|}{574 (15,94\%) } \\
\hline
\end{tabular}

Tabla 5.28. Volumen de Planes de Seguridad y Salud consultados que cumplen con el requisito del presente apartado, organizados por período de tiempo y sede provincial (por orden alfabético) de Castilla-La Mancha con inclusión de totales parciales por período y total global sobre el conjunto de PSSs consultados.

El porcentaje de cumplimiento del citado requisito sobre el cómputo global de PSSs examinados se mantiene bajo, con un 15,94\%, por debajo del 20,00\%. Esto implica deficiencias en la planificación preventiva y posterior redacción del Plan de Seguridad y Salud, que ha de ir acorde a la planificación previa de los 
trabajos, maquinaria a emplear, figuras y trabajadores intervinientes en la obra, etc.

Para el primer período de tiempo, la tasa de cumplimiento se sitúa en un $13,12 \%$, produciéndose una diferencia porcentual próxima a los diez puntos entre la sede con mayor cumplimiento (Guadalajara, con un 19,50\%) y la sede con menor cumplimiento (Ciudad Real, con un 9,80\%), lo que indica una distribución homogénea para las cuatro sedes que conforman este período.

En el segundo período, se produce un incremento con respecto a la tasa de cumplimiento vista en el primer período, con una diferencia porcentual de cinco con treinta y cinco puntos entre ambos períodos. El porcentaje de cumplimiento sobre el total parcial para este período se sitúa en un 18,47\%, muy próximo al $20,00 \%$, lo que implica un cumplimiento bajo pero aceptable de este requisito. Ya en lo referente a las cinco sedes que integran este período, el cumplimiento es homogéneo, con una diferencia porcentual de tan solo cinco con veinticinco puntos, entre la sede con mayor cumplimiento (Cuenca, con un 21,50\%) y la sede con menor cumplimiento (Guadalajara, con un $16,25 \%$, lo que indica un cambio en la tendencia con respecto al primer período en el que esta sede se posicionó como la de mayor cumplimiento). 


\subsubsection{1. ¿SE IDENTIFICAN Y EVALÚAN LOS MEDIOS AUXILIARES QUE SE PREVÉN EMPLEAR EN LA OBRA?}

Este subapartado, directamente relacionado con el apartado 5.4.3., se analizan los PSSs en los que además de aparecer identificados los medios auxiliares que se vayan a utilizar en la obra, éstos se evalúan, con cualquiera de los métodos de evaluación existentes.

En la Tabla 5.29 se recopilan los resultados obtenidos de la consulta de los PSSs para las cinco sedes y períodos de tiempo contemplados en el presente estudio.

\begin{tabular}{|c|c|c|c|c|c|}
\hline & \multicolumn{5}{|c|}{ PSS identifica y evalúa los medios auxiliares que se prevén emplear en obra } \\
\hline Período & Albacete & Ciudad Real & Cuenca & Guadalajara & Toledo \\
\hline 2008-2012 & 43 & 40 & 39 & 71 & - \\
\hline$\%$ & 8,60 & 8,00 & 13,00 & 17,75 & - \\
\hline T. Parcial/\% & \multicolumn{5}{|c|}{$193(11,35 \%)$} \\
\hline $2013-2016$ & 59 & 67 & 77 & 58 & 53 \\
\hline$\%$ & 14,75 & 16,75 & 19,25 & 14,50 & 17,67 \\
\hline T. Parcial/\% & \multicolumn{5}{|c|}{$314(16,53 \%)$} \\
\hline Total & \multicolumn{5}{|c|}{$507(14,08 \%)$} \\
\hline
\end{tabular}

Tabla 5.29. Volumen de Planes de Seguridad y Salud consultados que cumplen con el requisito del presente apartado, organizados por período de tiempo y sede provincial (por orden alfabético) de Castilla-La Mancha con inclusión de totales parciales por período y total global sobre el conjunto de PSSs consultados.

Con respecto al cómputo global de PSSs consultados, se observa un leve descenso con respecto a los datos obtenidos en el apartado anterior, situándose por debajo del 15,00\%, concretamente en el 14,08\%. En cualquier caso, se siguen encontrando en tasas de cumplimiento bajo.

Para el primer período de tiempo se obtiene un total parcial del 11,35\%, con una diferencia porcentual muy próxima a los diez puntos, entre la sede con más casos registrados (Guadalajara, con un $17,75 \%$ ) y la sede con menos casos (Ciudad Real, con un 8,00\%), lo que implica un cumplimiento heterogéneo entre los datos obtenidos en las cuatro sedes.

El total parcial obtenido en el segundo período es del $16,53 \%$, con una diferencia cercana a los cinco puntos porcentuales entre la sede con mayor cumplimiento (Cuenca, con un 19,25\%) y la sede con menor cumplimiento (Guadalajara, con un $14,50 \%)$. 


\subsubsection{2. ¿SE INCLUYE EL MANUAL DE INSTRUCCIONES YIO PROCEDIMIENTOS DE MONTAJE/DESMONTAJE/UTILIZACIÓN DE LOS MEDIOS AUXILIARES QUE SE PREVÉN EMPLEAR EN LA OBRA?}

En este subapartado, que guarda relación directa con los apartados predecesores, se recogen los PSSs que incluyen el manual de instrucciones para el correcto montaje de ese medio auxiliar o plan de montaje, utilización y desmontaje, o que en su defecto, incluyan procedimientos de trabajo seguros. Que se incluya este tipo de información en el Plan, ayuda a la hora de integrar la prevención en las labores de montaje/desmontaje de los medios auxiliares.

Los resultados obtenidos del análisis de los PSSs con respecto al cumplimiento del citado requisito se recogen en la Tabla 5.30 que se muestra a continuación.

\begin{tabular}{|c|c|c|c|c|c|}
\hline & \multicolumn{5}{|c|}{$\begin{array}{l}\text { PSS incluye el manual de instrucciones ylo procedimientos } \\
\text { de los medios auxiliares que se prevén emplear en obra }\end{array}$} \\
\hline Período & Albacete & Ciudad Real & Cuenca & Guadalajara & Toledo \\
\hline 2008-2012 & 21 & 26 & 22 & 55 & - \\
\hline$\%$ & 4,20 & 5,20 & 7,33 & 13,75 & - \\
\hline T. Parcial/\% & \multicolumn{5}{|c|}{$124(7,29 \%)$} \\
\hline 2013-2016 & 30 & 31 & 40 & 26 & 24 \\
\hline$\%$ & 7,50 & 7,75 & 10,00 & 6,50 & 8,00 \\
\hline T. Parcial/\% & \multicolumn{5}{|c|}{$151(7,95 \%)$} \\
\hline Total & \multicolumn{5}{|c|}{$275(7,64 \%)$} \\
\hline
\end{tabular}

Tabla 5.30. Volumen de Planes de Seguridad y Salud consultados que cumplen con el requisito del presente apartado, organizados por período de tiempo y sede provincial (por orden alfabético) de Castilla-La Mancha con inclusión de totales parciales por período y total global sobre el conjunto de PSSs consultados.

Si bien es cierto que el porcentaje global de cumplimiento es inferior al 8,00\%, y a priori se trataría de un porcentaje muy bajo de cumplimiento, en verdad es un porcentaje alto debido a que se trata de un requisito muy específico y que es raro de encontrar en los Planes. El porcentaje de cumplimiento es muy similar para ambos períodos de tiempo, con una diferencia porcentual inferior al punto, en concreto, de cero con sesenta y seis puntos.

La tasa de cumplimiento para el primer período se sitúa en un $7,29 \%$, con una diferencia porcentual próxima a los diez puntos, entre la sede con mayor porcentaje de cumplimiento (Guadalajara, con un 13,75\%) y la sede con menor porcentaje de cumplimiento (Albacete, con un 4,20\%). 
En lo que respecta al segundo período, se obtiene un porcentaje de cumplimiento del 7,95\%, similar al obtenido en el primer período. La diferencia porcentual que se obtiene entre la sede con mayor porcentaje de cumplimiento (Cuenca, con un 10,00\%) y la sede con menor porcentaje de cumplimiento (Guadalajara, con un 6,50\%) es inferior a los cuatro puntos, lo que muestra un cumplimiento homogéneo para los parciales de las cinco sedes. 


\subsection{4. ¿SE INCLUYEN EN EL PSS LOS PRODUCTOS QUÍMICOS QUE SE VAN A EMPLEAR EN LA OBRA?}

En este apartado se recopilan los PSSs que identifican los productos químicos que se van a emplear en la obra. Este requisito se torna de vital importancia a la hora de realizar una correcta planificación e integración de la prevención en la obra, al prever los EPIs y medidas de seguridad que se han de contemplar durante su manipulación y almacenaje en la obra. Puesto que se trata de productos que entrañan riesgos específicos para la salud de los operarios, que pueden producir diversas afecciones en la piel, e intoxicaciones por inhalación, etc., éstos han de quedar recogidos en el Plan.

En la Tabla 5.31 se exponen los resultados obtenidos en el estudio relativos al cumplimiento del presente requisito.

\begin{tabular}{|c|c|c|c|c|c|}
\hline & \multicolumn{5}{|c|}{ PSS incluye los productos químicos que se van a emplear en obra } \\
\hline Período & Albacete & Ciudad Real & Cuenca & Guadalajara & Toledo \\
\hline 2008-2012 & 99 & 107 & 61 & 74 & - \\
\hline$\%$ & 19,80 & 21,40 & 20,33 & 18,50 & - \\
\hline T. Parcial $/ \%$ & \multicolumn{5}{|c|}{$341(20,06 \%)$} \\
\hline 2013-2016 & 102 & 100 & 98 & 105 & 73 \\
\hline$\%$ & 25,50 & 25,00 & 24,50 & 26,25 & 24,33 \\
\hline T. Parcial/\% & \multicolumn{5}{|c|}{$478(25,16 \%)$} \\
\hline Total & \multicolumn{5}{|c|}{$819(22,75 \%)$} \\
\hline
\end{tabular}

Tabla 5.31. Volumen de Planes de Seguridad y Salud consultados que cumplen con el requisito del presente apartado, organizados por período de tiempo y sede provincial (por orden alfabético) de Castilla-La Mancha con inclusión de totales parciales por período y total global sobre el conjunto de PSSs consultados.

Sobre el cómputo global de PSSs analizados, se obtiene un porcentaje de cumplimiento del $22,75 \%$, lo que implica un cumplimiento bajo. El porcentaje parcial para ambos períodos es bastante similar, con una diferencia porcentual de tan sólo cinco puntos, lo que se traduce en un cumplimiento homogéneo del requisito.

En el primer período, se obtiene una tasa de cumplimiento del $20,06 \%$ sobre el total parcial, con una diferencia muy próxima a los tres puntos porcentuales en las cuatro sedes, lo que indica unos valores de cumplimiento del requisito muy similares. Ciudad Real se sitúa como la sede con más casos registrados, con un $21,40 \%$, frente al $18,50 \%$ de Guadalajara, que se sitúa como la sede con menos casos registrados. 
Para el segundo período, se obtiene un total parcial del $25,16 \%$, muy similar al obtenido en el primer período. Se produce una discrepancia cercana a los dos puntos porcentuales entre las sedes con mayor tasa de cumplimiento (Guadalajara, con un 26,25\%) y la sede con menor tasa de cumplimiento (Toledo, con un $24,33 \%$ ), de entre el total de las cinco sedes que conforman este período. 


\subsubsection{1. ¿SE INCLUYEN LAS FICHAS DE SEGURIDAD DE LOS PRODUCTOS QUÍMICOS QUE SE VAN A EMPLEAR EN OBRA EN EL PSS?}

En este subapartado, que viene condicionado por los resultados recogidos en el apartado 5.4.4., se compilan los PSSs que además de identificar los productos químicos que se van a emplear en la obra, incluyen las fichas de seguridad de los mismos. Las fichas de seguridad de los productos se tornan de vital importancia al contener toda la información y riesgos del producto, así como información relativa a la actuación ante emergencias o percances con los mismos.

Los resultados relativos al cumplimiento del presente requisito quedan recolectados y expuestos en la Tabla 5.32.

\begin{tabular}{|c|c|c|c|c|c|}
\hline \multirow[b]{2}{*}{ Período } & \multicolumn{5}{|c|}{$\begin{array}{l}\text { PSS incluye las fichas de seguridad de los productos químicos } \\
\text { que se van a emplear en obra }\end{array}$} \\
\hline & Albacete & Ciudad Real & Cuenca & Guadalajara & Toledo \\
\hline 2008-2012 & 0 & 0 & 0 & 0 & - \\
\hline$\%$ & 0,00 & 0,00 & 0,00 & 0,00 & - \\
\hline T. Parcial $/ \%$ & \multicolumn{5}{|c|}{$0(\mathbf{0}, \mathbf{0 0 \%})$} \\
\hline 2013-2016 & 0 & 0 & 0 & 0 & 0 \\
\hline$\%$ & 0,00 & 0,00 & 0,00 & 0,00 & 0,00 \\
\hline T. Parcial/\% & \multicolumn{5}{|c|}{$0(\mathbf{0}, \mathbf{0 0} \%)$} \\
\hline Total & \multicolumn{5}{|c|}{$0(0,00 \%)$} \\
\hline
\end{tabular}

Tabla 5.32. Volumen de Planes de Seguridad y Salud consultados que cumplen con el requisito del presente apartado, organizados por período de tiempo y sede provincial (por orden alfabético) de Castilla-La Mancha con inclusión de totales parciales por período y total global sobre el conjunto de PSSs consultados.

Sorprendentemente, no se han encontrado PSSs que cumplan con el citado requisito, para ninguna de las sedes ni períodos consultados, si bien es cierto que las expectativas no eran del todo optimistas. 


\subsubsection{LA EVALUACIÓN DE RIESGOS INTEGRADA EN EL PSS ¿SE AJUSTA A LO DETERMINADO EN EL ARTÍCULO 7 DEL REAL DECRETO 39/1997?}

En este apartado se pretende responder a la siguiente pregunta: En los casos en los que existe Evaluación de Riesgos integrada en el Plan de Seguridad y Salud ¿se ajusta ésta a lo marcado en el artículo 7 del Real Decreto 39/1997?

De esta forma se comprueba el mero cumplimiento de la legislación vigente en materia de prevención a la hora de redactar el Plan de Seguridad y Salud, que repercutirá de forma positiva en la correcta integración de la prevención en las actividades/trabajos de la obra. Los resultados obtenidos a propósito del presente estudio se exponen en la Tabla 5.33.

\begin{tabular}{|c|c|c|c|c|c|}
\hline \multirow[b]{2}{*}{ Período } & \multicolumn{5}{|c|}{$\begin{array}{c}\text { La Evaluación de Riesgos integrada en el PSS se ajusta a lo } \\
\text { determinado en el artículo } 7\end{array}$} \\
\hline & Albacete & Ciudad Real & Cuenca & Guadalajara & Toledo \\
\hline 2008-2012 & 0 & 1 & 2 & 0 & - \\
\hline$\%$ & 0,00 & 0,20 & 0,67 & 0,00 & - \\
\hline T. Parcial/\% & \multicolumn{5}{|c|}{$3(0,18 \%)$} \\
\hline $2013-2016$ & 7 & 2 & 0 & 1 & 0 \\
\hline$\%$ & 1,75 & 0,50 & 0,00 & 0,25 & 0,00 \\
\hline T. Parcial/\% $\%$ & \multicolumn{5}{|c|}{$10(0,53 \%)$} \\
\hline Total & \multicolumn{5}{|c|}{$13(0,36 \%)$} \\
\hline
\end{tabular}

Tabla 5.33. Volumen de Planes de Seguridad y Salud consultados que cumplen con el requisito del presente apartado, organizados por período de tiempo y sede provincial (por orden alfabético) de Castilla-La Mancha con inclusión de totales parciales por período y total global sobre el conjunto de PSSs consultados.

Sobre el cómputo global de los 3.600 PSSs estudiados, se anota un ínfimo $0,36 \%$ de cumplimiento sobre el citado requisito, lo que no puede siquiera ser tenido en cuenta al no alcanzar el 1,00\%. Porcentajes similares son los obtenidos para el primer y segundo período de tiempo, con datos que en ningún caso alcanzan el punto porcentual.

Para el primer período de tiempo se obtiene un 0,18\% sobre el total parcial, lo que denota el nulo cumplimiento de este requisito legislativo. La diferencia porcentual obtenida entre la sede con mayor cumplimiento (Cuenca, con un 0,67\%) y la de menor cumplimiento (Ciudad Real, con un 0,20\%) es de tan sólo medio punto. También se ha de mencionar que las otras dos sedes restantes no contienen ningún Plan que cumpla con el citado requisito, lo que resulta significativo del nulo interés que se muestra por el cumplimiento de este 
importante requisito que recoge el artículo 7 del Real Decreto 39/1997(BOE, 1997a).

Ya en lo referente al segundo período de tiempo consultado, si bien es cierto que se produce un incremento inferior al medio punto porcentual con respecto al primer período, se siguen obteniendo valores de cumplimiento prácticamente nulos, con un $0,53 \%$; en cualquier caso, hablamos de porcentajes inferiores al punto porcentual, por lo que no pueden ser tenidos en consideración. La diferencia porcentual que se produce para este período es de un punto y medio, lo que denota cumplimientos homogéneos para las cinco sedes analizadas, con Albacete como la sede con mayor cumplimiento, con un 1,75\%, en comparación con Guadalajara, como la sede con menor cumplimiento, con un $0,25 \%$. Entre medias de ambas sedes se encuentra Ciudad Real, con un 0,50\% de cumplimiento. Se ha de mencionar que las dos sedes restantes, Cuenca y Toledo, muestran un cumplimiento nulo, con valores del $0,00 \%$. 


\subsection{6. ¿EXISTE PLANIFICACIÓN PREVENTIVA EN EL PSS COMO RESULTADO DE LA EVALUACIÓN DE RIESGOS?}

Para el presente apartado, se centra las miras en la existencia o no de una planificación preventiva de la obra como resultado de la Evaluación de Riesgos.

La planificación preventiva de la obra resulta de vital importancia para contemplar y prevenir todos los riesgos que puedan darse durante el transcurso de la obra hasta su completa finalización.

Esta planificación preventiva de la obra descrita requiere de un estudio previo de la misma, de sus fases, de los solapes entre los trabajos que se producen en obra, de los tiempos estimados para la ejecución de cada fase del proyecto, lo que guarda relación directa con lo visto en el apartado 5.3.1., sobre el cronograma de la obra o diagrama de Gantt. De esta forma se concibe la obra como un todo, un conjunto conformado por la suma de muchas partes y de las relaciones directas e indirectas que se establecen entre cada una de las partes con otras. Los resultados relativos al cumplimiento de este requisito son los que siguen, y que quedan recogidos en la Tabla 5.34.

\begin{tabular}{|c|c|c|c|c|c|}
\hline \multirow[b]{2}{*}{ Período } & \multicolumn{5}{|c|}{$\begin{array}{c}\text { Existe planificación preventiva en el PSS como resultado } \\
\text { de la Evaluación de Riesgos }\end{array}$} \\
\hline & Albacete & Ciudad Real & Cuenca & Guadalajara & Toledo \\
\hline 2008-2012 & 0 & 1 & 0 & 0 & - \\
\hline$\%$ & 0,00 & 0,20 & 0,00 & 0,00 & - \\
\hline T. Parcial/\% & \multicolumn{5}{|c|}{$1(0,06 \%)$} \\
\hline 2013-2016 & 2 & 0 & 3 & 2 & 0 \\
\hline$\%$ & 0,50 & 0,00 & 0,75 & 0,50 & 0,00 \\
\hline T. Parcial/\% & \multicolumn{5}{|c|}{$7(0,37 \%)$} \\
\hline Total & \multicolumn{5}{|c|}{$8(0,22 \%)$} \\
\hline
\end{tabular}

Tabla 5.34. Volumen de Planes de Seguridad y Salud consultados que cumplen con el requisito del presente apartado, organizados por período de tiempo y sede provincial (por orden alfabético) de Castilla-La Mancha con inclusión de totales parciales por período y total global sobre el conjunto de PSSs consultados.

Como en el caso del apartado anterior, se vuelve a encontrar un porcentaje de cumplimiento sobre el cómputo global de los 3.600 PSSs analizados inferiores al medio punto porcentual (concretamente del $0,22 \%$ ), lo que indica el nulo cumplimiento que se hace del citado requisito.

El cumplimiento total parcial para el primer período de tiempo estudiado es prácticamente nulo, con un ínfimo $0,06 \%$, lo que hace que se encuentre más 
próximo del cero que del uno por ciento. Para este período, encontramos que de las cuatro sedes, únicamente la sede de Ciudad Real cuenta con un 0,20\% de cumplimiento, dejando tanto a Albacete, como a Cuenca y a Guadalajara con un $0 \%$ de casos consultados que presenten cumplimiento del citado requisito.

Ya en el segundo período de tiempo, se produce un incremento cercano al medio punto porcentual sobre el total parcial obtenido para el primer período de tiempo, en concreto para este período, se obtiene un cumplimiento parcial del 0,37\%. La diferencia porcentual que se produce entre la sede con mayor cumplimiento (Cuenca, con un 0,75\%) frente a la sede con menor cumplimiento de este requisito (Albacete y Guadalajara, ambas con un 0,50\%) es de tan solo cero con veinticinco puntos porcentuales, dejando las sedes de Ciudad Real y Toledo con un cumplimiento nulo, del 0,00\%. 


\subsubsection{LA PLANIFICACIÓN PREVENTIVA RECOGIDA EN EL PSS, ¿SE AJUSTA A LO DISPUESTO EN EL ARTÍCULO 9 DEL REAL DECRETO 39/1997?}

En este subapartado, que guarda relación directa con el apartado anterior (apartado 5.4.6.), se estudian los PSSs en los que, en el caso de existir la planificación preventiva integrada en el Plan de Seguridad y Salud, ésta se ajusta a lo dispuesto en el artículo 9 del Real Decreto 39/1997 (BOE, 1997a).

Que la planificación preventiva se ajuste a lo establecido por la legislación vigente es importante de cara a conseguir unos criterios de unificación para todo el territorio nacional. De esta forma, en este apartado se constata el cumplimiento de dicho requisito conforme a lo expuesto en el artículo 9 del citado Real Decreto, no dejando lugar a interpretaciones, ya que se trata de verificar y constatar dicho cumplimiento.

En la Tabla 5.35 se registran, sobre el total de PSSs consultados para el período de tiempo establecido, el número de Planes que cumplen con el presente requisito.

\begin{tabular}{|c|c|c|c|c|c|}
\hline \multirow[b]{2}{*}{ Período } & \multicolumn{5}{|c|}{ La planificación preventiva en el PSS se ajusta al artículo 9} \\
\hline & Albacete & Ciudad Real & Cuenca & Guadalajara & Toledo \\
\hline 2008-2012 & 0 & 0 & 0 & 0 & - \\
\hline$\%$ & 0,00 & 0,00 & 0,00 & 0,00 & - \\
\hline T. Parcial/\% & \multicolumn{5}{|c|}{$0(0,00 \%)$} \\
\hline 2013-2016 & 0 & 0 & 0 & 0 & 0 \\
\hline$\%$ & 0,00 & 0,00 & 0,00 & 0,00 & 0,00 \\
\hline T. Parcial/\% & \multicolumn{5}{|c|}{$0(\mathbf{0 , 0 0 \% )}$} \\
\hline Total & \multicolumn{5}{|c|}{$0(0,00 \%)$} \\
\hline
\end{tabular}

Tabla 5.35. Volumen de Planes de Seguridad y Salud consultados que cumplen con el requisito del presente apartado, organizados por período de tiempo y sede provincial (por orden alfabético) de Castilla-La Mancha con inclusión de totales parciales por período y total global sobre el conjunto de PSSs consultados.

El cumplimiento para el citado requisito es nulo para el total de las cinco sedes consultadas durante los dos períodos de tiempo contemplados (de 2008 a 2012 y de 2013 a 2016), lo que demuestra una obediencia nula de la legislación vigente conforme a este requisito de extrema importancia de cara a integrar la prevención en la planificación de los trabajos de la obra. 


\subsection{ANOMALÍAS E INCIDENCIAS RESEÑABLES}

En este último apartado, perteneciente al capítulo de resultados del estudio, se recogen todos aquellos hechos constatados durante las labores de análisis de los PSSs, que a pesar de no estar incluidos dentro de los distintos apartados que integra el checklist (Anexo I), es debido a su interés académico que se ha decidido incluirlos. Es por ello, que este último aparatado podría clasificarse como "cajón de sastre" o "miscelánea", por el hecho de integrar distintos aspectos de interés relativos a los PSSs consultados.

\subsubsection{EL PSS EN PAPEL, ¿ESTÁ VACÍO O EN BLANCO?}

Aunque en primera instancia pueda resultar sorpresivo, durante las labores de consulta de PSSs en las distintas sedes de la Autoridad Laboral de Castilla-La Mancha, se han encontrado PSSs que constaban únicamente de portada, quedando el contenido del plan vacío, con folios en blanco. Si bien es cierto que ésta no es una práctica habitual, el hallazgo no se limita a un único plan en una única sede, si no que se ha repetido el patrón en otras sedes, tal y como se recoge en la Tabla 5.36.

\begin{tabular}{|c|c|c|c|c|c|}
\hline \multirow[b]{2}{*}{ Período } & \multicolumn{5}{|c|}{ PSS en papel en blanco } \\
\hline & Albacete & Ciudad Real & Cuenca & Guadalajara & Toledo \\
\hline 2008-2012 & 2 & 1 & 1 & 0 & - \\
\hline$\%$ & 0,40 & 0,20 & 0,33 & 0,00 & - \\
\hline T. Parcial/\% & \multicolumn{5}{|c|}{$4(0,24 \%)$} \\
\hline 2013-2016 & 0 & 0 & 0 & 0 & 0 \\
\hline$\%$ & 0,00 & 0,00 & 0,00 & 0,00 & 0,00 \\
\hline T. Parcial/\% & \multicolumn{5}{|c|}{$0(0,00 \%)$} \\
\hline Total & \multicolumn{5}{|c|}{$4(0,11 \%)$} \\
\hline
\end{tabular}

Tabla 5.36. Volumen de Planes de Seguridad y Salud consultados que cumplen con el requisito del presente apartado, organizados por período de tiempo y sede provincial (por orden alfabético) de Castilla-La Mancha con inclusión de totales parciales por período y total global sobre el conjunto de PSSs consultados.

Los datos recogidos muestran que únicamente se han encontrado PSSs en blanco durante el primer período de tiempo estudiado, llegando a suponer un ínfimo $0,24 \%$ sobre el total parcial de las cuatro sedes. Lo que en cómputo global se traduce en un $0,11 \%$ de los PSSs consultados, lo que no deja de ser algo anecdótico, pero que ha de ser expuesto. Este fenómeno se produce 
debido a que el PSS pasa por ser un documento preventivo administrativo que habitualmente muere una vez que es registrado. La labor de la Autoridad Laboral no es la de revisarlo, si no la de registrarlo, por ello se han producido estos casos. Si bien es cierto que en honor a la verdad hay que indicar que en el caso de que se produzca un accidente en obra, entonces sí que se consulta el PSS, pero de no darse este supuesto, la vida del PSS termina al registrarse en Registro de la Autoridad Laboral pertinente. Esto facilita la mala praxis a la hora de elaborar este documento preventivo, como veremos a lo largo de los casos que quedan por exponer en el presente apartado de anomalías e incidencias reseñables. 


\subsubsection{EL CD QUE CONTIENE EL PSS, ¿ESTÁ VACío O NO SE PUEDE ABRIR?}

Si ya hemos visto en el apartado anterior los PSSs que, aun estando en papel, presentan deficiencias serias o graves, como encontrarse en blanco, ahora vamos a analizar los PSSs que encontrándose en formato digital (CD), se encuentran vacíos o no pueden ser abiertos. Si bien es cierto, que a día de hoy sigue sin ser obligatoria la tramitación online del Plan en Castilla-La Mancha, es desde el año 2013 que se produce un mayor incremento de presentaciones de PSSs en CD (frente al formato papel, aunque en muchos casos se encuentran con ambos formatos), debido a la comodidad que proporciona al usuario. Por ejemplo, se observa el caso de Castilla y León, que a lo largo del 2016 impulsó esta iniciativa, y que para 2018 realizará la implantación efectiva de la tramitación online del comunicado de apertura (JCYL, 2018) y el PSS a través de la plataforma habilitada para tal fin, a raíz de la implantación efectiva de la Ley 39/2015 (BOE, 2015). En el caso de Castilla-La Mancha, se sigue permitiendo la presentación en papel de dichos documentos, aunque se insta al usuario a utilizar la plataforma creada para tal fin. En la Tabla 5.37 se recoge de forma pormenorizada los PSSs que encontrándose en formato CD no contenían nada en su interior o que directamente no se podían abrir.

\begin{tabular}{|c|c|c|c|c|c|}
\hline & \multicolumn{5}{|c|}{ PSS en CD en blanco o no apertura } \\
\hline Período & Albacete & Ciudad Real & Cuenca & Guadalajara & Toledo \\
\hline 2008-2012 & 32 & 29 & 19 & 21 & - \\
\hline$\%$ & 6,40 & 5,80 & 6,33 & 5,25 & - \\
\hline T. Parcial/\% & \multicolumn{5}{|c|}{$101(5,94 \%)$} \\
\hline 2013-2016 & 38 & 42 & 37 & 35 & 31 \\
\hline$\%$ & 9,50 & 10,50 & 9,25 & 8,75 & 10,33 \\
\hline T. Parcial/\% & \multicolumn{5}{|c|}{$183(9,63 \%)$} \\
\hline Total & \multicolumn{5}{|c|}{$284(7,89 \%)$} \\
\hline
\end{tabular}

Tabla 5.37. Volumen de Planes de Seguridad y Salud consultados que cumplen con el requisito del presente apartado, organizados por período de tiempo y sede provincial (por orden alfabético) de Castilla-La Mancha con inclusión de totales parciales por período y total global sobre el conjunto de PSSs consultados.

Los datos recogidos muestran un claro aumento en el segundo período de tiempo analizado, lo que muestra una clara consonancia con el aumento de presentación de los PSSs en formato CD, frente al primer período de tiempo con clara prevalencia del papel sobre el CD. En el primer período de tiempo analizado, se observa un cumplimiento homogéneo del presente requerimiento, 
con una diferencia porcentual del entorno de un punto entre la sede con mayor número de CDs en blanco (Albacete, con un 6,40\%) y la sede con menor número de CDs en blanco (Guadalajara, con un 5,25\%), dejando un cómputo de 5,94\% para el total parcial de las cuatro sedes. Ya en el segundo período de tiempo analizado, se observa un aumento de casi cuatro puntos porcentuales con respecto al total parcial del primer período. Si se entra en detalle, se encuentra una distribución igualmente homogénea en las cinco sedes que conforman este segundo período, destacando Ciudad Real, con un 10,50\%. 


\subsubsection{EL PSS, ¿GUARDA RELACIÓN CON LA OBRA DESCRITA EN EL TÍTULO DEL DOCUMENTO?}

Otro de los hitos estudiados de gran importancia para poder entender la utilidad real o no de esta herramienta preventiva, es si guarda relación alguna con la obra que lleva por título el Plan. En este apartado se recogen todos aquellos planes que no guardan relación alguna entre el contenido del mismo y el título. Esto se torna meridiano con el siguiente ejemplo: para el contenido de un PSS que lleva por título de la obra "vivienda unifamiliar", se encontró que el contenido del mismo versa sobre la construcción de un polideportivo. Esto es más común de lo imaginable, por la razón que a continuación se expone, y es que entre PSSs presentados por una misma empresa para distintas obras, se aprecia que se reutiliza una y otra vez el primer plan presentado. Por ejemplo, una empresa que presenta un PSS para la ejecución de una vivienda unifamiliar, vuelve a presentar ese mismo PSS bajo distinto título para obras tan diversas como una nave, un polideportivo o incluso un edificio de viviendas. Llegados a este punto, hay que recordar lo ya mencionado en el apartado 5.5.1. del presente documento, que recoge la vida útil de este documento preventivo, que únicamente se registra, no se inspecciona o corrige a no ser que suceda un accidente en obra y se revise la documentación aportada. Es por ello, que en este apartado se recogen todos aquellos PSSs cuyo contenido no guarda relación alguna con el título del Plan.

Aunque se trata de una práctica no tan extendida, tal y como muestran los resultados obtenidos, sí que ha de ser recogida para intentar evitar este tipo de mala praxis en el futuro. En la Tabla 5.38 se muestran porcentajes de cumplimiento bastante homogéneos en ambos períodos de tiempo analizados, quedando el cómputo global de PSSs consultados con un porcentaje del 4,08\%, lo que muestra un bajo índice de este tipo de prácticas. 


\begin{tabular}{|c|c|c|c|c|c|}
\hline & \multicolumn{5}{|c|}{ PSS no guarda relación con la obra recogida en el título del mismo } \\
\hline Período & Albacete & Ciudad Real & Cuenca & Guadalajara & Toledo \\
\hline 2008-2012 & 18 & 19 & 11 & 15 & - \\
\hline$\%$ & 3,60 & 3,80 & 3,67 & 3,75 & - \\
\hline T. Parcial/\% & \multicolumn{5}{|c|}{$63(3,71 \%)$} \\
\hline 2013-2016 & 19 & 18 & 17 & 17 & 13 \\
\hline$\%$ & 4,75 & 4,50 & 4,25 & 4,25 & 4,33 \\
\hline T. Parcial/\% & \multicolumn{5}{|c|}{$84(4,42 \%)$} \\
\hline Total & \multicolumn{5}{|c|}{$147(4,08 \%)$} \\
\hline
\end{tabular}

Tabla 5.38. Volumen de Planes de Seguridad y Salud consultados que cumplen con el requisito del presente apartado, organizados por período de tiempo y sede provincial (por orden alfabético) de Castilla-La Mancha con inclusión de totales parciales por período y total global sobre el conjunto de PSSs consultados.

Los datos del primer período muestran una homogeneidad clara para con las cuatro sedes, obteniendo un total parcial del 3,71\%. En lo relativo al segundo período de tiempo estudiado. Se observa asimismo una homogeneidad parcial en los resultados de las cinco sedes analizadas, al igual que la presente durante el primer período de tiempo consultado, que deja un total parcial del 4,42\%. 


\subsection{4. ¿SE UTILIZA EL MISMO PSS PARA DISTINTAS OBRAS?}

Si en el apartado anterior se ha visto los casos en los que el PSS no guarda relación alguna con la obra que recoge el título del mismo, en este nuevo apartado se analiza los casos en los que se encontró un mismo PSS para distintas obras. Es de ley mencionar, que en estos casos suele tratarse de una misma empresa que utiliza el mismo Plan para sea cual sea la obra para la que presentan el PSS. Dicho esto, se pasa a analizar el cumplimiento de dicho requisito en la Tabla 5.39.

\begin{tabular}{|c|c|c|c|c|c|}
\hline \multirow[b]{2}{*}{ Período } & \multicolumn{5}{|c|}{ Mismo PSS para distintas obras } \\
\hline & Albacete & Ciudad Real & Cuenca & Guadalajara & Toledo \\
\hline 2008-2012 & 4 & 5 & 2 & 1 & - \\
\hline$\%$ & 0,80 & 1,00 & 0,67 & 0,25 & - \\
\hline T. Parcial/\% & \multicolumn{5}{|c|}{$12(0,71 \%)$} \\
\hline 2013-2016 & 3 & 4 & 3 & 3 & 3 \\
\hline$\%$ & 0,75 & 1,00 & 0,75 & 0,75 & 1,00 \\
\hline T. Parcial/\% & \multicolumn{5}{|c|}{$16(0,84 \%)$} \\
\hline Total & \multicolumn{5}{|c|}{$28(0,78 \%)$} \\
\hline
\end{tabular}

Tabla 5.39. Volumen de Planes de Seguridad y Salud consultados que cumplen con el requisito del presente apartado, organizados por período de tiempo y sede provincial (por orden alfabético) de Castilla-La Mancha con inclusión de totales parciales por período y total global sobre el conjunto de PSSs consultados.

Si se pone en perspectiva los resultados globales del estudio con respecto a este requerimiento, se obtiene un $0,78 \%$ sobre el total de los 3.600 PSSs consultados (lo que no llega a representar si quiera el 1,00\% de los casos), lo que muestra que no se trata de una práctica extendida en el Sector.

Con respecto de los datos obtenidos para el primer período de tiempo estudiado, se obtiene que esta práctica se extiende en un exiguo $0,71 \%$ de los casos, porcentaje similar a la diferencia porcentual que se obtiene al restar el porcentaje de la sede con mayor cumplimiento (Ciudad Real, con un 1,00\%) con respecto a la de menor cumplimiento (Guadalajara, con un 0,25\%), de entre las cuatro sedes estudiadas, obteniendo una variación de tan solo cero con setenta y cinco puntos porcentuales.

Para el segundo período de tiempo estudiado, se obtienen datos similares a los del primer período, con un total parcial del 0,84\% y una diferencia porcentual entre la sede con mayor cumplimiento del requerimiento (Ciudad Real y Toledo, con un 1,00\%) y la de menor cumplimiento (Albacete, Cuenca y Guadalajara, las 
tres sedes con un $0,75 \%$ ), de entre las cinco sedes consultadas, de cero con veinticinco puntos porcentuales. 


\subsection{5. ¿SE HACE REFERENCIA AL ESTUDIO O ESTUDIO BÁSICO DE SEGURIDAD Y SALUD EN EL PSS?}

En este apartado se recogen aquellos PSSs que hacen mención expresa al Estudio de Seguridad y Salud o al Estudio básico de Seguridad y Salud. Acerca de la obligatoriedad del Estudio de Seguridad y Salud o del Estudio básico de Seguridad y Salud, ésta queda contenida en el artículo 4, del capítulo II sobre disposiciones específicas de seguridad y salud del Real Decreto 1627/97 (BOE, 1997b), en el que se señala que:

1. El promotor estará obligado a que en la fase de redacción del proyecto se elabore un estudio de seguridad y salud en los proyectos de obras en que se den alguno de los supuestos siguientes:

a) Que el presupuesto de ejecución por contrata incluido en el proyecto sea igual o superior a 75 millones de pesetas.

b) Que la duración estimada sea superior a 30 días laborables, empleándose en algún momento a más de 20 trabajadores simultáneamente.

c) Que el volumen de mano de obra estimada, entendiendo por tal la suma de los días de trabajo del total de los trabajadores en la obra, sea superior a 500.

d) Las obras de túneles, galerías, conducciones subterráneas y presas.

2. En los proyectos de obras no incluidos en ninguno de los supuestos previstos en el apartado anterior, el promotor estará obligado a que en la fase de redacción del proyecto se elabore un estudio básico de seguridad y salud.

Es debido a ello que, habitualmente, se encuentre en el apartado correspondiente al objeto del Plan la frase arquetipo: “...este Plan tiene por objeto desarrollar el correspondiente Estudio de Seguridad y Salud redactado..." sin establecerse un mayor desarrollo que la misma frase. Hay que recordar que, el hecho de que se mencione esta herramienta, no implica que se haya tenido en cuenta durante la realización del Plan de Seguridad y Salud. De hecho, se trata de una praxis bastante habitual en el Sector, la de entender ambas herramientas preventivas como aisladas y no relacionadas; es decir, no se consulta el Estudio 
para la elaboración del Plan. En la Tabla 5.40 se recoge el cumplimiento que de dicha premisa se hace en los PSSs y que se ha podido comprobar durante la fase de análisis de dicho documento preventivo en las distintas sedes de la Autoridad Laboral.

\begin{tabular}{|c|c|c|c|c|c|}
\hline \multirow[b]{2}{*}{ Período } & \multicolumn{5}{|c|}{ Mención expresa al ESS o al EBSS en el PSS } \\
\hline & Albacete & Ciudad Real & Cuenca & Guadalajara & Toledo \\
\hline 2008-2012 & 333 & 387 & 205 & 301 & - \\
\hline$\%$ & 66,60 & 77,40 & 68,33 & 75,25 & - \\
\hline T. Parcial/\% & \multicolumn{5}{|c|}{$1.226(72,12 \%)$} \\
\hline 2013-2016 & 319 & 327 & 321 & 333 & 245 \\
\hline$\%$ & 79,75 & 81,75 & 80,25 & 83,25 & 81,67 \\
\hline T. Parcial/\% & \multicolumn{5}{|c|}{1.545 (81,32\%) } \\
\hline Total & \multicolumn{5}{|c|}{$2.771(76,97 \%)$} \\
\hline
\end{tabular}

Tabla 5.40. Volumen de Planes de Seguridad y Salud consultados que cumplen con el requisito del presente apartado, organizados por período de tiempo y sede provincial (por orden alfabético) de Castilla-La Mancha con inclusión de totales parciales por período y total global sobre el conjunto de PSSs consultados.

Se observa un elevado cumplimiento de dicho requisito, por valores que se acercan al $80 \%$ en el cómputo global de los PSSs consultados. Se observa un crecimiento en el segundo período, con un $81,32 \%$ de cumplimiento sobre el total parcial de las cinco sedes consultadas, con respecto al primer período de tiempo estudiado, que muestra valores más bajos de cumplimiento, de un $72,12 \%$ sobre el total parcial de las cuatro sedes.

Entrando en detalle, se observa que la varianza porcentual en ambos períodos es bastante heterogénea, con valores que rozan los once puntos porcentuales para el primer período de tiempo, diferencia que se reduce a dos puntos porcentuales para el segundo período, que obtiene valores homogéneos de cumplimiento en todas sus sedes. 


\subsection{6. ¿EL PSS ESTÁ FIRMADO?}

Como se ha visto en apartados anteriores, el Plan de Seguridad y Salud podrá realizarlo el propio personal de la empresa contratista o recurrir a cualquier empresa o persona externa para su realización. Asimismo, al tratarse de una obligación de la empresa contratista, el Plan de Seguridad y Salud debe ir firmado por un representante de la misma o por cualquier persona sobre la que se haya delegado dicha responsabilidad; tal y como recoge el artículo 7 del Real Decreto 1627/97 (BOE, 1997b). Si bien es cierto que en la $1^{\text {a }}$ Edición de la Guía Técnica del INSHT (INSHT, 2003) en su interpretación del Real Decreto 1627/97 (BOE, 1997b) no indica ninguna figura, ni siquiera la de un técnico, necesaria para la firma de los PSSs. Es en la $2^{\mathrm{a}}$ Edición de la Guía Técnica del INSHT (INSHT, 2012) que se indica que "el contratista tendrá que contar con el asesoramiento y asistencia de su Servicio de Prevención". De esta forma, sigue sin indicarse la figura necesaria para la firma del documento, sin embargo, introduce la necesidad de que dichos Planes sean supervisados por el Servicio de Prevención de la empresa contratista.

Dicho esto, se analizan los casos en los que para los PSSs consultados en los períodos recogidos en la Tabla 5.41 no aparece firma alguna, ni por parte del técnico redactor del Plan, ni por parte del Servicio de Prevención, ni por parte de la empresa contratista.

\begin{tabular}{|c|c|c|c|c|c|}
\hline \multirow[b]{2}{*}{ Período } & \multicolumn{5}{|c|}{ PSS no está firmado } \\
\hline & Albacete & Ciudad Real & Cuenca & Guadalajara & Toledo \\
\hline 2008-2012 & 101 & 99 & 79 & 90 & - \\
\hline$\%$ & 20,20 & 19,80 & 26,33 & 22,50 & - \\
\hline T. Parcial/\% & \multicolumn{5}{|c|}{$369(21,71 \%)$} \\
\hline 2013-2016 & 100 & 102 & 99 & 103 & 76 \\
\hline$\%$ & 25,00 & 25,50 & 24,75 & 25,75 & 25,33 \\
\hline T. Parcial/\% & \multicolumn{5}{|c|}{$480(25,26 \%)$} \\
\hline Total & \multicolumn{5}{|c|}{$849(23,58 \%)$} \\
\hline
\end{tabular}

Tabla 5.41. Volumen de Planes de Seguridad y Salud consultados que cumplen con el requisito del presente apartado, organizados por período de tiempo y sede provincial (por orden alfabético) de Castilla-La Mancha con inclusión de totales parciales por período y total global sobre el conjunto de PSSs consultados.

Los datos muestran que se trata de una práctica común, representando el $23,58 \%$ del total de los datos analizados (3.600 PSSs). Se observa un incremento de este requerimiento del primer al segundo período de tiempo estudiado, con una variación de tres con cincuenta y cinco puntos porcentuales. 
De forma detallada, se observa que durante el primer período se produce una variación de seis con cincuenta y tres puntos porcentuales entre la sede con mayor número de casos (Cuenca, con un 26,33\%), y la sede con menor número de casos (Ciudad Real, con un 19,80\%), para las cuatro sedes analizadas. Lo que deja un total parcial para este primer período del 21,71\%.

Ya en el segundo período se observan datos más homogéneos con apenas una variación de un punto porcentual entre la sede con mayor número de casos (Guadalajara, con un 25,75\%) y la de menor número de casos (Cuenca, con un 24,75\%). Si analizamos el total parcial de este período, para las cinco sedes analizadas, se obtiene un $25,26 \%$. 



\section{CAPÍTULO 6}

CONCLUSIONES Y PROPUESTAS 



\subsection{PUNTO DE PARTIDA}

La presente investigación, nacida de la necesidad de conocer la utilidad real o no del documento preventivo conocido como Plan de Seguridad y Salud en el Trabajo (planteamiento definido como punto de partida de la investigación), pone de manifiesto la escasa utilidad que de dicho documento se hace en las obras de construcción. A continuación, se recopilan las conclusiones que se han ido extractando a raíz de las labores de análisis de los resultados en conjunción con la metodología aplicada al estudio. Estas conclusiones se estructuran en tres apartados:

- Conclusiones generales.

- Conclusiones específicas.

- $\quad$ Propuestas de mejora. 


\subsection{CONCLUSIONES GENERALES}

1. Se trata de un documento con una corta esperanza de vida, ya que en un elevado porcentaje de los casos "muere" en el momento en que es registrado en la Autoridad Laboral correspondiente, siendo únicamente consultado fuera de este plazo en caso de accidente en la obra.

2. Visualizados los 3.600 PSSs, parece que en gran medida los redactores del Plan se preocupan más por el peso del documento (en torno al 20\% de los documentos consultados, concretamente 695 planes, tenían más de 200 páginas) que por el hecho de que el Plan se ajuste a la obra de forma específica. De todo ello se deduce que son muy extensos en algunos casos y demasiado generalistas, sin concreción alguna.

3. Resulta claro que se trata de un documento que no es revisado por la Autoridad Laboral, lo que justifica el haber encontrado PSSs en blanco, tanto en formato papel como en formato digital CD.

4. Se encuentran casos registrados en los que la figura que aprueba el Plan, el Coordinador de Seguridad y Salud, es la misma figura que lo redacta, incurriendo en un fraude de ley.

5. El hecho de que en el Plan no se recojan todas las figuras presentes en la obra, incluidos los trabajadores por cuenta propia y ajena, pone de manifiesto el escaso control y planificación de los trabajos. Una correcta identificación tanto en el plan como en la apertura de centro de trabajo evitaría trabajadores sin la formación necesaria, sin el reconocimiento médico y sin estar dados de alta en la obra, facilitando la labor de los inspectores.

6. La planificación de la Seguridad Vial sigue siendo una asignatura pendiente a la hora de integrar la prevención de Riesgos Laborales en todos los aspectos de la obra y de las labores auxiliares que implica la ejecución de los trabajos.

7. En un porcentaje considerable no se incluye en el Plan la partida dedicada a la Seguridad y Salud del presupuesto de la obra, únicamente aparece esta partida cuando los Planes hacen referencia al Estudio de 
Seguridad y Salud. El plan de Seguridad y Salud debe concebirse como una herramienta integradora donde debe recogerse en todos los casos, sin excepción (exista Estudio de Seguridad o Estudio básico de Seguridad y Salud) tanto el presupuesto como la justificación real de la compra efectiva de esa partida.

8. Que un porcentaje considerable de Planes no identifique ni evalúe la maquinaría ni medios auxiliares concretos de la obra, pone de manifiesto la poca utilidad real de este documento preventivo.

9. No se observa ninguna ficha de Seguridad y Salud anexa a los Planes visionados. Las fichas de seguridad de los productos químicos presentes en obra garantizan que ante un percance el trabajador tenga acceso a la información de emergencias y pautas de actuación necesarias a llevar a cabo, esta es una práctica muy poco extendida.

10. Se recogen documentos escritos mediante el procedimiento copia-pega, utilizando el mismo documento para distintas obras. Esto es permitido debido a que es un documento que únicamente se registra y que en caso de no haber accidentes no vuelve a ser consultado.

11. Se detecta un problema de base con este documento, que debería de ser como la propia obra de construcción, un organismo vivo en constante cambio, que fuese evolucionando según lo hace la obra y que todos los cambios y modificaciones son incorporados al cuerpo del documento, y que este se encuentre asequible para cualquier persona que quiera consultarlo.

12. A día de hoy se trata de un documento preventivo sin valor alguno a nivel de Seguridad y Salud en la obra, debiendo producirse un cambio en el modelo para que pueda adaptarse a la realidad de la obra.

13. Se trata de un documento que dista mucho de ser específico de la obra que se va a ejecutar y de los trabajos planteados en el mismo, a lo que se une el hecho de que los empresarios lo conciben como un mero trámite burocrático que se ha de cumplir, junto con el comunicado de apertura de centro de trabajo o la prescriptiva inscripción en el REA, es 
decir, no es entendido como una herramienta preventiva que pueda ser útil de cara a reducir la siniestralidad laboral de la obra.

14. No se identifican las figuras que han de estar presentes en obra, como en el caso del recuso preventivo, en gran parte porque se desconoce su función en materia de Prevención de Riesgos Laborales, así como sus incompatibilidades a la hora de poder ejecutar su trabajo de forma normal.

15. Un Plan de Seguridad y Salud debe de componerse de Evaluación de Riesgos y de Planificación Preventiva de los Trabajos, cosa que no se encuentra en la actualidad recogido en este documento.

16. El contratista elabora el Plan de Seguridad y Salud, tal y como indica el Real Decreto 1627/97. Pero si la función de un Plan es evaluar los riesgos específicos de la obra, ¿no debería ser realizado por un Técnico de Prevención de Riesgos Laborales con una carrera técnica habilitante de las funciones de CSS (Arquitecto, Arquitecto Técnico, Ingeniero e Ingeniero Técnico) y que quedase constancia en el mismo plan? Esto se torna meridiano el comprender que el contratista no tiene por qué tener conocimientos superiores en materia de prevención, por lo que deberá contratar su redacción a un técnico competente. 


\subsection{CONCLUSIONES ESPECÍFICAS}

En el presente apartado del documento de Tesis se recopilan todas las conclusiones específicas extractadas a raíz del análisis de los datos recogidos en el Capítulo 5 del citado documento. Estas permiten ahondar en la realidad preventiva de esta herramienta y en su puesta en valor o no a la hora de ser consultada por los trabajadores o las figuras en el transcurso de la obra. Sin más, se pasan a compendiar todas ellas en relación con su apartado correspondiente dentro del documento de la Tesis doctoral.

\subsubsection{FIGURAS JURÍDICAS QUE INTERVIENEN EN UNA OBRA DE CONSTRUCCIÓN}

Los resultados ponen de manifiesto la falta de inclusión de estas figuras en el Plan de Seguridad y Salud lo que implica la escasa o nula planificación preventiva que de la obra se hace, al no contemplar a la totalidad de los agentes intervinientes en la misma.

\subsubsection{PROMOTOR, CONTRATISTA, PROYECTISTA}

Si bien es cierto que son estas tres figuras las que son recogidas en la gran mayoría de los PSSs (en un 95,22\%), debido mayoritariamente a que son exigidas en el comunicado previo de apertura de centro de trabajo, sorprende en gran medida que estas figuras no estén contempladas en la totalidad de los casos analizados, en el $100,00 \%$ de los PSSs.

\subsubsection{RECURSO PREVENTIVO}

Resulta alarmante el escaso porcentaje en el que esta importante figura para el transcurso de la obra en materia de vigilancia de la Seguridad y Salud se encuentra reflejado en los PSSs, alcanzando un escaso 26,14\%. Esto es debido al escaso valor que se hace de esta figura y al desconocimiento de la misma, así como para los casos en los que se refleja, esto se hace más por miedo a la sanción económica que a la convicción de que esta figura sea de utilidad en la 
obra. Cabe destacar que tal y como recoge la normativa, cuando se producen solapes en los trabajos de distintos oficios en obras de construcción, siempre que los riesgos se vean agravados, ha de estar presente el recurso preventivo, caso más que habitual en la realidad de una obra de construcción, lo que indica la elevada tasa de incumplimiento que de este requisito se hace.

\subsection{RECURSO PREVENTIVO ES EL EMPRESARIO}

A modo anecdótico, esta figura preventiva es adoptada por el empresario en un $1,61 \%$ de los casos estudiados, lo que indica que se trata de una práctica poco habitual, ciertamente difícil de encontrar en las obras, ya que la esencia del Recurso Preventivo es la de vigilar los trabajos desde un punto de vista preventivo, e implica que esa persona esté en la obra de forma invariable, cuando es bien conocido que el empresario no suele hacer gran presencia en la obra.

\subsubsection{SUBCONTRATISTA}

En un $47,75 \%$ de los PSSs queda recogida esta figura, lo que implica que en un porcentaje superior al 50,00\% esta figura no es recogida, volviendo a incurrir en una falta absoluta de planificación preventiva de la obra, al ser sobra conocido que esta práctica, la subcontratación, favorece la siniestralidad laboral.

\subsubsection{TRABAJADOR AUTÓNOMO}

Si hay una figura que parece quedar siempre al margen de todo, esa es la del trabajador autónomo, tal y como reflejan los resultados, con únicamente un irrisorio $0,11 \%$ de PSSs en los que esta figura queda recogida. Debido a tratarse de una figura con responsabilidades, debería quedar recogida en el Plan, al igual que debería de adherirse al Plan del contratista.

\subsubsection{TRABAJADOR POR CUENTA AJENA}


Al igual que en el caso de la figura del trabajador autónomo, dejar reflejada la relación de trabajadores por cuenta ajena que van a realizar trabajos en la obra es una práctica muy poco habitual, por no decir inexistente, tal y como reflejan los resultados, con un $0,36 \%$ de los PSSs que lo incluyen. Resulta de vital importancia incluir el listado de trabajadores en obra, siendo pertinente incluir los certificados de aptitud médica y la formación de los mismos de cara a facilitar las labores de inspección y la labor del Coordinador, conociendo en todo momento los trabajadores que pueden estar presentes en el centro de trabajo.

\subsubsection{DIRECCIÓN FACULTATIVA}

Si bien este requisito se cumple en un alto porcentaje, con valores del 84,53\%, situación que resulta sorpresiva al no ser figuras recogidas en el comunicado de apertura del centro de trabajo, esto debería de tomarse como la norma de cara a incluir en el Plan todas las figuras, agentes y trabajadores involucrados en el proceso de construcción de la obra, lo que facilitaría el control preventivo de la obra, lo que llevaría aparejado las labores de una correcta planificación preventiva previa de la obra.

\subsubsection{COORDINADOR DE SEGURIDAD Y SALUD}

Aunque no pueda ser considerada la norma, sorprende encontrar un 3,58\% de casos en los que la figura del CSS es el propio redactor del Plan y el encargado de aprobar el mismo, incumpliendo la legislación vigente al respecto, al incurrir en un fraude de ley, por lo que este porcentaje se torna impensable si el PSS no fuese únicamente registrado (lo que indica que se ha de cambiar el procedimiento de registro de este instrumento, involucrando a la Autoridad Laboral).

\subsection{COORDINADOR DE SEGURIDAD Y SALUD EN FASE DE PROYECTO}

Esta figura se encuentra reflejada en el 4,61\% de los PSSs consultados, lo que acarrea un muy bajo nivel inclusión, fiel reflejo del desconocimiento de esta figura, que suele ser confundida con la del CSSFE, asumiendo que se trata de la 
misma figura que el CSSFP, cuando la realidad es que en la mayoría de los casos se trata de figuras distintas. La relevancia de la figura del CSSEP radica en la integración efectiva y responsable de la prevención en el proceso completo de la obra.

\subsection{COORDINADOR DE SEGURIDAD Y SALUD EN FASE DE EJECUCIÓN}

En contraposición con la figura del CSSFP, el CSSFE es reflejado en el 81,78\% de los casos, en un alto porcentaje, entendiendo que en un 18,22 \% esta figura no aparece o bien porque no es necesaria ya que no existe solape de actividades o actividades sucesivas con otras empresas o bien porque se les ha olvidado reflejarla. Al tratarse de uno de los requisitos exigidos en el comunicado de apertura del centro de trabajo suele considerarse en todos los Planes visionados. No obstante, el Plan debería recoger un apartado donde se justificase la existencia o no del Coordinador de Seguridad y Salud. 


\subsubsection{ASPECTO FORMAL DEL DOCUMENTO}

En este apartado se detectan todas las deficiencias que presenta el PSS y que deberían de formar parte del mismo, para conseguir una utilidad real del documento, que refleje la realidad preventiva de la obra y sirva de guía para su consulta durante la ejecución de los trabajos.

\subsubsection{UNIDADES O FASES DE OBRA}

Un bajo porcentaje de los PSSs consultados, el 10,64\%, refleja el organigrama de las fases de trabajos y solapes que se producen entre las distintas actividades. Estos datos son fiel reflejo de que no se lleva a cabo la labor previa de planificación preventiva para la gran mayoría de los PSSs.

\subsubsection{EL PSS CONTIENE MATERIAL GRÁFICO}

Este tipo de recursos empleados para facilitar la lectura rápida del documento únicamente son visibles en la mitad de los PSSs, concretamente en el 48,67\%, lo que indica que se trata de una herramienta no tan extendida como cabría esperar.

6.3.2.2.1. EL PSS CONTIENE MATERIAL GRÁFICO RELACIONADO CON LA OBRA O LA MAQUINARIA

Que únicamente el 2,72\% de los PSSs contemple incluir material gráfico específico relacionado con la obra o la maquinaria a emplear en la misma es fiel reflejo de la nula planificación preventiva que de los trabajos y equipos se hace por parte del redactor del Plan, que debería estar en comunicación directa con la empresa para poder incluir toda la maquinaria y equipos que esta prevea utilizar en la ejecución de los trabajos. 


\subsubsection{EL PSS CUENTA CON PAUTAS DE ACTUACIÓN ANTE EMERGENCIAS}

En este apartado se encuentra otro requisito que debería estar contemplado en todos los PSSs y que sorprendentemente sólo está recogido en el 32,97\% de los casos consultados, lo que conlleva una falta de previsión (así como de las labores conjuntas de planificación y Evaluación de Riesgos) que contemple estos riesgos, tan comunes en las obras de construcción.

\subsubsection{EL PSS CUENTA CON ITINERARIOS PARA LLEGAR A CENTROS ASISTENCIALES}

Si bien es de sobra conocido por el colectivo general, que en caso de accidente grave las primeras horas son cruciales para salvar la vida del accidentado, resulta indignante que un requisito como los itinerarios para llevar desde el centro de trabajo al centro asistencial $u$ hospital al accidentado no esté contemplado en todos los casos, y que únicamente quede recogido en el 38,00\% de los mismos.

\subsubsection{EL PSS CONTIENE PAUTAS DE ACTUACIÓN EN CASO DE RIESGO GRAVE E INMINENTE}

Este apartado, que recoge un derecho del trabajador, así como de las figuras que pueden decretar la paralización de los trabajos en caso de riesgo grave e inminente que no esté contemplado en el Plan, es en gran parte desconocido por la mayoría de los agentes involucrados en obras de construcción, tal y como demuestran los resultados obtenidos, con tan solo un 9,58\% de los Planes que contemplan este requisito. 


\subsubsection{EL PSS CUENTA CON PLAN DE EVACUACIÓN EN CASO DE INCENDIO}

Otro de los requisitos que impactan por su escaso cumplimiento es el presente, con un ínfimo $4,97 \%$ de los PSSs que lo recogen, cuando debería estar contemplado en el $100,00 \%$ de los casos, puesto que en las obras es una práctica muy inusual realizar simulacros de incendio, es por ello que contar con un plan de evacuación en caso de incendio resulta de extrema importancia para la seguridad de los trabajadores en la obra, así como del resto de personal presente en la misma.

\subsubsection{EL PSS CUENTA CON PROCEDIMIENTOS DE CONTROL DE SEGURIDAD} VIAL

En este caso, tan solo el 10,69\% de los PSSs consultados integra este requisito, lo que implica que no se contemplan los desplazamientos en la obra (labores de acopio, manejo de maquinaria en obra, desplazamientos a por repuestos, traslado de hormigón y prefabricados, etc.), cuando son estos momentos de especial peligrosidad que pueden derivar en accidente, incluidos los conocidos como in itinere.

\subsection{EL PSS CUENTA CON PLAN DE SEGURIDAD VIAL ESPECÍFICO}

Si ya resulta complicado encontrar medidas dirigidas a la seguridad vial de las acciones derivadas de la obra, únicamente el 0,06\% de los PSSs consultados presentan alguna medida específica de la obra detallada en el Plan, lo que es claro indicador de que se trata de un requisito que ni siquiera se contempla a la hora de redactar el Plan. 


\subsubsection{EL PSS CUENTA CON CAPÍTULO DEDICADO A LA SEGURIDAD Y SALUD EN LAS MEDICIONES Y PRESUPUESTO}

Que se incluya un capítulo dedicado a la seguridad y salud dentro del presupuesto de la obra indica que se contempla el gasto derivado de la compra de EPIs para los trabajadores, las señalizaciones que se van a emplear, las instalaciones sanitarias a emplear en obra, etc. Sin embargo, este requisito es contemplado solamente en el $34,64 \%$, lo que induce a pensar que en alguno de los casos restantes se producen malas praxis, como obligar al trabajador a que se compre sus propios EPIs (por desgracia se trata de una práctica bastante extendida en el sector, principalmente en las pequeñas empresas y microempresas) o abaratar costes en este capítulo (no proporcionando instalaciones sanitarias a los trabajadores). 


\subsubsection{EVALUACIÓN DE RIESGOS DE LA OBRA}

Debido a la flagrante deficiencia de este instrumento para contemplar la prevención de la obra, se decide analizar la integración de la Evaluación de los Riesgos, dando como resultado una vez más una falta alarmante de medidas específicas que contemplen los riesgos derivados de los trabajos, lo que implica una vez más una planificación preventiva deficiente. Esto podría solventarse con la modificación de este documento y sustitución por una serie de fichas de procedimientos de trabajo específicos de los trabajos a realizar que cada empresa elabore.

\subsubsection{EL PSS EVALÚA CADA FASE/TRABAJO/PUESTOIACTIVIDAD DE LA OBRA}

Que el 80,53\% de los PSSs recoja este requisito no sorprende, si bien es cierto que cabría esperar un 100,00\%. Lo que sí resulta relevante es que en este apartado se recogen las medidas, ya sean genéricas o específicas, de cara a la inclusión de la Evaluación de Riesgos de cada fase/trabajo/puesto/actividad de la obra. Es en el siguiente subapartado donde se evalúan y constatan si esas medidas son específicas para la obra que se detalla en el Plan.

$\begin{array}{llllllr}\text { 6.3.3.1.1. LOS } & \text { RIESGOS } & \text { Y } & \text { MEDIDAS } & \text { PREVENTIVAS } & \text { DE } & \text { CADA } \\ \text { FASE/TRABAJO/PUESTOIACTIVIDAD } & \text { SON } & \text { ESPECÍFICAS } & \text { DE } & \text { ESA }\end{array}$
FASE/TRABAJO/PUESTOIACTIVIDAD

El bajo porcentaje de cumplimiento de este requisito, el 13,91\% de los casos, certifica por desgracia que los Planes son documentos genéricos que no indagan en la obra que se detalla en el Plan, recurriendo a los tan socorridos corta-pegas, haciendo que un mismo Plan y las medidas contempladas en el mismo valgan para distintas obras y condiciones. 


\subsubsection{EL PSS IDENTIFICA LA MAQUINARIA/EQUIPOS QUE SE UTILIZAN EN OBRA}

Otro claro ejemplo de que los Planes son documentos genéricos es que únicamente en el $16,17 \%$ de los mismos se encuentra identificada la maquinaria/equipos que se prevén utilizar en la obra que detalla el Plan. Esto implica nuevamente una falta en las labores previas de planificación preventiva de la obra.

\subsection{EL PSS IDENTIFICA Y EVALÚA LA MAQUINARIA/EQUIPOS QUE SE UTILIZAN EN} OBRA

En concordancia con el apartado anterior, se concluye que tan sólo el 0,97\% de los PSSs identifica y evalúa la maquinaria/equipos que se prevén emplear en la obra, lo que demuestra el carácter generalista de los Planes y de la escasa utilidad real a nivel preventivo al no contemplar la evaluación de la maquinaria/equipos que se van a utilizar.

\subsubsection{EL PSS IDENTIFICA LOS MEDIOS AUXILIARES QUE SE PREVÉN UTILIZAR EN OBRA}

Para este requisito se repite el mismo patrón de documentos generalistas, y es que cuando se trata de que el Plan identifique los medios auxiliares que se van a utilizar, únicamente se encuentran identificados en el $15,94 \%$ de los casos, lo que nos da un claro ejemplo de que ni siquiera se contempla algo tan básico como los medios auxiliares que se van a emplear en obra.

\subsection{EL PSS IDENTIFICA Y EVALÚA LOS MEDIOS AUXILIARES QUE SE PREVÉN} UTILIZAR EN OBRA

Sorprende encontrar que, para este requisito, directamente relacionado con el anterior, el 14,08\% de los PSSs además de identificar los medios auxiliares los evalúan, aunque lo cierto es que deberían de haber sido coincidentes los porcentajes (con los obtenidos en el apartado anterior) para que se entendiese 
como un trabajo coherente de Evaluación de Riesgos. En cualquier caso, vuelve a ser un caso flagrante de documentos no específicos, que no contemplan apartados tan importantes como los recogidos en el resto de apartados del presente documento.

\subsection{EL PSS INTEGRA EL MANUAL DE INSTRUCCIONES YIO PROCEDIMIENTOS DE LOS MEDIOS AUXILIARES QUE SE PREVÉN UTILIZAR EN OBRA}

Como un ejemplo más de la escasa especificidad de este documento preventivo, se encuentra que tan solo el $7,64 \%$ de los PSSs integra el manual de instrucciones y/o procedimientos de los medios auxiliares que se van a emplear en la obra. Algo que resulta incomprensible, al ser este un requisito que ayuda en gran medida a los propios trabajadores en los procesos de montaje/desmontaje de los medios auxiliares, así como en la consulta de la correcta utilización de los mismos con garantías de seguridad del fabricante, lo que hace que se ejecuten los trabajos de forma segura para el trabajador.

\subsubsection{EL PSS INCLUYE LOS PRODUCTOS QUÍMICOS QUE SE VAN A UTILIZAR EN LA OBRA}

Nuevamente aparece un ejemplo más de la escasa o nula especificidad del Plan, que exclusivamente contempla incluir los productos químicos que se van a emplear en la obra en un $22,75 \%$ de los casos. Esto repercute negativamente en la seguridad de los trabajadores en obra y pone de manifiesto una deficiente labor de planificación por parte del redactor del Plan y de la empresa.

\subsection{EL PSS INCLUYE LAS FICHAS DE SEGURIDAD DE LOS PRODUCTOS QUÍMICOS QUE SE VAN A UTILIZAR EN LA OBRA}

Si hay un requisito que ejemplifica lo genérico de este documento es el de la inclusión de las fichas de seguridad de los productos químicos que se van a utilizar, que no se cumple en ninguno de los casos consultados, en un 0,00\% de los PSSs. Este requisito es una medida adicional de seguridad para los trabajadores, en caso de accidente al manipular dichos productos puedan 
consultar la información relativa a la actuación ante emergencias, así como conocer qué EPIs se necesitan para manipularlos de forma segura y correcta.

\subsubsection{LA EVALUACIÓN DE RIESGOS INTEGRADA EN EL PSS SE AJUSTA A LO DETERMINADO EN EL ARTÍCULO 7 DEL REAL DECRETO 39/1997}

De nuevo se encuentra un requisito que presenta un cumplimiento prácticamente nulo, con tan sólo un 0,36\% de PSSs que lo integran, lo que indica que, a pesar de existir legislación sobre este aspecto del documento (sobre cómo evaluar los riesgos conforme a lo dispuesto en el artículo 7 de la citada normativa), esta no se tiene en consideración a la hora de redactar el Plan e integrar de forma correcta la prevención de la obra (tal y como corroboran los resultados obtenidos).

\subsubsection{EXISTE UNA PLANIFICACIÓN PREVENTIVA EN EL PSS COMO RESULTADO DE LA EVALUACIÓN DE RIESGOS}

Si en los apartados anteriores se venía corroborando que existe una lacra generalizada en lo relativo a la Planificación Preventiva de la obra, los resultados obtenidos al respecto de este requisito específico, que atañe de forma directa a la Planificación como resultado de la Evaluación de Riesgos, demuestran que únicamente el $0,22 \%$ de los PSSs cumple con ello.

6.3.3.6.1. LA PLANIFICACIÓN PREVENTIVA SE AJUSTA A LO DISPUESTO EN EL ARTíCULO 9 DEL REAL DECRETO 39/1997

Si se riza el rizo y se comprueba si alguno de los PSSs integran la Planificación Preventiva como resultado de la Evaluación de Riesgos, se choca contra un muro, ya que no se encuentra ningún caso en el que se cumpla este requisito, de entre el visionado de 3.600 PSSs, lo que nuevamente pone de manifiesto que la planificación vuelve a ser un caballo de batalla que ha de incorporarse en el proceso de diseño y redacción del Plan de forma necesaria, y que debe de ser incorporada según lo que marca la legislación vigente. 


\subsubsection{ANOMALÍAS E INCIDENCIAS}

Este nuevo apartado pone de manifiesto todas aquellas deficiencias e incidencias reseñables del Plan debido a diversos factores, entre los que destacan que se trata de un documento que se entiende como un mero trámite administrativo, que únicamente se registra y es ahí donde termina su eficacia en la gran mayoría de las ocasiones, que se trata de un documento en el que prima el peso del documento (se han encontrado un montante considerable de documentos con más de 200 páginas) a la calidad del mismo, que se trata de un documento que no es revisado por la Autoridad Laboral (lo que da carta blanca a los redactores para hacer acciones de copia-pega, utilizar el mismo documento en distintas obras, etc.), que se trata de un documento con muy poca vida útil tal y como refleja el hecho de no presentar anexos en la gran mayoría de los casos, etc.

\subsubsection{EL PSS EN PAPEL EN BLANCO}

Si hay un requisito que mejor ejemplifique que se trata de un documento que no se revisa y que únicamente es registrado, ese es este, ya que se han encontrado un $0,11 \%$ de los PSSs completamente en blanco, contando solamente con la portada del documento. Es por ello que resulta vital la involucración de la Autoridad Laboral para evitar estas malas prácticas y conseguir que el documento tenga una utilidad real.

\subsubsection{EL CD QUE CONTIENE PSS EN BLANCO O NO SE PUEDE ABRIR}

Otro ejemplo de las malas praxis es encontrar que el 7,89\% de los CDs no tenían contenido alguno grabado en su interior o directamente no podían ser abiertos, lo que muestra que se trata de un documento que se elabora para cumplir con el requisito administrativo, aunque no se crea que tenga utilidad real, $y$ al que no se le dedica tiempo ya que el redactor del Plan es consciente de que nada más que se registra, pero no se revisa a no ser que se produzca un accidente en la obra. 


\subsubsection{EL PSS NO GUARDA RELACIÓN ALGUNA CON LA OBRA DESCRITA EN EL TÍTULO}

En este requisito se encuentra otro claro exponente de la nula especificidad con la que se elabora el Plan, ya que el $4,08 \%$ de los mismos no guarda relación alguna con la obra descrita en el título, con lo que esos documentos pasan por no tener validez alguna en materia de prevención de la obra, es decir, en esos casos, daría igual que existiese Plan o que no.

\subsubsection{MISMO PSS PARA DISTITNAS OBRAS}

Si hay un requisito que mejor caracterice la mala praxis a la hora de redactar el Plan, ese es el de utilizar el mismo PSS para distintas obras, que en muchos casos ni siquiera guardan relación. Un $0,78 \%$ de casos encontrados, muestran cómo el redactor del Plan reutiliza el mismo documento sin importar que se ajuste a la obra, mejor dicho, que coincida con la obra detallada.

\subsubsection{SE HACE REFERENCIA AL ESTUDIO O ESTUDIO BÁSICO DE SEGURIDAD Y SALUD EN EL PSS}

Este requisito se cumple en gran medida, en el $76,97 \%$, pero se ha de indicar que el hecho de que se haga mención al ESS o al EBSS en el documento, no implica que se haya consultado o tenido en cuenta a la hora de redactar el PSS, cosa que ha quedado de sobra documentado y refutado con los resultados mostrados en los demás apartados.

\subsubsection{EL PSS NO ESTÁ FIRMADO}

Sorprende encontrar que en el $23,58 \%$ de los casos estudiados, el PSS no está firmado por ninguna figura, lo que implica que se desconoce el autor del Plan y si se cumple la normativa vigente, teniendo que ser el redactor del Plan un Técnico Superior de PRL. 


\subsection{PROPUESTAS DE MEJORA}

1. Cambiar la configuración actual del documento y sustituirlo por fichas de procedimientos de trabajo de la empresa, de tal forma que cada empresa contratista o subcontratista que se adhiera (o se integre en el proceso) al Plan deba de hacerlo mediante la inclusión de sus propios procedimientos de trabajo, lo que profesionalizaría el Plan y le dotaría de un valor añadido, al obligar a establecer procedimientos concretos de trabajo previamente evaluados y contemplados en la planificación preventiva de la ejecución de los trabajos de la empresa.

2. Aprender de la legislación en materia de trabajos con riesgo de amianto, que especifica los contenidos mínimos que ha de contener el Plan de Trabajo, cosa que no sucede en el caso del Plan de Seguridad y Salud.

3. Asimilar los criterios de Evaluación de Riesgos contemplados en el Plan de Trabajo de amianto y extrapolarlo al Plan de Seguridad y Salud, con el consabido seguimiento por parte de la Autoridad Laboral, que garantiza el cumplimiento de lo recogido en el Plan.

4. Un mayor seguimiento del Plan de Seguridad y Salud por parte de la Autoridad Laboral, que no se limite al mero registro del documento, añadiría una utilidad real al mismo, siendo éste revisado y modificado cada vez que se detecten cambios o incumplimientos de los contemplado en el mismo.

5. Para mejorar su eficacia, el Plan de Seguridad y Salud debería incluir:

- La Evaluación de Riesgos específica (de las fases de la obra, equipos/maquinaria, puestos de trabajo, medios auxiliares, productos químicos, etc.).

- La Planificación Preventiva específica de los trabajos o fases de que se compone la obra.

- La formación de los trabajadores (mediante la inclusión de los diplomas o TPC actualizada). 
- La vigilancia de la salud (mediante los certificados de aptitud de los trabajadores).

- Los procedimientos de entrega de EPIs a los trabajadores (lo que asegura que se les entrega a los operarios las protecciones necesarias para ejecutar su trabajo de forma segura).

Apartados que ya recoge la legislación vigente en materia de $\mathrm{PRL}$ pero que no se tienen en cuenta a la hora de redactar el Plan. Es decir, el PSS ha de ser concebido como una Gestión integrada.

6. Asimilar parte del contenido del Plan de Autoprotección con el del Plan de Seguridad y Salud, con una normativa más restrictiva y que indique los contenidos mínimos que se han de implantar.

7. Que se ponga nombre y apellidos a todas aquellas figuras implicadas en la obra (trabajadores incluidos), y que se informe a los trabajadores del contenido del Plan de Seguridad y Salud, siendo accesible en cualquier momento de la obra para su consulta.

8. La persona encargada de redactar el PSS ha de pertenecer a la organización preventiva de la empresa (SPA, SPP, persona designada, etc., en cualquier caso, con titulación de Técnico Superior de Prevención de Riesgos Laborales con predilección sobre las titulaciones habilitantes de las funciones de coordinación de obras: Arquitecto, Arquitecto Técnico, Ingeniero, Ingeniero Técnico), que conozca los procedimientos de trabajo de la empresa, independientemente de que sea aprobado por el coordinador. 


\section{CAPÍTULO 7}

ORIENTACIÓN PARA FUTUROS TRABAJOS 



\subsection{FUTURAS LÍNEAS DE INVESTIGACIÓN}

Elaboración de un modelo detallado de contenidos mínimos que ha de conformar el cuerpo del documento del Plan de Seguridad y Salud en base a las graves deficiencias detectadas que sirvan de guía para el redactor del Plan. De esta forma se subsanarían las carencias que presenta actualmente este documento y se establecería una guía de contenidos mínimos que aúnen los requisitos exigibles a nivel nacional, evitando los agravios comparativos entre distintas Comunidades Autónomas.

Sustituir el actual documento preventivo conocido como Plan de Seguridad y Salud por un documento que integre los procedimientos preventivos de trabajo a modo de fichas, al que se le vayan adhiriendo todos los procedimientos de las empresas que participen en la obra, y que permita la modificación constante del mismo acorde a los cambios que se produzcan en la obra.

Aprender de la normativa más restrictiva que afecta a los trabajos de desamiantado (BOE, 2006c; UNE, 2014), que cubre un amplio espectro, desde las acciones formativas para los empresarios y trabajadores (más específica y detallada que la formación habitual que reciben los trabajadores del Sector de la Construcción), hasta la elaboración de un Plan de Trabajo que ha de ser muy detallado y específico de la obra a realizar, a modo de procedimientos de trabajo, para poder extrapolarlo a los Planes de Seguridad y Salud.

Realizar esta misma investigación con el documento preventivo conocido como la Evaluación de Riesgos, ya que se trata del otro documento preventivo con igual presencia en obra. De esta forma, se podría analizar el espectro global de los documentos preventivos en construcción, así como su realidad y eficacia, al poder comparar los datos obtenidos en esta investigación con los que muestren los resultados de este otro documento.

Realizar este mismo estudio en otras Comunidades Autónomas para observar si se producen desajustes en los resultados obtenidos, o si presumiblemente, se trata de datos extrapolables al total del territorio nacional.

Realizar una comparativa a nivel europeo, y posteriormente a nivel internacional, sobre el documento preventivo del Plan de Seguridad y Salud y la normativa que 
le afecta, observando qué país posee la normativa más restrictiva y en qué países este documento tiene una mejor integración en la obra, llegando a ser relevante y empleado a modo de consulta.

Establecer programas conjuntos, con la Autoridad Laboral, para cambiar el modelo actual y realizar un mayor seguimiento de las obras, a través de documentos activos y evolutivos, que permitan el seguimiento fidedigno y continuo de la realidad preventiva de la obra de construcción. Por ejemplo, mediante la creación de una herramienta automatizada online que emita alertas y notificaciones a la vez que permita el seguimiento actualizado del estado de la obra. 
ANEXOS 



\section{ANEXO I}

Checklist o lista de chequeo de los datos a comprobar en el documento preventivo denominado Plan de Seguridad y Salud (PSS).

1. Año del Plan de Seguridad y Salud:

$\begin{array}{llllll}\square & \text { 1. } 2008 & \text { 2. } 2009 & \square & \text { 3. } 2010 \\ \square & \text { 4. } 2011 & \square & \text { 5. } 2012 & \square & \text { 6. } 2013 \\ \square & \text { 7. } 2014 & \square & \text { 8. } 2015 & \square & \text { 9. } 2016\end{array}$

2. Aparecen reflejadas en el Plan las figuras del Promotor, Contratista y Proyectista:

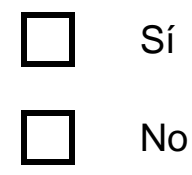

3. Aparece el nombramiento del Recurso Preventivo:

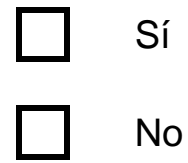

4. El Recurso Preventivo es el propio empresario de la obra:

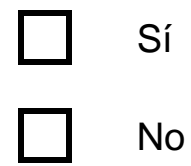

5. Aparece recogido el/los Subcontratista/s:

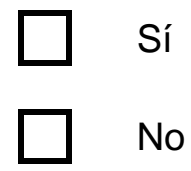

6. Aparece recogido el/los Trabajadores Autónomos:

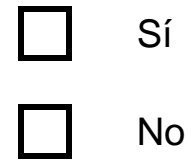


7. El documento recopila los Trabajadores por cuenta ajena de la obra:

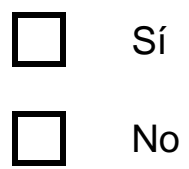

8. El documento del PSS incluye la Dirección Facultativa de la obra:

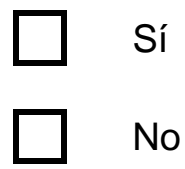

9. Se refleja la figura del Coordinador de Seguridad y Salud en fase de proyecto en el documento preventivo:

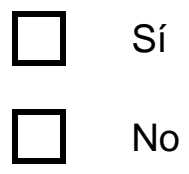

10. Se refleja la figura del Coordinador de Seguridad y Salud en fase de ejecución en el documento preventivo:

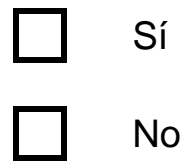

11. El Coordinador de Seguridad y Salud de la obra, encargado de aprobar el Plan, es el mismo que redacta el Plan:

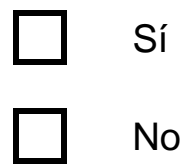

12. El documento integra las unidades o fases de obra (cronograma de trabajos):

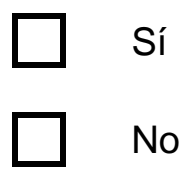

13. EI PSS contiene material gráfico:

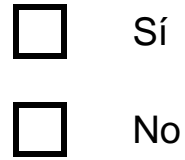


14. EI PSS incluye material gráfico relacionado con la obra o la maquinaria que se va a emplear en la obra:

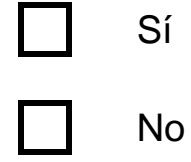

15. EI PSS cuenta con pautas de actuación ante emergencias:

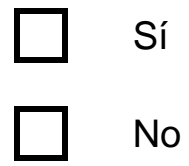

16. EI PSS recoge los itinerarios para llegar a los centros asistenciales/hospital:

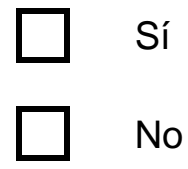

17. EI PSS incluye pautas de actuación en caso de riesgo grave e inminente:

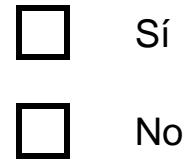

18. EI PSS cuenta con Plan de Evacuación en caso de incendio:

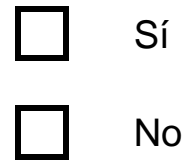

19. EI PSS integra procedimientos de control de Seguridad Vial:

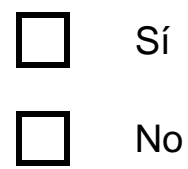

20. EI PSS incluye un Plan de Seguridad Vial específico para la obra que se detalla:

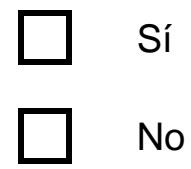


21. EI PSS incorpora un capítulo específico para la Seguridad y Salud de la obra dentro de las Mediciones y Presupuesto:

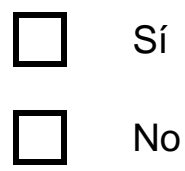

22. El documento en papel está en blanco/vacío:

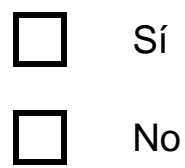

23. El CD que contiene el PSS está vacío o no se puede abrir:

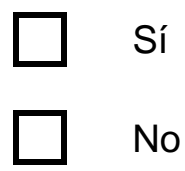

24. EI PSS guarda relación con la obra descrita en el título del documento:

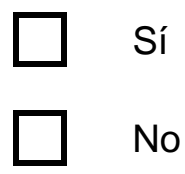

25. Se utiliza el mismo PSS en distintas obras:

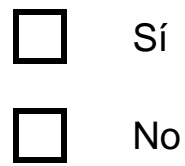

26. Se hace referencia al Estudio o Estudio Básico de Seguridad y Salud en el PSS:

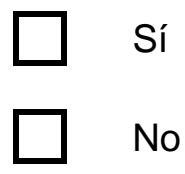

27. EI PSS está firmado:

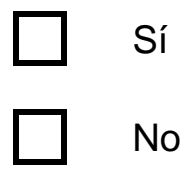


28. El PSS cuenta con anexos al mismo:

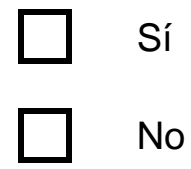

29. EI PSS evalúa cada fase/trabajo/puesto/actividad de la obra:

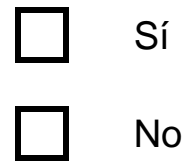

30. EI PSS evalúa cada fase/trabajo/puesto/actividad de la obra de forma específica:

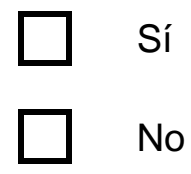

31. EI PSS identifica la maquinaria/equipos que se emplean en la obra:

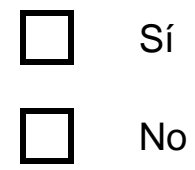

32. EI PSS identifica y evalúa la maquinaria/equipos que se emplean en la obra:

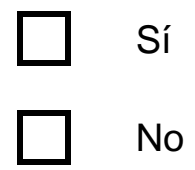

33. EI PSS identifica los medios auxiliares que se prevén emplear en obra:

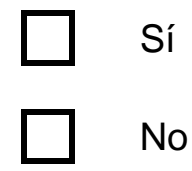

34. EI PSS identifica y evalúa los medios auxiliares que se prevén emplear en la obra:

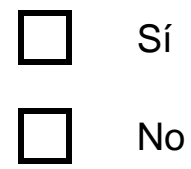


35. EI PSS incluye el manual de instrucciones y/o procedimientos de los medios auxiliares que se prevén emplear en obra:

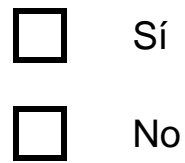

36. EI PSS incluye los productos químicos que se van a emplear en obra:

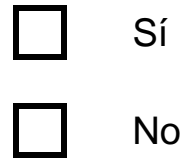

37. EI PSS incluye las fichas de seguridad de los productos químicos que se van a emplear en obra:

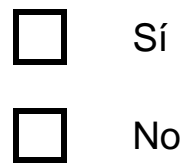

38. La Evaluación de Riesgos integrada en el PSS se ajusta a lo determinado en el artículo 7 del Real Decreto 39/1997:

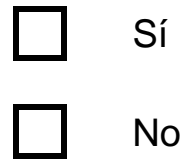

39. Existe planificación preventiva en el PSS como resultado de la Evaluación de Riesgos:

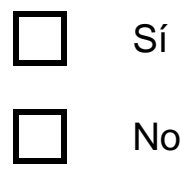

40. La planificación preventiva en el PSS se ajusta en el artículo 9 del Real Decreto 39/1997:

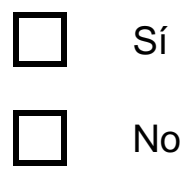


BIBLIOGRAFÍA Y REFERENCIAS 



\section{BIBLIOGRAFÍA Y REFERENCIAS}

Azofra, M. J., 2005. Cuadernos Metodológicos No26 - Cuestionarios CIS. Centro de Investigaciones Sociológicas. Madrid, 1999. ISBN: 9788474762723

Becerril, M., 2013. Un proceso de intervención sobre las conductas de seguridad y las condiciones de seguridad y salud en las obras de construcción. Tesis doctoral. Universidad de Valencia. Facultad de Psicología. Departamento de Metodología de las Ciencias del Comportamiento. Valencia, 2013.

Biggs, H.C., Sheahan, V.L., Dingsdag, D.P., 2005. A study of construction site safety culture and implications for safe and responsive workplaces. Australian Journal of Rehabilitation Counselling 11 (1), 1-7.

doi:10.1017/S1323892200000120

BOE, 1978. Constitución Española, de 29 de diciembre. Boletín Oficial del Estado, 311, 29/12/1978.

BOE, 1986. Real Decreto 555/1986, de 21 de febrero, por el que se implanta la obligatoriedad de la inclusión de un estudio de Seguridad e Higiene en el Trabajo en los proyectos de edificación y obras públicas. Boletín Oficial del Estado, 69, 21/03/1986.

BOE, 1990. Real Decreto 84/1990, de 19 de enero, por el que se da nueva redacción a los artículos $1^{\circ}, 4^{\circ}, 6^{\circ}$ y $8^{\circ}$ del Real Decreto 555/1986, de 21 de febrero, y se modifican parcialmente las tarifas de honorarios de Arquitectos, aprobadas por el Real Decreto 2512/1977, de 17 de junio, y de Aparejadores y Arquitectos técnicos aprobados por el Real Decreto 314/1979, de 19 de enero. Boletín Oficial del Estado, 22, 25/01/1990.

BOE, 1992. Directiva 92/57/CEE del Consejo, de 24 de junio de 1992, relativa a las disposiciones mínimas de seguridad y de salud que deben aplicarse en las obras de construcción temporales o móviles (octava Directiva específica con arreglo al apartado 1 del artículo 16 de la Directiva 89/391/CEE). Boletín Oficial del Estado, 245, 26/08/1992.

BOE, 1995. Ley 31/1995, de 8 de noviembre, de Prevención de Riesgos Laborales. Boletín Oficial del Estado, 269,10/11/1995.

BOE, 1997a. Real Decreto 39/1997, de 17 de enero, por el que se aprueba el Reglamento de los Servicios de Prevención. Boletín Oficial del Estado, 27, 31/01/1997.

BOE, 1997b. Real Decreto 1627/1997, de 24 de octubre, por el que se establecen disposiciones mínimas de seguridad y de salud en las obras de construcción. Boletín Oficial del Estado, 256, 25/10/1997. 
BOE, 1997c. Real Decreto 1215/1997, de 18 de julio, por el que se establecen las disposiciones mínimas de seguridad y de salud para la utilización por los trabajadores de los equipos de trabajo. Boletín Oficial del Estado, 188, 07/08/1997.

BOE, 1999. Ley 38/1999, de 5 de noviembre, de Ordenación de la Edificación. Boletín Oficial del Estado, 266, 06/11/1999.

BOE, 2000. Real Decreto Legislativo 5/2000, de 4 de agosto, por el que se aprueba el texto refundido de la Ley sobre Infracciones y Sanciones en el Orden Social. Boletín Oficial del Estado, 189, 08/08/2000.

BOE, 2003. Ley 54/2003, de 12 de diciembre, de reforma del marco normativo de la Prevención de Riesgos Laborales. Boletín Oficial del Estado, 298, 13/12/2003.

BOE, 2004. Real Decreto 171/2004, de 30 de enero, por la que se desarrolla el artículo 24 de la Ley 31/1995, de 8 de noviembre, de Prevención de Riesgos Laborales, en materia de coordinación de actividades empresariales. Boletín Oficial del Estado, 27, 31/01/2004.

BOE, 2006a. Ley 32/2006, de 18 de octubre, reguladora de la subcontratación en el Sector de la Construcción. Boletín Oficial del Estado, 250, 19/10/2006.

BOE, 2006b. Real Decreto 604/2006, de 19 de mayo, por el que se modifican el Real Decreto 39/1997, de 17 de enero, por el que se aprueba el Reglamento de los Servicios de Prevención, y el Real Decreto 1627/1997, de 24 de octubre, por el que se establecen las disposiciones mínimas de seguridad y salud en las obras de construcción. Boletín Oficial del Estado, 127, 29/05/2006.

BOE, 2006c. Real Decreto 396/2006, de 31 de marzo, por el que se establecen las disposiciones mínimas de seguridad y salud aplicables a los trabajos con riesgo de exposición al amianto. Boletín Oficial del Estado, 86, 11/04/2006.

BOE, 2007a. Resolución de 1 de agosto de 2007, de la Dirección General de Trabajo, por la que se inscribe en el registro y publica el IV Convenio Colectivo General del Sector de la Construcción. Boletín Oficial del Estado, 197, 17/08/2007.

BOE, 2007b. Real Decreto 1109/2007, de 24 de agosto, por el que se desarrolla la Ley 32/2006, de 18 de octubre, reguladora de la subcontratación en el Sector de la Construcción. Boletín Oficial del Estado, 204, 25/08/2007.

BOE, 2010. Real Decreto 337/2010, de 19 de marzo, por el que se modifican el Real Decreto 39/1997, de 17 de enero, por el que se aprueba el Reglamento de los Servicios de Prevención; el Real Decreto 1109/2007, de 24 de agosto, por el que se desarrolla la Ley 32/2006, de 18 de octubre, reguladora de la subcontratación en el sector de la 
construcción y el Real Decreto 1627/1997, de 24 de octubre, por el que se establecen disposiciones mínimas de seguridad y salud en obras de construcción. Boletín Oficial del Estado, 71, 23/03/2010.

BOE, 2015. Ley 39/2015, de 1 de octubre, del Procedimiento Administrativo Común de las Administraciones Públicas. Boletín Oficial del Estado, 236, 02/10/2015.

BOE, 2017. Resolución de 21 de septiembre de 2017, de la Dirección General de Empleo, por la que se registra y publica el Convenio Colectivo General del Sector de la Construcción. Boletín Oficial del Estado, 232, 26/09/2017.

BOE, 2018. Real Decreto 903/2018, de 20 de julio, por el que se desarrolla la estructura orgánica del Ministerio de Trabajo, Migraciones y Seguridad Social. Boletín Oficial del Estado, 176, 21/07/2018.

Bottani, E., Monica, L., Vignali, G., 2009. Safety management systems: performance differences between adopters and non-adopters. Safety Science 47 (2), 155-162. doi:10.1016/i.ssci.2008.05.001

Calderón, C.G., 2006. Análisis de los modelos de gestión de Seguridad y Salud en las PYMES del Sector de la Construcción. Tesis doctoral. Universidad de Granada. E.T.S. de Ingenieros de Caminos, Canales y Puertos. Departamento de Ingeniería Civil. Área de Ingeniería de la Construcción. Granada. Junio de 2006.

Camino López, M. A., Ritzel, D.O., Fontaneda, I., González, O.J., 2008. Construction industry accidents in Spain. Journal of Safety Research 39, 497-507.

doi:10.1016/j.jsr.2011.08.003

Cantonnet, J.I., 1999. "Análisis empírico comparativo de la siniestralidad en el sector de la construcción". Tesis doctoral. Universidad Politécnica de Valencia. E.T.S: de Ingenieros Industriales y de Telecomunicación. 1999.

Cantonnet, M.L., Aldasoro, J.C., Iradi, J., 2019. New and emerging management in small and medium-sized Spanish enterprises. Safety Science 113, 257-263.

https://doi.org/10.1016/i.ssci.2018.11.032

Carpio, A. J., 2017. Nueva metodología de evaluación de riesgos laborales adaptada a obras de edificación: nivel de la acción preventiva. Tesis doctoral. Universidad Politécnica de Madrid. Departamento de Construcciones Arquitectónicas y su Control. Madrid. 2017. $\underline{10.20868 / U P M . t h e s i s .47976}$ 
Champoux, D., Brun, J-P., 2003. Occupational health and safety management in small size enterprises: an overview of the situation and avenues for intervention and research. Safety Science 41, 301-318.

doi:10.1016/S0925-7535(02)00043-7

Círculo de Empresarios, 2014. La empresa mediana española. Informe Anual 2014. Documentos Círculo. Madrid. España.

COM, 2008. Comunicación de la Comisión al Consejo, al Parlamento Europeo, al Comité Económico y Social Europeo y al Comité de las Regiones relativa a la aplicación práctica de las Directivas 92/57/CEE (obras de construcción temporales o móviles) y 92/58/CEE (señalización de seguridad en el trabajo) en materia de salud y seguridad en el trabajo. Bruselas, 12 de noviembre de 2008.

De León, L.A., 2015. Formación del trabajador de la construcción en seguridad y su influencia en los accidentes laborales: El caso de Mallorca. Universidad Politécnica de Catalunya. Tesis Doctoral en Administración y Dirección de Empresas. España. http://hdl.handle.net/10803/319450

Directiva, 1991. Directiva 91/383/CEE del Consejo, de 25 de junio de 1991, por la que se completan las medidas tendentes a promover la mejora de la seguridad y de la salud en el trabajo de los trabajadores con una relación laboral de duración determinada o de empresas de trabajo temporal. Directiva 91/383/CEE, 25/06/1991.

http://www.insht.es/portal/site/Insht/menuitem.1f1a3bc79ab34c578c2e8884060961ca/?vg nextoid=12e6edb6b33a5110VgnVCM100000dc0ca8c0RCRD\&vgnextchannel=25d44a7f8 a651110VgnVCM100000dc0ca8c0RCRD

Directiva, 1992a. Directiva 92/85/CEE del Consejo, de 19 de octubre de 1992, relativa a la aplicación de medidas para promover la mejora de la seguridad y de la salud en el trabajo de la trabajadora embarazada, que haya dado a luz o en período de lactancia (décima Directiva específica con arreglo al apartado 1 del artículo 16 de la Directiva 89/391/CEE). Directiva 92/85/CEE, 19/10/1992.

http://www.insht.es/portal/site/Insht/menuitem.1f1a3bc79ab34c578c2e8884060961ca/?vg nextoid $=328589 \mathrm{~b} 7 \mathrm{de} 2 \mathrm{a} 5110 \mathrm{VgnVCM} 100000 \mathrm{dc0}$ ca8c0RCRD\&vgnextchannel=25d44a7f8 a651110VgnVCM100000dc0ca8c0RCRD

Directiva, 1992b. Directiva 92/57/CEE del Consejo, de 24 de junio de 1992, relativa a las disposiciones de seguridad y salud que deben aplicarse en las obras de construcción temporales o móviles (octava específica con arreglo al apartado 1 del artículo 16 de la Directiva 89/391/CEE)). Directiva 92/85/CEE, 19/10/1992. 
https://eur-

lex.europa.eu/LexUriServ/LexUriServ.do?uri=CONSLEG:1992L0057:20070627:ES:PDF

DOCE, 1988. DOCE n C 028/1, de 3 de febrero de 1988. Resolución del Consejo, de 21 de diciembre de 1987, relativa a la seguridad, la higiene y la salud en los lugares de trabajo. Diario Oficial de las Comunidades Europeas, 88/C 28/01, 03/02/1988.

https://eur-lex.europa.eu/legalcontent/ES/TXT/?uri=uriserv:OJ.C .1988.028.01.0001.01.SPA\&toc=OJ:C:1988:028:TOC

DOCE, 1989. DOCE nº L 183, de 29 de junio de 1989. Resolución del Consejo, de 12 de junio de 1989, relativa a la aplicación de medidas para promover la mejora de la seguridad y de la salud de los trabajadores en el trabajo. Diario Oficial de las Comunidades Europeas, 89/391/CEE, 29/06/1989.

https://www.boe.es/buscar/doc.php?id=DOUE-L-1989-80648

Durán, F., 2001. Informe sobre riesgos laborales y su prevención, la seguridad y la salud en el trabajo en España. "Informe Durán”. Ministerio de la Presidencia. Madrid. 2001.

Durán, F., Tudela, G., Valdeolivas, Y., 2008. Informe sobre la situación de la prevención de riesgos laborales en el sector de la construcción en España. Confederación Nacional de la Construcción. Madrid. 2008.

Eurostat - official EU statistics, 2016. Último acceso 18/07/2016.

http://ec.europa.eu/eurostat

Fariñas, J.C., Huergo, E., 2015. Demografía empresarial en España: tendencias y regularidades. Estudios sobre la Economía Española - 2015/24. Madrid. España.

FECYT, 2012. La conservación y reutilización de los datos científicos en España. Informe del grupo de trabajo de buenas prácticas. Fundación Española para la Ciencia y la Tecnología. Ministerio de Economía y Competitividad.

https://bib.us.es/sites/bib3.us.es/files/informe datos cientificos en esp.pdf

Fernández-Muñiz, B., Montes-Peón, J.M., Vázquez-Ordás, C.J., 2009. Relation between occupational safety management and firm performance. Safety Science 47, 980-991. doi:10.1016/i.ssci.2008.10.022

FLC, 2018. Glosario de términos del Diccionario de la Construcción. Fundación Laboral de la Construcción, 2018. Último acceso 08/09/2018.

http://www.diccionariodelaconstruccion.com/procesos-transversales-a-la-ejecucion-de-laobra/seguridad-y-salud/medios-auxiliares 
Forteza, F.J., Carretero-Gómez, J.M., Sesé, A., 2017. Occupational risks, accidents on sites and economic performance of construction firms. Safety Science 94, 61-76. https://doi.org/10.1016/j.ssci.2017.01.003

García, E.F., 2008. Diseño de un programa de integración de contenidos relacionados con la prevención de riesgos laborales en la enseñanza secundaria, bachillerato o formación profesional. León, octubre 2007 - junio 2008. Junta de Castilla y León. Valladolid.

https://bibliotecadigital.jcyl.es/es/consulta/registro.cmd?id=22450

González, F.A., 2001. La obligación empresarial de prevención de riesgos laborales. Tesis doctoral. Universidad de Murcia. Departamento de Derecho del Trabajo y la Seguridad Social. 2001.

Gutiérrez, M., 2002. Esbozo de un prontuario de reglas técnicas para la actuación del Fiscal en la siniestralidad laboral y la organización del servicio especial (praxis sobre uno de los posibles modelos). Estudios Jurídicos. Ministerio Fiscal 5, 11-56. Madrid.

Häkkinen, K., 1995. A learning-by-doing strategy to improve top management involvement in safety. Safety Science 20, 299-304.

doi:10.1016/0925-7535(95)00028-F

Hernández, D., 2015. What for is used preventive training? Theoretical discussion and practical implications: The case of unqualified jobs in the subcontracting firms in the construction sector in Spain. Cuadernos de Relaciones Laborales 33 (2), 331-356.

doi.org/105209/rev CRLA.2015.v33.n2.50319

Huete, L., 2007. La actuación del Ministerio Fiscal en Siniestralidad Laboral: una guía práctica. Fiscalía de la Audiencia Provincial de Ciudad Real. Último acceso 05/08/2016. http://www.fremap.es/pdf/prevencion/guiafis.pdf

Igartua, M. T., 1999. La obligación empresarial de garantizar la seguridad y salud en el trabajo. Tesis doctoral. Universidad de Sevilla. Departamento de Derecho del Trabajo y de la Seguridad Social. 1999.

INSHT, 2003. Guía Técnica para la Evaluación y Prevención de los Riesgos relativos a las Obras de Construcción, $1^{\text {a }}$ Edición. Instituto Nacional de Seguridad e Higiene en el Trabajo (INSHT). Ministerio de Trabajo y Asuntos Sociales. NIPO: 211-03-012-8. España.

INSHT, 2007. Estrategia Española de Seguridad e Higiene en el Trabajo 2007-2012. Instituto Nacional de Seguridad e Higiene en el Trabajo. Ministerio de Empleo y Seguridad. España. 
INSHT, 2009. Editorial. Seguridad y Salud en el Trabajo, 53, 5. Instituto Nacional de Seguridad e Higiene en el Trabajo. Madrid. Spain.

INSHT, 2011. Nota Técnica de Prevención (NTP) n 918. Coordinación de actividades empresariales (I). Instituto Nacional de Seguridad e Higiene en el Trabajo. Último acceso 05/08/2016.

http://www.insht.es/InshtWeb/Contenidos/Documentacion/NTP/NTP/Ficheros/891a925/9 $\underline{18 \mathrm{w} . p d f}$

INSHT, 2012. Guía Técnica para la Evaluación y Prevención de los Riesgos relativos a las Obras de Construcción, $2^{\mathrm{a}}$ Edición. Instituto Nacional de Seguridad e Higiene en el Trabajo (INSHT). Ministerio de Empleo y Seguridad Social. NIPO: 272-12-030-6. España.

INSHT, 2013. Balance final de la Estrategia Española de Seguridad y Salud en el Trabajo (2007-2012). Instituto Nacional de Seguridad e Higiene en el Trabajo. Ministerio de Empleo y Seguridad Social. Secretaría de Estado de Empleo. Madrid. Spain.

INSHT, 2014a. Informe sobre el estado de la seguridad y salud laboral en España, 2013. Instituto Nacional de Seguridad e Higiene en el Trabajo. Ministerio de Empleo y Seguridad. Spain.

INSHT, 2014b. Segunda Encuesta Europea sobre Riesgos Nuevos y Emergentes (ESENER 2), 2014. Agencia Europea para la Seguridad y Salud en el Trabajo (EUOSHA). Encuestas Nacionales de Condiciones de Trabajo y de Gestión de la Prevención. Instituto Nacional de Seguridad e Higiene en el Trabajo. Ministerio de Empleo y Seguridad. NIPO: 272-15-074-9. España.

INSHT, 2015. Estrategia Española de Seguridad e Higiene en el Trabajo 2015-2020. Instituto Nacional de Seguridad e Higiene en el Trabajo. Ministerio de Empleo y Seguridad. NIPO: 272-15-055-0. Spain.

JCYL, 2018. Comunicación de apertura o reanudación de la actividad centro de trabajo. Tramitación electrónica. Último acceso 30/12/2018.

https://www.tramitacastillayleon.jcyl.es/web/jcyl/AdministracionElectronica/es/Plantilla100 Detalle/1251181050732/Tramite/1241430205363/Tramite

Kanchana, S., Sivaprakash, P., Joseph, S., 2015. Studies on labour safety in construction sites. The Scientific World Journal, 2015.

doi.org/10.1155/2015/590810

Kim, S., Bajaj, D., 2000. Risk management in construction: an approach for contractors in South Korea. Cost Engineering 42 (1), 38-44. 
Liu, A.M.M., Cheung, S.O., 1994. Perceptions of risk distribution in construction contracts in Rowlinson, S. (Ed.), Proceedings: CIB (Conseil International du BaÃtiment) International Symposium. Commission W92 Procurement Systems "East Meets West", Department of Surveying, University of Hong Kong, Hong Kong, pp. 35-42.

López, A., Rubio, J.C., Gib, A., 2012. Analysis of construction accidents in Spain, 20032008. Journal of Safety Research, 43, 381-388.

doi:10.1016/j.jsr.2012.07.005

Lozano, R.V., 2015. Optimización de la figura del técnico coordinador de seguridad y salud en obras de edificación. Tesis doctoral. Universidad Politécnica de Madrid. Escuela Técnica Superior de Edificación. Departamento de Construcciones Arquitectónicas y su Control. Madrid. 2015.

Lyon, L., 2007. Dealing with Data: Roles, Rights, Responsibilities and Relationships Consultancy Report. UKOLN. University of Bath.

https://www.researchgate.net/profile/Liz Lyon/publication/242294704 Dealing with Data Roles Rights Responsibilities and Relationships Consultancy Report/links/02e7e52a 099cd050ea000000/Dealing-with-Data-Roles-Rights-Responsibilities-and-RelationshipsConsultancy-Report.pdf

Lyons, T., Skitmore, M., 2004. Project risk management in the Queensland engineering construction industry: a survey. International Journal of Project Management 22 (1), 51-61. doi:10.1016/S0263-7863(03)00005-X

MTSC, 2012. Guía de Contenidos Recomendables de un Plan de Seguridad y Salud, $1^{\text {a }}$ Edición. Mesa Técnica de Seguridad Laboral en la Construcción (MTSC). Depósito Legal: MU-1.072-2012. España.

Ministerio de Industria, Energía y Turismo. 2016. Estadísticas mensuales de las Pequeñas y Medianas Empresas en España. Último acceso 05/08/2016.

http://www.ipyme.org/es-ES/publicaciones/Paginas/estadisticaspyme.aspx

Ministerio de Trabajo, Migraciones y Seguridad Social, 2018a. Registro de Empresas Acreditadas [REA] Sector de la Construcción en España.

http://rea.mtin.gob.es/rea/

Ministerio de Trabajo, Migraciones y Seguridad Social, 2018b. Estadística de Accidentes de Trabajo. Año 2017. España.

http://www.empleo.gob.es/estadisticas/eat/eat17/Resumen resultados ATR 2017.pdf 
Ozmec, M.N., Karlsen, I.L., Kines, P., Andersen, L.P.S., Nielsen, K.J., 2015. Negotiating safety practice in small construction companies. Safety Science 71, 275-281.

doi:10.1016/j.ssci.2014.03.016

Paramio, A., 2009. Problemática de la subcontratación en la construcción: análisis jurídico y resoluciones prácticas. Lex Nova. Valladolid. España.

Peláez, F.J., 2006. Evaluación de la eficacia de los "Planes de Actuación Preferente (PAP)" desarrollados por las Comunidades Autónomas en el periodo 1999-2005, con el objetivo de reducir la incidencia de las lesiones por accidentes de trabajo. Ministerio de Trabajo y Asuntos Sociales (FIPROS 1005-39). Último acceso 05/08/2016.

http://www.seg-social.es/prdi00/groups/public/documents/binario/097544.pdf

Pérez, I., 2016. Estudio internacional sobre la figura del "promotor" como integrador de prevención de riesgos laborales en la materialización de proyectos. Modelo de gestión preventiva desarrollado. Tesis doctoral. Universidad Europea de Madrid. Programa de Doctorado en Técnicas Avanzadas en Construcción. Madrid. 2016.

REA, 2015. Registro de Empresas Acreditadas del Sector de la Construcción. Ministerio de Empleo y Seguridad Social. España.

Resolución, 1988. Resolución del Consejo de 21 de diciembre de 1987 relativa a la seguridad, la higiene y la salud en los lugares de trabajo (88/C 28/01). Diario Oficial $\mathrm{n}^{\circ} \mathrm{C}$ 028 de 03/02/1988.

Romero, A., Villena, B.M., Segarra, M., González, M.N., Rodríguez, A., 2018. Analysis and diagnosis of risk-prevention training actions in the Spanish construction sector. Safety Science 106, 79-91.

https://doi.org/10.1016/i.ssci.2018.02.023

Ros, A., Anduiza, R., 2007. Bases para la redacción de los Estudios de Seguridad y Salud. Proyectos de Arquitectura e Ingeniería. Editorial Adolfo Cazorla - UPM. ISBN: 978-84-6120699-5.

Rostami, A., Sommerville, J., Wong, L., Lee, C., 2014. Risk management implementation in small and medium enterprises in the UK construction industry. Engineering. Construction and Architectural Management 22 (1), 91-107.

doi:10.1108/ECAM-04-2014-0057

Santos, G., Barros, S., Mendes, F., Lopes, N. 2013. The main benefits associated with health and safety management systems certification in Portuguese small and medium enterprises post quality management system certification. Safety Science 51, 29-36. 
doi:10.1016/j.ssci.2012.06.014.

Segarra, M., Villena, B.M., González, M.N., Romero, A., Rodríguez, A., 2017. Occupational risk-prevention diagnosis: A study of construction SMEs in Spain. Safety Science 92, 104115.

http://dx.doi.org/10.1016/j.ssci.2016.09.016

Segarra, M., 2015. Integración de la Prevención de Riesgos Laborales en las PYMES del Sector de la Construcción. Tesis doctoral. Universidad de Castilla-La Mancha. Departamento de Ingeniería Civil y de la Edificación. Cuenca. 2015.

Sempere, A.V., Cardenal, M., 2000. Transposición de la Directiva Marco de Seguridad Laboral en diferentes países de la Unión Europea. Ed. Fundación Mapfre. Madrid. 2000.

Sobotka, A., Czarnigowska, A., 2005. Analysis of supply system models for planning construction project logistics. Journal of Civil Engineering and Management 11 (1), 73-82. doi.org/10.1080/13923730.2005.9636335

Suraji, A., Duff, A.R., Peckitt, S.J., 2001. Development of causal model of construction accident causation. Journal of Construction Engineering and Management 127 (4), 337344.

doi.org/10.1061/(ASCE)0733-9364(2001)127:4(337)

UNE, 2014. Amianto. Parte 1: Cualificación de empresas que trabajan con materiales con amianto (UNE 171370-1:2014). Aenor, 2014/12/17. ICS: 13.040.01 / Calidad del aire en general.

Werner, A. F., 2008. Apuntes sobre el desarrollo histórico de la salud en el trabajo. SOMETRA. Sociedad de Medicina del Trabajo. Argentina. 2008. 


\section{ÍNDICE DE FIGURAS}

Figura 1.1. Distribución de la población europea en millones de habitantes (orden descendiente)

Figura 1.2. Distribución de los accidentes de trabajo en PYMES de todos los sectores productivos: Índice de Incidencia

Distribución de los accidentes de trabajo en PYMES del Sector de la Construcción: Índice de Incidencia

Figura 1.4. Esquema de la estructura capitular de la Tesis doctoral, que muestra en qué capítulo del documento te encuentras

Figura 5.1. Línea temporal normativa en materia de PRL. Hitos más importantes

Organización de las figuras que pueden ser designadas o

asignadas para las labores de recurso preventivo, según lo recogido por el artículo 32 bis de la Ley de Prevención de Riesgos Laborales

Requisitos de acreditación de los recursos humanos y

Figura 5.3. materiales de las empresas subcontratistas establecidos 102 en el REA.

Limitación de los niveles máximos permitidos en la cadena

Figura 5.4. de subcontratación dentro de las obras de construcción 103 según se recoge en la Ley de Subcontratación 


\section{ÍNDICE DE TABLAS}

Tabla 1.1.

Tabla 3.1.

Tabla 3.2.

Tabla 3.3.

Tabla 3.4.

Tabla 3.5

Tabla 3.6.

Tabla 4.1.

Tabla 5.1.

Tabla 5.2.

Tabla 5.3.

Tabla 5.4.

Tabla 5.5.

Tabla 5.6.

Tabla 5.7.

Tabla 5.8

Tabla 5.9.
Empresas y Trabajadores inscritos en la Seguridad Social en diciembre de 2015. Fuente: Ministerio de Empleo y Seguridad Social (MEySS) (Ministerio de Industria, Energía y Turismo, 2016). En donde: a. (asalariados)

Hechos históricos relacionados con la Prevención de Riesgos Laborales. Fuente: García Redondo, E.F., 2008; Calderón Gálvez, C.G., 2006; Segarra Cañamares, M., 2015. Elaboración propia.

Hechos e iniciativas que han marcado el camino hacia la integración de la Prevención de Riesgos Laborales en la Unión Europea. Fuente: Segarra Cañamares, M., 2015. Elaboración propia.

Repaso a los principales hitos en materia legislativa que han marcado el camino hacia la integración de la Prevención de Riesgos Laborales en España. Fuente: Segarra Cañamares, M., 2015. Elaboración propia.

Cuadro resumen de las principales investigaciones realizadas en la línea de investigación de la tesis doctoral que han servido de referencia para la elaboración del trabajo.

Cuadro resumen comparativa Directiva 92/57 CEE (Directiva, 1992b) y el RD 1627/97 (BOE, 1997b).

Cuadro resumen comparativa RD 396/2006 (BOE, 2006c) $y$ el RD 1627/97 (BOE, 1997b).

Calendario orientativo de los días designados a cada una de las diferentes delegaciones de la JCCM.

Volumen de Planes de Seguridad y Salud consultados por año y sede provincial (por orden alfabético) de Castilla-La Mancha con inclusión de totales parciales (por sede para el período de tiempo comprendido entre 2008 y 2016) y total de planes consultados

Esquema de contenidos de los resultados recogidos en el capítulo de Resultados del documento de la tesis, compartimentados por grupos de contenidos afines con indicación de su localización en el documento (apartado/subapartado)

Tabla Promotor, Contratista, Proyectista

Recurso Preventivo

Recurso Preventivo es el Empresario

Subcontratista

Trabajador Autónomo

Trabajador por cuenta ajena 
Tabla 5.10. Coordinador de Seguridad y Salud en fase de proyecto

Situaciones más habituales que pueden darse y su equivalencia al respecto (a efectos del cómputo de

Tabla 5.11 empresas, únicamente se contabilizan aquellas que ejecutan obra), respecto de la determinación en obra del nombramiento de la figura del Coordinador de Seguridad y Salud en fase de ejecución

Tabla 5.12. Coordinador de Seguridad y Salud en fase de ejecución

Tabla 5.13. Incompatibilidad de la figura del Coordinador de Seguridad y Salud

Tabla 5.14. PSS cuenta con organigrama o fases de obra

Tabla 5.15. PSS contiene material gráfico

Tabla 5.16. PSS contiene material gráfico relacionado con la obra o la maquinaria

Tabla 5.17. $\quad$ PSS cuenta con pautas de actuación ante emergencias

Tabla 5.18. PSS cuenta con itinerarios para llegar a centros asistenciales

Tabla 5.19. PSS contiene pautas de actuación en caso de riesgo grave e inminente

Tabla 5.20. PSS cuenta con Plan de Evacuación en caso de incendio

Tabla 5.21. PSS cuenta con procedimientos de control de Seguridad Vial

Tabla 5.22. $\quad$ PSS cuenta con Plan de Seguridad Vial específico

Tabla 5.23. PSS cuenta con capítulo dedicado a la Seguridad y Salud en las Mediciones y Presupuesto

Tabla 5.24. PSS evalúa cada fase/trabajo/puesto/actividad de la obra

Tabla 5.25. PSS evalúa cada fase/trabajo/puesto/actividad de la obra de forma específica

Tabla 5.26. PSS identifica la maquinaria/equipos que se emplean en obra

Tabla 5.27.

PSS identifica y evalúa la maquinaria/equipos que se emplean en obra

Tabla 5.28. PSS identifica los medios auxiliares que se prevén emplear en obra

Tabla 5.29. PSS identifica y evalúa los medios auxiliares que se prevén emplear en obra

Tabla 5.30. PSS incluye el manual de instrucciones y/o procedimientos de los medios auxiliares que se prevén emplear en obra

Tabla 5.31. PSS incluye los productos químicos que se van a emplear en obra

Tabla 5.32. PSS incluye las fichas de seguridad de los productos químicos que se van a emplear en obra 
Tabla 5.33. La Evaluación de Riesgos integrada en el PSS se ajusta a lo determinado en el artículo 7

Tabla 5.34 Existe planificación preventiva en el PSS como resultado de la Evaluación de Riesgos

161

Tabla 5.35. La planificación preventiva en el PSS se ajusta al artículo 163

Tabla 5.36. $\quad$ PSS en papel en blanco 164

Tabla 5.37. PSS en CD en blanco o no apertura 166

Tabla 5.38. PSS no guarda relación con la obra recogida en el título 169

$\begin{array}{lll}\text { Tabla 5.39. Mismo PSS para distintas obras } & 170\end{array}$

Tabla 5.40. Mención expresa al ESS o al EBSS en el PSS 173

Tabla 5.41. PSS no está firmado $\quad 174$ 


